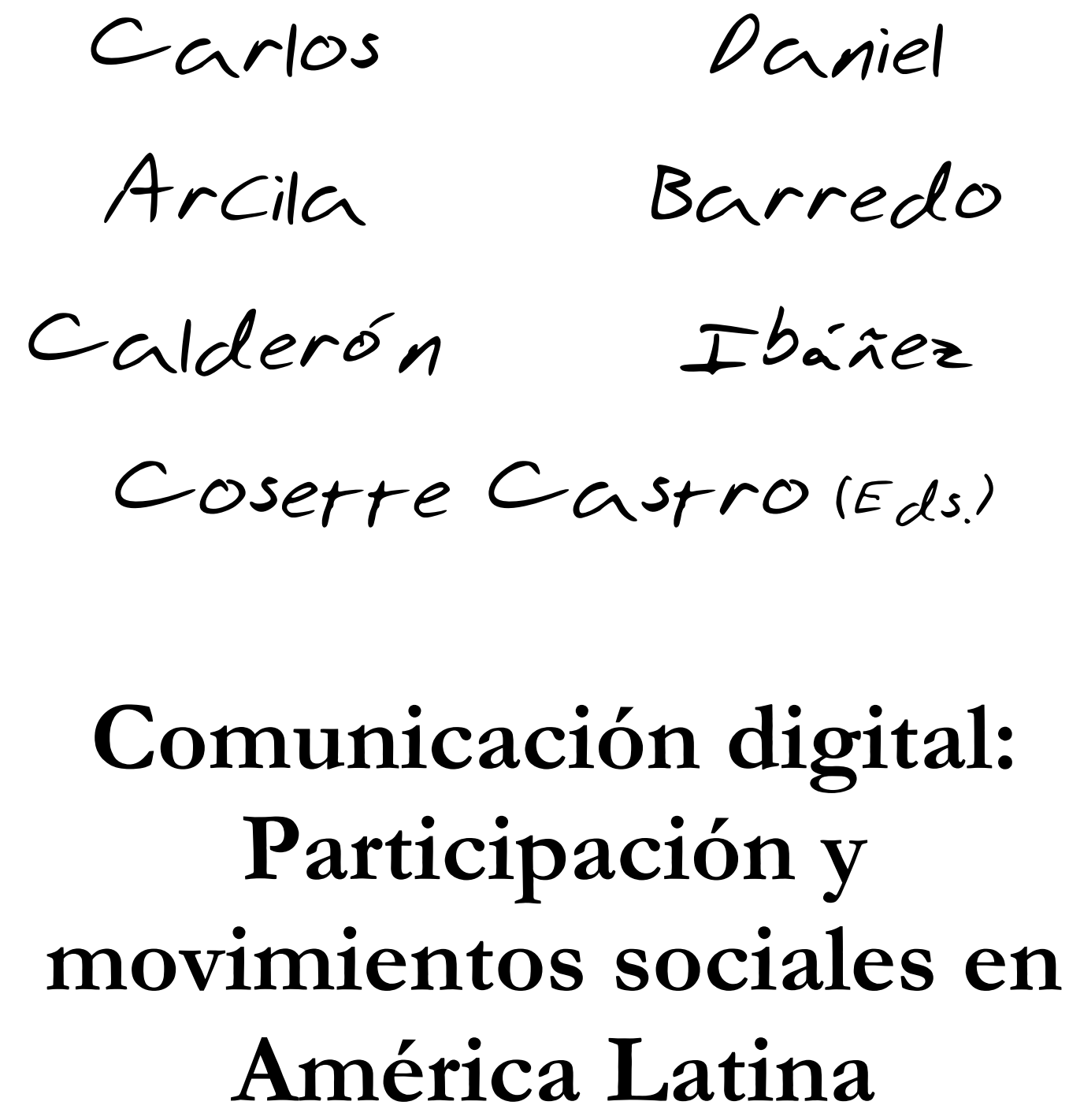

Cuadernos Artesanos de Comunicación / 121

ULL

Universidad de La Laguna

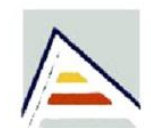

Universitat d'Alacant Universidad de Alicante

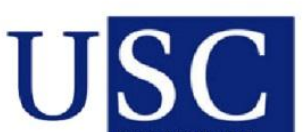

UNIVERSIDADE DE SANTIAGO
DE COMPOSTEL

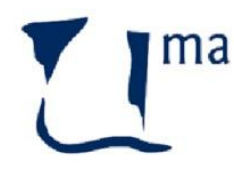

UNIVERSIDAD DE MALAGA

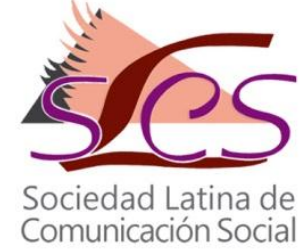




\section{Cuadernos Artesanos de Comunicación}

Coordinador editorial: José Manuel de Pablos - jpablos@ull.edu.es

Comité Científico

Presidencia: José Luis Piñuel Raigada (UCM)

Secretaría: Alberto Ardèvol (ULL)

- Miguel Vicente (Universidad de Valladolid, UVA)

- Ramón Zallo (Universidad del País Vasco, UPV-EHU)

- Núria Almiron (Universidad Pompeu Fabra, Barcelona, UPF)

- Francisco Campos Freire (Universidad de Santiago de Compostela)

- José Cisneros (Benemérita Universidad Autónoma de Puebla, BUAP)

- Bernardo Díaz Nosty (Universidad de Málaga, UMA)

- Carlos Elías (Universidad Nacional de Educación a Distancia, UNED)

- Paulina B. Emanuelli (Universidad Nacional de Córdoba, UNC)

- Marisa Humanes (Universidad Rey Juan Carlos, URJC)

- Juan José Igartua (Universidad de Salamanca, USAL)

- Xosé López (Universidad de Santiago de Compostela)

- Maricela López-Ornelas (Universidad Autónoma de Baja California, AUBC)

- Javier Marzal (Universidad Jaume I, UJI)

- José Antonio Meyer (Benemérita Universidad Autónoma de Puebla, BUAP)

- Ramón Reig (Universidad de Sevilla, US)

- Miquel Rodrigo Alsina (Universidad Pompeu Fabra, UPF)

- Xosé Soengas (Universidad de Santiago de Compostela)

- José Luis Terrón (Universidad Autónoma de Barcelona, UAB)

- José Miguel Túñez (Universidad de Santiago de Compostela, USC)

- Victoria Tur (Universidad de Alicante, UA)

* Queda expresamente autorizada la reproducción total o parcial de los textos publicados en este libro, en cualquier formato o soporte imaginables, salvo por explícita voluntad en contra del autor o autora o en caso de ediciones con ánimo de lucro. Las publicaciones donde se incluyan textos de esta publicación serán ediciones no comerciales y han de estar igualmente acogidas a Creative Commons. Harán constar esta licencia y el carácter no venal de la publicación.

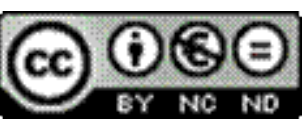

Este libro y cada uno de los capítulos que contiene (en su caso), así como las imágenes incluidas, si no se indica lo contrario, se encuentran bajo una Licencia Creative Commons Atribución-No

Comercial-Sin Derivadas 3.0 Unported. Puede ver una copia de esta licencia en http://creativecommons.org/licenses/by-nc-nd/3.0/ Esto significa que Ud. es libre de reproducir y distribuir esta obra, siempre que cite la autoría, que no se use con fines comerciales o lucrativos y que no haga ninguna obra derivada. Si quiere hacer alguna de las cosas que aparecen como no permitidas, contacte con los coordinadores del libro o con el autor del capítulo correspondiente.

* La responsabilidad de cada texto es de su autor o autora. 
Carlos Arcila Calderón/Daniel Barredo Ibáñez/Cosette Castro (Eds.)

\section{Comunicación digital: Participación y movimientos sociales en América Latina}

Cuadernos Artesanos de Comunicación / 121

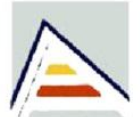

Universitat d'Alacant Universidad de Alicante

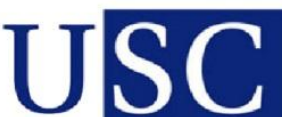

UNIVESIDADE DE SANTIAGO

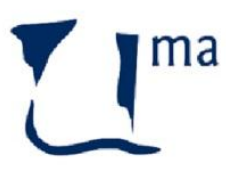

UNIVERSIDAD DE MÁLAGA

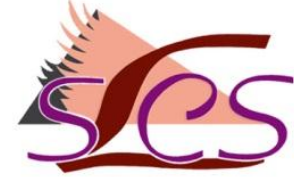

Sociedad Latina de Comunicación Social 
CAC- $121^{\circ}$ Comunicación digital: Participación y movimientos sociales en América Latina

Carlos Arcila Calderón/Daniel Barredo Ibáñez / Cosette Castro (Editores)

| Precio social: 9,40€ | Precio en librería: 12,25€ |

Editores: Javier Herrero y Milena Trenta

Diseño: F. Drago

Ilustración de portada: Fragmento del cuadro Mujer con bernegal, de Pedro de Guezala (1958).

Imprime y distribuye: F. Drago. Andocopias S. L.

c/ La Hornera, 41. La Laguna. Tenerife.

Teléfono: 922250554 | fotocopiasdrago@,telefonica.net

Edita: Sociedad Latina de Comunicación Social - edición no venal - La Laguna (Tenerife), 2017 - marzo - Creative Commons http://www.revistalatinacs.org/14SLCS/portada2017.html

Descargar en pdf:

http://www.cuadernosartesanos.org/\#121

Protocolo de envío de manuscritos con destino a CAC

http://www.cuadernosartesanos.org/protocolo.html

ISBN - 13: 978-84-16458-79-0

DL: TF-134-2017

DOI: $10.4185 / \operatorname{cac} 121$ 


\title{
Comunicación digital: Participación y movimientos sociales en América Latina
}

\begin{abstract}
América Latina es un sub-continente que, independientemente de sus niveles contextuales, está profundamente marcado por la brecha tecnológica. Alrededor de la mitad de los ciudadanos de esta parte del mundo carece de conexión a Internet, debido a problemas como la falta de desarrollo de las infraestructuras, o a la existencia de grandes capas poblacionales con escasos recursos económicos y, por tanto, con un irregular acceso a la red. Sin embargo, con este libro presentamos un conjunto de artículos que revela un continente en donde los intercambios a través de los medios sociales está adquiriendo una gran relevancia social. Desde la movilización social en el paro nacional agrario de Colombia -donde los campesinos de ese país emplearon la tecnología para generar un impacto nacional, frente a la labor cercana al oficialismo de los medios-, pasando por el empleo de las redes para contrastar el discurso oficial en Bolivia, hasta la exposición de diversos estudios de caso relacionados con la resistencia de los movimientos sociales en Brasil. Son estos algunos de los temas que se tratan a lo largo de los siguientes 11 capítulos, en los cuales se muestra la ebullición de las plataformas digitales a través de una cada vez mayor movilización de las sociedades latinoamericanas, con el fin de promover una erosión de esos factores que asientan la desigualdad generalizada $y$, en definitiva, para transformar, progresivamente, el autoritarismo histórico de sus democracias en sistemas más participativos e incluyentes.
\end{abstract}

\section{Keywords}

Movimientos sociales; América Latina; comunicación digital; participación

Arcila, C., Barredo, D. \& Castro, C. (Eds., 2017). Comunicación digital: Participación y movimientos sociales en América Latina. La Laguna, España: Cuadernos Artesanos de Comunicación. 


\section{Índice}

Introducción: El Grupo Temático en Comunicación Digital, Redes y Procesos: un marco interdisciplinar para abordar la investigación en nuevos medios y plataformas

1 O hacktivismo como instrumento de comunicação alternativa e de resistência

2 Redes y movimiento sociales, el caso del paro nacional agrario en Colombia

3 La novela Zapata: del periodismo digital a las redes sociales. Transmediatización y Regulación de las Redes Sociales en Bolivia.57

4 Participación política y medios de comunicación. Un estudio sobre los jóvenes ecuatorianos

5 Enunciação e visibilidade de vítimas nas redes sociais: formas de aparição do rosto.

6 Identidades urbanas nas redes: estratégias de resistência do Movimento Ocupe Estelita

7 “Las redes son el corazón”: Espacios, relaciones y conexiones en la expresión pública de los activistas en internet

8 La realidad sociodigitalizada. Participación ciudadana, redes sociales y medios masivos de comunicación en Córdoba, Argentina

9 The contribution user generated image on Facebook during the National Agrarian Strike in Colombia

10 Religião e Novas Territorialidades - A Igreja na Rede

11 El retroceso de una investigación: políticas públicas de inclusión digital en escuelas secundarias, en el marco de la restitución conservadora

12 Cyberbullying: Retos para una ciudadanía inclusiva, tolerante y respetuosa de las diferencias en el ciberespacio. 
La edición de este libro ha sido financiada por el proyecto de I+D "Esfera pública y participación ciudadana: un abordaje de la construcción de la interacción en los principales cibermedios colombianos (2016)", dirigido por el profesor Daniel Barredo y con financiación del fondo de proyectos de Gran Cuantía de la Universidad del Rosario (2017 - 2019). Los capítulos aquí recogidos fueron expuestos como ponencias en el Grupo Temático de Comunicación Digital, Redes y Procesos, en el marco del XIII Congreso de la Asociación Latinoamericana de Investigadores de la Comunicación, ALAIC, celebrado del 5 al 7 de octubre de 2016 en la Universidad Autónoma Metropolitana en México. 
A la Asociación Latinoamericana de Investigadores de la Comunicación, por su excelente labor como punto de encuentro de la movilización académica 


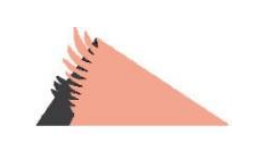

Introducción

\title{
El Grupo Temático en Comunicación Digital, Redes y Procesos: un marco interdisciplinar para abordar la investigación en nuevos medios y plataformas
}

\author{
Carlos Arcila Calderón. Universidad de Salamanca (España) \\ Daniel Barredo Ibáñez. Universidad del Rosario (Colombia) \\ Cosette Castro. Universidad Estatal Paulista (Brasil)
}

\begin{abstract}
A MÉRICA LATINA es un sub-continente que, independien1 temente las diferencias entre sus países, está profundamente marcado por la brecha tecnológica. Alrededor de la mitad de los ciudadanos de esta parte del mundo carece de conexión a Internet, debido a problemas como la falta de desarrollo de las infraestructuras, o a la existencia de grandes capas poblacionales con escasos recursos económicos y, por tanto, con un irregular acceso a la red. Sin embargo, con este libro presentamos un conjunto de artículos que revela una región en donde los intercambios a través de los medios sociales están adquiriendo una gran relevancia social. Desde la movilización social en el paro nacional agrario de Colombia -donde los campesinos de ese país emplearon la tecnología para generar un impacto nacional, frente a la labor cercana al oficialismo de los medios-, pasando por el empleo de las redes para contrastar el discurso oficial en Bolivia, hasta la exposición de diversos estudios de caso relacionados con la resistencia de los movimientos sociales en Brasil. Son estos algunos de los temas que se tratan a lo largo de los siguientes 11 capítulos, en los cuales se muestra la ebullición de las
\end{abstract}


plataformas digitales a través de una cada vez mayor movilización de las sociedades latinoamericanas, con el fin de promover una erosión de esos factores que asientan la desigualdad generalizada $\mathrm{y}$, en definitiva, para transformar, progresivamente, el autoritarismo histórico de sus democracias en sistemas más participativos e incluyentes.

Desde el Grupo Temático en Comunicación Digital, Redes y Procesos, que pertenece a la Asociación Latinoamericana de Investigadores en Comunicación, hemos concebido este libro que recoge el marco interdisciplinar en que se está moviendo la investigación en nuestro ámbito en América Latina para afrontar el examen de los nuevos medios y plataformas. Todo ello en un marco de respeto hacia las diferencias que identifican a esta parte del mundo, visible tanto en la heterogeneidad de lenguajes (se ofrecen capítulos en portugués, español e inglés), como de enfoques epistemológicos, ya que incluimos una variedad de perspectivas que comprenden desde la rica tradición de los ensayos o artículos de reflexión, hasta la aportación de datos empíricos originados desde lo cuantitativo o lo cualitativo. Nuestra labor editorial, por tanto, no estriba en la estandarización de los artefactos culturales que comprende esta publicación, sino en la amplificación de los contrastes y en la difusión de las posibles divergencias para conseguir trazar una hoja de ruta sobre las líneas de investigación en que se están moviendo los distintos grupos de nuestro continente.

En el primer capítulo, Karen Pacheco Fontenele analiza las relaciones existentes entre el hacktivismo y la comunicación alternativa, a través del análisis de los vídeos publicados por Anonymous en YouTube, un movimiento que, de acuerdo a la autora, tiende a fomentar con sus contribuciones una fractura del flujo informativo convencional. Por su parte, Jorge Aguilera, en el segundo capítulo se centra en examinar el caso del paro nacional agrario en Colombia, mediante el análisis de los vídeos publicados por los ciudadanos en YouTube. Además, tras las visitas del autor a los campesinos que formaron parte de la movilización, describe cómo el uso de las tecnologías de la información y la comunicación ha transformado incluso a unos ciudadanos que, habitualmente, suelen introducirse como actores principales de la brecha tecnológica. 
Alma Luz Forte y Luis Carlos Barrios Bueno, en el capítulo tercero, estudian el caso boliviano a partir de la denuncia de tráfico de influencias presentada por Evo Morales a Gabriela Zapata. Curiosamente, los investigadores hallaron que las redes sociales ejercieron un rol fundamental para reproducir las contradicciones gubernamentales, así como para provocar una reacción en la opinión pública que, finalmente, se materializó en el referéndum de 2016, según el cual se denegó al presidente andino la posibilidad de tener un tercer mandato. Pero a pesar de que pueden ser de gran utilidad para explicar algunos casos nacionales, como enunciado, lo cierto es que la influencia de las redes sociales se ve limitada en algunas regiones del continente debido a problemas como la falta de alfabetización digital o las deficiencias en el acceso de conexión a la red. Así, en el capítulo cuarto, Daniel de la Garza, Daniel Barredo Ibáñez y Carlos Arcila evalúan la participación política de los estudiantes de dos universidades de Ecuador. Además de constatar la brecha existente en este país, los autores aseguran que muchas de las reformas emprendidas por el gobierno de Rafael Correa se han limitado a la aprobación de normativas, sin un impacto transformador en el entorno, como se demuestra en el escaso interés que otorgan los estudiantes consultados sobre su involucramiento en los temas de las agendas públicas. Angie Biondi, en el capítulo quinto, estudia el dolor de las víctimas compartido cotidianamente a través de las redes sociales, un proceso que, de acuerdo a la autora, se cifra en dos posibles interacciones: la mirada hacia los sujetos de la imagen y, asimismo, la identificación del tipo de mirada que puede tener las implicaciones de quienes la observan.

En el siguiente capítulo, Nataly de Queiroz Lima y Heitor Costa da Lima Rocha se encargan de profundizar sobre las estrategias de resistencia del Movimiento Ocupe Estelita, de la ciudad de Recife, capital de Pernambuco, en Brasil. A través de este movimiento, se articularon las demandas sociales de forma horizontal, en un interesante ejercicio democrático en línea. Dentro del capítulo séptimo, Dorismilda Flores Márquez explica el relacionamiento que se produce entre los ciberactivistas, quienes de acuerdo a la autora establecen interacciones mediante plataformas como Whatsapp o Facebook, desde las que gestionan sus iniciativas. Pero es que el ciberactivismo, según se indica en este trabajo, se relaciona con el 
activismo fuera de línea y en, términos globales, con el intercambio interpersonal en la sociedad. En el octavo capítulo, Malvina Eugenia Rodríguez y Elizabeth Beatriz Theiler analizan nuevas formas de intercambio ciudadano a partir de un estudio de los contenidos publicados por los medios de la provincia de Córdoba, en Argentina. Las autoras, en este trabajo, concluyeron que los discursos de los medios tradicionales y de los medios en línea tienden a resultar antagónicos. María Isabel Villa Montoya, Javier S. Bautista y Jhon J. Herrera, en el noveno capítulo, indagan sobre las imágenes publicadas por los usuarios del portal de Facebook de Boyacá Noticias, durante el paro nacional agrario. Para estos autores, la difusión de imágenes ayudó a alimentar un discurso a la contra del oficial, a la vez que pudo favorecer la introducción de nuevos temas dentro de la agenda de los medios.

Más adelante, en el capítulo décimo, Karina Inácio de Araujo Lambert se encarga de reflexionar sobre cómo se ha adaptado la religión al espacio interactivo que promueve Internet. En ese sentido, se ha percibido sobre todo un interés de proyectar a los líderes eclesiásticos con el fin de asentar su autoridad en la red. La educación, con todo, favorece enormemente la emergencia de las ciudadanías digitales, si bien Leonardo González, Sebastián Novomisky, Claudia Suárez Baldo y Julia Barba Pertine, en el undécimo capítulo, critican el retroceso que ha sufrido Argentina en esta materia desde la restauración conservadora del presidente Mauricio Macri. Estos autores alertan de los problemas que puede correo la inclusión digital por el declive del desarrollo de tecnologías nacionales, en detrimento de las tecnologías ofertadas por las corporaciones. Por último, Patricia Henríquez estudia el ciberacoso en San Cristóbal (Venezuela). Es este un ámbito que entraña severos peligros y que, en definitiva, exige un pacto entre los padres, los profesores y los estudiantes y ofrece recomendaciones para el obligado "saber convivir" que debe identificar la difusión de emisiones a partir desde las plataformas digitales.

Todos estos temas, estimado lector, presentan una estupenda radiográfica de la participación, la comunicación digital y los movimientos sociales en el contexto latinoamericano. Asimismo, son una muestra de la producción intelectual del Grupo Temático 
Comunicación Digital, Redes y Procesos que se inició en 2014 con la publicación del libro An Overview to Digital Media in Latin America (Londres: University of West London). Este libro, junto con las discusiones que hemos mantenido en los tres últimos congresos en Montevideo, Lima y Ciudad de México, fortalece un espacio de amplia discusión y debate sobre la realidad de los medios digitales y su alcance en América Latina. 



\section{O hacktivismo como instrumento de comunicação alternativa e de resistência}

Karen Pacheco Fontenele. Universidade de Brasilia (Brasil). karenfontenele@hotmail.com

\section{Introdução}

Presente estudo investiga a relação existente entre hacktivismo, comunicação alternativa e resistência, partindo da análise dos vídeos postados pelo grupo Anonymous, no Youtube, de junho a setembro de 2016. O que está em foco é atendência dos hackers utilizarem o alcance das páginas governamentais como estratégia de disputa pelo sentido.

Aprioristicamente, deve-se observar que essa relação emerge em um contexto de propriedade cruzada dos meios de comunicação, porquanto o panorama atual dos canais brasileiros faz com que a liberdade de imprensa ainda seja bastante limitada pelos interesses de pequenos grupos detentores das mídias tradicionais (Lima, 2007). Nesse sentido, compreendendo os limites desses veículos em reproduzir o discurso dos grupos tidos como "marginalizados" e o poder de disseminação de informações da Internet, o presente artigo pretende analisar as ações hacktivistas como mecanismos de resistência e de comunicação alternativa.

\subsection{Hacktivismo}

Comumente encontramos reportagens que associam os hackers à criminalidade, um equívoco histórico que tem estereotipado 
erroneamente este grupo. Muitos estudos têm buscado inverter essa relação semântica, entre os quais situa-se $A$ Internet, escrito por Maria Ercília e Antonio Graeff. Nele, os autores objetivam esclarecer aos leigos alguns conceitos próprios da informática, em especial as noções de cracker e hacker.

Segundo Ercília e Graeff, o cracker-que também pode ser chamado de lammer- é aquele que viola a segurança de computadores, programas e redes alheios com finalidades maliciosas, tais como roubo, alteração e destruição de informações. O hacker, por sua vez, é o indivíduo que gosta de explorar e adquirir conhecimentos e detalhes de computadores, programas e redes como forma de remover limitações ou para a criação de novas possibilidades e usos não identificados originalmente.

Destarte, podemos dizer que o único fator comum a ambos é a habilidade frente a sistemas e programações, o que os induz a devotar grande parte de suas vidas ao estudo acerca dos mistérios da informática. A atividade do cracker está direcionada à sabotagem e invasão, muitas vezes visando à captação de dados que lhe rendam cifras, praticando o denominado roubo eletrônico. O hacker, por sua vez, desenvolve mecanismos para aprimorar a Internet, além de criar ferramentas que potencializam a computação.

Isso posto, percebe-se que, além das contribuições técnicas, os hackers têm trazido contribuições sociais praticando o chamado backtivismo. Este termo, derivado da junção de hacker e ativismo, diz respeito à prática de utilizar o espaço virtual como ferramenta de contestação e debate acerca da sociedade. Sendo assim, embora a prática de invasão aos sites de empresas e entidades governamentais aconteça há muitos anos, a novidade consiste nos motivos políticos que levam os grupos hackers a fazê-lo.

\subsection{Anonymous}

Definir os Anonymous é uma tarefa hercúlea e encerrálo na categoria de hacktivismo seria, certamente, limitar suas potencialidades. Ao observar as diversas facetas desse coletivo, pode-se afirmar que possui como característica fundamental a multiplicidade. Referindo-se 
aos movimentos contraculturais de sua época, Roszak (1968) descreveu os desafios decorrentes de sua pluralidade:

"Nos viria muito bem, por suposto, que esses zeitgeits, tão perversamente ectoplasmáticos, fossem movimentos organizados, com sua sede central, seu comitê executivo e um bom arquivo de declarações oficiais. Mas está claro que não é assim. Por isso, estamos obrigados a abordá-los ou aceitá-los com um certo temor, dispostos sempre a permitir que algumas exceções sejam coadas através do filtro das generalizações em grandes quantidades, mas sempre, também, na esperança de que, finalmente, o sólido ou autenticamente válido será mais do que o eliminado pelos filtros" (Roszak, 1968, p. 10).

Embora o objeto de estudo de Roszak fosse outro, seus apontamentos podem ser utilizados para analisar o fenômeno Anonymous. Com a pluralidade inerente ao espírito da cibercultura, esse grupo possui várias dimensões. No capítulo dedicado à descrição desse fenômeno mundial, em sua dissertação, Murilo Bansi Machado (2013) descreve a dificuldade decorrente dessa amplitude:

"Uma legião, um coletivo, uma ideia, uma rede, uma comunidade virtual, uma forma de ação, uma marca, um pressuposto, um conceito ou um movimento? Em meio a uma infinidade de outras caracterizações possíveis, todas essas designações já foram utilizadas por pessoas que, de alguma forma, estão relacionadas ao imenso conjunto heterogêneo e distribuído de grupos e indivíduos que agem politicamente, em conjunto ou de forma descoordenada, valendo-se do termo 'Anonymous' em várias partes do mundo. E todas elas, de alguma forma, mostram-se apropriadas." (Machado, 2013, pp. 68-69)

Sem descartar a grandiosidade desse fenômeno, o presente estudo limita-se a tratar da faceta hacktivista dos Anonymous. Nesse sentido, Gabriella Coleman (2011) aponta que 2008 pode ser entendido como o marco do direcionamento do grupo à ação coletiva, mais precisamente na onda de protestos contra a Igreja de Cientologia norte-americana. 
Nesse período, foi deflagrada uma série de ataques virtuais, além de inúmeros posts em sites, blogs e redes sociais chamando a atenção para o fato de que essa igreja estaria violando o sagrado princípio da liberdade de expressão. Paralelamente, também foram iniciadas diversas ações de negação de serviço contra sites dessa instituição. Com isso, o coletivo passava a utilizar a Internet como ativismo social.

Partindo desse viés, o presente artigo busca perscrutar as relações existentes entre o hacktivismo praticado por esse grupo e os conceitos de resistência e de comunicação alternativa.

\subsection{Hacktivismo, resistência e comunicação alternativa}

Para compreender o jogo de disputa de poder que se ergue na atualidade, deve-se considerar um dos pontos centrais do pensamento de Michael Foucault: a imprescindibilidade de se esquadrinhar conjuntamente os poderes midiáticos, as multinacionais e as novas instituições globais, dado que, por constituírem mecanismos de dominação fundamentais do mundo global, devem ser compreendidos por intermédio daquilo que pretendem proibir, afastar ou capturar (Alvim, 2010).

A esse respeito, Lemos (2002) ressalta que, dentre as particularidades das novas tecnologias, destacam-se a efervescência comunitária gerada por sua apropriação social e o caráter associativo resultante desse fenômeno. Tais características fazem com que a rede mundial seja elevada ao status de ágora virtual, de um novo espaço público.

Nesse contexto, a Internet se apresenta como uma possibilidade de resistência e os hackers, como agentes exponenciais de sua propagação. Essa postura de enfrentamento se apresenta como tentativa de disputa pelo sentido e, conforme aponta Foucault (2012), somente através da resistência se pode reverter o poder vigente: "De fato, as relações de poder são relações de força, enfrentamentos, portanto, sempre reversíveis. Não há relações de poder que sejam completamente triunfantes e cuja dominação seja incontornável" (Foucault, 2012, p. 232).

Analisando esse fenômeno, Manuel Castells (2011), no posfácio do livro A ética hacker e o espirito da era da informaşão -de Pekka Himanen- 
sintetiza o significado simbólico do impacto cultural gerado pelos avanços tecnológicos:

"Tecnologia é uma dimensão fundamental da mudança social. As sociedades evoluem e transformam-se através de uma complexa interação de fatores culturais, econômicos, políticos e tecnológicos. Por isso, a tecnologia precisa ser entendida dentro dessa matriz multidimensional. No entanto, a tecnologia tem sua própria dinâmica. O tipo de tecnologia desenvolvida e difundida numa sociedade configura decisivamente sua estrutura material" (Castells in Himanem, 2001, p. 137).

Portanto, colocar os hackers no ponto central da discussão enseja compreender melhor a lógica da rede mundial e dar um passo à frente acerca do estudo dessa mídia, uma vez que eles exercem papel relevante na democratização da informação. A gratuidade do serviço gerada por essas ferramentas tem um caráter político que visa à constituição de um produto democrático que amplie a participação e, portanto, a inclusão da sociedade no mundo digital. Dessa forma, percebe-se que, além das contribuições técnicas, os hackers têm trazido benefícios sociais e precisam, portanto, ser investigados sob o prisma da comunicação social.

Nesse viés, na obra Microfísica do poder, Michael Foucault (1992) inaugura um novo olhar sobre a temática. Se, anteriormente, os estudos vislumbravam no Estado sua expressão máxima, o filósofo francês propõe uma análise ascendente do poder - do micro para o macro. Ou seja, não o estuda enquanto dominação global e centralizada que se pluraliza, mas como algo que possui existência própria e formas específicas. E, conforme aponta Roberto Machado na Introdução da referida obra, essa abordagem não busca minimizar o papel do Estado nas relações de poder existentes, mas refutar a máxima de que o Estado seria o órgão central e único de poder.

Esse método, conhecido como Genealogia, encontra sua origem terminológica em Nietzsche e concerne à explicação do aparecimento do poder a partir de suas positividades. Assim, não o aborda enquanto algo irreversível, mas como um constante devir. Desse modo, não se exerce, mas se disputa. Isso porquê analisá-lo apenas 
sob o viés da repressão significa reduzi-lo ao aspecto puramente jurídico.

Nesse sentido, ao averiguar as ações dos Anonymous, nota-se que um de seus objetivos é desafiar as atuais estruturas de poder mediante a colaboração. Isso pode ser inferido desde a assinatura oficial do grupo, amplamente propagada em suas ações: "Nós somos Anonymous. Somos uma legião. Nós não perdoamos. Nós não esquecemos. Aguardem-nos".

Além disso, o símbolo que os representa - uma pessoa trajando terno escuro e sem um rosto - ressalta o caráter anônimo, colaborativista e horizontal do movimento. Ademais, a máscara de Guy Fawkes ${ }^{2}$ fora incorporada ao movimento, o que, conforme aponta Machado (2015), fez com que as pessoas se sentissem mais à vontade para realizar ações, chamando a atenção da imprensa e desafiando as facetas do controle.

O mesmo autor aponta que as tecnologias que controlam a sociedade também podem ser vistas pela capacidade que possuem de oferecer oportunidades de resistência. Além disso, elenca características essenciais da cultura hacker: liberdade total das informações, caráter universal, ilimitado e total do uso de computadores, ausência de hierarquia e zombaria à autoridade (Machado, 2015).

Nesse sentido, pode-se inferir que tais simbologias disseminadas pelos hacktivistas constituem expressões de confronto, de disputa pelo sentido. E, conforme sinaliza Foucault (1995), é necessário analisar o que está à margem do discurso do poder para compreender adequadamente as estratégias antagônicas que o desafiam. (Foucault, 1995, p. 234)

\footnotetext{
${ }^{1}$ Tradução para: "We are Anonymous. We are Legion. We do not forgive. We do not forget. Expect us".

2 Soldado inglês que tentou dinamitar o Parlamento britânico durante a Conspiração da Pólvora, em 1605. Responsável por guardar os artefatos que seriam utilizados na explosão, acabou preso e condenado à morte. A máscara em questão tornou-se popular por conta da história em quadrinhos $V$ de Vingança, de Alan Moore e David Lloyd, e principalmente pelo filme homônimo, assinado pelo diretor americano James McTeigue.
} 
Além disso, ao praticarem o chamado hacktivismo, os Anonymous chamam atenção para seus meios de comunicação e abrem, portanto, um espaço de comunicação alternativa que, conforme destaca Kaplún (1985, p.7), trata-se de "uma comunicação libertadora, transformadora, que tem o povo como gerador e protagonista". O autor esclarece que as mensagens são produzidas "para que o povo tome consciência de sua realidade" ou "para suscitar uma reflexão", ou ainda "para gerar uma discussão".

$\mathrm{O}$ que se percebe, portanto, é que a maioria das mensagens propagadas pelo grupo seguem no sentido de construir um caminho alterno às grandes mídias. Em um dos vídeos analisados, por exemplo, o grupo afirma: "Somos a voz do silêncio e os olhos da cegueira".

\section{Análise dos vídeos}

De junho a setembro de 2016, os Anonymous postaram vinte vídeos em seu canal oficial no Youtube. O conteúdo inclui três documentários (sobre Edward Snowden, Hillary Clinton e a Convenção Hacker DEFCON), além de diversas mensagens à população, com os mais variados temas.

De maneira geral, pode-se dizer que as principais problemáticas levantadas pelo grupo nesse período são: concentração de mídias, capitalismo, sociedade livre e aberta, manipulação, necessidade de vigilância social e meio ambiente.

Nota-se a tendência a conclamar a população para insurgir-se contra o atual sistema, empoderando os cidadãos e solicitando que permaneçam vigilantes para evitar a tirania.

Acerca da manipulação, há um vídeo especialmente voltado para a denúncia da falta de neutralidade na rede, em especial nas buscas do Google, ilustrada pelos resultados gerados quando se pesquisa o nome Hillary Clinton. Segundo o vídeo, as sugestões de busca fornecidas pelo site podem influenciar fortemente os resultados nas urnas e, por isso, o grupo sugere que o cidadão procure mecanismos próprios de pesquisa. 
Destarte, percebe-se que os Anonymous se colocam como "mensageiros da luz" e afirmam que suas ações não consistem em um levante contra o governo, mas em uma investida para colocar no poder quem de fato o detém: a população.

Além disso, divulgam seus perfis oficiais na Internet, convidando o povo a acompanhar suas ideias. Desse modo, pode-se afirmar que utilizam suas ações para fomentar seus veículos alternativos, nos quais expressam suas ideologias.

\section{Consideraçôes finais}

No contexto de propriedade cruzada dos meios de comunicação, o hacktivismo pode ser compreendido como um caminho alternativo de comunicação, pois, ao inserir mensagens em sites governamentais como forma de protesto, os hackers utilizam a visibilidade de grandes portais como mecanismo de resistência.

Essa lógica rompe com o tradicional fluxo, expresso na Teoria do Gatekeeper, segundo a qual o jornalista seria um tomador de decisões quanto ao que deveria ser publicado ou descartado. Se a comunicação flui por esses "portões" (gates), na cibercultura é difícil precisar onde eles começam e onde terminam, uma vez que o sistema de bits e bytes abre um leque de possibilidades e combinações nunca antes imaginado.

Se a comunicação alternativa está intrinsecamente ligada às manifestações dos excluídos das grandes mídias, pode-se vislumbrar a Internet como valioso espaço de manifestação popular, no qual os hackers navegam e disseminam seus pensamentos, oferecendo resistência ao poder vigente.

Sobrepesando esses fatos e a constante investida da grande mídia para criminalizar os hackers, pode-se supor que esse grupo pode estar sendo deslegitimado por um motivo latente: um movimento social que ganha força passa a contestar as instâncias sociais e estas não querem ser tiradas da inércia. 


\section{Referências bibliográficas}

ALVIM, Davis M. Pensamento indomado: História, poder e resistência em Michel Foucault e Gilles Deleuqe. São Paulo, Dimensões, 24, 193 207, 2010.

COLEMAN, Gabriella. Anonymous: from the lulz to collective action. The new everyday: a media commons project. 2011. Disponível em: <http://mediacommons.futureofthebook.org/tne/pieces/anon ymous-lulz-collective-action>. Acesso em: 9 de set. 2016.

ERCÍlIA, Maria; GRAEFF, Antônio. A Internet. Pubifolha. São Paulo, 2008.

FOUCAULT, Michel. O sujeito e o poder. In: DREYFUS, Hubert L.; RABINOW, Paul. Michel Foucault, uma trajetória filosófica: além do estruturalismo e da hermenêutica. Rio de Janeiro: Forense Universitária, 1995. . Ditos e Escritos IV : estratégias, saber-poder. Rio de Janeiro:

Forense Universitária, 2012.

KAPLÚN, Mário. El comunicador popular. Quito: CIESPAL, 1985. LEMOS, André. Cibercultura. Porto Alegre: Sulina, 2002.

LIMA, Venício A. de. LOPES, Cristiano Aguiar. Coronelismo eletrônico de novo tipo (1999-2004). As autorizações de emissoras como moeda de barganha política. Disponível em:

$<$ http://donosdamidia.com.br/media/documentos/Coronelis mo.pdf $>$. Acesso em: 23 de ago. de 2016.

MACHADO, Murilo B. Por dentro dos Anonymous Brasil: Poder e resistência na sociedade do controle. Universidade Federal do ABC, 2013.

.Entre o controle e o ativismo hacker: a ação política dos Anonymous Brasil. Disponível em:

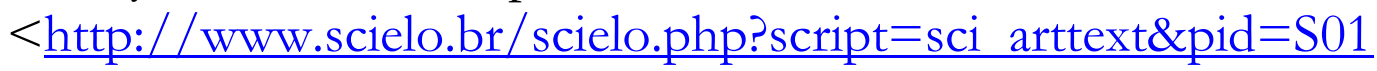
04-59702015001001531>. Acesso em: 03 de ago. de 2016.

PACHECO, Liliana. Wikileaks e Internet: O que poderá mudar no jornalismo a partir daqui. Disponível em: <http://www.ec.ubi.pt/ec/09/pdf/EC09-2011Mai-02.pdf.>. Acesso em: 28 de out. de 2011. 
ROSZAK, Theodore. El nacimiento de uma contracultura: Reflexiones sobre la sociedade tecnotrática y su oposición juvenil. Barcelona: Editorial Kairós, 1968.

ROVAI, Renato. Por trás da máscara de Guy Fawkes. Forum: outro mundo em debate, São Paulo, ano 9, n.101. p. 6-9, ago 2016. 


\title{
Redes y movimiento sociales, el caso del paro nacional agrario en Colombia
}

\author{
Jorge Aguilera. Universidad de Málaga (España). \\ jorgeaguileraphd@hotmail.com
}

El pasado mes de febrero fue laureada en la Universidad de Málaga España la tesis doctoral del Consultor Colombiano Jorge Aguilera. Dicho estudio que duró cerca de dos años analizó el manejo de medios móviles y uso de redes sociales desarrollada por la población campesina y en general la ciudadanía colombiana durante el Paro Agrario de 2013.

\section{Introducción}

— N AGOSTO de 2013 se evidencian ante la opinión pública colombiana los efectos económicos del TLC cuando el campesinado colombiano decide generar una marcha nacional denominada "Paro Nacional Agrario" arguyendo la pauperización de sus condiciones económicas producto de los tratados de libre comercio establecidos por Colombia con países como Estados Unidos y Canadá.

El origen de este trabajo de investigación tuvo que ver con la rápida viralización de los videos de denuncia sobre abuso policial contra los campesinos, que inundaron las redes sociales y conmocionaron la opinión pública nacional generando cambios de fondo en la percepción de personalidades, instituciones y el mismo gobierno. 
Dichos videos hechos con teléfonos celulares y rápidamente compartidos en redes sociales despertaron el arraigo campesino y la indignación a tal punto que la protesta pasó de un escenario on line a la off line, con cacerolazos nacionales y marchas internacionales a favor del movimiento campesino.

Este fenómeno es la respuesta de la apropiación de la tecnología como componente de la participación política que ha cambiado las reglas de juego entre la interacción del gobierno y los medios tradicionales de comunicación con la ciudadanía.

La posibilidad de utilizar la tecnología para hacer política, para mostrar el disgusto contra los representantes políticos o simplemente para hacer llegar un mensaje, se convierte en un nuevo desafío para los sistemas de comunicación y atención a las necesidades y requerimientos de los ciudadanos.

Las redes sociales y la web 2.0 han ampliado el espectro de comunicación de las masas, permitiendo a todos los sectores sociales y participantes tener voz y voto en un espacio global. Dicho espacio ha transformado durante la última década la percepción del pueblo colombiano, pues su influencia ha ocasionado el surgimiento de nuevos escenarios dialogantes distintos a los que permiten los medios de comunicación tradicionales.

Los movimientos sociales han utilizado siempre las herramientas comunicativas que tienen a su alcance para diseminar sus ideas, basta recordar el uso de la imprenta en los movimientos emancipadores de la colonia. En el caso del PNA los teléfonos celulares y el acceso a redes catapultaron dicha potencia.

\subsection{E1 momento tecnológico coyuntural}

La telefonía móvil ha tenido un gran crecimiento durante los últimos años del presente siglo. Según cifras de CEPAL (2010), en Colombia para el 2011 existían en promedio 92,3 suscripciones a telefonía celular por cada 100 habitantes, cifras que indican el gran impacto que ha tenido esta tecnología en el país, pero no se constituiría en un factor importante para la participación de los usuarios en las comunidades presentes en la red de no ser por la difusión de teléfonos inteligentes. 
En Colombia, ya en febrero de 2013 se visualizaba el uso de este tipo de tecnología, según informe de Flurry Mobile, Colombia lideraba en ese momento la tasa de adopción de móviles basados en Android e iOS.

Dicha consultora Flurry Mobile revelaba que el crecimiento de Smatphones a nivel mundial lo lideraba Colombia, como país más rápido en adoptar el uso de móviles basados en sistemas iOS y Android, por encima de Vietnam, Turquía, Ucrania, Egipto, China, Chile e India, entre otros.

De hecho, una encuesta de consumo digital en Colombia de ese mismo año realizado a partir de 1007 encuestas en 28 ciudades entre noviembre y diciembre de 2013 por la firma encuestadora IPSOS señalaba que 8 de cada 10 colombianos tenían acceso a internet, que el $77 \%$ de las personas de estrato 1 (menores recursos económicos) declaraba tener acceso a internet, del 2012 al 2013 el consumo de internet desde medios móviles paso del $22 \%$ al $33 \%$ con un crecimiento disparado de 11 puntos porcentuales en la población, del total de las personas con teléfonos móviles en el país, entre el 2102 y el 2013 se pasó de un 30 a un $42 \%$ el uso de teléfonos inteligentes, entre el 2012 y el 2013 el acceso a redes subió de un 73 a un 81\%, el $70 \%$ de la población declaró tener cuentas activas en redes sociales, y el 62\% declaró tener la facilidad para subir videos a internet.

En ese contexto no fue extraño encontrar en las visitas de campo que el teléfono móvil se había convertido en un elemento cotidiano y social, posterior al Paro Agrario no solo demostró su uso sino que se convirtió en una herramienta de coordinación de conocimiento e incluso de emancipación política.

\section{Metodología}

El presente trabajo tuvo el propósito de analizar la participación e incidencia de los videos ciudadanos a través de la plataforma YouTube en la construcción de opinión pública colombiana durante el caso del Paro Nacional Agrario de 2013. Para ello se propusieron tres pilares conceptuales que a la vez responden a tres etapas en la investigación: El ciudadano digital, El Estado y La Hiperpolítica. 
El primer paso de la investigación se centró en la revisión de documentación emitida por organismos estatales y otras entidades no gubernamentales dedicadas a la investigación de opinión; luego la caracterización de los ciudadanos digitales así como el efecto de sus acciones.

Para ello también se realizaron encuestas a los involucrados en el proceso, mediciones de la imagen del Estado, determinando la favorabilidad de los distintos sujetos o instituciones que se vieron involucradas como entes oficiales durante dicha situación de 2013.

Finalmente, tras comprender las características de los ciudadanos digitales que participaron en el movimiento de YouTube y sus acciones en la red, se buscó determinar las características del movimiento mismo, con un análisis más abstracto referente a la influencia hiperpolítica de las redes como canal alternativo de construcción de paradigmas sociales, democracia e identidad.

\subsection{Caracterización de los ciudadanos digitales}

En el primer paso metodológico se hizo necesario determinar los actores que influyeron en el Paro Agrario de 2013, respondiendo a la pregunta de ¿Cuál es el comportamiento de los actores del Paro Agrario de 2013 en relación a sus formas de distribución de la información y opinión en la plataforma YouTube? Se requirió caracterizar las acciones de quienes hicieron los videos de denuncia así como su comportamiento tanto en You Tube como en Facebook.

\subsection{Visitas de Campo}

El trabajo realizado tuvo un enfoque principalmente virtual, sin embargo es preciso mencionar la necesidad de un análisis de campo de la información obtenida; para ello fue necesario evaluar ciertas características de uso de la tecnologìa y la web por parte de los involucrados en las entrevistas.

\subsection{Contenidos Relevantes de YouTube en el momento del Paro Agrario en 2013.}

El contexto en el cual se desenvuelven los ciudadanos digitales en el momento del Paro Agrario no solo se relaciona con el lugar 
geográfico, sino la plataforma en la cual desempeñaron su participación en los eventos ocurridos.

Para efectuar el análisis del discurso audiovisual se tiene en cuenta lo expuesto por D’Angelo (2012) que establece que se trata de un enfoque cualitativo de investigación y análisis basado en la etnografía y el análisis crítico del discurso, enfocado al tratamiento de archivos audiovisuales.

Uno de los métodos aplicados en el ACD consiste en el análisis del discurso sociocognitivo, que se ilustra con el triángulo discurso (hecho comunicativo)-cognición (cognición social)-sociedad (relaciones).

A partir de la información consignada en las tablas fue posible realizar un análisis de naturaleza inductiva sobre la relación de la información textual y verbal con la de los signos no verbales (D'angelo, 2012: 130) que permitieron observar de forma clara las estructuras formales del discurso audiovisual.

La información recopilada de estos dos aspectos se completó con la información del contexto. Van Dijik (2003) propone que en el contexto se diferencie el ámbito local del global; mientras el contexto local se define en términos de las propiedades de la situación inmediata e interactiva en la que tiene lugar el acontecimiento comunicativo.

\subsection{Métricas aplicadas a la Social Media}

La medición de audiencias como muchas otras formas de medición ha sufrido cambios a lo largo de los años. Para el caso de páginas web, Rojo (2004) identifica sistemas de medición basados en el usuario, en la publicidad y en la web.

Páginas como YouTube donde se alojaron la mayoría de videos relacionados con el Paro Agrario tiene incluido un sistema de medición de audiencias que presenta variables como canal, fecha de publicación, número de reproducciones y de comentarios. Estos datos en general presentan el alcance de estos videos y permiten ver la opinión de su audiencia gracias a los comentarios. 
Aclarando que es habitual que estos datos presenten información parcial; de hecho algunos de los videos subidos por los usuarios durante el estudio fueron borrados dejando las medidas recogidas por este en otras fuentes, para este estudio se tomaron muestras de videos en YouTube publicados principalmente por canales de información independiente y videos personales de Facebook.

Como se ha explicado la información de tráfico que contienen estas páginas permite establecer las siguientes variables:

- Cantidad de vistas: Corresponde al total de vistas que posee el video alojado en la red, para esta variable se suma la cantidad de vistas que posea un video y sus copias.

- Cantidad de comentarios: Indica la cantidad de comentarios que el video posee sumando la cifra que alcance en todas sus copias.

- Veces compartidas: Indica la cantidad de veces que el video fue compartido por un usuario a otros usuarios, a su vez se distingue el medio entre YouTube, Facebook y Twitter.

- Cantidad de "no me gusta": Indica la cantidad de personas que indicaron que el video no les gustaba mediante el botón de "no me gusta" en YouTube.

\section{- Opinión Pública}

Otro de los factores decisivos del presente ejercicio de investigación se centra en la afectación en la imagen del presidente Juan Manuel Santos durante los eventos de estudio. Para medirlo se aplicaron encuestas que permitieron determinar si efectivamente los videos analizados previamente tuvieron un impacto en la opinión de los colombianos.

El segundo paso involucró la realización de encuestas y entrevistas a testigos y expertos en la materia, todo con el fin de indagar sobre los posibles efectos de los videos publicados en YouTube y su contexto.

\subsection{Entrevistas y encuestas a testigos y expertos}

Se realizaron de una serie de encuestas y entrevistas que abordaron las distintas preguntas arrojadas por el análisis de los datos obtenidos mediante la etnografía realizada en la investigación. 


\subsection{Encuesta con periodistas del sector agrario}

La encuesta a los periodistas que cubrieron el suceso (57) permitieron establecer las bases estadísticas sobre el impacto de la imagen general del Estado desde la perspectiva de los periodistas y su posición de legitimación frente a la sociedad inmersa en dinámicas digitales de formación de la opinión pública.

Para ello se establecieron dos etapas en la encuesta; la primera considerando el impacto en la reputación específica de la Policía Nacional, el presidente Juan Manuel Santos, Ministro de Agricultura, SAC, Gobierno Nacional en general y los Medios de Comunicación.

Una segunda etapa se hizo necesaria para evaluar el porcentaje de mejora o deterioro específico de las personas o instituciones mencionadas.

\subsection{Entrevistas con expertos y testigos}

Entrevistas semi-estructuradas cara a cara a expertos de la materia, asesores involucrados con las instituciones protagonistas y afectados directos durante el paro agrario, la lista incluyó autores y expertos en redes sociales, consultores en modernización del Estado y ciudadanía digital, así como y líderes campesinos de diferentes estamentos públicos y privados.

La entrevista se centró en el impacto que generó el uso de la tecnología por parte de los campesinos afectados durante el paro y las enseñanzas que dejaron los eventos vividos durante la situación de estudio.

\section{Resultados}

\subsection{Efecto en las redes, tipificación de los videos}

Para el año 2013 ese crecimiento en el consumo de celulares inteligentes, brindaba las condiciones necesarias para el empleo medios alternativos de comunicación e internet entre los campesinos.

De hecho, una encuesta de consumo digital en Colombia de ese mismo año realizado a partir de 1007 encuestas en 28 ciudades entre noviembre y diciembre de 2013 por la firma encuestadora Ipsos y presentada por el ministro Diego Molano en el 2013 señalaba que: 
- 8 de cada 10 colombianos tenían acceso a internet

- $77 \%$ de las personas de estrato 1 (menores recursos económicos) declara tener acceso a internet.

- Del 2012 al 2013 el consumo de internet desde medios móviles paso del $22 \%$ al $33 \%$ con un crecimiento disparado de 11 puntos porcentuales en la población.

- Del total de las personas con teléfonos móviles en el país, entre el 2102 y el 2013 se pasó de un 30 a un 42\% el uso de teléfonos inteligentes.

- Entre el 2012 y el 2013 el acceso a redes subió de un 73 a un $81 \%$

- El 70\% de la población declaró tener cuentas activas en redes sociales.

- El $62 \%$ declara tener la facilidad para subir videos a internet.

En ese contexto no fue extraño encontrar en las visitas de campo lo siguiente:

\subsection{Visitas de campo}

Durante las visitas se pudo observar cómo los campesinos empleaban el celular de manera cotidiana y naturalizada, utilizándola en sus diarios quehaceres de manera sistemática y consistente, además de utilizar modelos de última generación que brindaron las ventajas claves para hacer viral el movimiento, hechos bastante distantes del imaginario urbano donde se pensaba que este tipo de tecnologías solo se usaban por población joven radicada en las principales ciudades.

El uso de la tecnología en el caso de los campesinos observados se encuentra exento de una barrera educacional o formativa, es decir que los campesinos sin importar sus raíces o educación comparten en su mayoría el uso de celulares de última tecnología, relacionándole con sus realidades diarias (como por ejemplo viendo el video del nacimiento de una cabra en HD desde el celular de uno de ellos). 


\section{Figura 1. Campesinos compartiendo un video del nacimiento de una cabra}

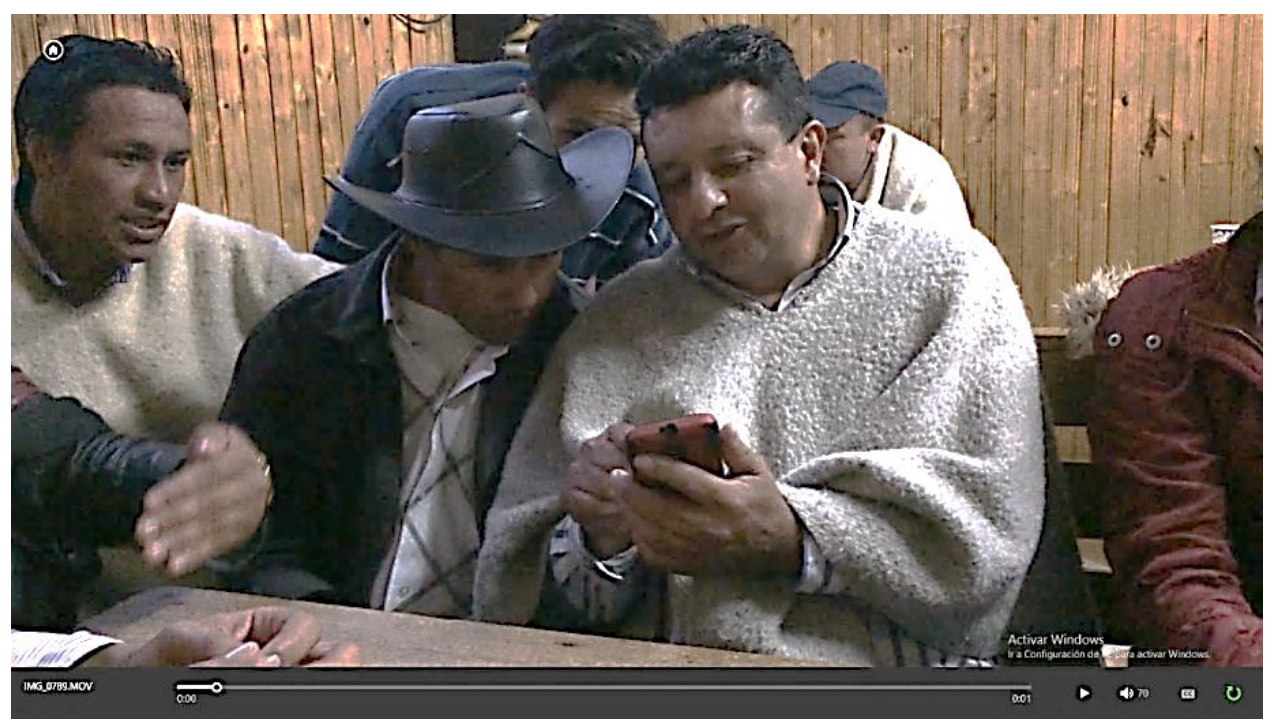

Fuente: elaboración propia

Otro de los principales usos observados durante las visitas se centró en las redes sociales como Facebook o WhatsApp en los que generan redes de comunicación para estar al tanto de las últimas noticias en la región de manera confiable; de hecho es el principal medio de transmisión de información relevante para la comunidad por lo que se convierte casi en un requisito para los campesinos tener un dispositivo con acceso constante a estas redes.

Durante y posterior al Paro Agrario no solo se demostró su uso sino que se convirtió en una herramienta de coordinación de conocimiento e incluso de emancipación política.

\subsection{La viralización de los videos}

Castell (2012) señala que las redes de indignados de caracterizan 'por la producción interactiva de significado propia de la auto comunicación de masas, refiriéndose a la posibilidad que tienen los ciudadanos den la red para ser productor, receptor y combinador de sus propios mensajes remezclando formatos o diversificando $y$ visibilizando estratégicamente información de su interés, construyendo además influencia e impacto sobre actores más poderosos que su individualidad. 
Deleuze y Guattari (1997) proponen la metáfora del rizoma para señalar ciertas características de los movimientos en red en donde los heterogéneos encuentran escenarios que los conectan de forma además abierta, excéntrica dinámica y reconstructiva cuando lo requiere.

Es así que de la información de los videos recopilados (Ver anexo 2. Videos visitas de campo) se podría establecer la siguiente estructura de viralización de los videos del paro agrario en YouTube:

- Videos de denuncia de los testigos presenciales. Generalmente hechos con teléfonos móviles, sin edición, frecuentemente con problemas de encuadre y donde se escucha la vOz de quien graba. Valga recordar el informe de Mintics de 2013 en donde señala que el $70 \%$ de la población había tenido experiencias subiendo videos a internet.

- Se comparte el video de denuncia a través de Facebook. Valga recordar que de acuerdo con el informe de Mintics de 2013 era la red por excelencia con un nivel de penetración superior al $70 \%$

- Algunas personas editaron haciendo compilaciones y compartieron el nuevo producto audiovisual.

- Usuarios más experimentados y con conocimiento técnico previo realizaron productos para compartir en redes a manera de cubrimiento noticioso.

- Pasan de on line a off line. Muestra de ellos son los videos de respaldo internacional que incluyen manifestaciones en la calle.

Como hecho a resaltar los noticieros con cada una de sus emisiones destacaron el costo diario del paro para la economía del país, pero nunca indicaron lo que habían perdido los campesinos por los TLC que habían provocado el PNA, que en ese momento se calculó superior a 2 billones de Dólares.

Tres elementos se hacen notorios en este ejercicio al comparar la información presentada por redes sociales y la transmitida por las emisiones centrales de RCN y Caracol: 
- RCN y Caracol cubren el Paro Agrario pero ocultan información de los desmanes de la policía, es este aspecto el que es denunciado por las redes sociales.

- Muestran el Paro Agrario como una catástrofe para el país, a diario indican cuánto se pierde en cada día de paro pero no mencionan cuánto han perdido los campesinos por el Tratado de Libre Comercio.

- No contrastan la información oficial cuando señalan que el paro está infiltrado por grupos terroristas.

Referente a la encuesta realizada a los periodistas que cubrieron el Paro Nacional Agrario de 2013, los resultados cuantitativos presentes se pueden tomar del total de la encuesta pues la misma se diseñó con un componente cuantitativo como principal referente en todas las preguntas (ver Anexo 3. Formato de encuesta aplicada a periodistas), a continuación se presenta una gráfica que indica las respuestas de los encuestados frente a la pregunta "Considera que los videos de denuncia presentados por los campesinos durante el Paro Agrario Colombiano, tuvieron un impacto positivo o negativo en la reputación de las siguientes personas o instituciones".

- Valga aclarar en este punto que se logró ubicar al 100\% de los periodistas que cubrieron el Paro Nacional Agrario gracias a la gestión y convocatoria hecha por la Sociedad de Agricultores de Colombia - SAC para este ejercicio.

- Los resultados de la primera pregunta indican un contundente impacto negativo en instituciones y personas como la Policía Nacional, el Presidente Juan Manuel Santos y el Ministro de Agricultura, quienes según los encuestados tuvieron un 100\% de impacto negativo, efecto ello de los eventos ocurridos en el Paro Agrario. Las demás instituciones aunque no tuvieron un contundente $100 \%$ de impacto negativo, si mantuvieron la misma tendencia, lo cual indica que el PNA tuvo en general un impacto negativo sobre las instituciones y personas responsables de la gestión gubernamental, mientras las estrategias mediáticas para desprestigiar el movimiento campesino al parecer no tuvieron efecto. 
Figura 2. Impacto de los videos de denuncia presentados por los campesinos sobre la reputación

Impacto de los videos de denuncia

(Presentados por los campesinos) sobre la reputación de:

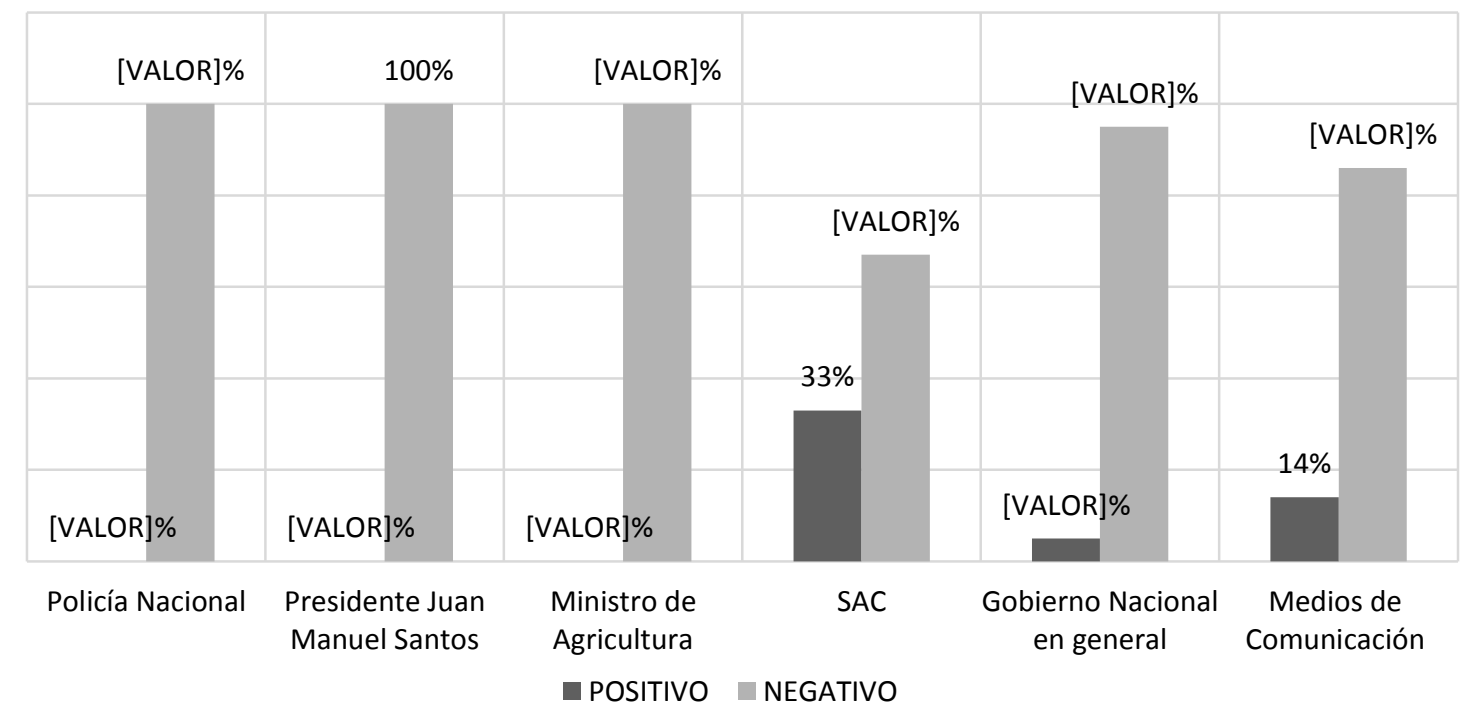

La tabla muestra los resultados de las encuestas realizadas en campo sobre la imagen de ciertas instituciones estatales y el gobierno nacional. . Fuente: Elaboración propia

Se puede evidenciar una tendencia negativa por parte de la opinión pública referente a la imagen de las personas o instituciones involucradas en el PNA, los encuestados además registraron su opinión referente a las posibles razones que impulsaron este impacto negativo:

\section{Policía Nacional:}

- Se evidenció la mala administración y el nivel de crueldad de la institución.

- La Policía agredió a los campesinos y contribuyó a negar la realidad.

- La Policía abusó de la autoridad y utilizó la fuerza desmedida sobre la población civil. 


\section{Presidente Juan Manuel Santos:}

- Intentó engañar al país, mintió.

- No tuvo un conocimiento de la realidad.

- Le faltó autoridad para controlar a los militares.

- Mostró indiferencia.

- Desconoció una situación evidente que después tuvo que reconocer

- Murió con la frase "el tal paro agrario NO existe".

- Las redes sociales le cobraron su actitud.

\section{Ministerio de Agricultura:}

- Nunca logró llegar a un acuerdo.

- El ministerio mintió.

- Fue cómplice del presidente.

- Indiferente ante la magnitud del problema.

- No hubo una postura a favor de los campesinos

- Permitió que César Pachón (Uno de los líderes del paro) tuviera todo el protagonismo de representación

- Fue altamente incompetente, desconoció el clamor popular.

\section{Sociedad de Agricultores de Colombia -SAC:}

- Intentó ser el puente de conversación entre el gobierno y los campesinos, pero no lo logró.

- No hubo un acuerdo favorable, no se reconoce a la SAC como legítimos voceros Campesinos.

- A regañadientes reconoció el Paro Agrario.

- Faltó de liderazgo sectorial.

Gobierno nacional en general:

- Olvido a los campesinos.

- No apoyó a los campesinos.

- Fue mentiroso e indolente.

- Permitió que los campesinos llegaran a su máximo nivel de pobreza. 
- No hizo una gestión adecuada que permitiera a los campesinos recuperar lo perdido.

- Se salió de control el paro.

\section{Medios de comunicación:}

- Trataron de favorecer al gobierno.

- Los canales privados siempre estarán a favor del gobierno.

- Mostraron a los campesinos como delincuentes.

- Se evidenció la falta de ética de los medios.

- No informaron objetivamente.

- Desinformaron el efecto de las redes sociales, dentro de lo posible, los medios registraron y cubrieron a favor de los campesinos.

Resultados de la encuesta aplicada a periodistas: ¿En qué porcentaje se perdió la imagen de las siguientes Personas o Instituciones?

Figura 3. Impacto de los videos de denuncia presentados por los campesinos en la pérdida de imagen.

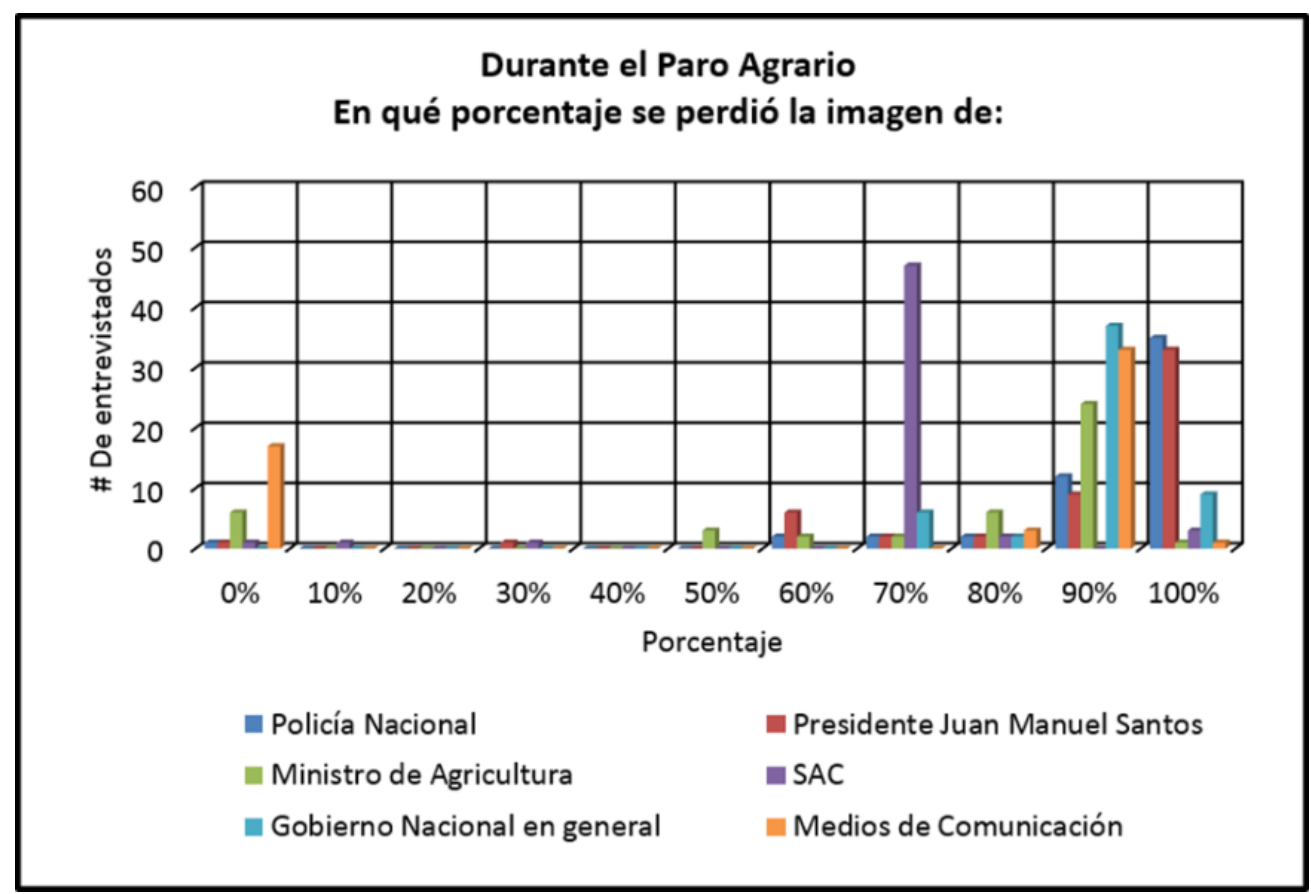

Fuente: Elaboración propia.

La tabla muestra los resultados de las encuestas realizadas con periodistas sobre la imagen de ciertas instituciones estatales y el gobierno nacional. 


\subsection{Medios tradicionales vs redes sociales}

Hasta ahora la comunicación había sido pensada para una sociedad de masas, la radio la prensa y la televisión, fueron planteadas desde un uso unidireccional de la información, de hecho de lo observado hasta el momento, durante el PNA los principales medios de Colombia, audiovisuales e impresos, sirvieron de protección institucional, o por lo menos ello quisieron.

Sin embargo, tras las jornadas de protestas del sector agrario, se observó adhesión de múltiples sectores. Los medios se vieron presionados a incluir el tema en sus agendas y pronto el Tratado de Libre Comercio con los Estados Unidos generó una imagen negativa del presidente Juan Manuel Santos.

De acuerdo a la teoría agenda setting de Maxwall y Donald Shaw, una aparente selectividad en los temas entre los noticieros producto de la jerarquización de la información generò desconfianza en cuanto a su neutralidad.

Los campesinos recurrieron a sus propios medios y en sus manos estaban los dispositivos móviles y las redes sociales., entre ellas Youtube, para difundir abiertamente lo que estaban vivenciando.

Uno de los participantes en el paro señaló en la entrevista realizada en 2014 que inicialmente usaban celulares sencillos y sin servicio de datos, "pero al ver que los noticieros decían cosas que no eran, decidimos cambiar los teléfonos celulares para informar nosotros mismos". ( Ver entrevista Segundo Riaño)

El balance de esta situación que muestra la importancia y relevancia de la redes sociales y de YouTube para dar a conocer videos de graves abusos de la fuerza pública contra los manifestantes, el grado de violencia perpetrado por la fuerza pública en especial por el ESMAD, y la baja notoriamente de credibilidad de la policía nacional.

Otro factor a tener en cuenta referente a la credibilidad de los medios de comunicación señala la fuente de la cual proviene su información, y la manera en la cual las instituciones tratan de generar un sesgo y control de la información a partir del control de contenido mismo de los medios de comunicación tradicionales, dejando claro un interés y 
control de unos individuos en la emisión de la información. (Amelrame, 2013: 3)

A pesar de la gravedad del mismo los medios se vieron obligados a transmitir la menor cantidad de información posible sobre el hecho, elemento que permitió a los ciudadanos pensar en un control de la información por parte de las instituciones involucradas en los eventos. Lo que posteriormente dio mayor fuerza a los medios alternativos de denuncia empleados durante el PNA (Twitter, YouTube).

De forma resumida el tema de paro agrario empieza a aparecer en prensa desde el 17 de agosto de 2013, pero no toma fuerza hasta el 20 de agosto alcanzando su pico el 21 con $35.8 \%$ del espacio en prensa dedicado al tema, a partir de este punto comienza a fluctuar entre el $20 \%$ y el $2 \%$ hasta que el tema desaparece finalmente el 7 de agosto de 2013.

\section{Figura 4. Influencia del gobierno en los medios de comunicación}

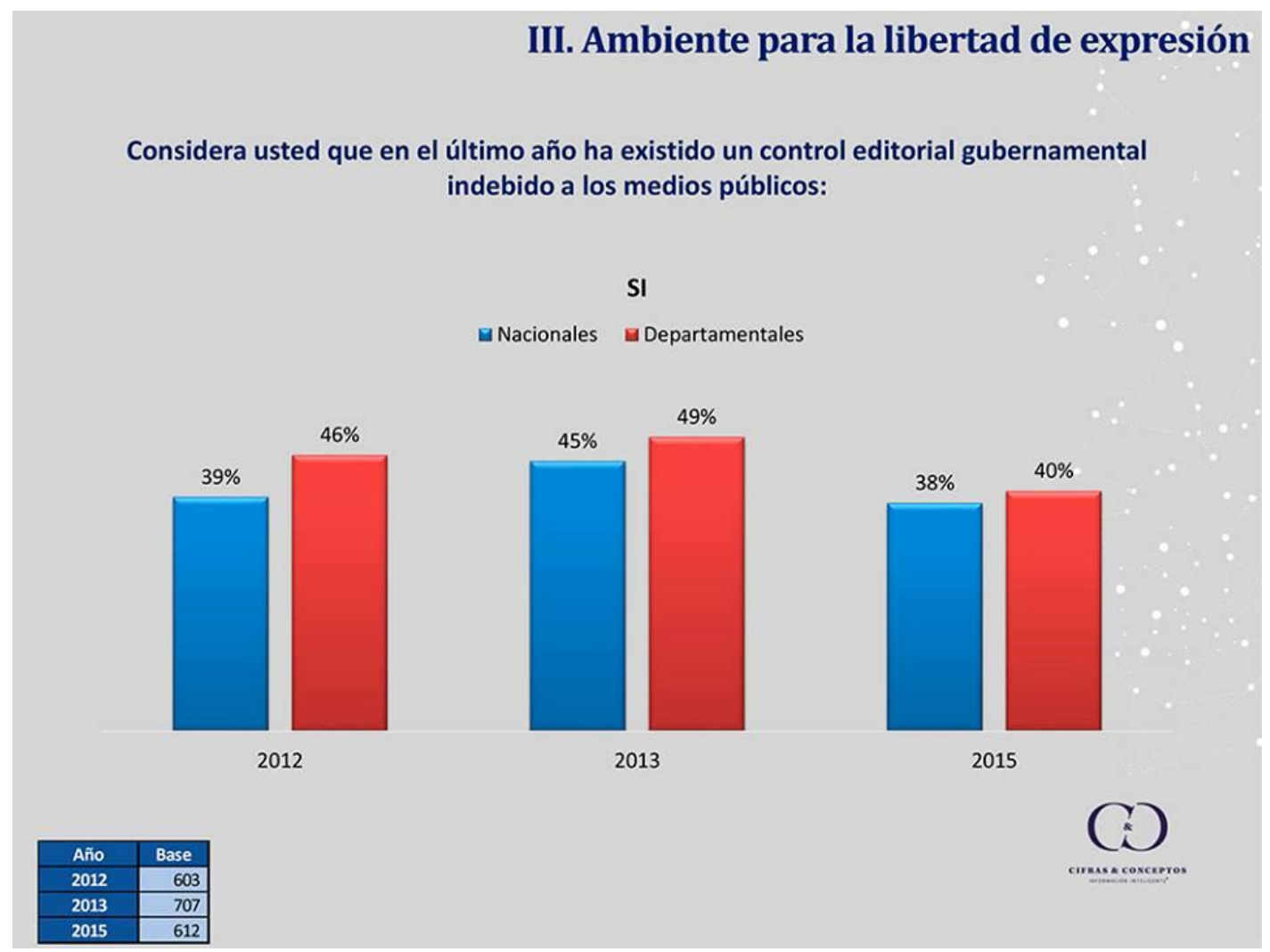

Fuente: Fecolper 
Sin embargo, según el informe que la Federación Colombiana de Periodistas - Fecolper - presenta año tras año y realizada por la firma Cifras y Conceptos, en el 2013 en una encuesta realizada a 707 periodistas el $45 \%$ de quienes trabajan en medios nacionales y el 49 de los que trabajan en medios regionales (departamentales) señalaron que se había presentado una injerencia indebida en las posturas editoriales de sus respectivos medios de comunicación por parte del gobierno (Fecolper 2015).

Este hecho tangible demuestra no solo el origen de la intencionalidad editorial de los medios presentada ese año 2013 sino que además da respaldo a las conductas primero de invisibilización y después de propaganda negativa hacia el movimiento campesino, dicho incluso por los mismos periodistas.

\subsection{Efecto de las redes sociales en el PNA}

Si tenemos que definir el ciberactivismo desarrollado durante el PNA, podemos decir que detrás del manejo de las redes sociales no hubo una estrategia de comunicaciones, ni un equipo de comunicaciones o un community manager con una estrategia digital, se encontró que quienes colaboraron con divulgación activa en redes lo hicieron por iniciativa propia y por vinculación emocional, de forma aleatoria no estructurada ni planeada, logrando los siguientes efectos:

- Visibilizar el paro rompiendo el bloqueo mediático y la estrategia del gobierno.

- Desmentir los mensajes de los medios de comunicación que repetían la propaganda gubernamental a tal punto que los medios terminaron cubriendo la protesta y visibilizando a los campesinos.

- Solidarizar a la ciudadanía con el movimiento.

- Convertir la problemática campesina en un tema de interés para el país.

- Vincularon más personas al paro, personas dentro de su región de influencia que incluso estaban indecisas.

- Ampliaron el impacto. Los mensajes de apoyo internacional dieron otro contexto a las acciones gubernamentales para invisibilizar el paro. 


\subsection{Los teléfonos móviles fueron determinantes}

Si bien Wincour (2009) nos señala cómo los dispositivos móviles son elementos simbólicos para controlar la incertidumbre, es decir, mecanismos para que las personas a partir del uso y la consulta de los medios móviles gestionen la incertidumbre dentro de la dinámica del futuro continuo, lo observado en la investigación del PNA arrojó una realidad donde la intervención del celular trasciende dicha función. Castells (2012) señala que los medios de comunicación por medio de las TICS generan un movimiento que conecta las mentes para contestar al poder, el uso de los medios móviles en este movimiento campesino tuvo como origen elementos de necesidades de coordinación y visibilización en respuesta a la campaña desinformativa de los medios de comunicación frente a lo que estaba sucediendo en el país, se notó entonces un uso del celular desde el punto de vista de la ciudadanía virtual, generando espacios en las redes sociales para la comunicación no solo en busca de resolver una incertidumbre, sino para formar una red social de conformación de identidad y "sociedad".

Otro de los elementos encontrados fue el uso de los medios móviles por población muy adulta y con bajo nivel de escolaridad pero con referentes de conocimiento y de uso desde sus hijos o familiares jóvenes, factor que nos demuestra como la inclusión de un cierto sector demográfico en los ejercicios sociales de las redes de internet no se sujetaban a edad o posición económica, sino a características de cercanía con los eventos ocurridos en las zonas más afectadas por el paro agrario, respondiendo a un cinismo político producto de la variedad cultural y específicamente las condiciones precarias (Castells, 2012), que se generaron en contra de los campesinos.

El uso de los medios móviles y el acceso a las redes sociales genera no solo conexiones, también genera dinámicas de solución, de apropiación y de vivencia política de los participantes, como se ha insinuado ya en lo expuesto anteriormente, los celulares son parte de la conformación de sociedad, y una sociedad virtual además que tiene como finalidad denunciar a los gobiernos producto de la pérdida de confianza en los medios tradicionales de información que cohesionó con una sociedad que sin fe en sus instituciones (Castells, 2012). Gracias a su participación y a hacer parte de la cadena de denuncia, 
los campesinos de sintieron protagonistas no solo de su propia realidad sino de un momento histórico en un escenario virtual donde asumieron una posición crítica y menos dispuesta a reconocer a los medios de comunicación tradicionales debido a sus claras conexiones con los organismos establecidos de poder (Alonso et al, 2005), y que habían asumido una estrategia de desprestigio contra sus exigencias.

El éxito de ser visibles, de romper el cerco informativo de los canales institucionalizados de noticias fue el elemento clave del PNA del año 2013, donde efectivamente ante la estrategia de invisibilización de los medios de comunicación a nivel nacional, los campesinos lograron visibilidad a través de las redes sociales, generando un manejo activo de estas plataformas en su red social y trascendiendo cuando los mensajes llegaron a ser replicados por usuarios de las redes sociales en las principales ciudades del país, especialmente Bogotá.

En gran medida gracias a las condiciones tecnológicas de sus dispositivos que permitían trascender de la comunicación por medio de texto, añadiendo elementos como la fotografía y video, causando un impacto mediático mucho más profundo (Cotarelo y Olmeda, 2014), en conjunto a una red social contactada con los procesos virtuales como medio principal de transmisión y creación de la información relevante para la mayoría del colectivo (Alonso et al, 2005).

\subsection{Los medios de comunicación perdieron credibilidad y confianza}

En el PNA hubo una característica muy particular y es que quiénes construyen la discusión no son propiamente los personajes políticos que interactuaban con los medios de comunicación, sino los ciudadanos entrando en el escenario de lo político inicialmente a través de la denuncia de eventos que atentan contra una población en desventaja, como bien lo menciona (Boje, 1995) sino desatando y cohesionando inconformidades que sin saberlo el ciudadano, eran masivas.

Así mismo, el concepto de la subjetividad en la ficción del nuevo espacio público planteado por Cotarelo y Olmeda (2014), en el que se manifiesta el tema de acercarse al testigo, al que está cerca, plantea 
nuevas formas de percibir cuál es la realidad del país, alejada de lo que pudiesen pretender los medios de comunicación tradicionales. Esta argumento se puso claramente al descubierto durante el PNA, cuando hubo un acercamiento a aquellos que mostraban los videos, ocasionando de esta manera, un escenario de participación política en el que se promulga una denuncia social de lo que se estaba presentando con los entes de control del Estado y aún más importante desde la mirada e intereses que competían a un sector de la sociedad que hasta el momento no había expresado sus necesidades de manera relevante para el resto de la sociedad.

Es en esta situación en la que se genera una opinión en lo público y en la que se hacen públicas una serie de circunstancias que estaban presenciándose (vídeos con una fuerte carga visual que apelaba a los sentimientos de las personas, no opiniones), que conllevaron a la unión de las personas en torno a la percepción de injusticia que se sentía en ese momento y que terminó generando deterioro de la imagen de aquellos medios tradicionales que optaron por no mostrar lo que estaba ocurriendo.

El discurso de los medios de comunicación tradicionales perdió su credibilidad, pues se hizo evidente que respondían a intereses de una élite económica cuya prioridad es mantenerse en el poder. Al sentirse los campesinos engañados y que no habían sido respaldados por los individuos que habían elegido para protegerlos, encontraron además en los medios de comunicación tradicionales una nefasta complicidad con quienes les habían perjudicado. Al acontecer este fenómeno, intervienen las redes sociales en un rol de discusión de lo político, Facebook se convierte en una herramienta para el debate de la legitimación del poder, dando opinión abierta a los distintos colombianos indignados con los eventos ocurridos, en una plataforma que permite acompañar la denuncia con opinión. Si bien es importante recalcar que dicha denuncia nace en Youtube, es crucial comprender que se viraliza en Facebook y se argumenta en Twitter, todo girando en torno a una serie de videos que denunciaban lo ocurrido de manera contundente y con un claro discurso político en contra de los organismos de poder en el país. Esto se distribuyó por la red sobrepasando las fronteras de Colombia, para finalmente tomar 
dimensiones internacionales y legitimar las protestas de la población campesina.

Cuando el tema de la protesta campesina llega a Twitter, comienzan a opinar los líderes provenientes del periodismo y el sector público con alto nivel de credibilidad e influencia y que repercuten decididamente en el efecto hacia el gobierno.

Como dato curioso, el PNA también permitió ver que los medios eran novatos en temas digitales y que hasta ese momento estaban ingresando en los escenarios transmedia. Medios de comunicación como noticieros y emisoras radiales que comenzaron a ingresar en discusiones de las redes sociales, se vieron avasallados por el debate, los señalamientos y las acusaciones de la ciudadanía, elemento que potencializó el descenso de su ya perdida credibilidad.

\subsection{La relación entre el debate virtual y la movilización física en la calle}

Facebook facilitó la gran viralización de la denuncia de los vídeos publicados en YouTube y Twitter fue la plataforma en que la opinión tuvo gran relevancia, debido al tipo de actores que comenzaron a debatir allí. Se desarrolló entonces una maquinaria que se autoconstruyó que se autodeterminó, al mejor estilo de la autopoiesis de Maturana (1998), que no solo cumplió una función de denuncia, sino además generó un acto de hiperpolítica que comenzó a cuestionar la forma en la cual el país estaba siendo administrado.

También encontramos en el PNA el asunto de la movilización con un nuevo elemento hasta ahora poco definido, los "autoconvocados", actores testigos de la red que se unieron como participantes en la calle sin tener más vínculos aparentes que un sentimiento colectivo, con ellos hallamos la relación entre lo virtual y lo físico y el momento en el que transitamos del primer al segundo contexto y que precisamente se exhibió en los cacerolazos que se hicieron en el marco del Paro Agrario, cuando la gente decidió salir a protestar tanto en Boyacá como en el centro del país y en otros lugares del mundo por lo que estaba pasando en el sector agrario. 


\subsection{Cambios de percepción en la opinión pública sobre el Estado}

Gracias a las redes sociales, nuevas formas de asociación y resistencia política han surgido en diversas partes del mundo, los movimientos de redes sociales han demostrado ser efectivas al emplear los nuevos medios de comunicación para expresar las desigualdades e injusticias que existen en la actualidad y que nunca fueron cubiertos por los medios masivos de comunicación.

Tomando como referencia los documentos de Castells (2012), Chomsky (2012) y Alazan (2012) sobre movimientos de indignados en Egipto, Islandia, España y México, todos ellos hacen uso de las redes sociales para convocar marchas y generar opinión, pero guardan entre si ciertas características frente a las cuales vale la pena comparar el PNA de Colombia a manera de establecer similitudes y diferencias. (Ver tabla 17)

En la tabla 17 se presentan las características generales de cada una de forma comparativa.

\section{Tabla 2. Tabla comparativa movimientos de indignados}

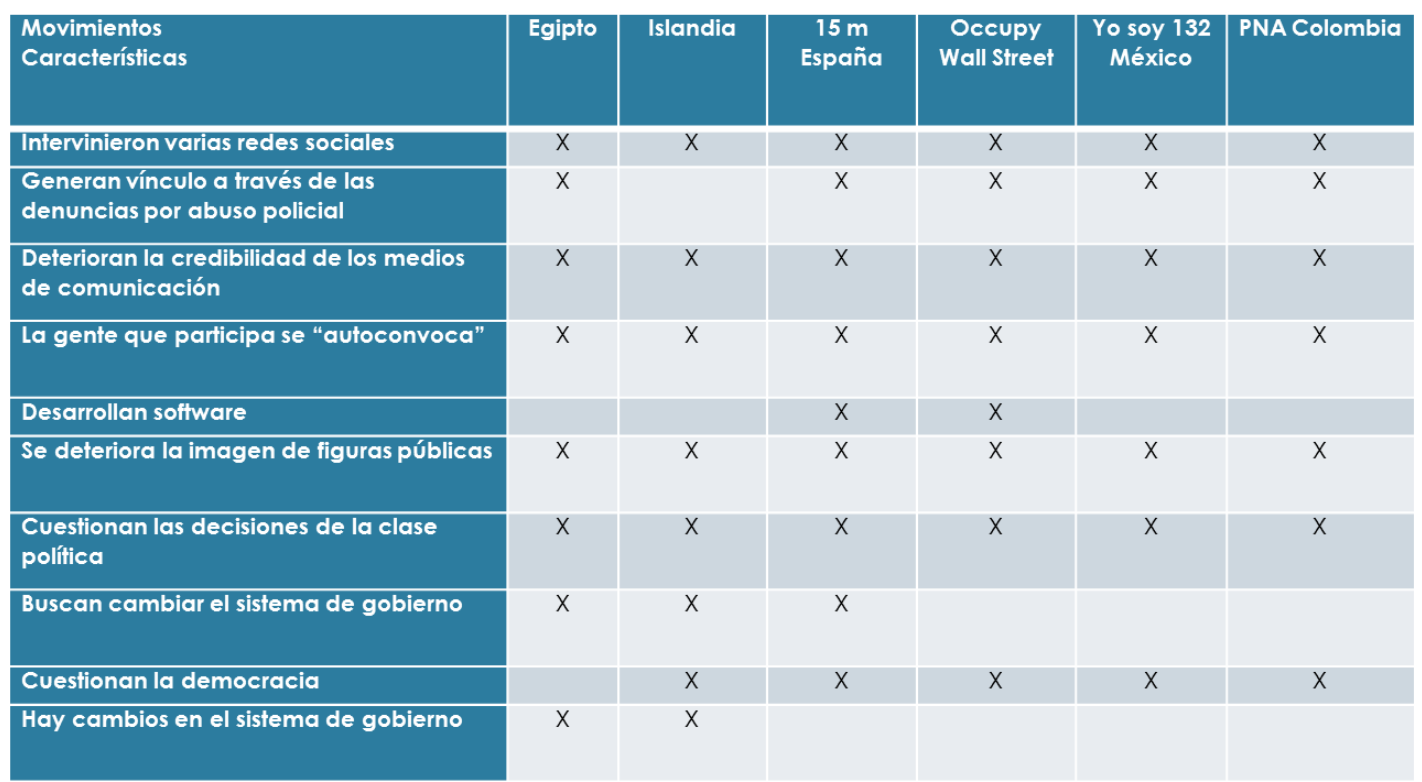

La tabla presenta una comparación en la ejecución de acciones y objetivos de cada movimiento indicando con $\mathrm{X}$ las variables que cumple

Fuente: Elaboración propia 
Una vez comparadas las cuentes es posible establecer similitudes y diferencias del uso de redes sociales en el PNA frente a otros movimientos donde podemos observar que aunque se cuestionó la legitimidad de las decisiones de gobierno, en ningún momento por ejemplo se pretendió cambiar ni al gobierno, ni a la forma de gobierno.

Incluso curiosamente, dos años después de la negociación con el gobierno no se hacen tangibles los acuerdos pactados.

\subsection{En resumen}

Figura 5. Efecto del uso de redes sociales por parte del campesinado durante el paro agrario de 2013 en Colombia

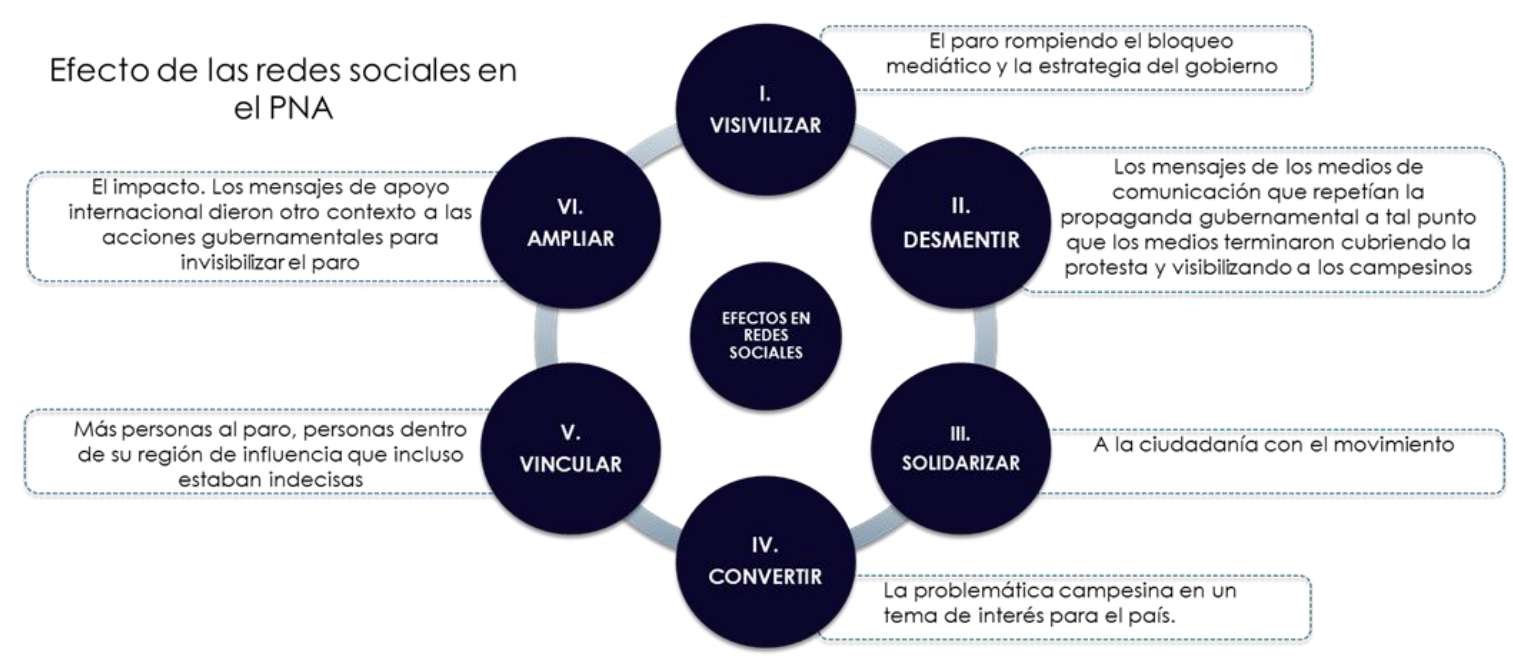

Fuente: Elaboración propia.

Al cierre de estos resultados y desde una perspectiva global vemos dos grandes versiones en puja. De un lado la globalización con consecuencias económicas y sociales graves y con una seria incidencia en la distancia entre ricos, cada vez más ricos, y pobres, cada vez más pobres (Téngase en cuenta la migración de la clase media hacia variables de pobreza) como lo señalan Klein (2007) e incluso Alonso (Alonso y Arzoz, 2005)

$\mathrm{Y}$ de otro los movimientos que han sido producto del rechazo a los efectos de la globalización, que en casos como el PNA de Colombia 
en 2013 se enfocaron más en los TLC sin asociar sus orígenes a la práctica globalizadora.

Al respecto Ramón (2014) indica la oportunidad de una nueva democracia directa, que parte del hastío de la ciudadanía y que se ha fortalecido en experiencias desde la primavera árabe hasta movimientos como el 15M, la acampada de Wall Street y el movimiento 132 en México, en búsqueda de participación e incidencia ciudadanos en las decisiones políticas aprovechando las oportunidades que brinda el escenario tecnológico.

Sin embargo, Alejandro Piscitelli en la entrevista realizada para el presente ejercicio indicó que el pulso entre la economía y la comunicación ciudadana vía tecnológica, lo ganará la economía que es quien determina el rumbo y el comportamiento de las decisiones políticas.

De hecho al cierre de este estudio en diciembre de 2015, el gobierno nacional se enfrentaba a un nuevo Paro Campesino provocado por el incumplimiento de los acuerdos de 2013.

\section{Conclusiones}

Se puede concluir que efectivamente el perfil de los campesinos ha cambiado drásticamente y dista bastante del imaginario que se tiene del mismo en las grandes ciudades colombianas. Sus dinámicas sociales y de producción han cambiado radicalmente y se han convertido en usuarios permanentes de la tecnología y redes sociales que hoy referencian incluso como fundamental para estar "informados y ser tenidos en cuenta".

La tabla 1. presenta en orden de mayor a menor los títulos de los videos que tuvieron mayores valores en las variables de vistas, veces compartidas y comentarios.

Sobre los resultados observados en el listado se menciona que los videos compartidos en Facebook son los que más vistas tienen indicando que esta fue la plataforma más efectiva para distribuir los videos, también se observa que existe una relación directa entre número de vistas $\mathrm{y}$ veces compartidas, pero al tratarse de comentarios, YouTube presenta mayores resultados. 


\title{
¿Cuántos videos se pueden encontrar del Paro Agrario en YouTube aproximadamente?
}

\author{
En Google $\quad$ Aproximadamente 508.000 resultados \\ En YouTube $\quad$ Aproximadamente 22.900 resultado
}

Al utilizar como palabras de búsqueda en YouTube :

\section{PALABRA DE BUSQUEDA \# DE REGISTROS}

\begin{tabular}{|l|l|}
\hline Paro Nacional Agrario 2013 & 22.900 aprox \\
\hline Paro Nacional Agrario & 35.000 aprox \\
\hline Paro Agrario & 46.000 aprox \\
\hline Paro Agrario 2013 & 34.700 aprox \\
\hline
\end{tabular}

Tabla 1

\begin{tabular}{|c|c|c|}
\hline \multicolumn{3}{|c|}{ Por Número de reproducciones } \\
\hline & Dirección & Repro \\
\hline 1 & $\begin{array}{l}\text { https://www.facebook.com/ingagronomica.uptche/vid } \\
\text { eos/vb.100002988790066/423811201061836/?type= } \\
\underline{2}\end{array}$ & 889842 \\
\hline 2 & $\begin{array}{l}\text { https: / } / \text { mwn.facebook.com/photo. php?v=101516408 } \\
\text { 85712017\&set=vb.680187016\&type=2\&theater }\end{array}$ & 485796 \\
\hline 3 & https://youtu.beN1 bzNrD4108 & 413848 \\
\hline 4 & https://youtu.be/msxcvunypdw & 303311 \\
\hline 5 & https://wnw.youtube.com/watch?v=HJwBDg9oiCw & 230740 \\
\hline 6 & https://youtu.be/G8_v5Aer54 & 126561 \\
\hline 7 & https://youtu.be/4ysFtbhaGgg & 109908 \\
\hline 8 & https://youtu.be/S8Fw4mFLB6c & 77132 \\
\hline 9 & https://wnw.youtube.com/watch?v=f8f8AOkfCuc & 77132 \\
\hline 10 & https: //youtu.beN1 bzNrD4108 & 36220 \\
\hline
\end{tabular}

\begin{tabular}{|c|c|c|}
\hline \multicolumn{3}{|c|}{ Por Número de veces compartido } \\
\hline & Dirección & Compartido \\
\hline \multirow[t]{2}{*}{1} & https://mww.facebook.com/photo.php?v=101516408 & \multirow[t]{2}{*}{97308} \\
\hline & 85712017\&set=vb.680187016\&type=2\&theater & \\
\hline \multirow[t]{3}{*}{2} & https://www.facebook.com/ingagronomica.uptche/vi & \multirow[t]{3}{*}{2976} \\
\hline & deos/vb.100002988790066/423811201061836/?typ & \\
\hline & $e=2$ & \\
\hline 3 & https://www.youtube.com/watch?v=HJwBDg9oiCw & 1316 \\
\hline 4 & https://youtu.be/U4XCPk2EMDA & 1108 \\
\hline 5 & https://youtu.be/msxcvunypdw & 1100 \\
\hline 6 & https://youtu.be/4ysFtbhaGgg & 551 \\
\hline 7 & https://youtu.be/G8 v5Aer54. & 509 \\
\hline 8 & https://wnw.youtube.com/watch?v=f8f8A0kfCuc & 273 \\
\hline 9 & https://youtu.be/S8Fw4mFLB6c & 182 \\
\hline 10 & https://youtu.beN1 bzNrD4108 & 112 \\
\hline
\end{tabular}

\begin{tabular}{|c|c|c|}
\hline \multicolumn{3}{|c|}{ Por Número de comentarios } \\
\hline & Dirección & Coment \\
\hline 1 & https://youtu.be/msxcvunypdw & 1727 \\
\hline 2 & https://youtu.be/U4XCPk2EMDA & 739 \\
\hline 3 & https://wnw.youtube.com/watch?v=HJwBDg9oiCw & 734 \\
\hline 4 & https://youtu.be/GG8 v5Aer54 & 470 \\
\hline 5 & https:///youtu.be/4ysFtbhaGgg & 218 \\
\hline 6 & https://wnw. youtube.com/watch?v=f8f8A0kfCuc & 131 \\
\hline 7 & https://youtu. be N1 bzNrD4108 & 105 \\
\hline 8 & $\begin{array}{l}\text { https://hww.facebook.com/ingagronomica.uptche/videos/v } \\
\text { b. 100002988790066/423811201061836/type }=2\end{array}$ & 38 \\
\hline 9 & https://youtu.be/5UbBd-PR8SA & 34 \\
\hline 10 & https://wnw.youtube.com/watch?v=uZBCFF6cLLg & 28 \\
\hline
\end{tabular}

Registro de clasificación de los videos viralizados, de acuerdo al número de reproducciones, número de veces compartido y numero de comentarios 
En ellos no existe de forma explícita y audiovisual un documento que vincule directamente al gobierno del presidente Juan Manuel Santos y las acciones de la policía u otro indicio que explique por qué su imagen se vio tan afectada; sin embargo, si se identifica en el cubrimiento de la noticia por parte de los medios nacionales y su reinterpretación por parte de las redes sociales. Son relevantes los archivos que muestran la posición del presidente Juan Manuel Santos ante la situación, quien afirmó que el Paro Nacional Agrario no existía.

Es clave tener en cuenta que las redes, dada su condición supra territorial y más relacional, tuvo un efecto que trascendió las fronteras colombianas y generó un mensaje global de apoyo al sector campesino.

\section{Entrevistas}

Segundo Riaño: Participante paro Agrario.

https://www.youtube.com/watch?v=GqS9-WmqPV4

Lázaro Rojas: Participante Paro Agrario.

https://www.youtube.com/watch?v=OGC5kDIJK6Q

Ramón Ramón: Experto en ciudadanía digital.

https://www.youtube.com/watch?v=aDEYvt-1QUY

Alejandro Piscitelli: Experto en Ciudadanía Digital.

https://www.youtube.com/watch?v=QDMm1TW3QQU

\section{Referencias}

Aguado, J. M. y Castellet, A. (2013). Periodismo móvil e información ubicua. Aguado, J.M; Feijóo, C. y Martínez, I.J. (Coords.) La comunicación móvil: Hacia un nuevo ecosistema digital. Barcelona: Gedisa.

Alcazan, ArnauMonty, Axebra, Quodlibetat, Sunotissima, S. L., Take'TheSquare, y Toret. (2012). Tecnopolitica internet y $r$ evoluciones (Primera edición.). Barcelona: Romanyá Valls, S.A.

Alonso, A. y Arzoz, I. (2005). Cibergolem: La quinta columna digital. Antitratado comunal de hiperpolitica. Barcelona: Gedia S.A. 
Amelrame. (2013) ¿Cómo cubrieron 3 periódicos colombianos el Paro Agrario 2013? Mi análisiscon@pageonex. Disponible en: https://aquideomnibusdubitandum.wordpress.com/2013/09 /10/como-cubrieron-3-periodicos-colombianos-el-paroagrario-2013-mi-analisis-con-pageonex/

Arnau, J. (1995). Metodología de la investigación psicológica. En M.T. Anguera, J. Arnau, M. Ato, R. Martínez, J. Pascual y G. Vallejo (eds.), Métodos de Investigación en Psicología (pp. 23-44). Madrid: Síntesis-Psicología.

Bauman, Z. (2002) Modernidad Liquida. Barcelona: Fondo de cultura económica de España.

Benavides, J. (2011). Impacto de las tecnologias de la información y las comunicaciones (TIC) en el desarrollo y la competitividad del país. Recuperado de:

http://www.fedesarrollo.org.co/wpcontent/uploads/2011/08/Impacto-de-lasTecnolog $\%$ C3\%ADas-de-la-Informaci $\%$ C3\%B3n-y-lasComunicaciones-TIC-Informe-Final-Andesco.pdf

Boje, D. (1995). Stories of the Storytelling Organization: A postmodern analysis of Disney as "Tamara-Land", Academy of Management Journal, 38 (4), 997-1035. Recuperado de: http://business.nmsu.edu/ dboje/papers/DisneyTamaralan d.html

Botero, L.H. (2006) Teoría de Públicos, Lo público y lo privado en la perspectiva de la comunicación. Medellín: Sello editorial. Caldevilla Domínguez, D. (2010). Las Redes Sociales. Tipología, uso y consumo de las redes 2.0 en la sociedad digital actual. Documentación de las ciencias de la información, 33 (45-68). Recuperado de: http://dialnet.unirioja.es/servlet/articulo?codigo $=3250105$ Castells, M. (2012). Redes de Indignación y Esperanza. Madrid: Alianza. CBO (2013). Paro agrario en Colombia 2013. Bogotá: Prezi. Recuperado de:

https:/ / prezi.com/7i24coif4lsp/paro-agrario-en-colombia$2013 /$ 
Chikeino. (2013, Agosto 30). Paro nacional agrario, Bogotá, Colombia (29 de Agosto, 2013). [Archivo de video]. Recuperado de: https:/ / www.youtube.com/watch?v=uZBCFF6cL4g Chomsky, N. (2012). Ocupar W all Street, Indignados en el epicentro del capitalismo mundial. Barcelona: Ediciones Urano S.A.

CM Populares. (2013, Agosto 20) Policía agrede a manifestantes en Paro Nacional Agrario y popular [Archivo de video]. Recuperado de: https:/ / www.youtube.com/watch?v=1goQtyClmbY D’Angelo (2012). Procedimiento alternativo: método de análisis de discurso audiovisual, en Discurso en la Web: Pobreza en Youtube. Bogotá: Grafiweb.

Deleuze, G. y Guattari, F. (1997). Mil mesetas. Capitalismo y esquizofrenia. Valencia: Pre-textos.

Echeverri, M. (2006) Conflicto y hegemonía en el suroccidente de la Nueva Granada, 1780-1800. Fronteras de la Historia, 11 (355387). Bogotá: Redalyc.

Recuperado de: http://www.redalyc.org/articulo.oa?id=83301111 Echandía, C. (2013). Violencia contra sindicalistas en medio del conflicto colombiano. Recuperado de:

http://www.economiainstitucional.com/esp/vinculos/pdf/no29/cec handiao29.pdf

El Ciudadano. (2014). Chomsky alerta sobre el colapso de las democracias europeas, Chile. Recuperado de: http://www.elciudadano.cl/2014/01/29/102095/chomskyalerta-sobre-el-colapso-de-las-democracias-europeas/

Fazio, H. (1998). La globalización: Una aproximación desde la historia. Colombia: Universidad de Los Andes.

Felcolper. (2015). La encuesta que perdieron los medios. La Silla Vacía. Disponible en: http://lasillavacia.com/historia/la-encuestaque-perdieron-los-medios-52030

Franco, N. (2014). Por qué las instituciones están en crisis. Semana. Disponible en: http://www.semana.com/nacion/articulo/instituciones-encrisis / 409100-3

FCForum. (2012). Carta para la innovación, la creatividad y el acceso al conocimiento. @axebra; EDRI; FCForum; Acero Martín, F; Rowan, Jaron; Martínez Rubén y Levi, Simona. (Eds.) 
Cultura libre digital: Nociones básicas para defender lo que es de todos. Barcelona: Icaria editorial, S.A.

Full Interesante. (2013, Agosto 20). Policía robando comida a campesinos. [Archivo de video]. Recuperado de:

https://www.youtube.com/watch?v=4ysFtbhaGgg\&feature =youtu.be

Full Interesante. (2013, Agosto 25). Policía disparando contra los manifestantes en Paipa identificado. [Archivo de video]. Recuperado de:

https://www.youtube.com/watch?v=msxcvunypdw\&feature =youtu.be

Full Interesante. (2013, Agosto 28). EL TAL PARO NACIONAL AGRARIO SI EXISTE Apoyo a nuestros campesinos Comparte. [Archivo de video]. Recuperado de: https:/ / www.youtube.com/watch?v=ZYX7T1dH72o

García Canclini, N. (2012). Jóvenes, culturas urbanas y redes digitales. Madrid: Ariel.

Gardner, H. y Davis, K. (2014). La generación App. Biblioteca Howard Gardner. Caracas: Paidós.

Gurak, L. J., y Logie, J. (2003). Internet Protests, from Text to Web. In Hyperactivism: Online activism in theory and practice. Taylor y Francis Books, Inc.

Hard, M. y Negri, A. (2004). Multitud. Barcelona. Paidós.

Hawkins, D. J. (2009). Reconfiguración del Estado colombiano: el difícil balance entre consenso y coerción. Íconos. Revista de ciencias sociales, (25), 105-116. Recuperado de:

http://www.flacso.org.ec/docs/i35hawkins.pdf

Hine, C. (2000). Etnografia V irtual. Barcelona: Editorial UOC.

Ipsos. (2013). Colombia opina 2013-3. La gran encuesta, medición 9. Bogotá D.C.: Ipsos

Ivoskus, D. (2008). Vivir Conectados. Buenos Aires: Grupo Editorial Norma.

Keck, M., y Sikkink, K. (2000). Activistas sin fronteras. México: Siglo XXI.

Kidd, D. (2003). 2. Indymedia.org: A New Communications Commons. Mccaughey, M y Ayers, M.D. (Eds.), Cyberactivism: Online Activism in Theory and Practice. (pp. 47-70). Gran Bretaña: Routledge. 
Kozinets, R. (2010). Netnography. Doing Ethnographic Research Online.

Londres: Sage Publications Ltd.

Lévy, P. (2007). Cibercultura: La cultura de la sociedad digital. Barcelona: Rubí.

Levine, R., Locke, C., Searls, D., y Weinberger, D. (2000). Internet: La posibilidad de que empleados y clientes sean escuchados. Medellín: Norma S.A.

López Montaño, C. (2012). Agro Ingreso Seguro no es una telenovela. Bogotá: Portafolio.co. Recuperado de:

http://www.portafolio.co/opinion/agro-ingreso-seguro-noes-una-telenovela

Maturana, H. (1998) De Máquinas y Seres Vivos: Autopoiesis, La organización de lo vivo. Santiago de Chile: Editorial Universitaria S.A.

Martínez, R. (2012). Cultura libre digital: Nociones básicas para defender lo que es de todos. Barcelona: Icaria editorial, S.A.

Mancera, A. y Pano, A. (2013). El discurso politico en Twitter. Barcelona: Anthropos Editorial.

Maseri, S. G. (2012) Colombia debe prepararse para reformas laborales si quiere que demócratas estudien el TLC. Colombia: Editorial El Tiempo. Recuperado de: http://www.eltiempo.com/archivo/documento/CMS$\underline{3736550}$

Meridian Group. (2015) Estudio del Paro Agrario. Disponible en: http://meridiangroup.com/paroagrario/

Monedero, J.C. (2015). Curso urgente de politica para gente decente. Bogotá: Planeta.

Montaño C. L. (2012). El impacto del TLC con Estados Unidos.

Recuperado de:

http://www.recalca.org.co/el-impacto-del-tlc-con-estadosunidos/

Negrete PH. (2013, Agosto 23). ESMAD Arremete contra estudiantes y civiles desarmados. En la Calera. [Archivo de video]. Recuperado de:

https://www.youtube.com/watch?v=S8Fw4mFLB6c\&featur $\mathrm{e}=$ youtu.be

Negroponte, N. (1995) Being Digital (Ser Digital). Buenos Aires: Atlántida. 
Naomi Klein. (2007). La Doctrina del Shock: El Auge del Capitalismo del Desastre. Paidós Ibérica

Noticias Caracol. (2013, Agosto 25). Santos dice que paro agrario no existe al informar sobre asesinato de un policía. [Archivo de video]. Recuperado de:

https://www.youtube.com/watch?v=bbIf6NICl4w

Padilla, M. (2012). El kit de la lucha en internet. Madrid: Traficantes de Sueños.

Pardo, B. (2013, Agosto 23). ¿Cómo les parece? [Archivo de video]. Recuperado de:

https:/ /www.facebook.com/photo.php?v=10151640885712

$017 \&$ set $=$ vb. 680187016\&type $=2 \&$ theater

Pardo, N. (2012). Discurso en la web. Pobreza en YouTube. Bogotá:

Grafiweb.

Portafolio.co (2013). Colombia, número uno en crecimiento de 'smartphones'.

Recuperado de: http://www.portafolio.co/portafolio-

plus/cifras-ventas-telefonos-inteligentes-colombia

Porter, J. (2008). Designing for the Social Web. Newriders.

Ramón Ramón. Entrevista personal, 06 de diciembre de 2014,

México D.F

Red Boyacá. (2013, Agosto 23). Tibasosa ESMAD arremete contra

familias inocentes. [Archivo de video]. Recuperado de:

https://www.youtube.com/watch?v=jG8_v5Aer54\&feature $=$ youtu.be

Rheingold, H. (2004). Multitudes inteligentes. La próxima revolución social. Barcelona: Editorial Gedisa S.A.

Rousseau, J.J. (1993). El contrato Social, Barcelona: Altaya

Roberts, K. (2005). Sisomo, el futuro en pantallas. Barcelona: Ediciones Urano, S.A.

Sánchez Zuluaga, U. H; Botero Montoya, L. H. y Giraldo Dávila, A. F. (2012). Modelos de comunicación digital. Medellín: Sello editorial Universidad de Medellín.

Salter, L. (2003). Democracy, New Social Movements, and the Internet: A Habermasian Analysis. In Cyberactivism: Online activism in theory and practice (Primera edición.). London: Norma S.A.

Scolari, C. (2008). Hipermediaciones: Elementos para una teoría de la comunicación digital interactiva. Barcelona: Gedisa, S.A. 
Segundo Riaño, Entrevista personal, mayo 07 de 2013, Bogotá. Colombia

Sierra Caballero, F. (2013). Ciudadanía, Tecnología y Cultura (Primera edición.). Barcelona: Romanyá Valls, S.A.

Subirats, J. (2011). Otra sociedad, otra política. De "no nos representan" a la democracia de lo común. Barcelona: Icaria editorial.

Tascón, M. y Quintana, Y. (2012). Ciberactivismo: Las nuevas revoluciones de las multitudes conectadas. Madrid: Editorial Catarata.

Tapscot, D. y Williams, A. D. (2010) Wikinomics: la nueva economía de las multitudes inteligentes. Barcelona: Paidós.

Tereré, E. y Barranquero Carretero, A. (2013). De mitos sublimes y digitales. Revista de estudios sociales para el desarrollo de la comunicación, 8 (27-47). Recuperado de: http://dialnet.unirioja.es/servlet/articulo?codigo $=4518738$

Tibabosa Boyacá. (2013, Agosto 23). Ataque ESMAD en Santa Teresa -Tibasosa a hijo de campesino. [Archivo de video]. Recuperado de: https://www.youtube.com/watch?v=N1bzNrD4108\&feature =youtu.be

Tilly, C. y Wood, L. (2009). Los movimientos sociales, 1768 -2008. Desde sus orígenes hasta Facebook. España: Editorial Crítica.

Tibabosa Boyacá. (2013, Agosto 23). Tibasosa-Abuso de autoridad y robo por parte del ESMAD en el sector Santa Teresa. [Archivo de video]. Recuperado de: https://www.youtube.com/watch?v=U4XCPk2EMDA\&feat ure $=$ youtu.be

Tobasura, I. y Rincón, L. (2007). La protesta social agraria en Colombia 1990-2005: Génesis del movimiento agrario. Recuperado de: http://lunazul.ucaldas.edu.co/downloads/Revista24 6.pdf Valencia Rincón, J.C. y García Corredor, C.P. (2014). Movimientos sociales e internet. Bogotá: Pontificia Universidad Javeriana. Wincour, R. (2009). Robinson Cruzoe ya tiene celular. México: Siglo XXI. 


\title{
La novela Zapata: del periodismo digital a las redes sociales. Transmediatización y Regulación de las Redes Sociales en Bolivia
}

\author{
Alma Luz Forte. Asociación Boliviana de Investigadores en \\ Comunicación ABOIC (Bolivia). alma.luz.forte@gmail.com
}

Luis Carlos Barrios Bueno. IDERTIC Asociación de Investigadores del Derecho de las TIR (Bolivia). lcbarrios@gmail.com

\section{Introducción}

— L 21 de febrero del 2016 se vivió en Bolivia el Referendo 1 Constitucional 2016, consulta democrática en la que se votó por el Sí o el No a la modificación de la Constitución, dicho referéndum daría la posibilidad de un tercer mandato a la fórmula Evo Morales Álvaro García Linera, quienes gobiernan el país desde el año 2005 en representación del Movimiento al Socialismo (MAS), partido de tendencia e ideología de izquierda.

La derrota del Sí se atribuyó al poder de las redes sociales descargando la frustración de una pérdida que puso en debate el discurso y la posibilidad de regularlas. En diversos países del mundo, se habla de reglamentar las redes sociales, en Bolivia el Gobierno ampara la necesidad de debatir su regularización. En este contexto, las redes sociales adquieren una importancia mayor frente a la baja cantidad de medios independientes y críticos y, además, a la censura y 
límites a la libertad de expresión de periodistas opositores a la línea de Gobierno.

Casos de periodistas como Carlos Valverde, que destapó el escándalo Zapata y la empresa china $\mathrm{CAMC}^{3}$, enfrentando procesos judiciales por sus denuncias, o Amalia Pando que tuvo que renunciar a medios de comunicación radial por asfixias económicas o cierres de licencias para acallar sus críticas, son ejemplos de cómo el Derecho a la Comunicación e Información (DIC) es vulnerado en el país en una de sus tantas formas.

Raúl Peñaranda, periodista, analista y ex director del periódico Página Siete, denuncia en su libro "Control Remoto", cómo el gobierno de Evo Morales creó una red de medios paraestatales y un plan para acosar a la prensa independiente: "En Bolivia, en los últimos años, el Gobierno ha desplegado una estrategia para controlar importantes medios de comunicación a través de comprarlos mediante empresarios amigos o instalarlos directamente. Su presencia, que reduce las voces independientes, hace que la calidad de la democracia decaiga." (Peñaranda, 2014).

Desde el punto de vista de la información política, las redes sociales, especialmente Facebook y Twitter, ayudaron en el proceso del Referéndum a amplificar noticias divulgadas por los medios independientes $\mathrm{y}$, de esa manera, ayudaron a que los electores tomaran decisiones. Para algunos especialistas, las redes sociales van camino a convertirse en el "quinto poder" y el "meme", como "unidad mínima de información que puede ser transmitida", podría dar lugar, como dijo José Luis Exeni, a la "memetización" de la política.

En suma, las redes sociales, como espacios digitales llegaron para quedarse, como escenario y como actor. Comicios Mediáticos II

\footnotetext{
${ }^{3}$ El 3 de febrero Carlos Valverde, periodista cruceño, denunció a Gabriela Zapata Montaño, quien mantendría una relación afectiva con el presidente Evo Morales, el periodista presentó un certificado de nacimiento del hijo de ambos nacido en el año 2007. Además, Gabriela Zapata de 29 años fungía como gerente comercial en la sucursal boliviana de la empresa china Engineering CO. Ltda (CAMC - sigla en inglés) con quien el país firmó contrato millonarios, la denuncia investiga un presunto caso de tráfico de influencias.
} 
plantea que "el tránsito que tiene lugar entre los medios de difusión tradicionales y las nuevas tecnologías de la información y la comunicación, concretamente las redes sociales digitales, es un hecho que no es nuevo en el mundo de la comunicación, y que responde a lo que se conoce como un fenómeno de transmediatización, que a través de sus propios procesos puede llegar a modificar los vínculos sociales, los modos de producción y el reconocimiento de discursos que tienen lugar al momento de emitir y recibir un mensaje" (Rocha, 2015).

Aproximadamente, unos cinco millones de personas usan las redes sociales en Bolivia ${ }^{4}$, días previos al Referéndum, las noticias que circulaban en medios digitales se convirtieron rápidamente en memes simples, con un toque de humor muy bien logrado, como una forma de satirizar el poder. En ese contexto, las redes sociales fueron para el MAS y para el presidente Evo Morales, las responsables principales en tumbar gobiernos.

En ese sentido, la presente ponencia pretende:

- Comparar la relación entre géneros y formatos del periódico digital y su representación paralela en redes sociales digitales (transmediatización) referidas al caso Zapata que incidió en el resultado del referéndum constitucional 2016, dando lugar a la discusión sobre la Regulación de las Redes Sociales en Bolivia.

El objetivo busca a través de una metodología de análisis comparativo y observación directa entre medios digitales de periodismo y redes sociales hacer un paralelismo y comprender como "la novela Zapata", con sus denuncias de irregularidades y corrupción del poder ejecutivo, afectó el resultado del referéndum con la victoria de un No a la posibilidad de repostulación del binomio presidencial actual. Consecuentemente impulsando un debate enardecido sobre la necesidad estatal de regular las redes sociales en Bolivia.

${ }^{4}$ Bolivia es uno de los países de Sudamérica con menores niveles de conectividad, solo por encima de Venezuela, y a la cola del resto de los países. Según datos del 2014 la mayor cantidad d conexiones se hace desde telefonía móvil, un $95,2 \%$ de los bolivianos se conecta a través de su celular, el $5 \%$ restante lo hace a través de otras tecnologías (ADSL, WiFi, satelital, etc.) 


\section{Estado de la cuestión}

\subsection{Referéndum Constitucional 2016 en Bolivia}

La cuestión de la reelección presidencial es una temática latente en Bolivia y en varios países de Latinoamérica, se debatió una cuestión similar en el año 2013, donde a través de una ley denominada de Aplicación Normativa, se habilitó al presidente Evo Morales para repostular en las elecciones generales de 2014 (Vargas Lima, 2015).

El 21 de febrero de 2016, los resultados del Referéndum fueron favorables a la postura del NO, alcanzando un porcentaje del $51,30 \%$, que se posicionó sobre un SI que llegó al 48,70\%, según los datos consolidados del Tribunal Supremo Electoral de Bolivia ${ }^{5}$ (Ver Gráfico $\mathrm{N}^{\circ} 1$, Anexo II).

Los resultados favorables al NO se interpretaron como un embate desde las redes sociales, que lograron afectar la imagen presidencial en un rechazo creciente frente a las incertidumbres de "la novela Zapata" difundida en miles de memes compartidos por los cibernautas, y además, a la incapacidad de los seguidores de la línea de gobierno de interactuar en las redes para revertir la embestida digital.

\subsection{La transmediatización}

El espacio público cada vez más complejo, amplio y mediatizado, que tiene como escenario a los medios de difusión tradicionales, en el que se juega la contienda política discursiva, se relaciona con el espacio público "virtual" en el que se juega la misma esencia de lo político, pero desde actores, formas y dinámicas propias del carácter digital que emerge de la web (Rocha, 2015).

Este tránsito que tiene lugar entre los medios de difusión tradicionales y las NTIC, concretamente las redes sociales digitales se conoce como transmediatización, que es un término relacionado al concepto de "narrativa transmediática", introducido por Henry Jenkins, en un artículo publicado en Technology Review en el 2003, y que sirve para nombrar las experiencias narrativas que se despliegan a través de varios medios o plataformas (Scolari, 2009).

${ }^{5}$ http://www.oep.org.bo/ 
En la experiencia boliviana, las redes sociales cobran mayor importancia desde las elecciones del 2014 con fines de campaña y de propaganda, con la presencia de cuentas de candidatos, uso de memes e infografías. Recién en las votaciones recientes del 21 de febrero del Referéndum se las asume como elementos claves de afectación en los resultados electorales.

\subsection{Argumentos sobre la regulación de las redes sociales en Bolivia}

En Latinoamérica, el impulso de regulación de redes sociales no es nuevo. De Chile a México, Ecuador y Argentina se observa cómo los gobiernos y legisladores entienden internet como un espacio caótico y donde la población expresa sus pasiones con desenfreno, donde no es el "Estado de Derecho" quien reina, sino la sátira, la crítica sin fundamentos, la difamación y el insulto anónimo. En el fondo, es miedo a la crítica y los procesos descentralizados que la internet implica (Perez de Achá, 2016).

En el contexto boliviano, Morales se dijo víctima de una "guerra sucia" llevada a cabo en internet mediante opiniones anónimas que son capaces de "tumbar gobiernos" (Layme, 2016) y que comparó con "recolectores de basura" (Página Siete, 2016) En una rueda de prensa en La Paz, Morales además dijo que "quienes usan las redes sociales con mentiras están haciendo perder valores a las nuevas generaciones." Ese mismo día el vicepresidente de la Cámara de Diputados, Víctor Borda, anunció un proyecto de ley para regular las redes sociales, que concibe entre sus principales planteamientos la tipificación de delitos en el marco de las nuevas actuaciones de los ciudadanos en las redes sociales, como Facebook y twitter.

Varios expertos coincidieron en que una regulación de estos espacios recargará la justicia, traerá la censura previa y hasta criminalizaría el accionar de los usuarios. Además, la regulación de las redes es inviable porque las empresas de redes sociales tienen sus sedes en otros países con normas ajenas al Estado Plurinacional de Bolivia. El usuario al crear su cuenta acepta un contrato de adhesión para la protección de privacidad con la empresa, el pago son sus datos personales y la información que genera a partir de sus interacciones con otros usuario de la red. 


\section{Metodología}

La técnica utilizada fue la observación directa:

Primera Fase: del sitio web de Página Siete, (objetivo: monitorear la cantidad de noticias publicadas digitalmente sobre el caso Zapata, observando aspectos cuantitativos y cualitativos, desde el 3 de febrero al 3 de abril.

Segunda fase: de las redes sociales Facebook y Twitter (mismo periodo de observación), obteniendo datos sobre las publicaciones en relación a estados y memes referidos al tema de la ponencia. Ver ficha siguiente:

\section{Tabla 1. Ficha de Cuentas de Facebooky Twitter monitoreadas}

\begin{tabular}{|c|c|c|c|}
\hline $\begin{array}{c}\text { Nombre de la } \\
\text { Cuenta }\end{array}$ & URL - Redes & Fecha de inicio & $\begin{array}{l}\text { Seguidores } \\
\text { Publicaciones }\end{array}$ \\
\hline \multirow[t]{2}{*}{ Página Siete } & http://www.paginasiete.bo & 2010 & 176. 562 seguidores \\
\hline & http://www.twitter.com/pagina_siete & Abril de 2010 & $\begin{array}{c}134.052 \text { seguidores } \\
127 \text { me gusta } \\
64.143 \text { Tweets }\end{array}$ \\
\hline \multirow[t]{2}{*}{$\begin{array}{l}\text { Carlos Valverde } \\
\text { Bravo } \\
\text { Periodista }\end{array}$} & $\begin{array}{l}\text { https://www.facebook.com/carlos.valve } \\
\text { rdebravo/ }\end{array}$ & 2015 & $\begin{array}{l}\text { 181.985 Seguidores } \\
\text { (al } 5 \text { mayo 2016) }\end{array}$ \\
\hline & https://twitter.com/CFValverde & Junio de 2011 & $\begin{array}{c}\text { 49.769 Seguidores } \\
1.356 \text { Me gusta } \\
10.449 \text { Tweets } \\
\text { (al } 5 \text { mayo 2016) }\end{array}$ \\
\hline $\begin{array}{l}\text { MM Mucha } \\
\text { Mierdanga } \\
\text { Anónimo }\end{array}$ & $\begin{array}{l}\text { https://www.facebook.com/muchaofici } \\
\text { al }\end{array}$ & $\begin{array}{l}24 \text { de septiembre de } \\
2015\end{array}$ & 169.805 seguidores \\
\hline $\begin{array}{l}\text { No a La } \\
\text { Reeleccion De Evo } \\
\text { Morales } \\
\text { Organización } \\
\text { política }\end{array}$ & $\begin{array}{l}\text { https://www.facebook.com/No-a-La- } \\
\text { Reeleccion-De-Evo-Morales- } \\
\underline{127677474048403 /}\end{array}$ & & 42.968 seguidores \\
\hline
\end{tabular}

Fuente: elaboración propia 


\section{Resultados \\ 4.1. Primera Fase:}

Se presentan los datos principales del monitoreo realizado al periódico digital "Página Siete", encontrando 563 noticias digitales, referidas al caso Zapata - Morales, vinculadas al Referéndum Constitucional 2016 y al debate de Regulación de las Redes Sociales.

\section{Tabla 2. Ficha de monitoreo del periódico digital Página Siete}

\begin{tabular}{|c|c|c|c|c|c|c|}
\hline $\begin{array}{c}\mathrm{N}^{\circ} \text { total } \\
\text { noticias } \\
\text { monitoreadas } \\
3 \text { feb-3 abril }\end{array}$ & $\begin{array}{c}\text { Fecha mayor } \\
\mathrm{N}^{\circ} \text { noticias } \\
\text { monitoreadas } \\
\text { l de marzo }\end{array}$ & $\begin{array}{l}\text { Fecha menor } \\
\mathrm{N}^{\circ} \text { noticias } \\
\text { monitoreadas } \\
3 \text { de febrero }\end{array}$ & $\begin{array}{l}\text { Promedio de } \\
\text { noticias } \\
\text { monitoreadas } \\
\text { por día }\end{array}$ & $\begin{array}{c}\text { Mayor } \\
\text { flujo de } \\
\text { noticias } \\
10 \text { al } 16 \\
\text { de } \\
\text { febrero }\end{array}$ & $\begin{array}{c}\mathrm{N}^{0} \text { de días } \\
\text { monitoreados }\end{array}$ & $\begin{array}{c}\text { Cronología } \\
\text { del caso } \\
\text { monitoreado } \\
\text { por rangos } \\
\text { de } 7 \text { días }\end{array}$ \\
\hline 563 & 23 & 0 & 9,49 & 86 & 60 & 9 \\
\hline
\end{tabular}

Fuente: elaboración propia

Con respecto al monitoreo, puntualizamos que: el mayor número de noticias digitales en la página referidas al tema se publicaron el 1 de marzo sumando un número de 23 noticias, en su contraparte el día en que menos noticias se publicaron fue el 3 de febrero, día en que estalló el caso por la noche, con ninguna noticia referida al tema. El promedio de noticias fue de 9 notas por día, existiendo un flujo mayor de noticias entre el 10 al 16 de febrero sumando un total de 86 noticias en la semana. (Ver Tabla 2)

El caso Zapata - Morales se narra cronológicamente en la Tabla $\mathrm{N}^{\circ} 3$ (ver Anexos) a partir de 9 rangos de siete días cada uno, en los que se específica el número de noticias publicadas en la semana, una descripción narrativa de la evolución de "la novela Zapata" y las etiquetas o categorías que aglutinan los hitos principales de la cronología de hechos en torno al tema. La última columna analiza las redes sociales puntualizando los temas que se transmediatizaron en relación a "la novela Zapata" desde la información circulante en medios nacionales. 


\subsection{Segunda Fase:}

\section{Influencia de los medios tradicionales en twitter}

El periódico digital Página Siete (Rivero, 2016) se encuentra posicionado en Twitter, en el séptimo lugar de los medios tradicionales influyentes de Bolivia (Ver Gráfico N² 2 , Anexo II).

Realizando un análisis a través de Hashtagify (2016), se desprenden varios hashtags (HT) que se relacionan a Gabriela Zapata, siendo el HT “\#China” el que más twets y retwitts obtuvo, sin embargo el HT \#EvoMorales fue twitteado y/o retwitteado mayor cantidad de veces por los usuarios influyentes de esta red social. Seguido del HT \#TraficodeInfluencias (Ver Gráfico $\mathrm{N}^{\circ} 3$, Anexo II).

\subsection{Análisis de Redes Sociales por rangos:}

A continuación se presentan estados de cuentas y memes representativos viralizados en las redes sociales (Facebook), que aluden a los hechos que mayor repercusión tuvieron en el tiempo del monitoreo. Se presentan los mismos nueve rangos, por periodos de tiempo, analizados del medio tradicional Página Siete en la fase uno, así como el análisis de las capturas de pantalla de estados y memes transmediatizados.

\section{- Rango 1: del 3 al 9 de febrero}

Las publicaciones de la cuenta de Facebook de Valverde, incluyen la denuncia que se presentaría en su programa de Tv, la inclinación hacia el voto por el $\mathrm{NO}$ al referéndum y su invitación a compartirlo, la ironía del miedo a las represalias por la denuncia realizada y la duda sobre si el presidente reconoció o no a Zapata.

El estado del 7 de febrero muestra con una captura de pantalla el número creciente de seguidores, alcanzando 3.795 reacciones a la publicación. Destacan dos estados en este rango de análisis: uno con 6.685 reacciones y 1.153 veces compartido y que refiere a la persecución al periodista (mensajero) por el Gobierno; y dos, el estado que refiere a lo académico de Zapata y su puesto en la empresa, alcanzando 4.426 reacciones y 628 compartidos. 


\section{Imagen 1. Capturas de pantalla de Facebook del 3 al 9 de febrero}

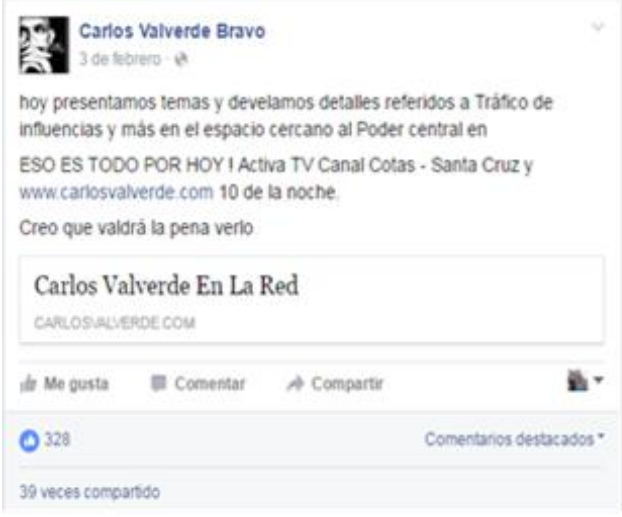

Hoy es 3 de febrero... Me quedan 18 dias para seguir diciendo que mi
voto es NO... Si creés en esto y también decis NO... Hacé que circule
ith Me pusta 3051
1307 comentar veces compartido

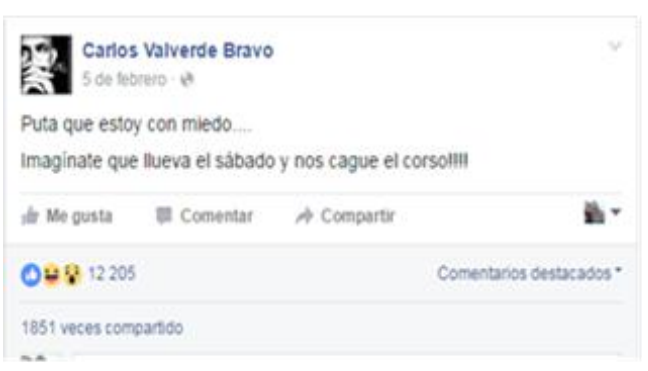

Carlos Valverde Bravo

6 de tebrero : a

y no será que no la reconoció? en 7 años está mucho más operada y no se parece "a la originar" y por eso dijo que no tuvo contacto con ella?

\begin{tabular}{|c|c|c|c|}
\hline It Me ousta & In Comentar & $A$ Compartir & 党 \\
\hline $0 \div 7054$ & & & Comentanos destacados ${ }^{*}$ \\
\hline
\end{tabular}

1372 veces compartido

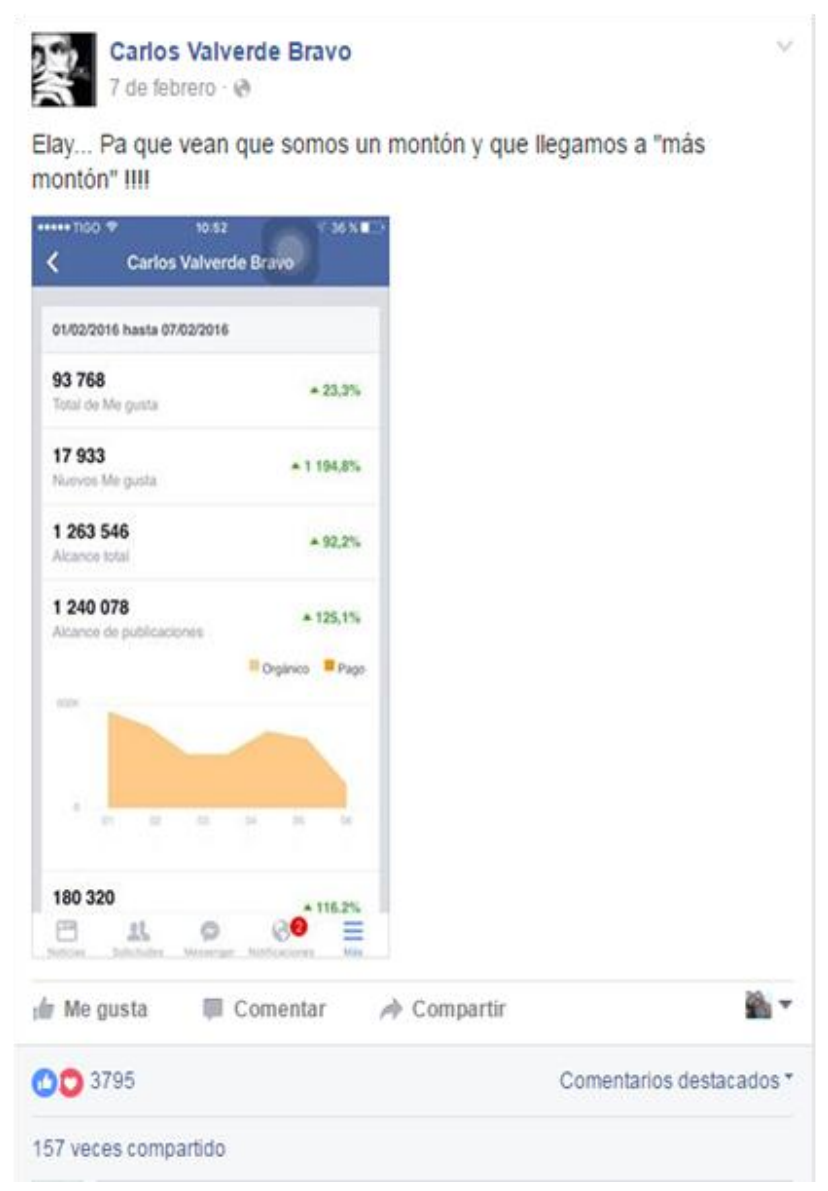




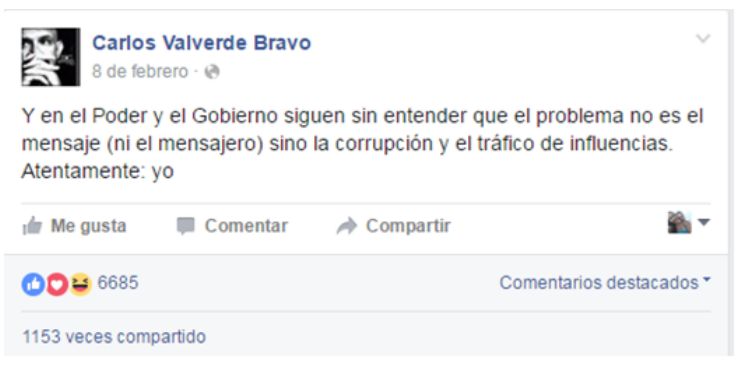

Carlos Valverde Bravo compartió su publicación 9 de febrero - a

El sábado escribi esto, hoy, el presidente dijo esto (mierda! Ni que fueras brujo, Valverde)

http://eju.tv/.../evo-admite-estuvo-gabriela-carnaval-2015-la ...

\section{Carlos Valverde Bravo
6 de febrero.}

y no será que no la reconoció? en 7 años está mucho más operada y no se parece "a la original" y por eso dijo que no tuvo contacto con ella?

Me gusta $\quad \rightarrow$ Comentar $\Rightarrow$ Compartir

(1)누 2679
Carlos Valverde Bravo

9 de febrero $\cdot a$

Y con una mejor libreta universitaria... La ponían de presidenta de la empresa y hasta ministra de "emprendo y miento"

I Me gusta $\quad$ Comentar $\Rightarrow$ Compartir

(1) $=8426$

Comentarios destacados

698 veces compartido

Carlos Valverde Bravo

10 de febrero - a

me queda claro que tener temor es humano y que vencerlo es el reto; to otro, es cobardía y eso es una opción personal ... eso no es para mi. Me niego a ser cobarde... y listo !!!!

1. Me gusta Comentar $\Rightarrow$ Compartir

(1) 11270

1437 veces compartido

Fuente: elaboración propia

\section{- Rango 2: del 10 al 16 de febrero}

Los estados de Valverde del 10 y 11 de febrero, refieren a la persecución y el ejercicio de valentía frente a las amenazas del gobierno y a las garantías enmarcadas en la libertad de prensa y el apoyo de periodistas cruceños (11.270 reacciones y 1.437 compartidos).

El estado que mayor número de reacciones obtiene 11.812 y 3.432 compartidos, es el que Valverde alude a la conspiración que lo acusa el Gobierno. Se suman los temas de falsa titulación del vicepresidente y de Zapata, y la réplica al ministro Quintana por las acusaciones al periodista. La cuenta MM postea el 11 de febrero un meme que ironiza el desconocimiento de Evo hacia Zapata, (1.619 reacciones y 696 compartidos) 


\section{Imagen 2. Capturas de pantalla de Facebook del 10 al 16 de febrero}

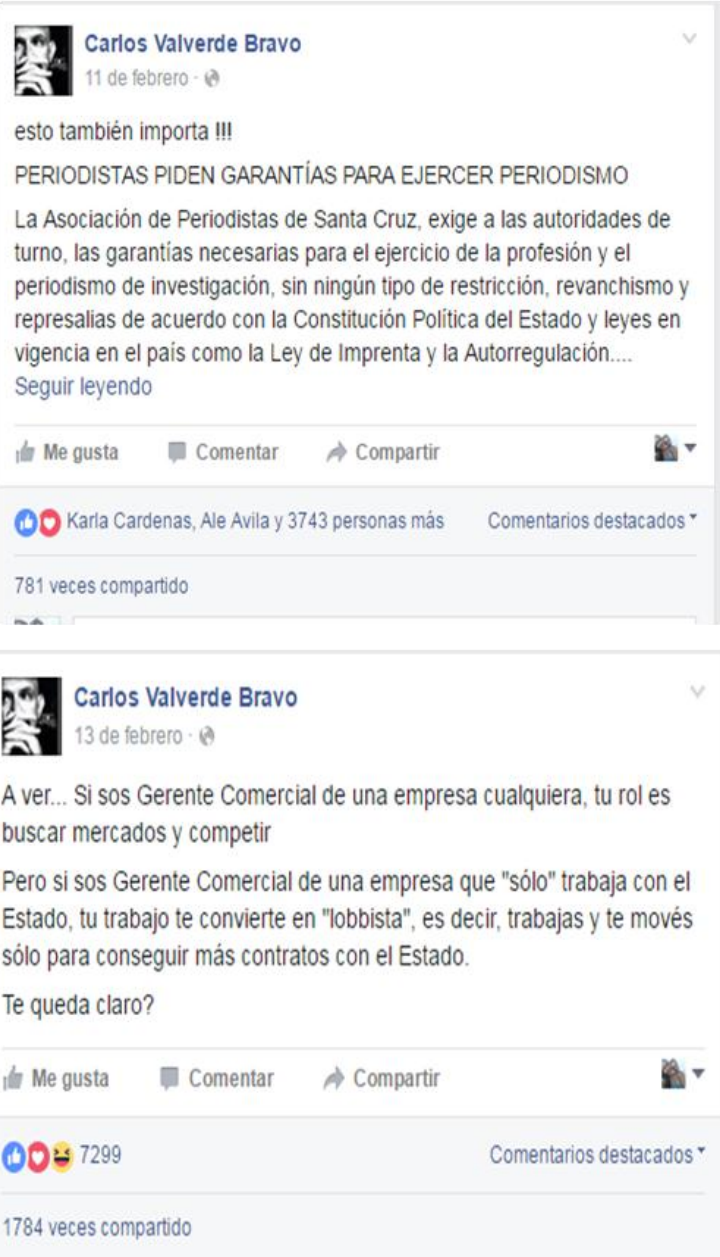

\section{Mucha Mierdanga}

LA FRASE DEL AÑO jhajahajha

Video de ronico cobrando millones a evo por usar su nariz como excavadora: www. youtube. com/watch? $v=9 A Q x e j 6 h E 7 \mathrm{U}$

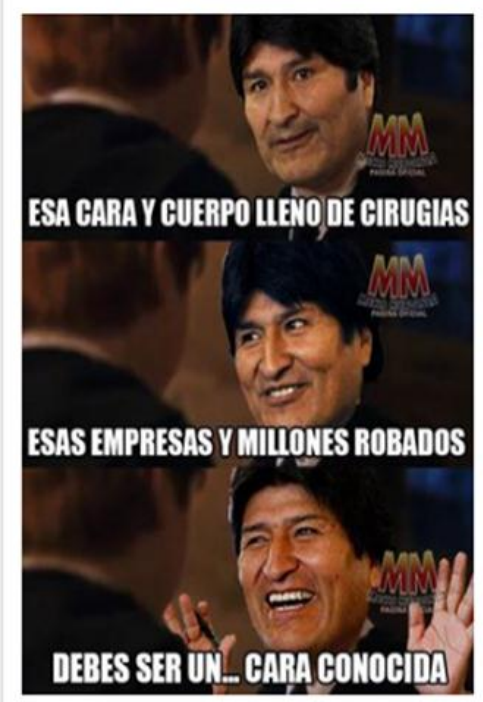

\begin{tabular}{|c|c|c|c|}
\hline Me gusta & W. Comentar & $\rightarrow$ Compartir & 点 \\
\hline $0+81619$ & & & Comentarios destacados \\
\hline
\end{tabular}


14 de febrero... quedan 7 dias para seguir diciendo que votare NO porque acá se va la suerte y el futuro del país. Si creés en esto y también decis NO... Hacé que circule.

\begin{tabular}{lll} 
It) Me gusta Comentar $\rightarrow$ Compartir & \\
\hline (1) 5832 & Comentarios destacados
\end{tabular}

2568 veces compartido

Carlos Valverde Bravo

15 de febrero $\cdot$ aे

a ver...

Se cae la pantomima Garcia Linerista j!! Si el Vice-Presidente no es matemático y tampoco sociólogo, como es que pudo ser docente de tantas universidades?

En la Universidad Gabriel René Moreno se hizo un doctorado dirigido por él sin tener título

Convengamos, se puede invitar a gente para que de clases sin título por las circunstancias, por ejemplo guarani; eso porque previamente no existió la disciplina académica... 0 en arte, por las capacidades de esa gente, pero Sociologia???? Qué pasa? Estamos hablando de una disciplina que tiene calidad académica desde el siglo XIX

Cada vez peor, no?

$\begin{array}{ll}\text { Itr Me gusta Comentar } \rightarrow \text { Compartir } \\ \text { (1) } 6728 & \text { Comentarios destacados }\end{array}$

2823 veces compartido
Carlos Valverde Bravo

13 de febrero $\cdot$ a

En Un burdo esfuerzo por distraer, el Presidente Morales me "acusa" de haberme reunido en diciembre con el Encargado de Negocios de EEUU, cosa que si hice; tomamos desayuno en el lobby del Hotel Los Tajibos, donde habia mucha gente y no estábamos escondidos y conversamos acerca de mi libro COCA.TERRITORIO,PODER Y COCAINA; y de la situación de Bolivia y de EEUU.

Soy periodista y, por supuesto me interesa conversar con un representante extranjero (más aún si es de EEUU, por la situación que vive ese pais y su relación con el nuestro).

El Presidente Morales, el Canciller Choquehuanca y otros funcionarios de Estado se han reunido con el diplomático norteamericano en Palacio de Gobierno, a puertas cerradas ; porque no me puedo reunir yo, en un lugar público con la misma persona?

Me preocupa y me alegra que el Presidente me mande seguir... Me alegra porque ya se a quien culpar o responsabilizar si me pasa alguna cosa rara 0 extraña y me preocupa porque no es correcto que en un pais democrático se siga a un periodista 0 a cualquier ciudadano.

Sigo sosteniendo que el tema en cuestión es el tráfico de influencias ejercitado por el Presidente con relación a la Sra Zapata.

Solo espero que en este afán de intentar distraer a la opinión pública no intenten "acusar al Gringo de haber embarazado a la Señora en cuestión"; no están lejos de esa u otra locura que hace que el Presidente se convierta en un hazme reir

(Si esto no fuera tan patético, yo estuviera riendo)

Carlos Federico Valverde Bravo

Pviden

It Me gusta $\rightarrow$ Comentar $\rightarrow$ Compartir

(1) 11812

Comentarios destacados *

3432 veces compartido

Carlos Valverde Bravo

16 de febrero - e

Qué manera de hablar huevadas el JRQuintana ese. Para ser infidente debi ser confidente; en este caso:cómplice. No soy ni seré. Punto, vuelvo a 10 mio

Me gusta Comentar $\rightarrow$ Compartir

0905474

Comentarios destacados *

630 veces compartido

Fuente: elaboración propia

\section{- Rango 3: del 17 al 23 de febrero}

Destaca el 18 de febrero un video del apoyo de los cruceños a la libertad de prensa y a Valverde en la marcha pacífica realizada en Santa Cruz, (69.221 reproducciones, 8.053 reacciones y 1.720 compartidos). 
El 21 día del Referéndum, los estados refieren a la posibilidad de fraude, a la defensa del NO y a los resultados alcanzando el mayor número de reacciones un estado con datos estadísticos del resultado (12.858 reacciones y 10.521 compartidos). En la cuenta MM los memes refuerzan la politización hacia el voto por el NO, denuncian las situaciones de fraude y alientan al festejo por los resultados preliminares, destaca un video que guía en el voto al NO relatando aspectos de "la novela Zapata" (281.502 reproducciones, 4.011 reacciones y 13.165 compartido).

El 22 de febrero, destaca un estado publicado sobre el debate de uso de redes sociales propuesto por Evo al asumir que estas "tumban gobiernos" (4.121 reacciones y 1.058 compartidos).

El 23 de febrero, se suma un estado, que alude a la aparición de los cocaleros y su iniciativa legislativa de regular las redes sociales, con 6.723 reacciones y 2.472 veces compartido.

\section{Imagen 3. Capturas de pantalla de Facebook del 17 al 23 de febrero}
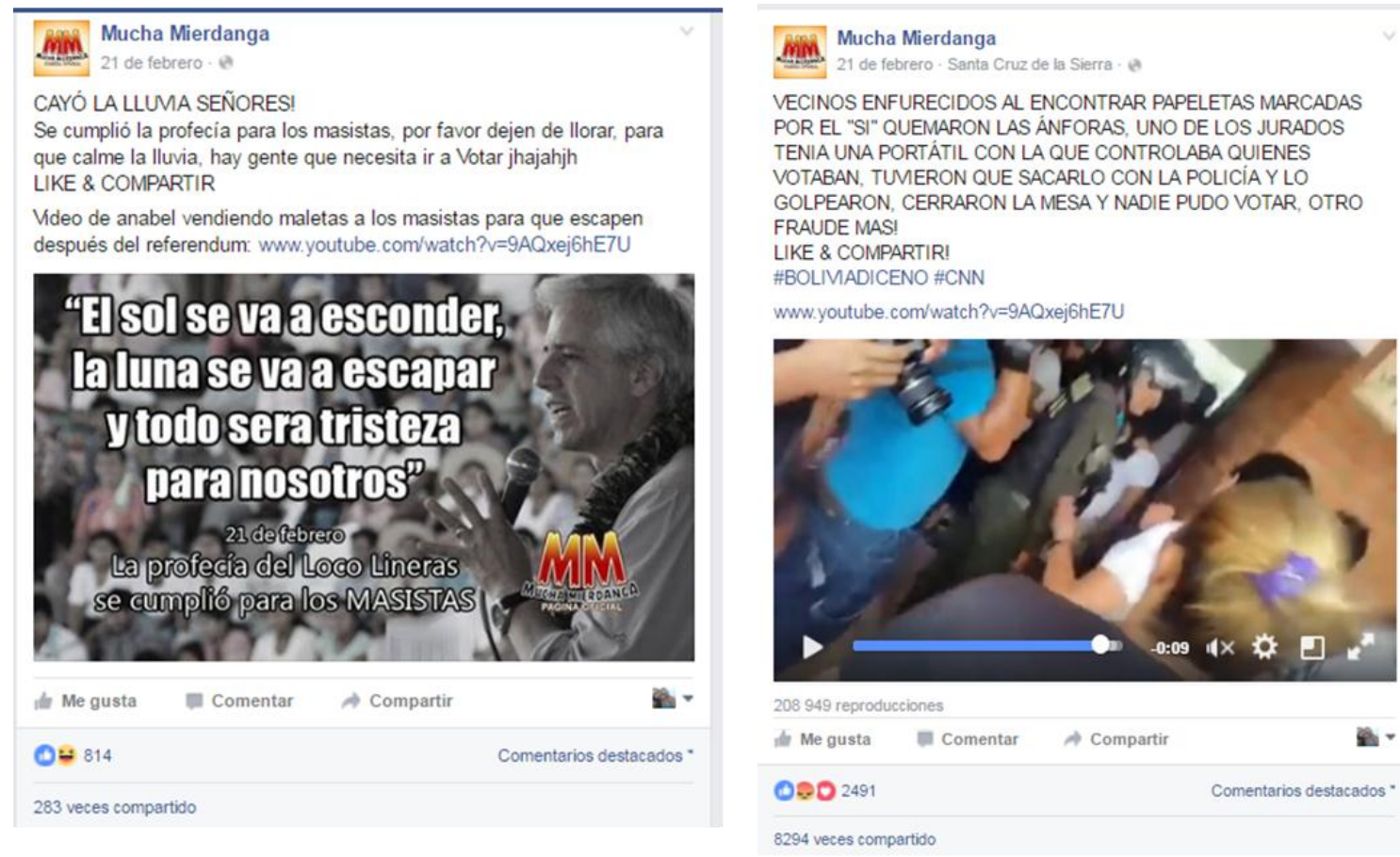
20.2.

Carlos Valverde Bravo con Ornella Baldini Bascunan.

Por favor, no alarmen a la gente que se preocupa

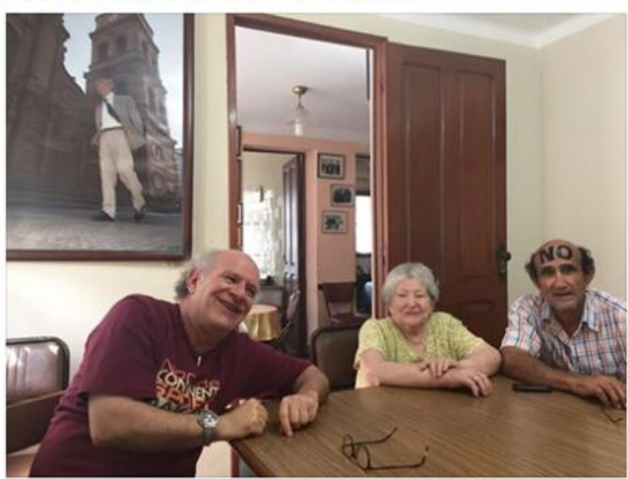

Me gusta $\quad$ Comentar $\&$ Comparti

ㄴ.

$0=09992$

Comentarios destacados

1056 veces compartic

\section{(3)}

Carlos Valverde Bravo

Con estos resultados es claro que hubo marea roja I!! Es imposible que se revierta, salvo que se intervenga el TSE; defendamos el NO, con tod nuestra energia I!!! En plazas, calles y en redes... EI NO. No se toca I!!!

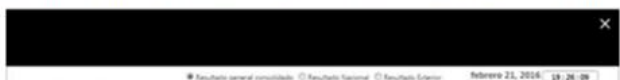

$-\infty \ldots$
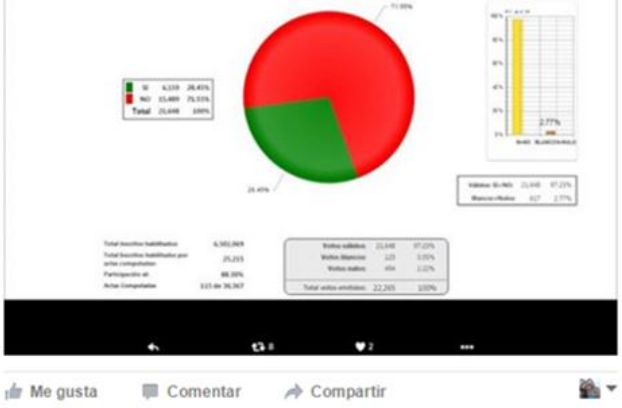

OO. Ximena Suarez Molina y 12857 personas más Comentarios destacados. 10521 veces compartido
23. Carlos Valverde Bravo

-1 21 de febrero-a

Si no pudiste votar, tenés que quedarte, la corte dice que va a haber votaciỏn ; quẻdate, no sea que "alguien vote por vos"

If Me gusta Comentar $\nrightarrow$ Compartir

OP :3 3994 Comentarios destacados.

2369 veces compartido

20. Carlos Valverde Bravo

21 de febrero-es

Vaya amabilidad del Tribunal electoral... Algunas papeletas ya llegan marcadas para evitar que nos agachemos a hacerlo nosotros!

Me gusta comentar $\nrightarrow$ Compartir

QQ : 7947 Comentarios destacados.

3875 veces compartido

23. Carlos Valverde Bravo

7if 22 de febrero- 4

"Empate técnico", significa: no entiendo nada de números pero "debo decir" algo rimbombante

\begin{tabular}{|c|c|c|c|}
\hline Iil Me gusta & Enentar & $A$ Compartir & r \\
\hline Oت 6845 & & & Comentarios destacados - \\
\hline
\end{tabular}

1413 veces compartido

3. Carlos Valverde Bravo

22 de febrero - e

Noche apasionada : Acabaste?

Si, y vos? Casi.

es empate técnico?

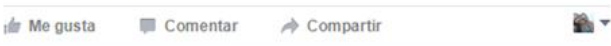

$0=03712$

Comentarios destacados * 
juguemos "al empate técnico" !

Cómo es eso?

Vos me ganás y yo te digo que no y después vemos cómo lo manipulamos

It Me gusta

OLe 4456 Comentarios destacados

907 veces compartido

\section{Carlos Valverde Bravo}

23 de febrero - e

me pasaron esto

https://www.change.org/p/oea-auditor\%C3\%ADa-a-referéndum-bo..

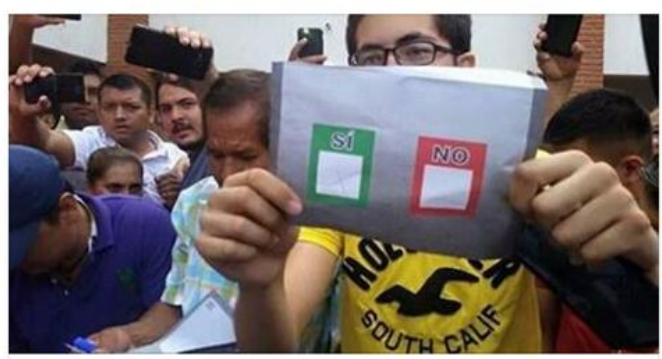

OEA: Auditoría a Referéndum Bolivia 2016, contra la lucha al fraude electoral

Durante el Referéndum llevado a cabo en Bolivia en el 2016, la democracia fue atropellada por diversos actos fraudulentos, el Tribunal Supremo Electoral está... CHANGEORG

If Me gusta $\quad$ Comentar $\Rightarrow$ Compartir

10) 1611 Comentarios destacados

657 veces compartido

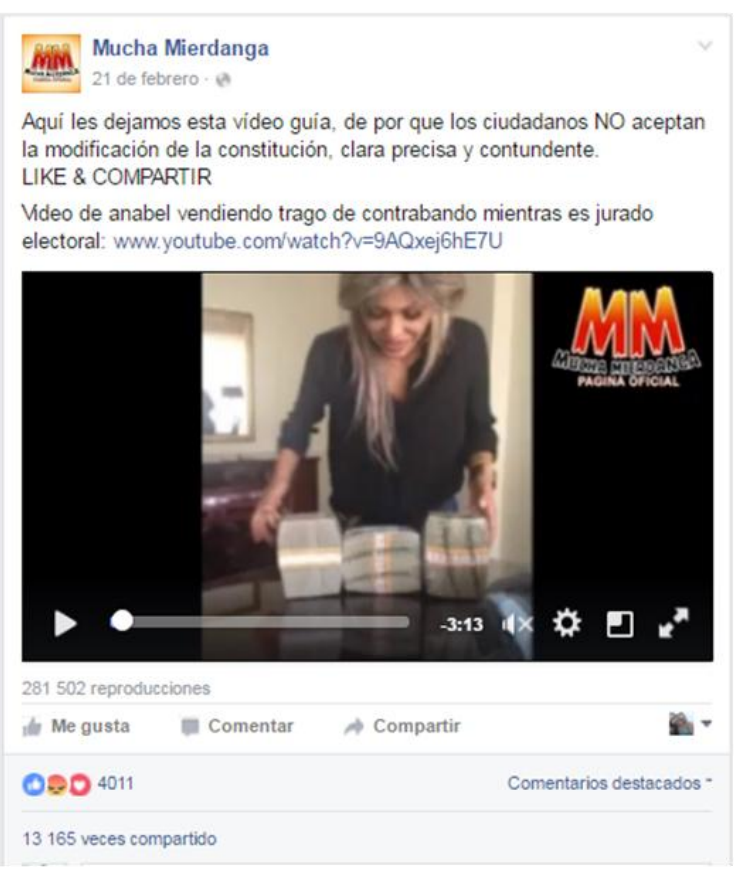

Carlos Valverde Bravo

22 de febrero - e

"Evo propone debatir uso de redes sociales, dice que tumban

gobiernos"... Gobiernos no; Dictadores: "Primavera Arabe" y... también en las urnas

It Me gusta Comentar $\rightarrow$ Compartir
$0=04121$

1058 veces compartido

y aparecieron "ellos"

Cocaleros presentarán proyecto de ley al Legislativo para regular las redes sociales

Un dia de estos deberian decir dónde va la Coca de Chapare (porque no va a los mercados tradicionales - supongo que tendrá que ver con "Redes Comerciales")

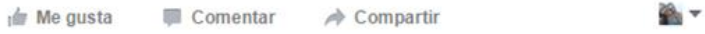

(1) Comentarios destacados 6723

2472 veces compartido

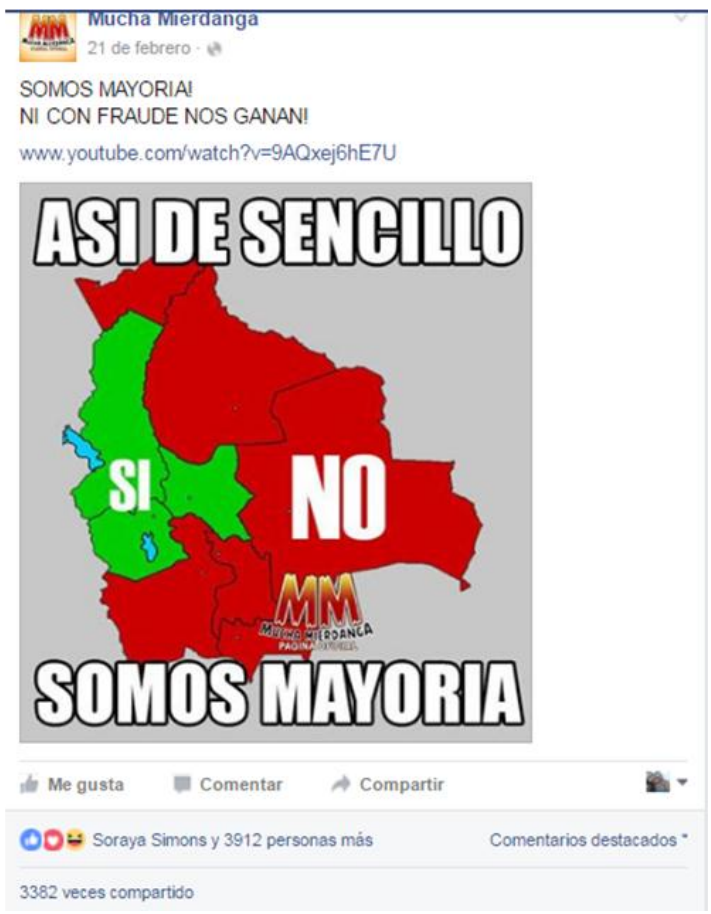

Fuente: elaboración propia 


\section{Rango 4: del 24 de febrero al 1 de marzo}

Valverde, postea en su muro, el 24 de febrero un estado que ironiza la predicción de Linera sobre la salida del sol, sumado a la falsedad de sus títulos (8.991 reacciones y 1538 compartidos).

El 28 de febrero, un largo estado, con 14.357 reacciones y compartido 6.871 veces, alude a la relación de Gabriela Zapata con su hijo y la intervención de las instituciones encargadas de velar por los Derechos Humanos.

Destaca el 29 de febrero la entrevista de Valverde con Oppenheimer por $\mathrm{CNN}$, el video obtiene 61.173 reproducciones, 3.890 reacciones y 2.022 compartidos.

\section{Imagen 4. Capturas de pantalla de Facebook del 24 de febrero al 1 de marzo}
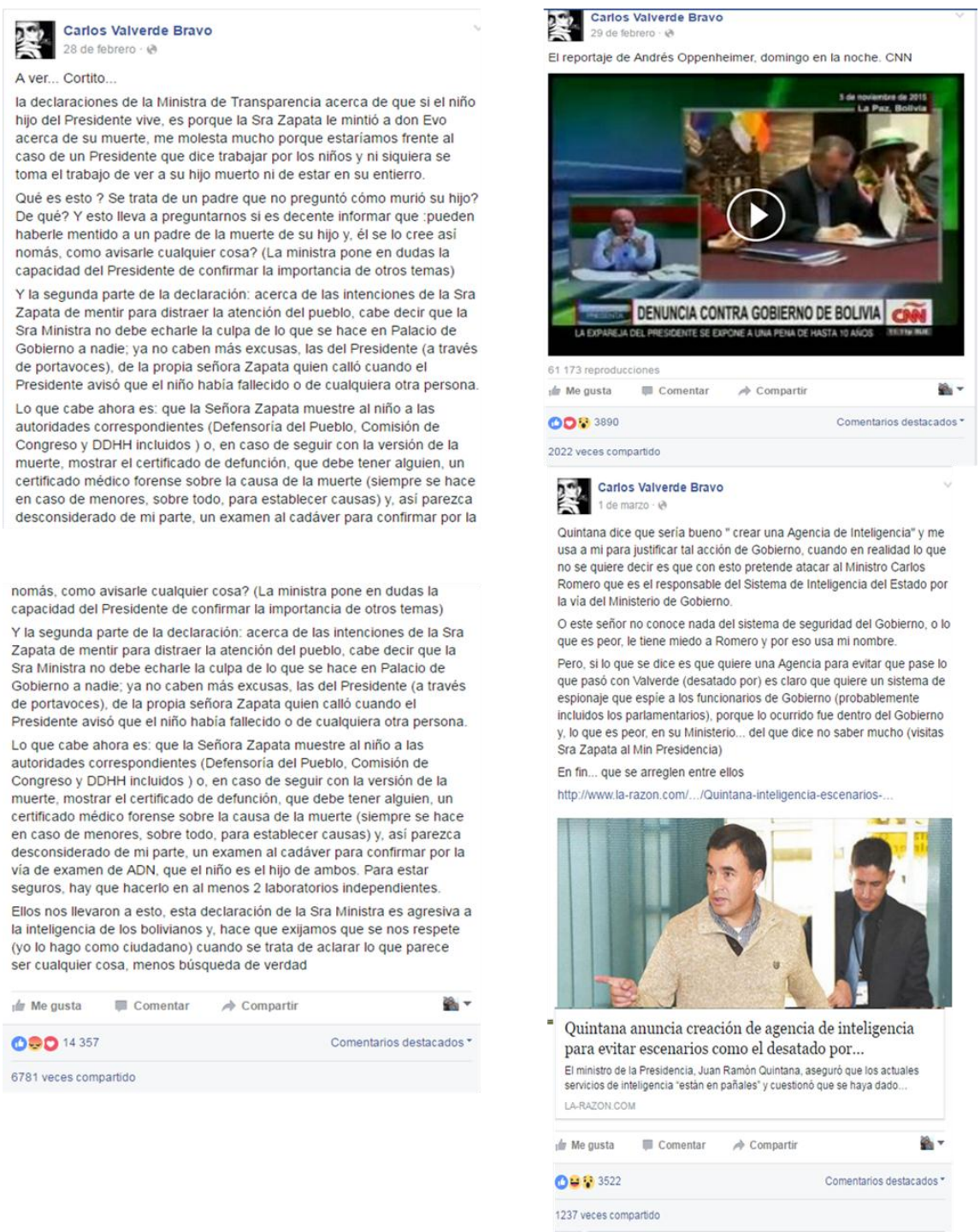
mmmmm no será matemático ni sociólogo pero da para "encargado del tiempo"... hace 2 dias que no sale el sol

It Me gusta Comentar $\rightarrow$ Compartir
1538 veces compartido
(1) $8991 \quad$ Comentarios destacados

Carlos Valverde Bravo

de marzo - e

Y siguiendo con las confirmaciones

\#BoliviaenContacto asegura que la Fiscalia revela que 40 veces Gabriela Zapata usó ambientes del Ministerio de la Presidencia para sus reuniones Te queda claro?

Me gusta Comentar $\Rightarrow$ Compartir

(1): 2799

Fuente: elaboración propia

\section{- Rango 5: del 2 al 8 de marzo}

El 2 de marzo resalta el estado de Valverde en cuanto a la movilización entorno a su casa, (13.960 reacciones y 7.870 compartidos).

Se suma un video que se viraliza con 242.928 reproducciones, 4.506 reacciones y 6.304 veces compartido, de una entrevista del vicepresidente.

\section{Imagen 5. Capturas de pantalla de Facebook del 2 al 8 de marzo}

Carlos Valverde Bravo

2 de marzo - e

Raro movimiento policial en la esquina de mi casa sobre radial Castilla.

Detienen a todos los vehiculos. Aviso si pasa algo

1.t Me gusta $\quad$ w Comentar $\Rightarrow$ Compartir

Comentarios destacados.

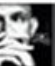

Carlos Valverde Bravo

2 de marzo : a

Que quede claro:

Ahora va en serio: los micrófonos, las libretas y boligrafos y las pantallas de TV no conspiran ni corrompen; para eso está el gobierno

1. Me gusta $\quad$ Comentar $\Rightarrow$ Compartir

Cுல 4061 
Socialista, Matemático y Sociólogo se definió el Licenciado sin titulos y no los necesita) en PENTAGONO.

(Debe haber sido el 2010)

NO LO DIJE YO !!!!

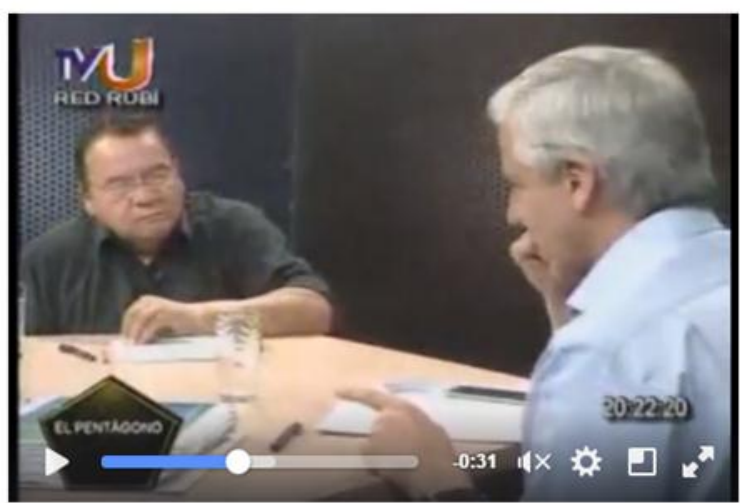

242928 reproducciones

ine gusta $\quad$ - 1 Comentar $\Rightarrow$ Compartir

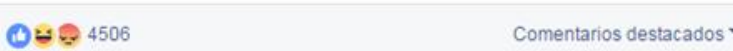

6304 veces compartido
Carlos Valverde Bravo

6 de marzo - e

Vuelve el "gatillo fácil" a la policia?

Redes sociales y medios de comunicación obligan a al policia a reconocer que los muertos a los se presentó a los medios fueron detenidos horas antes (pero fueron liberados, dicen)

Esa no es la policial que queremos los ciudadanos III... Ver más

1. Me gusta Comentar $\Rightarrow$ Compartir

C): $: 2064$

Comentarios destacados

548 veces compartido

3. Carlos Valverde Bravo

6 de marzo - ef

Peor que un gobernante corrupto, es el que sabiendo que es corrupto sale a defenderlo, en vez de reclamarle

Me gusta $\quad \Rightarrow$ Comentar $\Rightarrow$ Compartir

C) 7236

1210 veces compartido

Lo dejo claro: ningún insulto del Presidente va a distraer la necesidad
que, como ciudadano, tengo de que aclare su responsabilidad: debe decir
cuál fue su rol en el Poder adquirido por Gabriela Zapata en su Gobierno
desde el 2010 en adelante
Es claro que si no se aclara se estará tapando la corrupción
Me gusta $\quad \Rightarrow$ Compartir 7428 Comentar
2149 veces compartido

Fuente: Elaboración propia

\section{- Rango 6: del 9 al 15 de marzo}

Un video compartido por Valverde alude a la distracción del discurso del Ministro Quintana que no aclara los hechos de corrupción, con 74.243 reproducciones, 3.493 reacciones y 3.131 veces compartido.

Destaca un meme de la cuenta MM, donde Homero Simpson ironiza el control en las redes que pretende el gobierno, (2.176 reacciones y 1.284 compartido). 


\section{Imagen 6. Capturas de pantalla de Facebook del 9 al 15 de marzo}

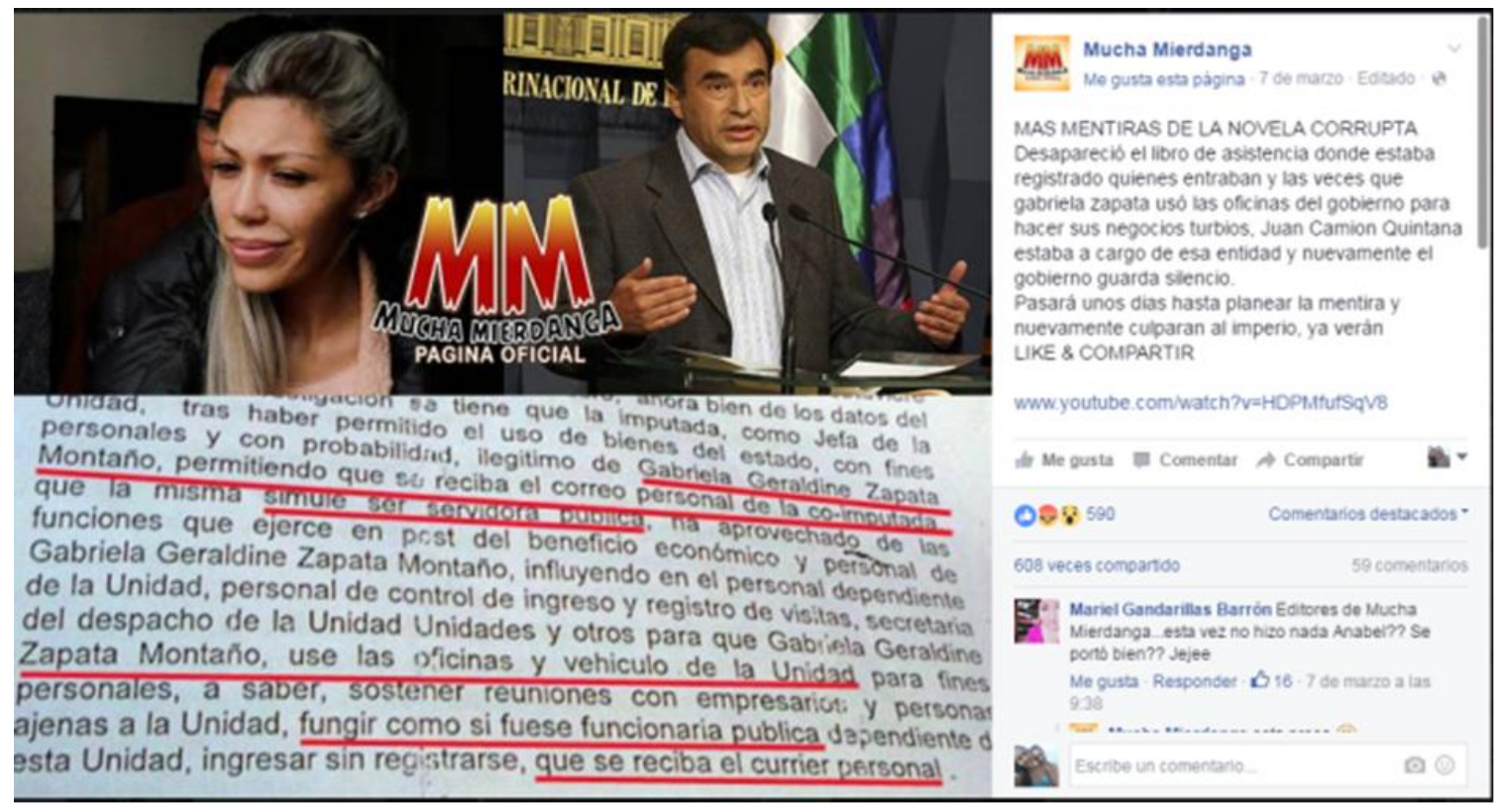

\section{Carlos Valverde Bravo \\ 9 de marzo - (2)}

Lo importante es no distraer nada; el Presidente debe aclarar su rol con relación al Poder logrado por la Sra Zapata. Lo demás ... es distracción y una trampa al pais

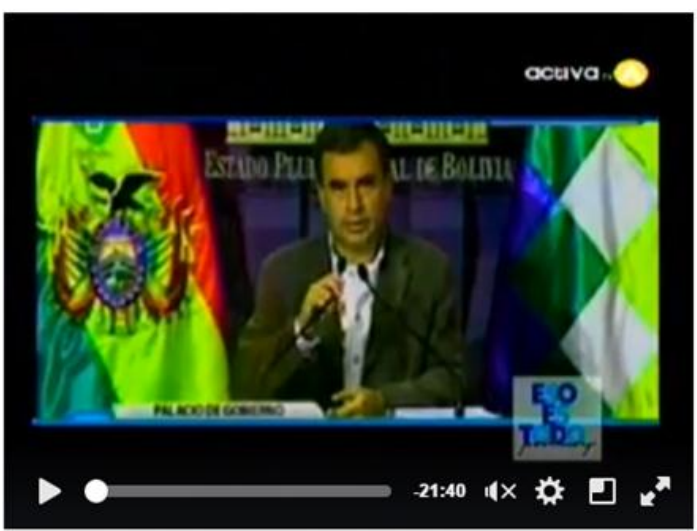

74243 reproducciones

If Me gusta Comentar $\rightarrow$ Compartir $3493 \quad$ Comentarios destacados

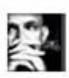

Carlos Valverde Bravo

10 de marzo - e

El gobierno no "rifa" el país, lo está vendiendo "por debajo de la mesa". (como cantaba Luis Miguel)

1. Me gusta Comentar $\Rightarrow$ Compartir
496 veces compartido

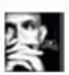

Carlos Valverde Bravo

3 de marzo $\cdot$ e

Alguien sabe si don Andrés Oppenheimer le alabó su bonito sombrero?

Ifir Me gusta

winentar

$\rightarrow$ Compartir

손

다눙 1809

Comentarios destacados -

131 veces compartido 

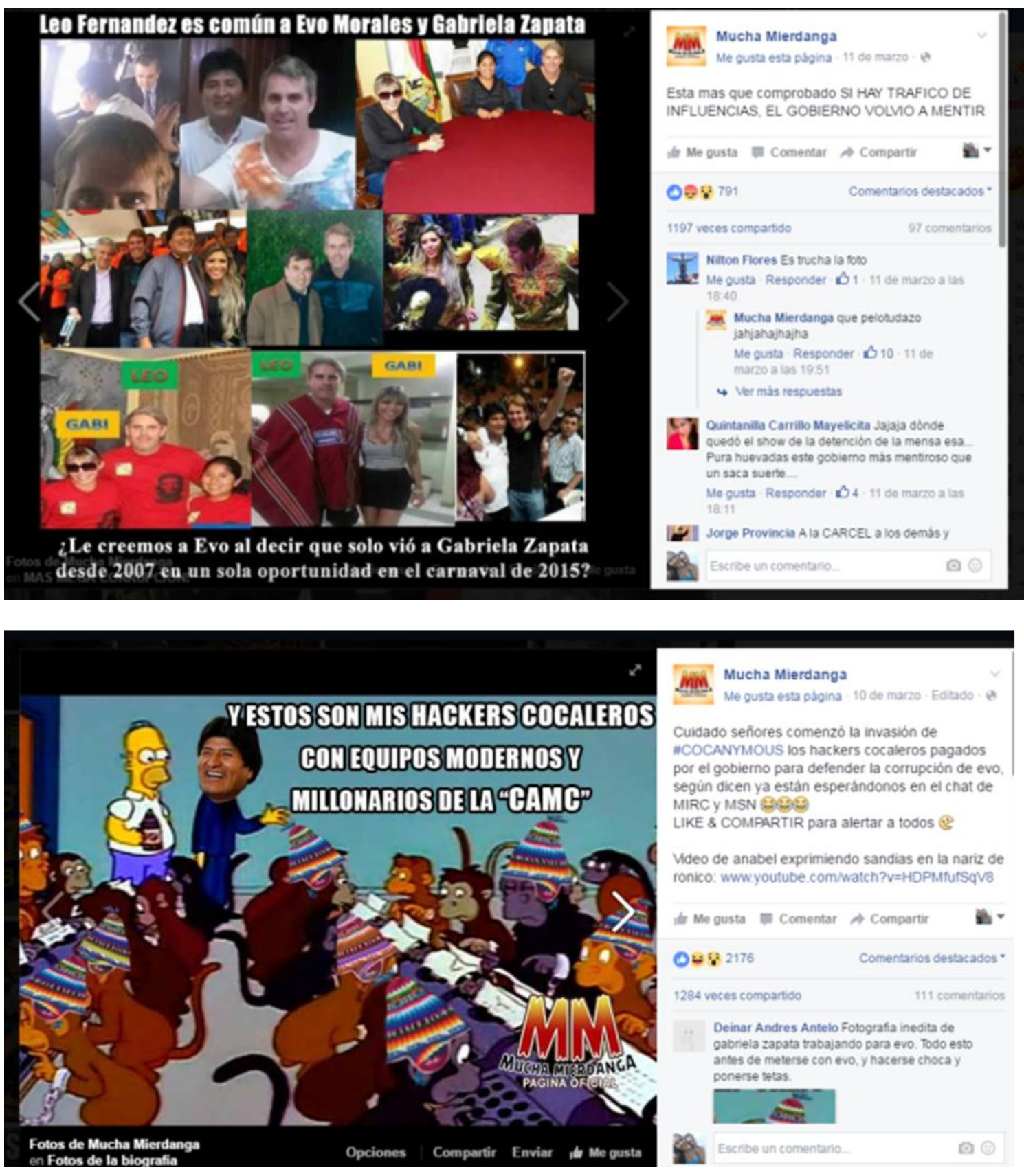

Fuente: Elaboración propia

\section{- Rango 7: del 16 al 22 de marzo}

Los estados de la cuenta del periodista Valverde se focalizan en la relación Zapata hijo sobre si nació o no, y el reconocimiento legal. Se ironiza el día del padre, y el festejo no merecido del presidente referente a la fecha, (5.459 reacciones y 1.243 compartidos).

El sitio MM en dos memes, señalan como una vergüenza nacional el rol de padre del presidente, en tanto al hijo que no nació pero que reconoció, (3.392 reacciones y 2.833 compartidos). 


\section{Imagen 7. Capturas de pantalla de Facebook del 16 al 22 de marzo}

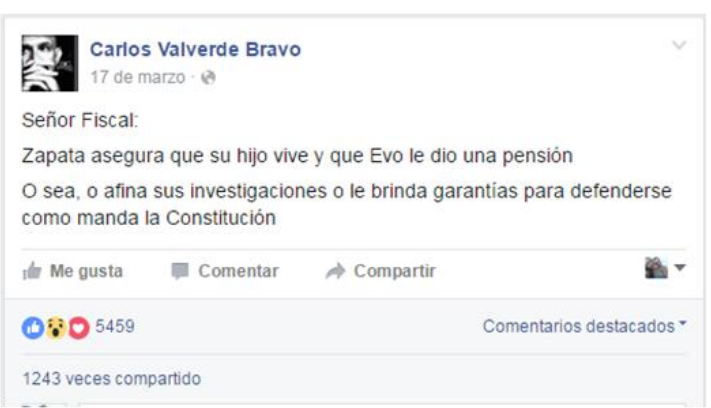

\section{Carlos Valverde Bravo \\ 18 de marzo - ep}

Y ahora resulta que no nació nomas, dice Paco... Pero también que el Presidente lo reconoció ... Urgente! Cambien libreto o ministros!!!

$$
\text { ine gusta Comentar } \rightarrow \text { Compartir }
$$

OP: 4300 Comentarios destacados:

883 veces compartido

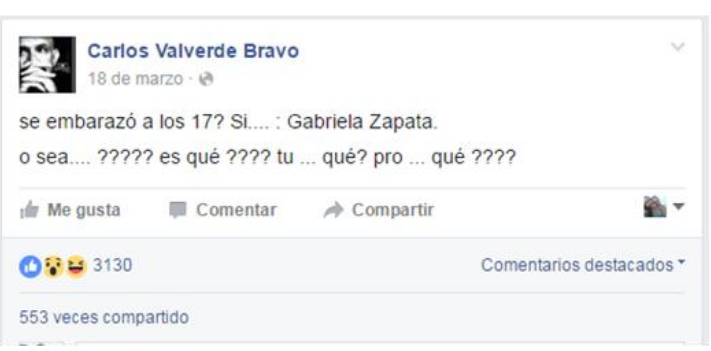

Carlos Valverde Bravo
se embarazó a los 17 ? Si.... : Gabriela Zapata.
o sea.... ????? es qué ???? tu ... qué? pro .... qué ????
1. Me gusta Comentar $\rightarrow$ Compartir
553 veces compartido

Carlos Valverde Bravo
Zeñor Fiscal:
O sea, o afina sus investigaciones o le brinda garantias para defenderse
como manda la Constitución
1243 veces compartido

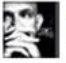

Carlos Valverde Bravo 18 de marzo $\cdot$ a

Y ahora resulta que no nació nomas, dice Paco... Pero también que el Presidente lo reconoció ... Urgente! Cambien libreto o ministros!!!

If Me gusta 1 Comentar $\rightarrow$ Compartir
883 veces compartido 4300

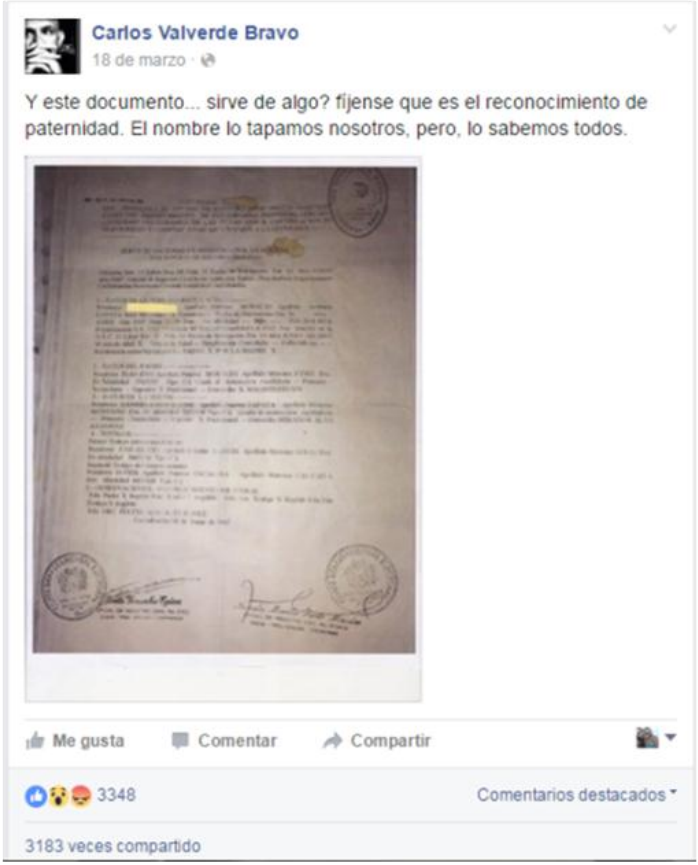




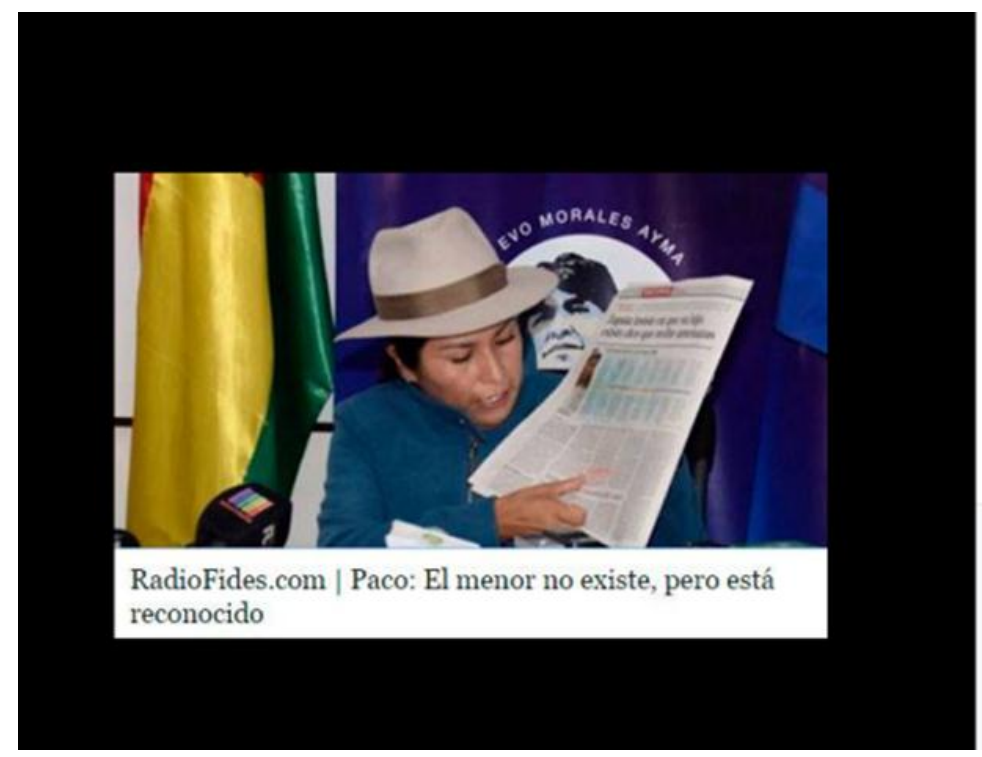

Mim. Mucha Mierdanga

Me gusta esta página - 19 de marzo - Editado - ef

LA NUEVA PAYASADA DE LA MINISTRA

Ministra paco asegura que "el hijo de evo fue

reconocido por su padre, pero nunca existio"

ademas asegura que gabriela zapata miente y que este fue un plan tramado desde que ella tenia 17

años, con la oposicion y el imperialismo

jhajahajhajhajahjahjahajhajhajha

UIKE \& COMPARTIR

Mideo de anabel rasurando la pelona de la ministra paco: www.youtube com/watch? $v=i x$ HitMNvgpOC

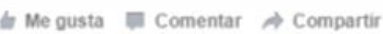

a.

Ö 1077 Comentarios destacados 1018 veces compartido

2. Anoel Gabriel Oblitas Velasquez $Q$ mujer más

3 voluda estipida coiuda con todo el respeto a la Me gusta Responder $B_{137}-19$ de marzo a las

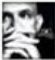

Carlos Valverde Bravo

Presentamos un documento de reconocimiento de paternidad que se contrapone a la Investigación de la Fiscalia General del Estado https://Www.facebook.com/permalink.php...

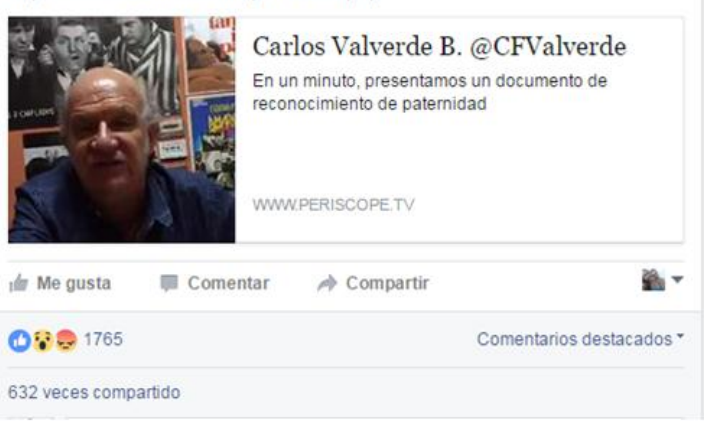

Carlos Valverde Bravo

to 19 de marzo

Pero siguen sin preguntarle a la Sra Zapata cuál fue su relación con el Poder desde el 2010 y con las empresas chinas. Cómo llegó donde llegó... Eso es tan importante como la verdad acerca de su hijo

itu Me gusta $\quad$ in Comentar $\rightarrow$ Compartir

(1) 2718 Comentarios destacados *

504 veces compartido

\section{Carlos Valverde Bravo}

22 de marzo -

Y una vez que se presente EI Niño... Los oficiosos ministros de "la negación" y el Fiscal, se irán a sus casas o habrán pasado "la prueba obsecuente"? (te acordás de las pruebas del jabón de la TV?)

If Me gusta Comentar $\Rightarrow$ Compartir
337 veces compartido

20.7. Carlos Valverde Bravo
18 de marzo 9

Min Paco: el presidente lo ha asistido y lo ha reconocido... A ver, no era que no nació?

\begin{tabular}{|c|c|c|c|}
\hline Me gusta & D. Comentar & $\Rightarrow$ Compartir & 贯 \\
\hline O 132342 & & & Comentarios destacados \\
\hline
\end{tabular}

20. Carlos Valverde Bravo

Y en solidaridad "con el que sabemos"... El día del padre no se festeja entre los "azules"

1. Me gusta Comentar $\Rightarrow$ Compartir
698 veces compartido

\section{Ex 20 de marzo - e}

Supongo que "eso es todo" ( por hoy)

http://noticiasfides.com/.../exoficial-de-registro-civil-dic...

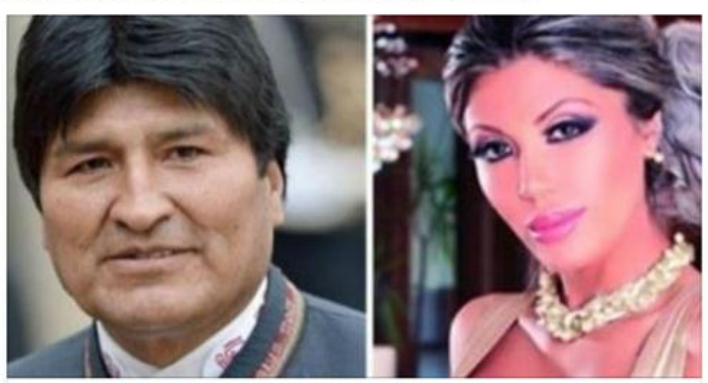

Exoficial de registro civil dice que es totalmente válido el reconocimiento del hijo de Evo y...

Ivette Gonzales quien inscribió el 2007 al niño, dijo que entregó la información a Sereci dependiente del Tribunal Supremo Electoral.

NOTICIASFIDES.COM I DE NOTICIAS FIDES

16. Me gusta $\quad \rightarrow$ Comentar $\rightarrow$ Compartir

(1): 1699 Comentarios destacados:

682 veces compartido 


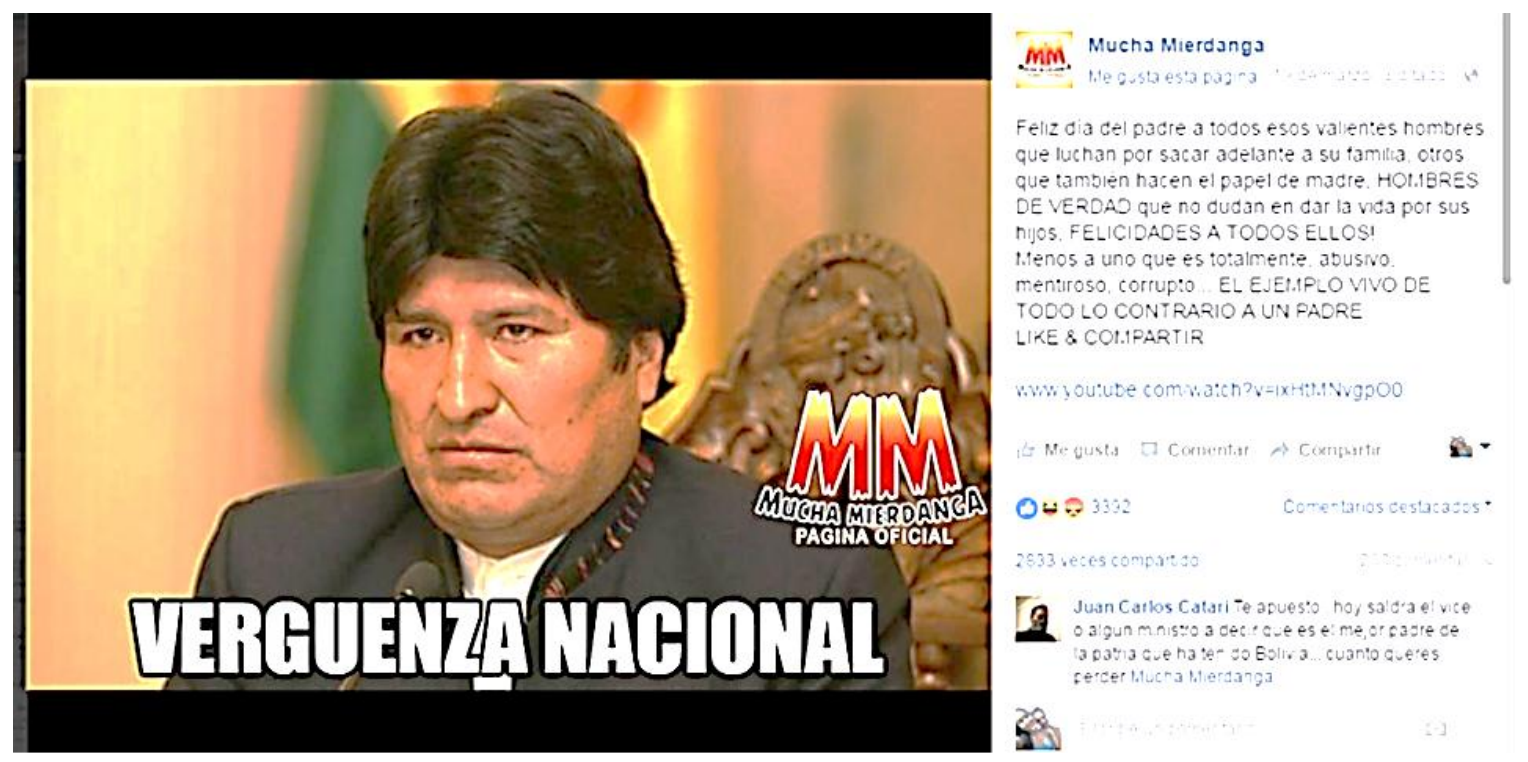

Fuente: elaboración propia

\section{- Rango 8: del 23 al 29 de marzo}

Los estados aluden a la relación del Ministro Quintana con Gabriela Zapata, el rey y las hormonas amazónicas se viralizan en diferentes sitios de Facebook (Valverde, MM, No a la Reelección) y Twitter (Valverde).

Se impulsa la propuesta oficialista de regular las redes sociales en un meme de MM con 1.521 reacciones y 529 compartidos.

Imagen 8. Capturas de pantalla de Facebook del 23 al 29 de marzo

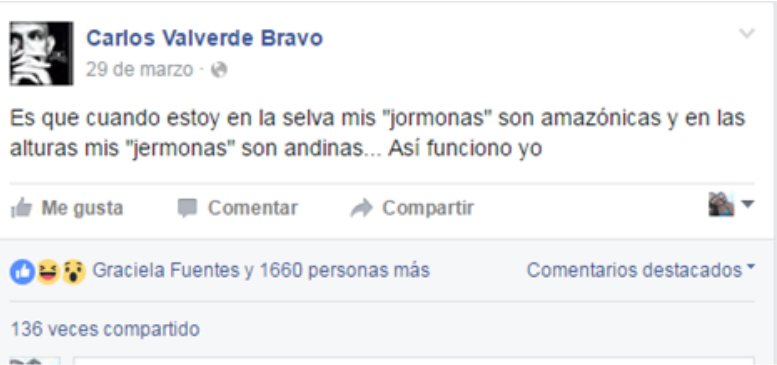

Carlos Valverde Bravo
29 de marzo ?
Y si te digo que Min Presidencia contrato a ITC (empresa a la que Zapata
millones... Que me decis? (aclaro que fue la Contraloria la que compró,
no el Min de la Presidencia.- posteada la aclaración el 30 de marzo)
1222 veces compartido




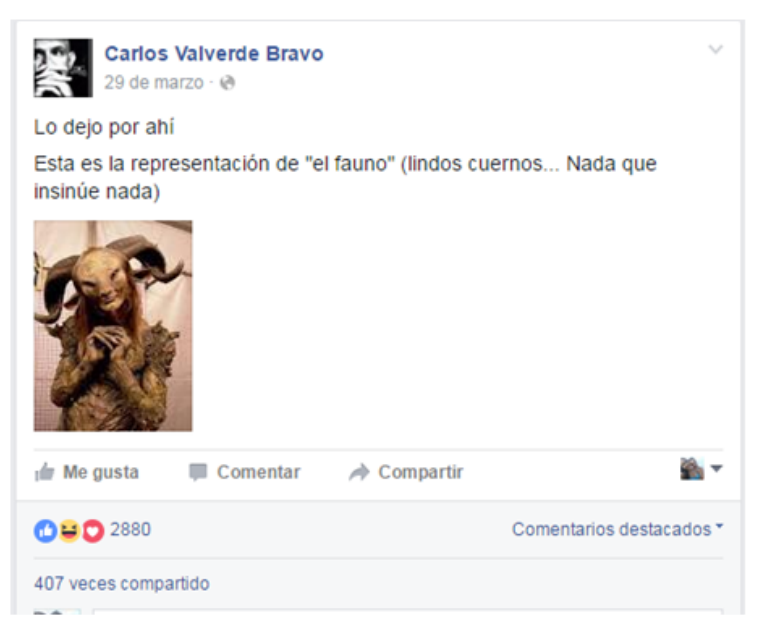

敢

Carlos Valverde Bravo

29 de marzo $\cdot$ e

Athos, Porthos, Aramis y Dártagnan... uno para todos y todos para uno El, ella y su "servidor" ... una para todos????

\begin{tabular}{|c|c|c|c|}
\hline Me gusta & Comentar & $\Rightarrow$ Compartir & 量 \\
\hline (1) 1403 & & & Comentarios destacados ${ }^{-}$ \\
\hline
\end{tabular}

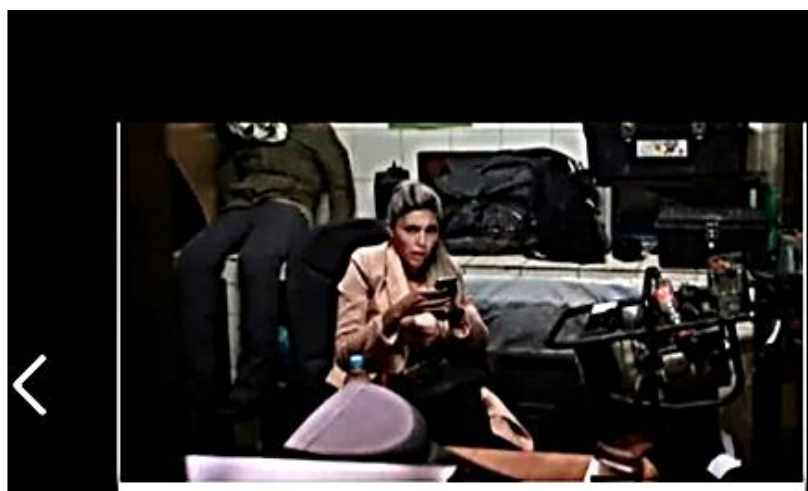

Hijo de Evo Morales y Gabriela Zapata está al tanto de los problemas de su madre en Bolivia

El abogado de Gabriela Zapata Montaño. Eđuardo León, afirmó en entrevista con Radio Fides que su defendida mantiene una comunicación permanente con su... FaHACEEQRIMANANT

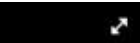
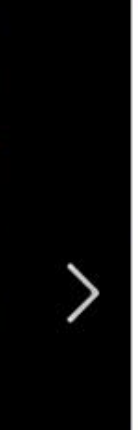

Carlos Valverde Bravo

29 de marzo - e

Es que cuando estoy en la selva mis "jormonas" son amazónicas y en las alturas mis "jermonas" son andinas... Asi funciono yo

Ine gusta Comentar $\rightarrow$ Compartir

(1) Graciela Fuentes y 1660 personas más Comentarios destacados *

136 veces compartido

Y si cualquier dia de estos se confirma que JR Quintana llamó a alguien influyente para que contraten a Zapata en CAMC? Y que las órdenes (devolviendo el servicio) para que contraten a dicha Empresa las hubiera dado JRQ? El tema es saber si el 1 daba la instrucción o si el Ministrito se tomaba la atribución.

Dicen en el entorno de la señora que ella no se hace problema de que la procesen por complicidad y estaria dispuesta a someterse a un proceso abreviado, pero ... que por delante está decidida a llevarse con ella al "principal autor intelectual de todo"

La pregunta es: será que JRQ se juega por el 1?

If Me gusta Comentar $\Rightarrow$ Compartir

(1): 1863 Comentarios destacados *

775 veces compartido
Mucha Mierdanga

SE VENE EL FINAL DE LA NOVELA CORRUPTAI Gabriela zapata anuncia que en estos dias dará a conocer a su hijo, UNICEF ya garantizo la seguridad de los 2 , dice que habla con su pequeño todo el tiempo y que el esta al tanto de lo que sucede, el niño ya no aguanta el dia de hablar sucede, el niño ya no aguanta el dia de hablar
frente a todos sobre su padre y la rabia que le tiene (:)

ALISTEN LAS PIPOCAS Y GASEOSAS ESTO SERA EPICOI

vamos a vender eI DVD en los mejores mercados

del pais $($ )

LIKE \& COMPARTIRI

MIRA EL TRAILER AQUi: www youtube com watch?v=ixHtMNvgPOO

1. Me gusta $a$ Comentar $\rightarrow$ Compartir

O: 1195 Comentarios destacados *

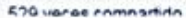

28 Escribe un comentario 

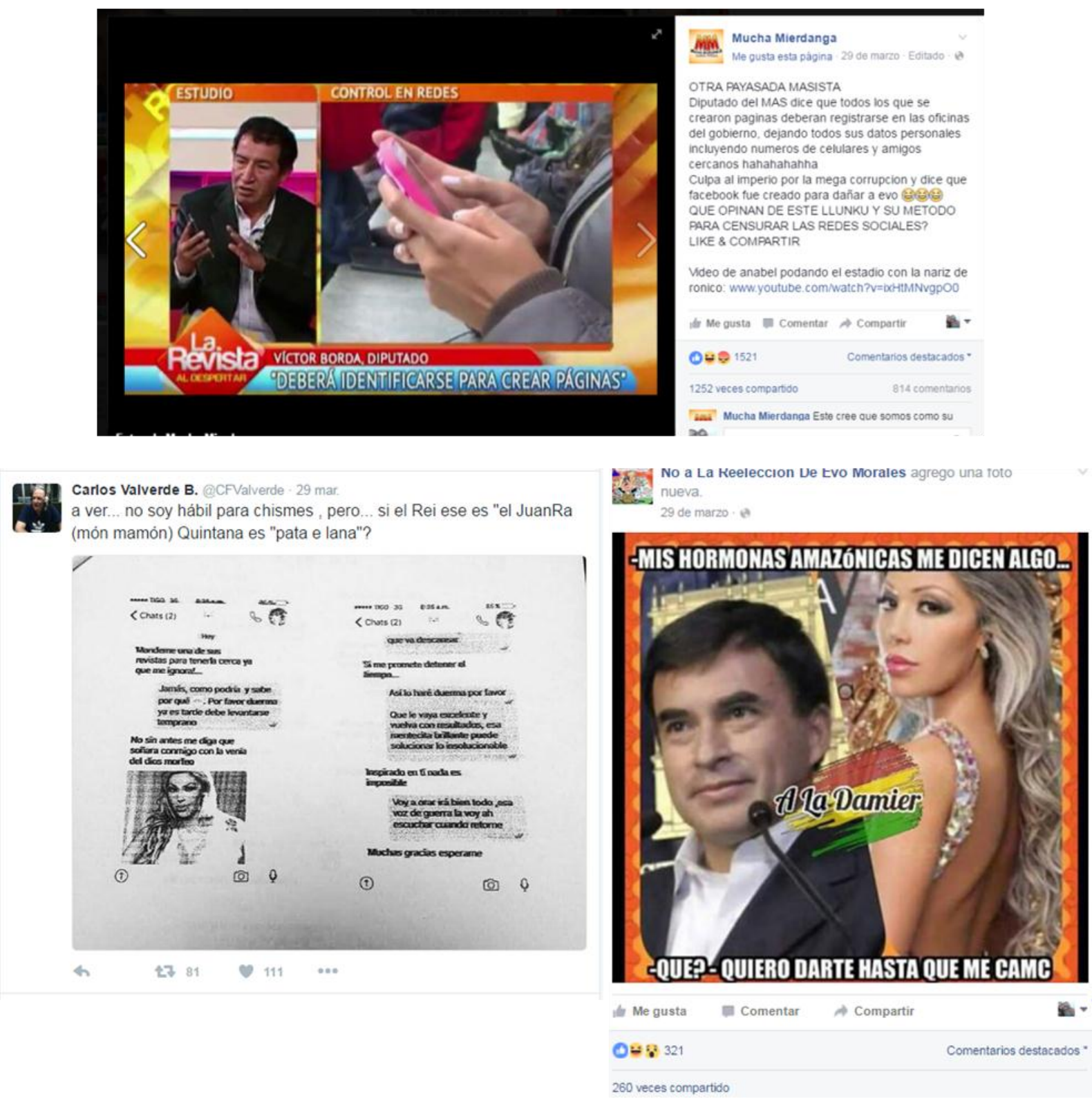

Fuente: elaboración propia

\section{- Rango 9: del 30 de marzo al 3 de abril}

Los memes y estados publicados, se centran en el triángulo de Zapata, Quintana y el presidente Morales, suman en la ironización la figura del hijo que no aparece, las frases de rey y semental amazónico, superando las tres mil reacciones de los seguidores.

La relación de las redes sociales con el resultado del referéndum reaparece sumado a la idea de conspiración internacional, (958 reacciones y 421 compartido). 


\section{Imagen 9. Capturas de pantalla de Facebook del 30 de marzo al}

3 de abril

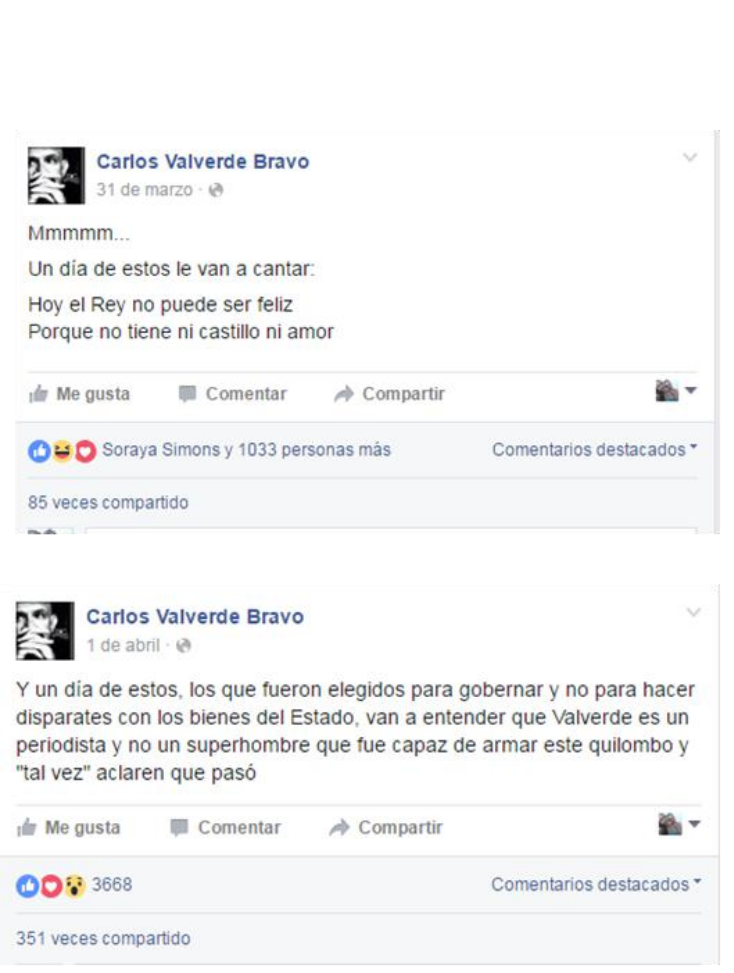

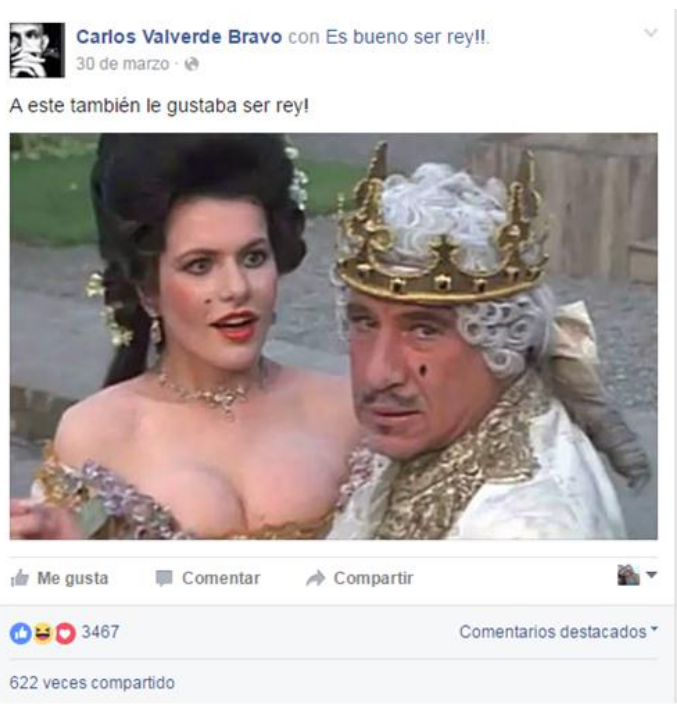

Yla pregunta es:
Cuánto tiempo más, dura "el semental" amazónico en el cargo?
I.te Me gusta $\quad \rightarrow$ Compartir
457 veces compartido $3236 \quad$ Comentarios destacados"
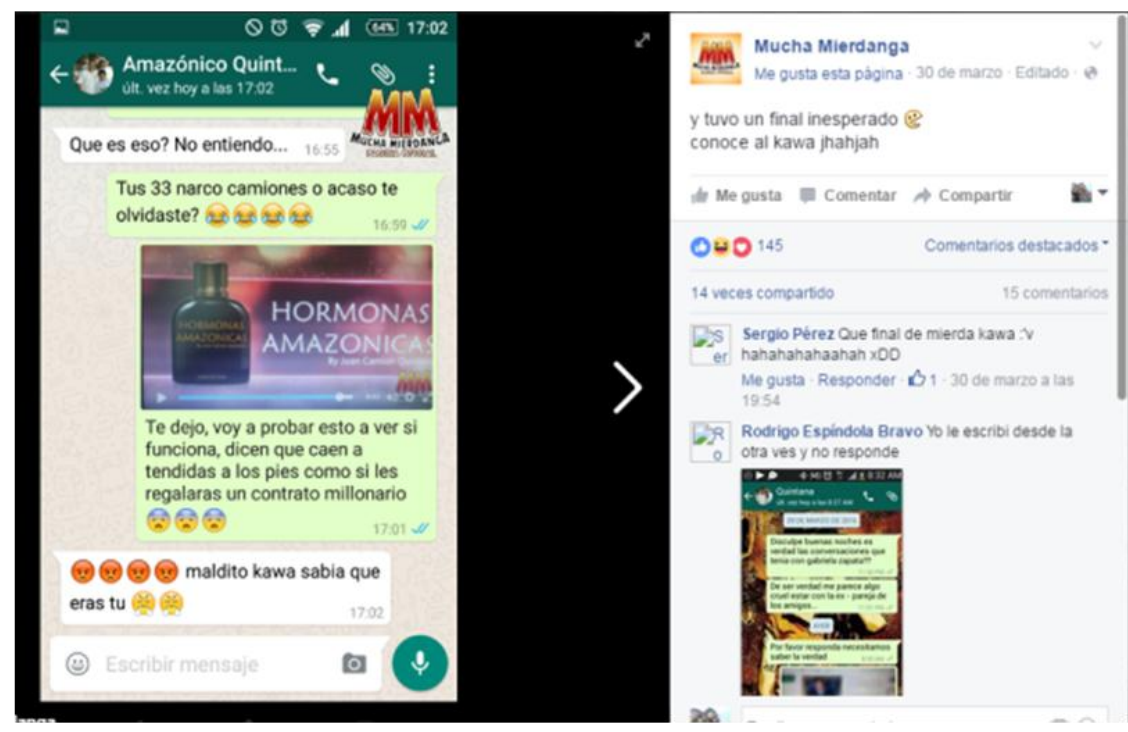

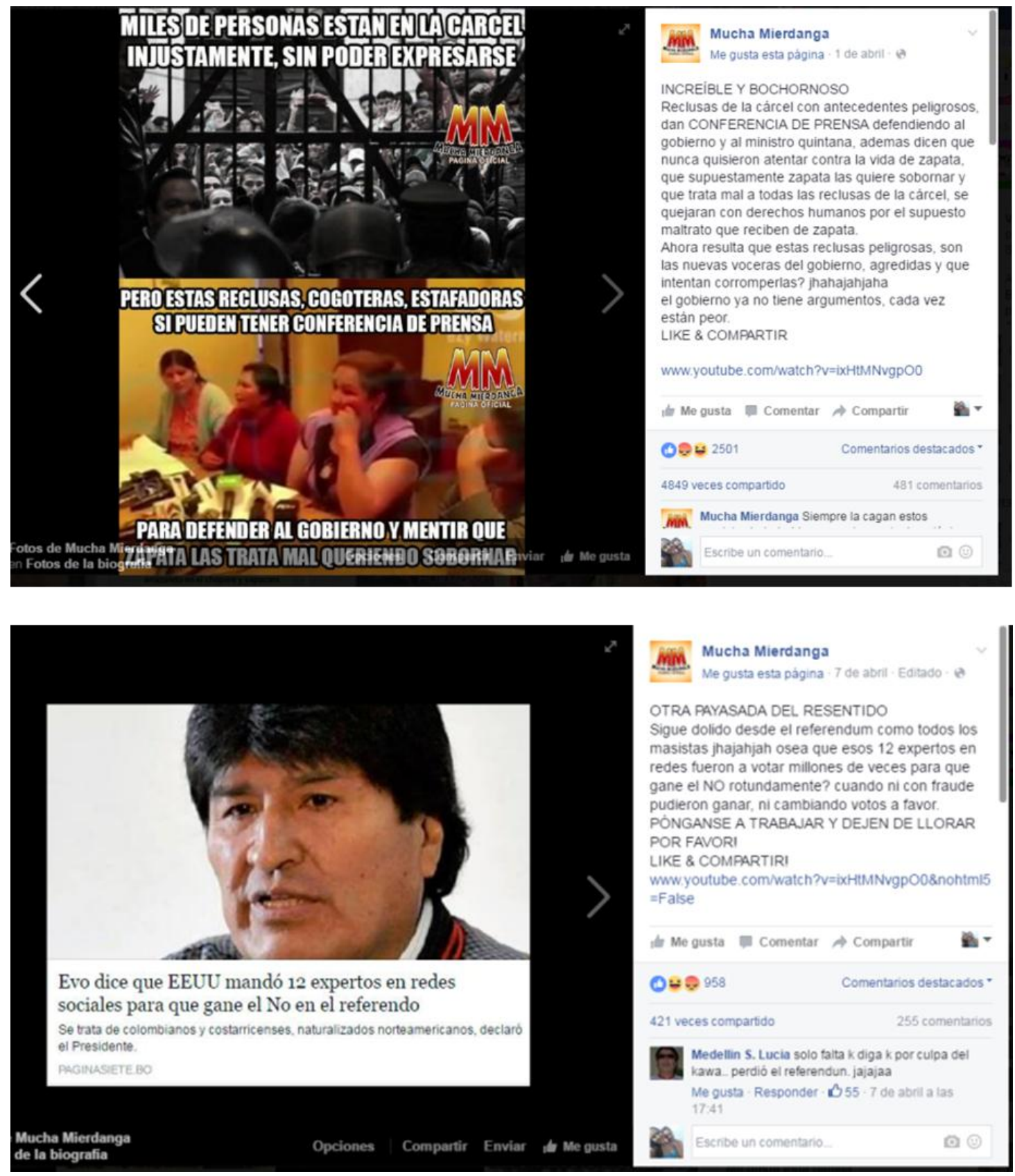

Fuente: elaboración propia

\section{Conclusiones}

A manera de conclusiones podemos indicar:

1. El caso de "La Novela Zapata" es un importante elemento al momento de referirse a la influencia de las redes sociales en la realidad social boliviana.

2. Luego de haber estallado mediáticamente el denominado "tráfico de influencias", la imagen del Presidente Evo Morales y del Gobierno Central se vio afectado en cuanto a la 
aceptación de la gente y las percepciones sobre el manejo de los recursos del Estado, influyendo en la decisión de los ciudadanos votantes en el Referéndum Constitucional 2016.

3. La transmediatización, como un fenómeno que se va produciendo cada vez con mayor presencia, es aún un concepto en construcción, donde llevar discursos desde los medios formales de comunicación a las redes sociales digitales o a la inversa, será motivo de mayores estudios en el caso boliviano.

4. En el espacio público, el discurso político juega sus estrategias en los medios tradicionales y en los digitales con nuevas dinámicas, como el fenómeno llamado "memetización" de la política que, en resumen, refiere a la utilización de la sátira (Memes) como un recurso de la ciudadanía para la expresión de sus emociones e intereses.

5. La transmediatización de la información y su influencia en las esferas públicas está dando como resultado un intento de subsunción del Gobierno central a la cabeza del Presidente Evo Morales, para la utilización de las Tecnologías de la Información y Comunicación (TIC) con una mayor seriedad y profesionalismo, como se observa en la creación una entidad especializada en el área de comunicación que se ocupará de la promoción de la gestión de gobierno en el ámbito de las redes sociales.

6. Como una de las consecuencias de "La Novela Zapata", llega a lo mediático el discurso de regular las redes sociales en Bolivia, surgiendo por un lado, los primeros proyectos oficialistas de algunos dirigentes de organizaciones sociales y por el otro, iniciativas legislativas de defensa del derecho y la libertad de expresión. Sin embargo, no se tiene una propuesta concreta de regulación (a la fecha).

\section{Referencias}

Hashtagify. (Abril de 2016). Recuperado el 03 de Abril de 2016, de Hashtagify: http://hashtagify.me/hashtag/gabrielazapata 
Página Siete. (25 de Febrero de 2016). Recuperado el 20 de Abril de 2016, de http://www.paginasiete.bo/nacional/2016/2/25/redessociales-como-recolector-basura-87892.html

Bolpress. (28 de septiembre de 2015). Bolpress. Recuperado el 24 de abril de 2016, de http://www.bolpress.com/art.php?Cod=2015092801

Callada, P. (2015). La Sal de la Democracia. En M. (. BIANCHI, ¿Qué Democracia para el Siglo XXI? (págs. 217-227). Democracia en Red - Asuntos del Sur.

Exeni R., J. L. (2015). Comicios Mediaticos II; Medios de difusión y redes sociales digitales en las elecciones de 2014 en Bolivia. La Paz: IDEA Internacional.

Layme, B. (23 de Febrero de 2016). Página Siete. Recuperado el 20 de Abril de 2016, de http://www.paginasiete.bo/decision2016/2016/2/23/evoalgunos-paises-redes-tumban-gobiernos-87687.html

Pallero, J. (Marzo de 2016). Access Now. Recuperado el 20 de Abril de 2016, de Access Now:

https://www.accessnow.org/cms/assets/uploads/2016/03/Ar gumentos_Bolivia_social_media2.pdf

Peñaranda, R. (2014). Control remoto. Quinta edición. La Paz: Peñaranda . Perez de Achá, G. (24 de marzo de 2016). Derechos Digitales.

Recuperado el abril de 24 de 2016, de Derechos Digitales: https://www.derechosdigitales.org/9841/la-guerra-sucia-enredes-sociales/

Rivero, P. (16 de Marzo de 2016). Pablo Andrés Rivero, Blog. Recuperado el 04 de Abril de 2016, de Pablo Andrés Rivero, Blog:

http:/ / pabloarivero.blogspot.com/2016/03/twreportebomedios-de-bolivia-en.html\#more

Rocha, V. F. (2015). Redes sociales digitales. En E. R. Coord., Comicios Mediáticos II (pág. 310). La Paz: IDEA.

Vargas Lima, A. E. (Enero de 2015). La Reelección Presidencial en la Jurisprudencia del Tribunal Constitucional Plurinacional de Bolivia. la Ilegítima Mutación de la Constitución a través de una Ley de Aplicación Normativa. Revista Boliviana de Derecho(19), 446-469. 
Villegas, T. S. (2011). Regulación de medios y periodismo:posiciones desde la prensa. En O. N. Medios, Medios a la Vista 2 (pág. 262). La Paz: Fundación Unir Bolivia.

\section{Anexo I}

\section{Tabla 3. Matriz de monitoreo del periódico digital Página Siete}

\begin{tabular}{|c|c|c|c|c|}
\hline $\begin{array}{l}\text { Días mo- } \\
\text { nitoreados } \\
\text { / fechas }\end{array}$ & $\begin{array}{l}\mathrm{N}^{\circ} \text { de noti- } \\
\text { cias m oni- } \\
\text { toreadas }\end{array}$ & Cronología del caso & $\begin{array}{c}\text { Categorías / Etique- } \\
\text { tas }\end{array}$ & $\begin{array}{c}\text { Redes Sociales tem as } \\
\text { que se transm ediati- } \\
\text { zaron }\end{array}$ \\
\hline $\begin{array}{l}\text { Rango } 1 \\
3 \text { al9 de } \\
\text { febrero }\end{array}$ & 38 & $\begin{array}{l}\text { E1 } 3 \text { de febrero el periodista Carlos Valverde denuncia en su } \\
\text { programa televisivo "Todo por hoy" en la ciudad Santa } \\
\text { Cruz, por Activa TV. Ese día no se re gistran noticias en el } \\
\text { medio digital Página Siete. } \\
\text { La oposición exige investigación y declaración oficial fren- } \\
\text { te a la posible paternidad reconocida por Morales producto } \\
\text { de su relación con Gabriela Zapata. } \\
\text { Se sum a a la denuncia los contratos millonarios con la em- } \\
\text { presa china CAMC y al tráfico de influencias y conflicto de } \\
\text { intereses. } \\
\text { E1 gobiemo aduce un ataque brutal de la oposición, guerra } \\
\text { sucia previa al referéndum obedeciendo a una cam pafa de } \\
\text { desestabilización financia da por Estados Unidos. } \\
\text { Zapata refleja su admiración al presidente en su cuenta de } \\
\text { Facebook. } \\
\text { Evo reconoce a Zapata y al hijo, pero sostiene que murió, } \\
\text { desconoce su relación, distanciamiento, niega tráfico de } \\
\text { influencia. } \\
\text { Zapata em presaria, joven, ejecutiva CAMC, estilo de vida } \\
\text { lujosa. } \\
\text { CAMC solicita investiguen sus contratos. } \\
\text { Caso Zapata adquiere relevancia intemacional BBC Mundo, } \\
\text { hija de Evo apoya a su padre negando la relación con Zapata } \\
\text { desde su cuenta de Twitter. Gobiemo anuncia procesosa } \\
\text { Valverde. } \\
\text { Redes sociales circulan invitación falsa que involucran a } \\
\text { Morales -Zapata como padrinos de un bautism o. } \\
\text { Proceso a Valverde por dar nom bre de nifio Asamblea Per- } \\
\text { manente de Derechos Humanos. } \\
\text { Redes sociales muestran fotos Facebook relación cercana } \\
\text { Morales - Zapata, Morales sostiene resistir las Redes Socia- } \\
\text { les por Bolivia, } \\
\text { Prensa intemacional (ABC de Espana), Samuel Doria Medi- } \\
\text { na induce a votar por el No en el referéndum. }\end{array}$ & $\begin{array}{l}\text { Zapata-Valverde } \\
\text { Zapata-Evo Pareja } \\
\text { Zapata- Hijo } \\
\text { Zapata-Cam c } \\
\text { Zapata-Referéncum } \\
\text { Zapata- Redes So- } \\
\text { ciales }\end{array}$ & $\begin{array}{l}\text { Alerta a la Denuncia } \\
\text { Voto por el NO } \\
\text { Reconocimiento de } \\
\text { Evo a Zapata } \\
\text { Am enazas de proce- } \\
\text { sos a Valverde } \\
\text { Form ación académi- } \\
\text { ca de Zapata. }\end{array}$ \\
\hline
\end{tabular}




\begin{tabular}{|c|c|c|c|c|}
\hline $\begin{array}{c}\text { Rango } 2 \\
10 \text { al } 16 \\
\text { de febre- } \\
\text { ro }\end{array}$ & 86 & $\begin{array}{l}\text { Oficialism o y oposición solicitan investiga ción a CAMC, } \\
\text { denuncias de contratos millonarios. } \\
\text { Morales admite fotografia del Facebook con Zapata, pero no } \\
\text { la reconoció. } \\
\text { Zapata declara: erjuiciará a difama dores } \\
\text { Versiones contradictorias de Zapata y Linera. } \\
\text { Zapata infractora de tránsito. Zapata sin título profesional. } \\
\text { Lo privado vs lo público. } \\
\text { Record visitas a Página Siete (117.500 visitas por caso Za- } \\
\text { pata) } \\
\text { Ministros piden no usar nifios, hablan de guerra sucia } \\
\text { Imagen presidencial afectada por corrupción puede influir } \\
\text { en resultados del Referéndum para opositores, ministros } \\
\text { descartan influencia. } \\
\text { Encuestas reflejan bajas en la credibilidad al presidente. } \\
\text { Oficialism o califica de "truchas" a las encuestas. } \\
\text { Tem or porque influencia de caso Zapata- Morales sume } \\
\text { votosal NO, indecisos van por el NO. } \\
\text { Poder de Redes Sociales } \\
\text { Enjuiciamiento a Valverde, apoyo de periodistas cruceños. } \\
\text { Hermana de Zapata, apoya al No, familia en contra. } \\
\text { Prensa internacional INFOBAE Argentina "C orrupción en } \\
\text { Bolivia", Ministra exige pruebas al medio. } \\
\text { Idea de conspiración. }\end{array}$ & $\begin{array}{l}\text { Zapata-Cam c Zapata } \\
\text {-Evo Pareja } \\
\text { Zapata Redes Socia- } \\
\text { les } \\
\text { Zapata- Valverde } \\
\text { Zapata-Hijo Zapata- } \\
\text { Referéndum }\end{array}$ & $\begin{array}{l}\text { Persecución y ame- } \\
\text { nazas al periodista } \\
\text { Valverde } \\
\text { Apoyo de periodistas } \\
\text { crucefios } \\
\text { Denuncia de conspi- } \\
\text { ración de Valverde } \\
\text { Falsedad de titula- } \\
\text { ción de Zapata y del } \\
\text { vicepresidente }\end{array}$ \\
\hline $\begin{array}{c}\text { Rango } 3 \\
17 \text { al } 23 \\
\text { de febre- } \\
\text { ro }\end{array}$ & 50 & $\begin{array}{l}\text { Idea de Conspiración: V alverde agente de EEUU } \\
\text { Marcha de apoyo en Santa Cruz a V alverde } \\
\text { Redes sociales: H ashtags HFondioc y \#Zapata, tendencias } \\
\text { que influyen en Referéndurn. Silencio electoral no acalla las } \\
\text { redes sociales. } \\
\text { Facebook y Twitter com plican cam paña de Evo. Sugiere } \\
\text { debatirlas porque traen “confronta ción" } Y \text { "tum ban gobier- } \\
\text { nos" } \\
\text { Indecisos y Redes Sociales por el NO. } \\
\text { Prensa internacional Infobae: Los medios del mundo refle- } \\
\text { jan el escándalo sexual y de corrupción de Evo Morales en } \\
\text { Bolivia('The New York Tim es', 'The Guardian', 'ABC'y } \\
\text { 'CNN') } \\
\text { Cierre de Campaña electoral. } \\
\text { Investigación a CAMC, boletas de garantía y contratos }\end{array}$ & $\begin{array}{l}\text { Zapata -V alverde } \\
\text { Zapata- Redes Socia- } \\
\text { les } \\
\text { Zapata -Referéndum } \\
\text { Zapata Cam c }\end{array}$ & $\begin{array}{l}\text { Falsedad de titula- } \\
\text { ción del vicepresi- } \\
\text { dente } \\
\text { Marcha cruceña de } \\
\text { apoyo a V alverde } \\
\text { (video) } \\
\text { Referéndum, voto } \\
\text { por el NO, fraude y } \\
\text { resultados } \\
\text { Redes sociales, regu- } \\
\text { lación y uso, pro- } \\
\text { puestas legislativas }\end{array}$ \\
\hline
\end{tabular}




\begin{tabular}{|c|c|c|c|c|}
\hline $\begin{array}{c}\text { Rango } 4 \\
24 \text { de } \\
\text { febrero al } \\
1 \text { de mar- } \\
\text { xo }\end{array}$ & 82 & $\begin{array}{l}\text { Derrota de Evo Morales, se la atribuye a las redes } \\
\text { "recolector de basura". } \\
\text { Redes Sociales: Linchamiento digital, hum illación viral. } \\
\text { Fiscalía admite denuncia de Zapata contra Valverde } \\
\text { Imputación y aprehensión a Gabriela Zapata por tráfico de } \\
\text { influencia. Zapata encarcela da en Obrajes } \\
\text { Tía de Zapata sostiene que el hijo está vivo } \\
\text { Gobiemo exige que Zapata presente al hijo } \\
\text { Defensoría del Pueblo indica vulneración de derechos de la } \\
\text { niñez } \\
\text { Hijo será presenta do en m edios internacionales. } \\
\text { Evo quiere recoger a su hijo si estuviera vivo. ¿V ive o no? } \\
\text { CNN (Oppenheim er) entrevista a Valverde } \\
\text { Choque, amiga de Zapata, aprehendida } \\
\text { Valverde investiga nex os entre Zapata y Quintana } \\
\text { Quintana propone crear Agencia de Inteligencia }\end{array}$ & $\begin{array}{l}\text { Zapata -Valverde } \\
\text { Zapata- Redes Socia- } \\
\text { les } \\
\text { Zapata -Referéndum } \\
\text { Zapata-Privada De } \\
\text { Libertad } \\
\text { Zapata - Hijo } \\
\text { Zapata- Quintana }\end{array}$ & $\begin{array}{l}\text { Creación de Agencia } \\
\text { de Inteligencia pro- } \\
\text { puesta por Quintana } \\
\text { Relación Zapata y su } \\
\text { hijo, vulneración de } \\
\text { derechos del nifio, } \\
\text { instituciones defen- } \\
\text { soras de derechos } \\
\text { Oppenheim er entre- } \\
\text { vista a V alverde por } \\
\text { CNN }\end{array}$ \\
\hline $\begin{array}{c}\text { Rango } 5 \\
2 \text { al } 8 \\
\text { de marzo }\end{array}$ & 83 & $\begin{array}{l}\text { Resultado referéndum fue un "jalón de orejas" } \\
\text { Aprehenden a chofer vincula do a depósitos } \\
\text { Vincula ción con Quintana, niega conocerla. } \\
\text { Quintana crea Agencia de Inteligencia } \\
\text { Gobierno am enaza a Zapata para que no divulgue im ágenes } \\
\text { del hijo } \\
\text { Evo querella a Zapata por violencia psicoló gica a su hijo } \\
\text { Familia de Zapata no presentará al hijo } \\
\text { Fiscalía allana vivienda de Zapata y toma docum entos } \\
\text { Caso Zapata provoca renuncia de vicem inistra } \\
\text { Quintana sostiene que medios desaparecerán por mentir al } \\
\text { país (incluido Pagina Siete) descalifica a CNN y otros inter- } \\
\text { nacionales por dar credibilidada V alverde } \\
\text { Redes Sociales: Am enaza de muerte a Evo, memes racistas } \\
\text { y discrim inadores } \\
\text { Prensa internacional: Oppenheim er escribe sobre } \\
\text { "corrupción ma miva" en el país } \\
\text { Crisis de im agen del presidente afecta al MAS } \\
\text { Investigación de CAMC, contratos }\end{array}$ & $\begin{array}{l}\text { Zapata -V alverde } \\
\text { Zapata- Redes Socia- } \\
\text { les } \\
\text { Zapata-Referéndum } \\
\text { Zapata-Hijo } \\
\text { Zapata- Quintana } \\
\text { Zapata- Cam c }\end{array}$ & $\begin{array}{l}\text { Persecución a Val- } \\
\text { verde, actos de dis- } \\
\text { tracción } \\
\text { Encubrim iento de los } \\
\text { hechos de corrupción }\end{array}$ \\
\hline
\end{tabular}

\begin{tabular}{|c|c|c|c|c|}
\hline $\begin{array}{c}\text { Rango } 6 \\
9 \text { al } 15 \text { de } \\
\text { marzo }\end{array}$ & 58 & $\begin{array}{l}\text { Quintana cuestiona a CNN } \\
\text { Investigación a CAMC, le givlativo solicita inform es } \\
\text { COB y cam pesinos requieren "oxigenación" en ministerios } \\
\text { Oposición requiere libros de visitas de Gestión Social desa- } \\
\text { parecido } \\
\text { Redes sociales: cuestionadas y abandonadas por el oficialis- } \\
\text { mo } \\
\text { Chofer, Choque investigados por Fiscalia } \\
\text { Leo Fernández, jugador de futbol, amigo de Evo y Zapata } \\
\text { Investigación CAMC } \\
\text { Campaña del Si fue coordinada en oficinas de Zapata }\end{array}$ & $\begin{array}{l}\text { Zapata- Redes Socia- } \\
\text { les } \\
\text { Zapata- Quintana } \\
\text { Zapata- Cam c } \\
\text { Zapata- Referéndum }\end{array}$ & $\begin{array}{l}\text { Discurso de Quintana } \\
\text { distractivo } \\
\text { Redes sociales, uso y } \\
\text { control del oficialis- } \\
\text { mo } \\
\text { Vinculación Zapata, } \\
\text { Evo, Leo Fernández, } \\
\text { mentiras }\end{array}$ \\
\hline $\begin{array}{c}\text { Rango } 7 \\
16 \text { al } 22 \\
\text { de marzo }\end{array}$ & 56 & $\begin{array}{l}\text { Fiscalia sostiene que certificado que presento Zapata sobre } \\
\text { su hijo es falso. "le mintieron a Evo" "¿Le has toca do la } \\
\text { pancita" a Gabriela Zapata?" } \\
\text { Zapata tem e por su vida y ratifica hijo en común con Evo, } \\
\text { Gobierno da garantías. Tem en tra slado a otra penitenciaría } \\
\text { Registro com prueba que Evo conoció a su hijo y dio pensio- } \\
\text { nes. Escalera, chofer y amigo de Evo, testigo del reconoci- } \\
\text { miento } \\
\text { Zapata: Hijo vive en el exterior por su seguridad } \\
\text { Aparecen ecografías y fotografias. } \\
\text { Zapata "¿Cree que una niña de } 17,18 \text { años, le va a engañar } \\
\text { a un hombre de } 48,47 \text { años?" "Cum pli con 'mantener ocul- } \\
\text { to" al hijo de Evo" } \\
\text { Oficialism o prepara "bom bardeo" en redes sociales para el } \\
2019\end{array}$ & $\begin{array}{l}\text { Zapata- Hijo } \\
\text { Zapata- Redes Socia- } \\
\text { les }\end{array}$ & $\begin{array}{l}\text { Docum ento de reco- } \\
\text { nocim iento del hijo. } \\
\text { Discursos contradic- } \\
\text { torios de ministros y } \\
\text { fiscales. }\end{array}$ \\
\hline
\end{tabular}




\begin{tabular}{|c|c|c|c|c|}
\hline $\begin{array}{c}\text { Rango } 8 \\
23 \text { al } 29 \\
\text { de marzo }\end{array}$ & 65 & $\begin{array}{l}\text { Am plian im puta ción a Zapata } \\
\text { Zapata acusa a Quintana de "armarlo todo", m entir y traicio- } \\
\text { nar al presidente } \\
\text { Tía de Zapata: ONU, OEA y UNICEF protegerán al hijo } \\
\text { Investigación CAMC, contratos y ejecutivos } \\
\text { Zapata tra sladada a Miraflores, cárcel de m áx im a seguridad. } \\
\text { Salud se deteriora, Gobiemo aduce no vulnerar derechos. } \\
\text { Oposición: "no es perse guida política es perseguida marital" } \\
\text { Fiscalía convoca a Quintana } \\
\text { Aparecen Chats con Quintana "mi rey" HAdiosMiRey, hash- } \\
\text { tag que desató jocosas reacciones en Twitter } \\
\text { Cocaleros alistan proyecto de Ley sobre regulación de Re- } \\
\text { des }\end{array}$ & $\begin{array}{l}\text { Zapata- Quintana } \\
\text { Zapata-Hijo } \\
\text { Zapata- Cam c }\end{array}$ & $\begin{array}{l}\text { Zapata involucra a } \\
\text { Quintana, conversa- } \\
\text { ciones de whatsapp } \\
\text { publican la relación y } \\
\text { se viralizan frases } \\
\text { como mi rey las hor- } \\
\text { monas amazónicas } \\
\text { Ley de regulación de } \\
\text { redes }\end{array}$ \\
\hline $\begin{array}{c}\text { Rango } 9 \\
30 \text { de } \\
\text { marzo al } \\
3 \text { de abril }\end{array}$ & 45 & $\begin{array}{l}\text { Zapata sufre daño psicológico en la cárcel, la drogarony } \\
\text { am enazaron de muerte. } \\
\text { Quintana niega relación sentim ental con Zapata, of rece su } \\
\text { celular. } \\
\text { Zapata ofrece más pruebas de su relación con Quintana } \\
\text { Plantean que quien habrá cuenta de Facebook se registre } \\
\text { Oposición exige renuncia de Quintana } \\
\text { Redes sociales: usuarios creen que Quintana miente al presi- } \\
\text { dente }\end{array}$ & $\begin{array}{l}\text { Zapata-Privada de } \\
\text { Libertad } \\
\text { Zapata-Redes So- } \\
\text { ciales } \\
\text { Zapata-Quintana }\end{array}$ & $\begin{array}{l}\text { Relación de Zapata } \\
\text { con Quintana, trián- } \\
\text { gulo am oroso con el } \\
\text { presidente. } \\
\text { Registro de usuarios } \\
\text { en redes sociales, } \\
\text { regulación } \\
\text { Conferencia de pren- } \\
\text { sa de privadas de } \\
\text { libertad }\end{array}$ \\
\hline
\end{tabular}

Fuente: elaboración propia

\section{Anexo II}

\section{Gráfico 1: Resultados Referéndum Constitucional 2016}

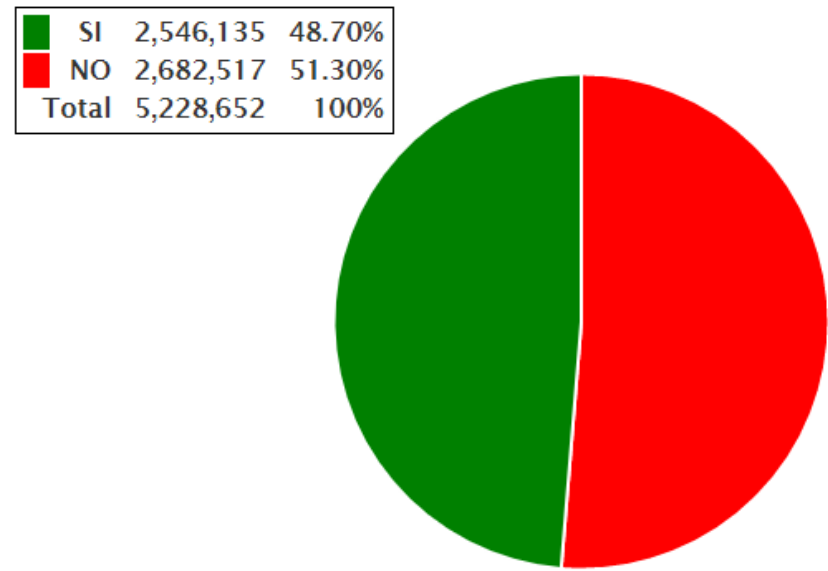

\begin{tabular}{|c|c|c|c|c|}
\hline Total inscritos habilitados: & $6,502,069$ & \multicolumn{2}{|c|}{ Votos válidos: $5,228,652$} & \multirow{3}{*}{$\begin{array}{r}95.22 \% \\
1.25 \% \\
3.52 \%\end{array}$} \\
\hline $\begin{array}{l}\text { Total inscritos habilitados por actas } \\
\text { computadas: }\end{array}$ & $6,502,069$ & \multirow{2}{*}{\multicolumn{2}{|c|}{$\begin{array}{rr}\text { Votos blancos: } & 68,845 \\
\text { Votos nulos: } & 193,422\end{array}$}} & \\
\hline Porcentaje de Participación: & $84.45 \%$ & & & \\
\hline Actas com putadas: & 30,367 de 30,367 & \multicolumn{2}{|c|}{ Total votos emitidos: $5,490,919$} & $100,00 \%$ \\
\hline
\end{tabular}

Fuente: Órgano Electoral Plurinacional, 2016 


\section{Gráfico 2. Medios de Bolivia en Twitter, indicador de influencia $^{6}$}

Comportamiento del indicador de influencia de los 10 medios más influyentes (sept 2015 - mar 2016)
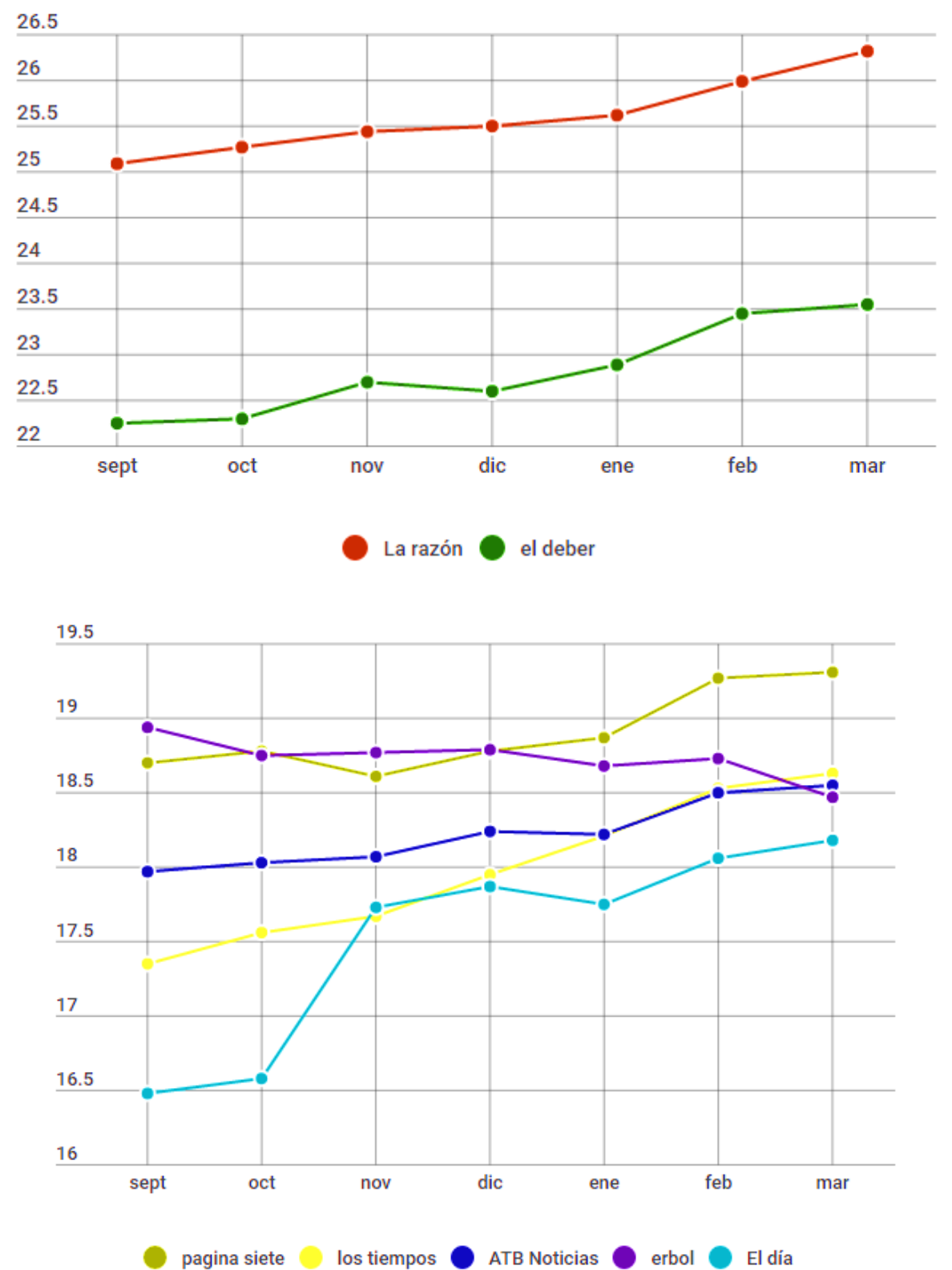

\footnotetext{
${ }^{6}$ Este indicador se obtiene a partir de un indicador integrado por los RT, menciones y clic en enlaces publicados durante el mes observado. La cantidad de seguidores (ver tabla más abajo) no es un indicador determinante, sino que pesa más la interacción y respuesta de la audiencia, menciones o retuits.
} 


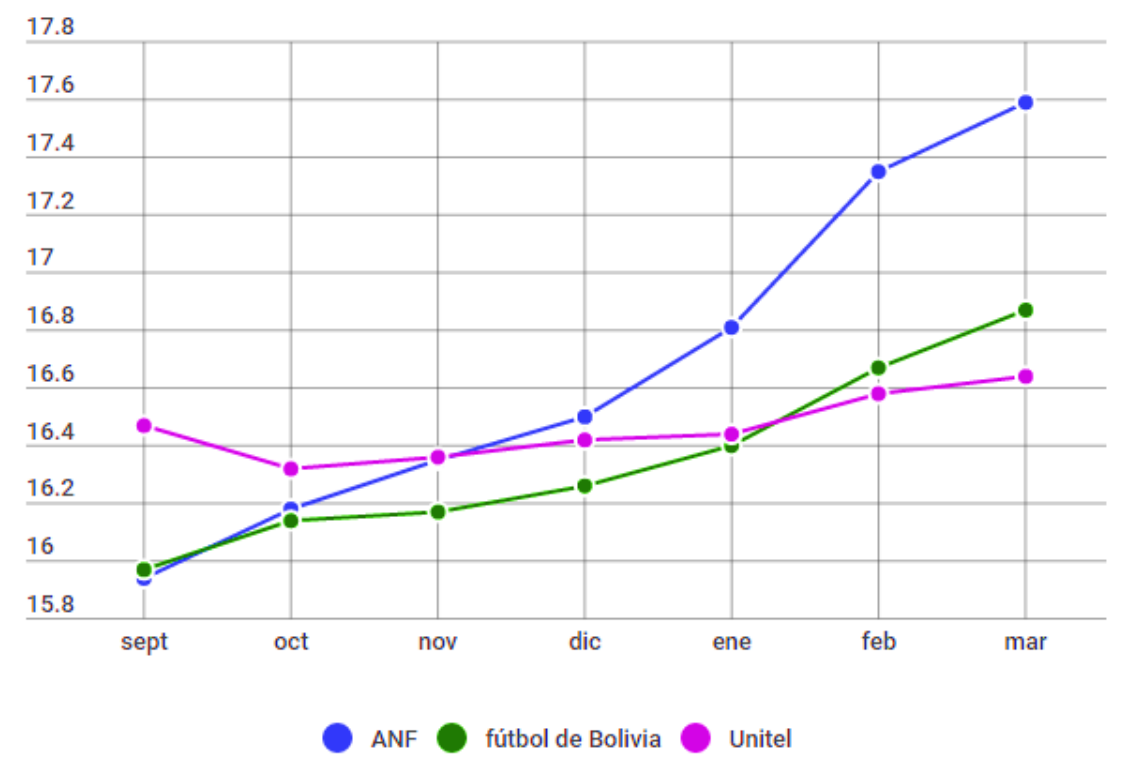

Fuente: Rivero, 2016

\section{Gráfico $\mathbf{N}^{\circ} 3$}

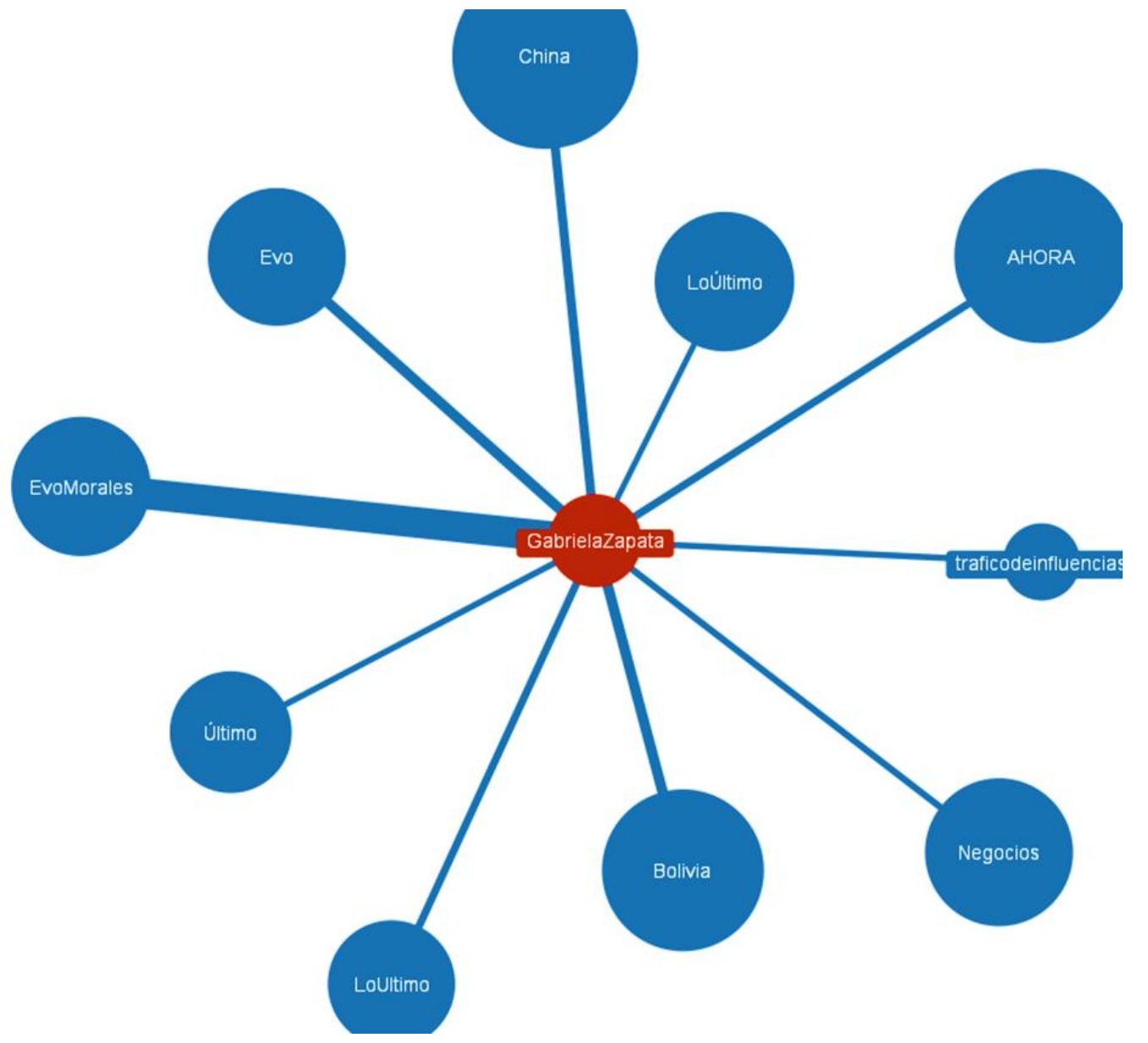




\begin{tabular}{|c|c|c|c|c|c|c|}
\hline Hashtag & $\Leftrightarrow$ & Popularity & $\boldsymbol{v}$ & Correlation $\Leftrightarrow$ & Weekly Trend $\vec{\nabla}$ & Monthly Trend $\vec{\nabla}$ \\
\hline \#GabrielaZapata & & 30.8 & & $100 \%$ & $+11.4 \boldsymbol{\Delta}$ & -3.9 \\
\hline \#China & & 74.8 & & $8.1 \%$ & -0.9 & -0.4 \\
\hline \#AHORA & & 69.4 & & $6.1 \%$ & +0.9 & +0.4 \\
\hline \#Bolivia & & 63.5 & & $10.1 \%$ & -0.1 & -3.1 \\
\hline \#Negocios & & 56.9 & & $4.7 \%$ & -0.2 & -0.4 \\
\hline \#LoÚltimo & & 52.9 & & $3.4 \%$ & -2.8 & +1.5 \\
\hline \#EvoMorales & & 52.8 & & $39.2 \%$ & +4.6 & -3.7 \\
\hline \#Evo & & 52.1 & & $10.1 \%$ & 0.0 & -1.3 \\
\hline \#LoUltimo & & $47.1^{\circ}$ & & $6.1 \%$ & -2.0 & -0.7 \\
\hline \#Último & & 44.5 & & $4.1 \%$ & +0.6 & +2.2 \\
\hline \#traficodeinfluencias & & 23.3 & & $4.1 \%$ & 0.0 & +3.2 \\
\hline
\end{tabular}

Fuente: Hashtagify, 2016 


\section{Participación política y medios de comunicación. Un estudio sobre los jóvenes ecuatorianos $^{7}$}

Daniel Javier de la Garza Montemayor. Universidad Autónoma de Nuevo León (México). danieldelagarza@gmail.com

Daniel Barredo Ibáñez. Universidad del Rosario (Colombia). daniel.barredo@,urosario.edu.co

Carlos Arcila Calderón. Universidad de Salamanca (España). carcila@usal.es

\section{Introducción}

En la última década, la participación a través de las redes sociales ha tenido un elevado protagonismo en la esfera política ecuatoriana, como un escenario de intercambio cuyo uso eficiente se relaciona, por ejemplo, con la victoria electoral de Rafael Correa en su primera campaña electoral (León, 2007). A través de medios como Twitter, Facebook o YouTube, entre otros, se abre la posibilidad de emprender una interacción entre los actores de las Administraciones públicas y los electores, algo especialmente importante para un país que, como Ecuador, ha tenido décadas basadas en liderazgos institucionales verticales, corrupción y, en general, desconfianza social. Sin embargo, estudios como el de Barredo, Arcila, Arroyave \& Silva (2015).

\footnotetext{
El proceso de adaptación e interpretación de los datos forma parte de las actividades del proyecto "Esfera pública y participación ciudadana: un abordaje de la construcción de la interacción en los principales cibermedios colombianos (2016)", financiado por el fondo de proyectos de Gran Cuantía de la Universidad del Rosario (2017 - 2020).
} 
Desde la llegada al poder del llamado gobierno de la Revolución Ciudadana, se han efectuado numerosas reformas legales para promover una mayor participación de la ciudadanía con las instituciones, una mayor integración social en la gestión simbólica y, en la medida de lo posible, una erosión de las brechas tecnológicas y culturales que se asocian a sus regiones. Desde la Constitución de 2008, hasta la Ley Orgánica de Participación Ciudadana (2010), pasando por la Ley Orgánica de Comunicación (2013) o la Ley Orgánica de Educación Superior (2010), lo cierto es que todos estos entramados normativos comprenden su materialización mediante la creación de instituciones afines a sus objetivos.

En este capítulo, abordaremos la participación política de una población estratégica para la democracia ecuatoriana: los estudiantes universitarios. Para ello, compararemos las percepciones de los estudiantes de una universidad privada y urbana, la Universidad de las Américas (UDLA), y los de una universidad pública y enclavada en el entorno rural, la Universidad Laica Eloy Alfaro de Manabí (ULEAM).

\section{Marco teórico}

\subsection{Los medios ecuatorianos. Apuntes sobre la regulación comunicacional}

Una de las mayores preocupaciones de los sucesivos gobiernos de Rafael Correa ha sido la comunicación, toda vez que autores como Checa - Godoy (2012) alertaban de la baja credibilidad social de los medios ecuatorianos, habitualmente vinculados a los intereses corporativos, más que al interés social. Por su parte, Barredo, Pérez Zúñiga, Vivas y Fernández (2015) concluyeron que un tercio de los encuestados en Quito y en Riobamba encontraban más fiables a las redes sociales, como vehículos informativos, antes que a los medios de comunicación convencionales (p. 106).

En 2013, se aprobó la Ley Orgánica de Comunicación [LOC], un instrumento legislativo que, de acuerdo a algunos autores, ha sido un eficaz instrumento para mejorar la calidad periodística $\mathrm{y}$, asimismo, favorecer una mayor democratización comunicacional

Otros autores, en cambio, opinan que la LOC ha ayudado a consolidar el monopolio estatal de los medios (Basabe-Serrano \& Martínez, 2014; Arcos, 2014, p. 16). 
Es cierto que, como se evidencia en el estudio de Checa \& Barredo (2017), entre 2008 y 2015, en términos generales se produjo un notable descenso de más de treinta puntos porcentuales en las percepciones de amenazas a la integridad física de los periodistas ecuatorianos (p. 42); pero en este mismo trabajo se muestra que, al comparar la evolución de las principales fuentes de amenaza, han disminuido las presiones relacionadas con las de los grupos económicos o los directores de los medios y, de forma bastante llamativa, han entrado en esta lista actores que, como la SUPERCOM o la CORDICOM, tienen como misión garantizar los preceptos establecidos en la LOC (p. 43). Pero los principios fundacionales, basados en esa aludida democratización comunicacional, se han enquistado en el incumplimiento de algunos supuestos estructurales, como el art. XX que establece el reparto de frecuencias

Asimismo, a menudo estas nuevas instituciones -lideradas por funcionarios designados por el propio presidente, como explica XXX-, se encargan de seguir los mandatos de la agenda gubernamental:

El estilo personalista y confrontacional del presidente Correa ha marcado la política ecuatoriana de los últimos nueve años. La llamada "Revolución Ciudadana", en efecto, tuvo el ímpetu de un líder que no acepta críticas. Sus constantes ataques a los medios de comunicación, a través de sus sabatinas y de sanciones administrativas basadas en la Ley de Comunicación, son muestra de su voluntad para suprimir la libertad de prensa y la libertad de expresión.

(Vera \& Llanos, 2016, p. 163)

Estos mismos ataques se han percibido en ámbitos importantes para la democracia contemporánea, como son las redes sociales. La publicación de tuits o memes puede traer como consecuencia el arresto del usuario (El Universo, 2011, 4 de diciembre); o bien la intervención del propio presidente de la República, solicitando la cancelación de la cuenta en Facebook del supuesto agresor (El Comercio, 2015, 26 de enero). 


\subsection{La brecha tecnológica y el estímulo de la participación política}

Alrededor del $11,5 \%$ de la población ecuatoriana de entre 15 y 49 años se identifica, según cifras oficiales, como analfabeta digital (INEC, 2017, 27 de enero). De acuerdo a este mismo informe, solo unos 4 de cada 10 hogares (el 36\% del total) tenían acceso a Internet en 2016. La cifra desciende abruptamente al discriminar a los hogares en los entornos rurales: unos ocho de cada diez, esto es, el 16,4\% carecían de acceso a Internet en 2016 (INEC, 2016, p. 7). Con respecto de los teléfonos celulares, los datos oficiales también presentan una realidad fuertemente mediatizada por la falta de recursos económicos, los problemas de infraestructura $\mathrm{y}$, en definitiva, la brecha tecnológica: a nivel nacional, en 2016 unas 4 de cada 10 personas no tenían siquiera celular, mientras que en las áreas rurales esta cifra ascendía hasta las 6 de cada 10 (el 44,5\% de las personas no disponía de este importante dispositivo de conexión), según leemos en INEC (2016, p. 23).

Pero si las dificultades de acceso a Internet tienden a identificar los rasgos estructurales de una sociedad apegada, en gran medida, a los mecanismos de interacción offline, es lógico pensar que las rutinas de participación del espacio público tienden a trasladarse en la arena digital. Así, Ayala \& Calvache (2009), al analizar las formas de integrar a la sociedad dentro de los medios de comunicación públicos, concluyeron existía una enorme indiferencia o falta de interés por colaborar activamente en las plataformas mediáticas. Ese mismo problema lo avistaron Coronel \& Mier (2011) con respecto de la participación política, un síntoma procedente quizá de las décadas de corrupción y desconfianza en las instituciones que caracterizan la historia reciente del país. Durante los años de gobierno de Rafael Correa, entre 2007 y 2016, se pusieron en marcha algunas iniciativas tendentes a profundizar el concepto de empoderamiento social. De esta forma, el Consejo Nacional Electoral de Ecuador inauguró en 2013 Voto Transparente, una plataforma web que pretendía motivar una mayor interacción entre los gobernantes y los gobernados (Barredo \& Silva, 2014). Menos de un lustro después, mientras escribimos estas líneas intentamos acceder a ese portal y nos encontramos con que está inactivo, y eso a pesar de la proximidad de 
las elecciones presidenciales de $2017^{8}$. Es decir, la autodenominada Revolución Ciudadana -que según Céspedes (2010, 30 de agosto) fue una estrategia de posicionamiento de las siglas de Rafael Correa-, tras la aprobación de la nueva Constitución de 2008, se ha encargado crear organismos que, como el Consejo de Participación Ciudadana y Control Social, se erigen como conjuntos demagógicos monumentales, más que como plataformas que instituyen la participación de forma transversal. Sobre esto último, la evidencia empírica resulta abundante. Por ejemplo, según Schneider \& Welp (2015), la descentralización promovida por la Constitución de 2008, no ha sido todavía convenientemente aplicada; de hecho, estas investigadoras aseguran que "las Administraciones Zonales de Quito no aplican ninguno de los principios básicos de la democracia representativa" (p. 29), y eso a pesar de que Quito, como capital del país, posee una de las mayores infraestructuras institucionales, al albergar al gobierno de la nación. Y que, según el art. 5 de la Ley Orgánica de Participación Ciudadana de 2010, el Estado "garantiza" el desempeño ciudadano a través de la democracia directa. Sobre el mecanismo de la silla vacía que concede vOz a la ciudadanía en los plenos consistoriales-, al estudiar su funcionamiento entre 2011 y 2013, Castro (2015) describe un uso irregular en una provincia clave como Pichincha -que alberga a la capital del país-, donde la mitad de los municipios no la implementó, y donde se observaron casos vinculados a un abuso monopólico por parte de algunos supuestos representantes. Por su parte, la manifestación de la disidencia política en Ecuador, que es un proceso fundamental dentro de la cultura democrática institucional, resulta muy compleja en un país donde Vera \& Llanos (2016) alertan de la "intransigencia" presidencial y, sobre todo, la "intimidación política" (p. 15) que ejerce el aparato gubernamental. Dicha intimidación, según estos investigadores, se ejerce desde el control político de la justicia - con el consiguiente levantamiento de causas judiciales contra los opositores-, pero también desde la comunicación, tanto a través de las redes sociales, como mediante el Enlace Ciudadano que presenta el presidente de la República.

\footnotetext{
${ }^{8}$ Nuestro último intento de acceder al portal fue en los primeros días del mes de febrero de 2017 tanto a través del icono situado en la portada de la referida institución electoral arbitral, como a través de la siguiente dirección: http://vototransparente.cne.gob.ec/
} 
Obviamente, hay que vincular la falta de profundización de la participación social ecuatoriana dentro de la cultura latinoamericana, en tanto que Schneider \& Welp (2015, p. 38), al analizar los diseños institucionales de grandes capitales como Bogotá, Caracas, Montevideo, Quito y Buenos Aires, observaron que -salvo en la capital uruguaya-, en todos esos lugares existía una regulación de la democracia participativa, pero ésta no tendía a activarse.

\section{Resultados}

\subsection{Consumo de medios digitales y convencionales}

En este caso se puede observar que el uso de los medios convencionales en términos generales, tanto en el caso de la universidad pública como en la universidad privada en la que se realizó el estudio, no superaba a la media. En este sentido, podría decirse que el bloque de los medios tradicionales (Televisión, prensa escrita, radio y revista impresa) es consultado en buena medida por los estudiantes encuestados, entre quienes destaca el abultado consumo de televisión en ambos casos (Privada: $M=2.56, D E=1.56$ ) y (Pública: $M=2.65, D E=1.59$ ), que es el mayor dentro de los medios convencionales.

Tabla 1. Consumo de medios de los estudiantes consultados en Manta (ULEAM) y Quito (UDLA)

\begin{tabular}{lllllll}
\hline & Opción & Universidad & $\begin{array}{l}\text { Porcentaje } \\
\text { Total }\end{array}$ & $\boldsymbol{F}$ & $\boldsymbol{M}$ & $\boldsymbol{D E}$ \\
& Mayoritaria & & & & & \\
\hline $\begin{array}{l}\text { Consumo } \\
\text { Televisión }\end{array}$ & Rara vez & Privada & $30.8 \%$ & 56 & 2.56 & 1.56 \\
& A menudo & Pública & $30.9 \%$ & 82 & 2.65 & 1.59 \\
\hline $\begin{array}{l}\text { Consumo } \\
\text { Prensa }\end{array}$ & Rara vez & Privada & $47.2 \%$ & 85 & $\mathbf{1 . 9 1}$ & 1.48 \\
$\begin{array}{l}\text { Escrita } \\
\text { Consumo }\end{array}$ & Siempre & Privada & $28.9 \%$ & 52 & $\mathbf{3 . 1 9}$ & 1.58 \\
$\begin{array}{l}\text { Prensa } \\
\text { Digital }\end{array}$ & Rara vez & Pública & $27.7 \%$ & 73 & $\mathbf{2 . 5 8}$ & 1.69 \\
\hline $\begin{array}{l}\text { Consumo } \\
\text { Radio }\end{array}$ & Rara vez & Privada & $45 \%$ & 81 & 1.75 & 1.48 \\
& Rara vez & Pública & $47.7 \%$ & 124 & 1.72 & 1.52 \\
\hline
\end{tabular}




\begin{tabular}{lllllll}
\hline $\begin{array}{l}\text { Consumo } \\
\text { Revista } \\
\text { Impresa }\end{array}$ & Rara vez & Privada & $38.9 \%$ & 70 & 1.30 & 1.35 \\
\hline $\begin{array}{l}\text { Consumo } \\
\text { Redes } \\
\text { sociales }\end{array}$ & $\begin{array}{l}\text { Casi } \\
\text { siempre }\end{array}$ & Pública & $45.2 \%$ & 117 & 1.54 & 1.45 \\
& $\begin{array}{l}\text { Casi } \\
\text { siempre }\end{array}$ & Pública & $61.4 \%$ & 162 & 4.11 & 1.39 \\
\hline $\begin{array}{l}\text { Consumo } \\
\text { Blogs }\end{array}$ & Rara vez & Privada & $39.9 \%$ & 71 & 1.53 & 1.49 \\
& Rara vez & Pública & $30.3 \%$ & 79 & 2.11 & 1.65 \\
\hline
\end{tabular}

Nota: $\mathrm{N}=$ (Pública=265, Privada=182). El valor mínimo es de 0, y el valor máximo es de 5 . Existen 6 valores:

Nunca (0), Rara vez (1), A menudo (2), No lo tengo claro (3), Casi siempre (4) y Siempre (5).

También resulta interesante distinguir que entre los dos públicos en los que se realizó el estudio existieron diferencias importantes en cuanto a consultar la prensa escrita. Mientras que el $47.2 \%$ de los entrevistados de la universidad pública contestaron que "rara vez" leían la prensa escrita, el 35.1\% manifestó en la universidad pública de Manta que lo hacía "muy a menudo". En general, como se mencionó con anterioridad, tanto en la UDLA $(M=1.91, D E=1.48)$, como en la ULEAM $(M=2.26, D E=1.50)$, se registraron unos consumos por debajo de la media, aun cuando se observó una mayor tendencia a leer la prensa escrita en el caso de los estudiantes de Manabí.

En el caso de los medios digitales, se obtuvo una respuesta ligeramente por encima de la media en el caso de la universidad privada $(M=3.19, D E=1.58)$ y una respuesta cercana a la tercera parte en cuanto a que "siempre" consultaban estos medios (28.9\%), mientras que en el caso de la universidad pública la tendencia fue a estar por debajo de la media $(M=2.58, D E=1.69)$ con el $27.7 \%$ de estudiantes que afirmaron que rara vez consultaban la prensa digital. Y ello a pesar de que, por ejemplo, un 79,5\% de los jóvenes ecuatorianos de entre 25 y 34 años tenía un 2016 un celular en activo (INEC, 2017, 27 de enero). 
El dato más relevante de este segmento es que el medio que fue más consultado por parte de los estudiantes fueron los medios sociales. No obstante lo anterior, en este caso las diferencias fueron notables. Mientras que en la universidad privada $(M=3.35, D E=1.47)$ el $36.5 \%$ de los estudiantes declararon que "casi siempre" consultaban las redes sociales, una clara mayoría en el caso de la universidad pública $(M=4.11, D E=1.39)$ manifestaron lo mismo en un $61.4 \%$.

\subsection{Participación fuera de línea}

Otra de las dimensiones que se tomó en cuenta para el presente artículo es el de la participación política fuera de línea. Para ello se enlistaron nueve diferentes opciones de participación política que son las siguientes: Votar, asistir a mítines electorales, apoyar una campaña política, firmar en una consulta pública, participar en organizaciones estudiantiles, asistir a una conferencia, contactar a un político, buscar contribuir a influir en políticas públicas y participar en organizaciones no gubernamentales.

En ambos grupos, no se observó que existiese una gran participación política por parte de los jóvenes encuestados, salvo en un par de casos que se señalará de manera posterior. Existieron diferencias relevantes en ambos grupos en el caso de 4 de las 9 diferentes alternativas de respuesta que se dieron en el sondeo. En primer lugar, cuando se preguntaba a los estudiantes qué frecuencia habían ejercido su derecho al voto, en el caso de la universidad privada en Quito, Ecuador $(M=.99, D E=1.48)$, el $55.8 \%$ manifestó que "nunca" lo había hecho, mientras que en el caso de la universidad pública en Manta de la provincia de Manabí $(M=3.57, D E=1.86)$, el $53.7 \%$ manifestó que lo había hecho. Esto podría estar relacionado con el hecho de que los jóvenes encuestados en el caso de la universidad privada aún no hubieran tenido la edad legal para sufragar en las elecciones presidenciales del 2013. Sin embargo, también es importante tomar en cuenta que en Quito y en Manabí se celebraron elecciones locales en el 2014. También es conveniente recordar que el voto en la República del Ecuador tiene un carácter obligatorio para las personas mayores de 18 años, de acuerdo al artículo 6.1 de la Constitución de 2008. 
Apoyar una campaña política también fue una de las opciones más rechazadas en ambos grupos, sólo que la intensidad fue distinta. En el caso de la UDLA $(M=1.80, D E=1.79)$, un $29.3 \%$ de los encuestados afirmaron que "nunca" habían apoyado una campaña, mientras que en la ULEAM $(M=.92, D E=1.40)$ el $54.6 \%$ de los alumnos manifestaron la misma respuesta.

Tabla 2. Participación fuera de línea de los estudiantes consultados en Manta (ULEAM) y Quito (UDLA)

\begin{tabular}{|c|c|c|c|c|c|c|}
\hline & $\begin{array}{l}\text { Respuesta } \\
\text { mayoritaria }\end{array}$ & Universidad & $\begin{array}{l}\text { Porcentaje } \\
\text { Total }\end{array}$ & $F$ & $M$ & $D E$ \\
\hline \multirow[t]{2}{*}{ Votar } & Nunca & Privada & $55.8 \%$ & 101 & .99 & 1.48 \\
\hline & Siempre & Pública & $53.7 \%$ & 139 & 3.57 & 1.86 \\
\hline \multirow{2}{*}{$\begin{array}{l}\text { Mítines } \\
\text { electorales }\end{array}$} & Nunca & Privada & $59.7 \%$ & 108 & .81 & 1.33 \\
\hline & Nunca & Pública & $50.2 \%$ & 131 & 1.05 & 1.45 \\
\hline \multirow{2}{*}{$\begin{array}{l}\text { Apoyar una } \\
\text { campaña }\end{array}$} & Nunca & Privada & $29.3 \%$ & 53 & 1.80 & 1.79 \\
\hline & Nunca & Pública & $54.6 \%$ & 143 & .92 & 1.40 \\
\hline \multirow{2}{*}{$\begin{array}{l}\text { Firmar en una } \\
\text { consulta } \\
\text { pública }\end{array}$} & Nunca & Privada & $43.1 \%$ & 78 & 1.14 & 1.43 \\
\hline & Nunca & Pública & $45.2 \%$ & 119 & 1.14 & 1.55 \\
\hline \multirow{2}{*}{$\begin{array}{l}\text { Participar en } \\
\text { organizaciones } \\
\text { estudiantiles }\end{array}$} & Nunca & Privada & $40.3 \%$ & 73 & 1.34 & 1.57 \\
\hline & Rara vez & Pública & $41.3 \%$ & 109 & 1.26 & 1.41 \\
\hline \multirow{2}{*}{$\begin{array}{l}\text { Asistir a una } \\
\text { conferencia }\end{array}$} & Nunca & Privada & $71.3 \%$ & 129 & .59 & 1.19 \\
\hline & Rara vez & Pública & $43.4 \%$ & 115 & 1.13 & 1.33 \\
\hline \multirow{2}{*}{$\begin{array}{l}\text { Contactar a un } \\
\text { político }\end{array}$} & Nunca & Privada & $62.4 \%$ & 113 & .75 & 1.29 \\
\hline & Nunca & Pública & $63.5 \%$ & 167 & .67 & 1.20 \\
\hline \multirow{2}{*}{$\begin{array}{l}\text { Contribuir en } \\
\text { influir en } \\
\text { políticas } \\
\text { públicas }\end{array}$} & Nunca & Privada & $57.5 \%$ & 104 & 1.05 & 1.60 \\
\hline & Nunca & Pública & $67 \%$ & 179 & .62 & 1.18 \\
\hline ONG & No lo tengo & Privada & $33 \%$ & 60 & 3.59 & 1.20 \\
\hline
\end{tabular}




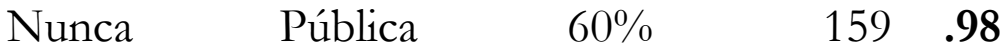

Nota: $\mathrm{N}=$ (Pública=265, Privada=182). El valor mínimo es de 0, y el valor máximo es de 5 . Existen 6 valores:

Nunca (0), Rara vez (1), A menudo (2), No lo tengo claro (3), Casi siempre (4) y Siempre (5).

Otra pregunta en la que se vislumbró una diferencia entre ambos grupos, fue cuando se les cuestionó si habían asistido a una conferencia de contenido político. En el caso de la universidad privada $(\mathrm{M}=.59, \mathrm{DE}=1.19)$, el $71.3 \%$ manifestó nunca haberlo hecho, mientras que en el otro grupo $(\mathrm{M}=1.13, \mathrm{DE}=1.33)$, el $43.1 \%$ declaró que "rara vez" había asistido a un evento como este.

Por último, otro de los elementos en los que existió una gran distancia entre los sujetos de investigación de ambos centros fue en el caso de participar en una ONG. Mientras que en el caso de la UDLA $(M=3.59, D E=1.20)$, el $33 \%$ se encontraba ambivalente con un "no lo tengo claro", en la ULEAM $(M=.98, D E=1.60)$, una mayoría de 60\% manifestó que nunca había formado parte de una organización no gubernamental.

\subsection{Participación política en redes sociales}

En este caso, es importante destacar que tanto en las universidades públicas como en las privadas se observó, en general, poca participación política en los medios sociales. Sin embargo, como en el apartado anterior sobre la participación política fuera de línea, en este caso también se identificaron diferentes sustantivas entre ambos grupos.

En cuanto a la búsqueda de información sobre política, en el caso de la UDLA $(M=2.28, D E=1.59)$ la respuesta mayoritaria fue que "rara vez" los estudiantes buscaban información sobre política en redes, mientras que en el caso de la ULEAM $(M=1.52$, $D E=1.49)$, el $45 \%$ de los estudiantes consultados declararon que se informaban a través de estos medios. 
Otra diferencia importante se encontró en la pregunta que cuestionaba si los jóvenes compartían contenido humorístico de contenido político en redes (Memes). Mientras que en el caso de la UDLA $(M=2.43, D E=1.55)$ el $34.6 \%$ declaró que lo hacía "muy a menudo", en la ULEAM $(M=1.40, D E=1.46)$ el $32.5 \%$ manifestó no acostumbrar a hacerlo en ningún caso.

Participar en discusiones sobre política en este medio virtual también representó una diferencia notable en estos dos grupos. Mientras que el $30.9 \% \quad(M=2.15, \quad D E=1.61)$ en la UDLA "a menudo" acostumbraba hacerlo, el $42.9 \%(M=2.65, D E=1.59)$ en la ULEAM no lo hacía "nunca".

Tabla 3. Participación política en redes sociales de los estudiantes consultados en Manta (ULEAM) y Quito (UDLA)

\begin{tabular}{|c|c|c|c|c|c|c|}
\hline & $\begin{array}{l}\text { Respuesta } \\
\text { mayoritaria }\end{array}$ & Universidad & $\begin{array}{l}\text { Porcentaje } \\
\text { Total }\end{array}$ & $F$ & $M$ & $D E$ \\
\hline \multirow{2}{*}{$\begin{array}{l}\text { Busco } \\
\text { información } \\
\text { sobre } \\
\text { política }\end{array}$} & Rara vez & Privada & $33 \%$ & 60 & 2.28 & 1.59 \\
\hline & Rara vez & Pública & $45 \%$ & 123 & 1.52 & 1.49 \\
\hline \multirow{2}{*}{$\begin{array}{l}\text { Leo } \\
\text { contenido } \\
\text { humorístico }\end{array}$} & Rara vez & Privada & $35.7 \%$ & 65 & 1.73 & 1.66 \\
\hline & Rara vez & Pública & $33.3 \%$ & 88 & 1.78 & 1.52 \\
\hline \multirow{2}{*}{$\begin{array}{l}\text { Comparto } \\
\text { contenido } \\
\text { humorístico }\end{array}$} & A menudo & Privada & $34.6 \%$ & 63 & 2.43 & 1.55 \\
\hline & Nunca & Pública & $32.5 \%$ & 86 & 1.40 & 1.46 \\
\hline \multirow{2}{*}{$\begin{array}{l}\text { Leo } \\
\text { discusiones }\end{array}$} & Nunca & Privada & $34.1 \%$ & 62 & 1.55 & 1.67 \\
\hline & Rara vez & Pública & $32.8 \%$ & 87 & 1.57 & 1.57 \\
\hline \multirow{2}{*}{$\begin{array}{l}\text { Participo en } \\
\text { discusiones }\end{array}$} & A menudo & Privada & $30.9 \%$ & 56 & 2.15 & 1.61 \\
\hline & Nunca & Pública & $42.9 \%$ & 114 & 1.07 & 1.37 \\
\hline \multirow{2}{*}{$\begin{array}{l}\text { Veo un } \\
\text { video de } \\
\text { contenido } \\
\text { político }\end{array}$} & Nunca & Privada & $41.4 \%$ & 75 & 1.36 & 1.61 \\
\hline & Rara vez & Pública & $43.2 \%$ & 114 & 1.47 & 1.43 \\
\hline
\end{tabular}




\begin{tabular}{lllllll}
\hline $\begin{array}{l}\text { Comparto } \\
\text { un video de } \\
\text { contenido } \\
\text { político }\end{array}$ & Nunca & Privada & $38.7 \%$ & 70 & 1.33 & 1.57 \\
\hline $\begin{array}{l}\text { Publico } \\
\text { opiniones }\end{array}$ & Nunca & Priblica & $49.2 \%$ & 131 & .94 & 1.37 \\
$\begin{array}{l}\text { personales } \\
\text { sobre } \\
\text { política }\end{array}$ & Nunca & Pública & $46.0 \%$ & 121 & $\mathbf{1 . 0 0}$ & 1.37 \\
\hline
\end{tabular}

\begin{tabular}{|c|c|c|c|c|c|c|}
\hline \multirow{2}{*}{$\begin{array}{l}\text { Doy un like } \\
\text { a un } \\
\text { comentario }\end{array}$} & Nunca & Privada & $37.9 \%$ & 69 & 1.34 & 1.55 \\
\hline & Rara vez & Pública & $27.6 \%$ & 74 & 1.96 & 1.81 \\
\hline \multirow{2}{*}{$\begin{array}{l}\text { Posteo } \\
\text { información } \\
\text { sobre } \\
\text { política }\end{array}$} & Nunca & Privada & $33 \%$ & 60 & 1.82 & 1.84 \\
\hline & Nunca & Pública & $51.5 \%$ & 137 & .84 & 1.25 \\
\hline
\end{tabular}

\begin{tabular}{lllllll}
\hline $\begin{array}{l}\text { Sigo cuentas } \\
\text { de políticos }\end{array}$ & Nunca & Privada & $27.5 \%$ & 50 & 1.91 & 1.79 \\
& Nunca & Pública & $38.6 \%$ & 102 & 1.33 & 1.58 \\
\hline $\begin{array}{l}\text { Sigo cuentas } \\
\text { de }\end{array}$ & Nunca & Privada & $59.7 \%$ & 108 & $\mathbf{. 7 6}$ & 1.24 \\
$\begin{array}{l}\text { periodistas, } \\
\text { líderes de } \\
\text { opinión }\end{array}$ & Rara vez & Pública & $35.0 \%$ & 93 & $\mathbf{1 . 4 0}$ & 1.54 \\
\hline
\end{tabular}

\begin{tabular}{lllllll}
\hline $\begin{array}{l}\text { Contesto } \\
\text { comentarios } \\
\text { de políticos }\end{array}$ & Nunca & Privada & $35.2 \%$ & 64 & $\mathbf{1 . 6 8}$ & 1.80 \\
\hline $\begin{array}{l}\text { Firmo } \\
\text { peticiones }\end{array}$ & Siempre & Pública & $66.3 \%$ & 175 & $\mathbf{. 6 1}$ & 1.12 \\
$\begin{array}{l}\text { sobre } \\
\begin{array}{l}\text { asuntos } \\
\text { colectivos }\end{array}\end{array}$ & Nunca & Pública & $41.8 \%$ & 130 & 4.07 & 1.62 \\
& & & & 130 & $\mathbf{1 . 2 0}$ & 1.65 \\
\hline
\end{tabular}

Nota: $\mathrm{N}=$ (Pública=265, Privada=182). El valor mínimo es de 0, y el valor máximo es de 5 . Existen 6 valores:

Nunca (0), Rara vez (1), A menudo (2), No lo tengo claro (3), Casi siempre (4) y Siempre (5). 
Publicar opiniones personales sobre política en redes sociales como Facebook y Twitter es una acción que en promedio los estudiantes de la universidad privada $(M=2.65, D E=1.59)$ están más dispuestos a realizar que aquellos que atienden a la universidad pública (Pública: $M=1.00, D E=1.37)$. En este sentido, casi la mitad de los encuestados de la ULEAM (46\%) contestaron que "nunca" publicaban opiniones propias en estos medios.

En el caso de postear información sobre política en el espacio virtual personal de cada usuario, la diferencia también es notable. En el caso de la UDLA $(M=1.82, D E=1.84)$, el 33\% manifestó que "nunca lo hace", mientras que en el caso de la ULEAM $(M=.84, D E=1.25)$ esta cifra incrementa a una mayoría del 51.2\%.

Seguir cuentas de políticos y líderes de opinión resulta más probable en el caso de los jóvenes de la universidad pública $(M=1.40$, $D E=1.54)$ que en el caso de la universidad privada $(M=.76$, $D E=1.24$ ), con un $35 \%$ que rara vez lo hace en el primer caso, frente a un $59.7 \%$ en el segundo. En cuanto a replicar comentarios que se hacen a los políticos, el $66.3 \%$ de la ULEAM $(M=.61, D E=1.12)$ manifestó nunca hacerlo, frente al $35.2 \%$ de la privada $(M=1.68$, $D E=1.80)$.

Por último, en esta categoría, en donde existió la mayor divergencia fue en la pregunta en torno a si acostumbraban firmar peticiones sobre asuntos colectivos, en donde una mayoría de $71.8 \%$ de los alumnos de la UDLA $(M=4.07, D E=1.62)$ manifestó lo acostumbraba hacer "siempre", mientras que en el extremo opuesto, un $48.9 \%$ de los alumnos de la ULEAM $(M=1.20, D E=1.65)$ contestaron que "nunca" habían realizado tal acción.

\subsection{Relaciones entre variables}

Conviene aclarar en este punto que el análisis factorial que se realizó para el presente instrumento en un estudio previo, contribuyó a que el mismo pudiese dividirse en tres factores diferentes de distintas modalidades de participación política a través de las redes sociales. En primer lugar, se tiene el comportamiento que denominamos como "usuario pasivo". Las acciones que tienden a definir a este usuario es el consumo de información sobre política en los medios sociales. En 
otras palabras, se limita a obtener noticias, leer opiniones o comunicados.

Tabla 4. Relación entre participación política online y participación política fuera de línea de los estudiantes consultados en Manta (ULEAM) y Quito (UDLA)

\begin{tabular}{llll}
\hline & $\begin{array}{l}\text { Usuario } \\
\text { pasivo }\end{array}$ & $\begin{array}{l}\text { Replica a } \\
\text { otros }\end{array}$ & $\begin{array}{l}\text { Comparte } \\
\text { contenidos }\end{array}$ \\
\hline Votar & -.004 & -.048 & -.033 \\
Mítines electorales & -.052 & -.052 & -.033 \\
Apoyar una campaña & .018 & .062 & .040 \\
$\begin{array}{l}\text { Firmar en una consulta } \\
\text { publica }\end{array}$ & .001 & -.054 & -.006 \\
$\begin{array}{l}\text { Participar en } \\
\text { organizaciones }\end{array}$ & .015 & $.114^{*}$ & -.004 \\
estudiantiles & & & \\
$\begin{array}{l}\text { Asistir a una } \\
\text { conferencia }\end{array}$ & -.046 & -.030 & -.014 \\
Contactar a un político & -.035 & .041 & .040 \\
$\begin{array}{l}\text { Influir en políticas } \\
\text { públicas }\end{array}$ & .000 & $.448^{* *}$ & .024 \\
Colaborar en una ONG & -.038 & $.444^{* *}$ & $.376^{* *}$ \\
\hline
\end{tabular}

Nota: ${ }^{*} p<.05,{ }^{*} p<.01,{ }^{* * *} p<.001$. Los coeficientes de Pearson en negritas indican las asociaciones más estrechas.

En cuanto al segundo caso, que es la categoría de "replica a otros", el usuario deja de ser pasivo y busca información de manera más decidida sobre aquellos medios o personalidad que le sean afín. Es posible que también en este caso pueda pronunciarse sobre un asunto en particular. $\mathrm{Y}$ en cuanto al tercer caso, el usuario que "comparte contenido" es aquel que comparte información periodística o audiovisual que considere merezca ser expuesta entre sus contactos. 
En este caso se buscó determinar si estos patrones de participación política en redes sociales se relacionaban con las diferentes formas de participación política en el mundo real. En términos generales, no se encontraron muchas correlaciones positivas, salvo en casos específicos que conviene señalar.

Por ejemplo, participar en asociaciones estudiantiles se relacionaba de forma positiva con ser un usuario que replica a otros, la segunda modalidad que implica que el usuario busca información política sobre asuntos y personajes con los que simpatiza $(\mathrm{r}=.114 \mathrm{p}<.05)$. Otra de las relaciones positivas que se encontraron con esta modalidad de participación política en redes sociales fue la acción de influir en políticas públicas $(\mathrm{r}=.45 \mathrm{p}<.01)$ y colaborar en una organización no gubernamental $(\mathrm{r}=.44 \mathrm{p}<.01)$.

En el caso de la modalidad de quienes compartían contenidos en redes sociales, también se encontraba relacionada con haber participado en una ONG $(r=.38 \mathrm{p}<.01)$. En este sentido, se puede argüir que existe poca relación entre aquellos usuarios que participan activamente en redes sociales y su participación fuera. Es posible que en este resultado, influyera el que la participación en redes sociales que se observó en los jóvenes universitarios ecuatorianos fuera en realidad muy escasa.

\section{Conclusiones}

A pesar del innegable interés gubernamental por establecer un nuevo marco legislativo comunicacional en el país con un enfoque participativo e integrador, según hemos podido observar, no se ha producido un gran estímulo de la participación en las plataformas digitales en unos usuarios referenciales como son los estudiantes universitarios. Más bien, nuestros resultados coinciden con los aportados por otros estudios, en los que se ha visibilizado que la participación de los jóvenes se da todavía sobre todo asociada a los escenarios convencionales (Milosevic \& Zezelj, 2017). Y ello a pesar del desarrollo de instrumentos como la Ley Orgánica de Participación Ciudadana, con sus consiguientes instituciones que, como el Consejo de Participación Ciudadana y Control Social, tendrían que haber estimulado una mayor profundización en el concepto de democracia participativa, es decir, en el involucramiento de la ciudadanía en los 
asuntos públicos a nivel local, regional y nacional. Pero de acuerdo a la evidencia aportada en las páginas anteriores, de igual modo que otros asuntos importantes de la agenda gubernamental que, como el cambio de la matriz productiva -que para Vera \& Llanos (2016) no solo se ha incumplido, sino que aspectos como la falta de pagos a las empresas y las "altas cargas impositivas" (p. 152) han perjudicado gravemente a las industrias y comercios del país-, parece que la participación de los jóvenes se ha quedado en normativas confusas y abstractas, sin fomentar un cambio en las rutinas pasivas asumidas históricamente por la ciudadanía ecuatoriana.

En nuestro análisis, además, hemos observado diferencias notables que delimitan la existencia de dos grupos claramente identificados por factores como la brecha tecnológica, la desigualdad en el reparto y acceso a los recursos, y la brecha, en definitiva, entre lo urbano y lo rural. Sorprende esta conclusión, sobre todo si tenemos en cuenta que la Ley Orgánica de Educación Superior, de 2010, en conjunto con procesos como el de acreditación y aseguramiento de la calidad, intenta estandarizar el sistema de educación superior ecuatoriano, algo que nuevamente vemos que no se ha cumplido. Desde ese punto de vista, encajamos aspectos como las rutinas de acceso a la información, en que los estudiantes de la universidad privada están mediatizados por lo digital, mientras que los de la pública todavía se orientan referencialmente a través de los medios convencionales, como la prensa escrita.

A diferencia de otros estudios, en este caso no se encontró una relación entre la mayoría de los elementos de la participación política tradicional con la participación política en línea. En este caso, esto podría deberse a que, en términos generales, la participación política en redes resulta bastante escasa en el Ecuador, aun considerando que una enorme mayoría de los encuestados declararon que utilizaban las redes sociales por encima de cualquier otro medio disponible. Lo anterior se encuentra en concordancia con la tendencia de la juventud en otros países de América Latina a informarse a través de los medios digitales, sin que esto signifique que se identifique un patrón importante en el caso de la ciberpolítica. Existe también un notable desgaste en la utilización de los medios convencionales, que es una tendencia que también puede observarse en otros contextos. 


\section{Referencias}

Arcos, C. (2014). "El fusilamiento mediático: nuevas armas en el ejercicio del poder en Ecuador". En: Cuvi, J. (Ed.). La restauración conservadora del correísmo <pp. 13 - 17>. Quito, Ecuador: Montecristi Vive.

Ayala, A. \& Calvache, M. B. (2009). Percepción sobre los medios públicos en Ecuador. Quito, Ecuador: CIESPAL.

Barredo Ibáñez, D. \& Silva, R. (2014). Interacción institucional, participación democrática y transparencia. Chasqui, Revista Latinoamericana de Comunicación, 126, 4 - 13.

Barredo Ibáñez, D.; Arcila, C.; Arroyave, J. \& Silva, R. (2015).

Influence of Social Networks in the Decision to Vote: An Exploratory Survey on the Ecuadorian Electorate. International Journal of E-Politics, 6(4), 15-34.

Barredo Ibáñez, D., Pérez Zúñiga, J. M., Vivas, R., \& Fernández, M. (2015). "El periodismo ecuatoriano en entredicho. Descenso de credibilidad y nuevas perspectivas comunicacionales". En Barredo, D., Oller, M. y Hernández, S. (Eds.). La Comunicación y el Periodismo de Ecuador frente a los desafíos contemporáneos <pp. 107 126>. La Laguna: Sociedad Latina de Comunicación Social. Basabe-Serrano, S. \& Martínez, J. (2014). Ecuador: cada vez menos democracia, cada vez más autoritarismo... con elecciones. Revista de Ciencia Política, 34(1), 145-170, 2014.

Castro, J. L. (2015). La silla vacía y el dilema de la participación ciudadana en el Ecuador. Ius Humani, 4, 299-330.

Céspedes, H. Y. (2010, 30 de agosto). El Estratega que hizo a Rafael

Correa Presidente. Consultado el 11/02/2017 de: http://www.lajornadanet.com/diario/opinion/2010/agosto/30 $-2 . \mathrm{html}$

Checa, F. \& Barredo Ibáñez, D. (2017). Medios públicos y libertad de expresión en la percepción de los periodistas: un estudio comparativo (2008-2015). Revista Latinoamericana de Ciencias de la Comunicación, 13(24), 36-47.

Checa - Godoy, Antonio (2012). La Banca y la propiedad de los medios: el caso de Ecuador. Revista Latina de Comunicación Social, $67,125-147$.

Coronel, G. \& Mier, A. (2011). Impacto del Twitter en Ecuador, caso 30S. Consultado el 11/02/2017 de: 
http://www.iiis.org/CDs2011/CD2011CSC/CISCI_2011/Pap ersPdf/CA806GT.pdf

El Comercio (2015, 26 de enero). Crudo Ecuador recibe amenazas y

Ministro del Interior presenta denuncia. Retrieved from:

http://www.elcomercio.com/actualidad/

crudo-ecuador-amenazas-twitter-joseserrano.html

El Universo (2011, 4 de diciembre). Leyes no se refieren a delitos que se cometan en redes sociales. Retrieved from:

http://www.eluniverso.com/2011/12/04/1/1355/leyes-

refieren-delitos-cometan-redes-sociales.html

INEC (2016). Tecnologías de la Información y Comunicaciones (TIC'S) 2016. Consultado el 11/02/2017 de:

http://www.ecuadorencifras.gob.ec/documentos/webinec/Estadisticas_Sociales/TIC/2016/170125.Presentacion_Ti cs_2016.pdf

INEC (2017, 27 de enero). El analfabetismo digital en Ecuador se reduce en 10 puntos desde el 2012. Consultado el 11/02/2017 de: http://www.ecuadorencifras.gob.ec/el-analfabetismodigital-en-ecuador-se-reduce-en-10-puntos-desde-el-2012/

Milosevic, J. S. \& Zezelj, I. L. (2017). Civic activism online: Making young people dormant or more active in real life? Computers in Human Behavior, 70, 113 - 118.

Schneider, C. \& Welp, Y. (2015). Diseños Institucionales y (des) equilibrios de poder: las instituciones de participación ciudadana en disputa. Revista mexicana de ciencias políticas y sociales, 60(224), 15-43.

Vera, S. \& Llanos, S. (2016). Ecuador: La democracia después de nueve años de la" Revolución Ciudadana" de Rafael Correa. Revista de ciencia politica, 36(1), 145-175. 


\title{
Enunciação e visibilidade de vítimas nas redes sociais: formas de aparição do rosto ${ }^{9}$
}

\author{
Angie Biondi. Universidade Tuiuti do Paraná (Brasil). \\ angiebiondina@gmail.com
}

\section{Introduçâo}

R ELATOS diários de doenças, autorretratos (selfies) em acidentes, Lviolências sofridas e agravos de toda sorte têm se proliferado nas redes sociais. O sujeito comum parece ter encontrado, nas redes sociais, um espaço propício para declarar a verdade de suas dores bem como para agregar, em torno de si, um conjunto de seguidores e fazer de sua luta, muitas vezes, uma causa legítima a se engajar, aderir, compartilhar, enfim, se solidarizar de algum modo. Nas circunstâncias em que o sofrimento é o mote principal da exposição, os sujeitos partilham do mesmo espaço de visibilidade, e também de construção de narrativas sobre a própria vida, onde a voz principal é a da vítima, pois é ela quem encarna a legítima instância moral e política de suas dores e dos modos como desafia a morte.

Temos observado que uma profusão de causas individuais tem comparecido nas redes sociais como Facebook, Instagram, blogs e fotologs que, não raro, são multiplicadas pelos meios de comunicação tradicionais. São causas que se declaram legítimas e justificáveis em

\footnotetext{
${ }^{9}$ Este texto é resultado parcial de realização da pesquisa "Solidariedade em redes: visibilidade e experiência de vítimas na cultura contemporânea", com recursos do $\mathrm{CNPq}$ /Brasil, e desenvolvido em parceria com a Profa. Dra. Ângela Salgueiro Marques (UFMG).
} 
tempos de uma precária e insuficiente participação do Estado e que se orientam à ação direta aos sofredores. São os próprios sofredores que articulam criativamente seus relatos a fim de convocar formas de adesão a suas histórias e causas que passam por variados campos de afinidade, interações afetivas, bem como um chamado à responsabilidade ética.

Para isso tem sido comum particularizar os sofrimentos, lhes atribuir um rosto e uma consistência individual concretizada com a produção destes relatos de si (Butler, 2015), embasando, na própria experiência de vida, a dor que lhe consome cotidianamente. As vítimas ainda não estão mortas, mas suas narrativas flertam com a morte, ao mesmo tempo desafiando-a e atraindo-a para si, através da descrição minuciosa de doenças, sofrimentos infindáveis, lágrimas e desespero.

A forma de enunciação do sofrimento e a configuração de diferentes lugares narrativos de vítimas nos interessam sob duas dimensões específicas: a primeira, refere-se ao gesto de relatar a si mesmo (Butler, 2015; Rago, 2013), à produção de testemunhos fundamentados em um valor de verdade do sujeito que sofre e enuncia sua própria experiência da dor manejando uma dimensão subjetiva da vítima sob um revestimento afetivo que, muitas vezes, é apropriado por estratégias de um capitalismo flexível que tem investido em engajamentos e interações moduladas em rede. Sob esse aspecto, exploramos o modo como oferecer um relato de si mesmo não se confunde com narrar fatos somente, mas implica um ato expor o logos (pano de fundo racional e valorativo) que sustenta um modo de vida, além de um retorno a si mesmo depois de ter sido interpelado pelo outro.

A segunda dimensão associa-se à atribuição de um rosto ao sofrimento e ao clamor das vítimas. Aqui recuperamos a noção de "rosto" tal como discutida por Lévinas (1999; 2011) e Butler (2011; 2015), de modo a salientar a dimensão ética presente na vocalização do sofrimento e da precariedade do outro e de seu corpo.

\section{Rosto e vidas precárias}

Em junho de 2014, a campanha Amigos do Pedrinho, criada nas redes sociais pela mãe, Aline Bagarão, no dia 16 de maio, divulgou 
que uma arrecadação em dinheiro, em pouco mais de um mês, já tinha atingido o valor de $\mathrm{R} \$ 964$ mil. Ainda era preciso chegar ao montante de $\mathrm{R} \$ 2$ milhões para realizar, nos Estados Unidos, o transplante de intestino que salvaria a vida do garoto, que nasceu com uma síndrome rara no órgão.

A página criada para a campanha, até então, já contava com 124 mil compartilhamentos. Além disso, celebridades e famosos se engajaram e também replicaram e curtiram a página. A iniciativa da mãe de Pedrinho prosseguiu e ganhou mais adeptos ao longo do ano. Outras ações foram promovidas a fim de arrecadar o montante necessário para o transplante do garoto. Rifas, bazar, material promocional foram comercializados, foi publicado um livro intitulado "Biografia em branco do Pedrinho" e um site "Amigos do Pedrinho", para auxiliar na divulgação da campanha e fornecer informações dos dados bancários para doações. Sua página no Facebook, "Ajude o Pedrinho a continuar sorrindo", que antes funcionava como um diário exclusivo do dia-a-dia do Pedrinho, ganhou uma proporção maior com a divulgação de outros casos de crianças com síndromes e doenças raras que precisam de tratamento e cirurgias especiais. Em 16 de dezembro de 2014, o perfil "Ajude o Pedrinho a continuar sorrindo" se aliou a outras páginas semelhantes e formaram a comunidade Clique da Esperança.

Além do Pedrinho, Davi Miguel, Ana Júlia, Sofia, Yasmim, Nicolly, Flávia, Nicolas e outras tantas crianças se juntam, todos os dias, à comunidade, com suas páginas do Facebook e, em geral, através dos seus pais, divulgam suas síndromes raras, sua rotina de tratamento doloroso, mas também de esperança e luta. É comum encontrar nas páginas diárias os detalhes dos sintomas, o uso de novas medicações, o dia de exames, as recaídas e também os momentos de superação, as brincadeiras, os presentes, cartinhas e mensagens de amigos, parentes e desconhecidos que chegam, solidários, aos seus leitos.

Na história de vida do Pedrinho, em 13 de novembro de 2014, ele chegou a Miami e, a partir daí seus relatos foram intensificados no intuito de prestar explicações sobre cada momento do tratamento pré-operatório do garoto. A resposta dos seguidores é imediata. A cada registro ou pequena descrição do seu dia, milhares de curtidas e compartilhamentos são realizados. 
"Nosso príncipe", "nosso guerreiro", "nosso menino", como frequentemente se refere a mãe do garoto, invoca a união e solidariedade dos seguidores - a esta altura, já participantes, inscritos na história - junto às descrições acompanhadas com fotos e vídeos do tratamento e do transcorrer do dia. Suas mensagens são deixadas como demonstrações de uma manutenção deste espírito coletivo; "nosso" - é um indicador linguístico de pertencimento comum e, através dele, Aline, muitas vezes, assume o lugar de fala do próprio Pedrinho. É comum despedir-se "com fé", "paz no coração", beijinhos do Pedrinho", "obrigada, Pedrinho". Não raro, a mãe alterna os papeis e, ao mesmo tempo em que assume a identidade da narradora e companheira fiel, também descreve sensações e desejos como se fosse o próprio garoto em votos de agradecimento e união.

A condição de Pedrinho é precária, uma vez que sua vida está sempre, de alguma forma, nas mãos do outro. De acordo com Butler (2015), “a vida precária é a condição de estar sob uma condição politicamente induzida, na qual certas populações sofrem com redes sociais e econômicas de apoio deficientes e ficam expostas de forma diferenciada às violações, à violência e à morte" (p.46). Interessante notar que, para essa autora, a relação entre precariedade e infância é relacionada por meio da criação de solidariedade. É exatamente porque um ser vivo pode morrer que é necessário cuidar dele para que possa viver. Apenas nas condições nas quais a perda tem importância o valor da vida aparece efetivamente (p.32).

Os relatos sobre a condição precária de Pedrinho acima mencionados oscilam entre a prática do registro que solicita a convocação do outro para ver e compartilhar a dor que se vive, mas também sublinham a reivindicação moral colocada pela partilha do sofrimento de quem interpela e pede ajuda ao outro: “não me deixe morrer!". Rosto é o nome que Lévinas (1999; 2011) atribui ao fato de que estamos vulneráveis aos atos dos outros e não podemos evitar sua abordagem, seja ela violenta ou acolhedora. Assim, o rosto não se encontra diante de nós, mas cima de nós: é o outro que me pede para que não o deixe morrer só, que não me torne cúmplice de sua morte. Essa forma de interpelação nos remete à noção de rosto;

(...) aquele rosto olhando em direção a mim, em sua expressão - em sua mortalidade - convoca-me, demanda-me, ordena-me: como se a 
morte invisível enfrentada pelo rosto do outro... fosse um 'problema meu'. Como se, desconhecido pelo outro que já, na nudez de seu rosto, ele afeta, ele 'me reportasse' antes mesmo de confrontar-se comigo, antes de se tornar a morte que me encara, a mim mesmo, face a face. A morte do outro homem coloca-me sob pressão, chamame à responsabilidade, como se eu, pela minha possível indiferença, tornasse-me cúmplice daquela morte, invisível ao outro que é exposto a ela; como se mesmo antes de ser condenado, tivesse que responder pela morte do outro, e não deixá-lo só em sua solidão mórbida (Lévinas, 1999, pp.24-25).

Lévinas (2011) propõe que o rosto se manifesta no face-a-face entre os homens, e no gesto de acolhimento daquele que me antecede, do absolutamente outro e sobre quem também tenho responsabilidade.

Os rastros que configuram o rosto envolvem, portanto, uma alteridade que nos remete à responsabilidade ética que se eleva contra as anulações individuais decorrentes das homogeneizações, das maquinações e das máquinas. Esse rosto, irredutível a uma composição biológica e fenotípica se defende das empresas, das técnicas e das instituições. A movimentação filosófica levinasiana libera da mesmidade a alteridade concretizada no rosto revelado pela imagem e, por consequência, amplia o entendimento do Outro que me antecede e que também está no para-além dos limites impostos pela imagem, pela reprodutibilidade técnica que a prolifera e por sua contínua acessibilidade fomentada pelos sujeitos e instituições.

Ainda sobre a questão da responsabilidade, Judith Butler afirma que "aquilo que nos vincula moralmente tem a ver com como o discurso do Outro se dirige a nós de maneira que não podemos evitá-lo ou mesmo dele desviar" (Butler, 2011, p.15). O que é moralmente vinculante, para ela, não é definido pelos indivíduos, mas se apresenta a eles de forma inesperada, mas sem que a eles seja dada uma chance de negar uma resposta. Nesse sentido, ela aciona a noção de rosto de Lévinas para explicar "a maneira pela qual outros fazem reivindicações morais sobre nós, direcionam demandas morais a nós, as quais não pedimos, mas que não somos livres para recusar" (Butler, 2011, p.16). Butler recupera a reflexão que Lévinas faz acerca da responsabilidade ressaltando que a interpelação moral do rosto não acontece porque o rosto está diante de nós, mas porque paira 
acima de nós: "é o outro diante da morte, olhando através dela e a expondo. $\mathrm{O}$ rosto é o outro que me pede para que não o deixe morrer só, como se o deixar seria se tornar cúmplice de sua morte. Portanto, o rosto diz a mim: não matarás" (Butler, 2011, p.16).

Se o desejo de matar se realiza, o outro escapa de nós, seu rosto desaparece. A presença do rosto se torna mais palpável, por assim dizer, quando somos tentados a anulá-lo e não conseguimos. Por isso, quando nos expomos à vulnerabilidade do rosto desafiamos nosso próprio direito de existir, e também o gesto de existir longe do outro. Ficamos cientes da precariedade do outro:

Responder ao rosto, entender seu significado quer dizer acordar para aquilo que é precário em outra vida ou, antes, àquilo que é precário à vida em si mesma. Isso não pode ser um despertar, para usar essa palavra, para minha própria vida e, dessa maneira, extrapolar para o entendimento da vida precária de outra pessoa. Precisa ser um entendimento da condição de precariedade do Outro. É isto que faz com que a noção de rosto pertença à esfera da ética (Butler, 2011, p.19).

Nas reflexões feitas por Lévinas, o rosto é um apelo ético por acolhimento, responsabilidade e reconhecimento da precariedade. $\mathrm{O}$ rosto é um vestígio da presença de um Outro que, por mais que esteja próximo, mantém-se à distância. Por isso, ele é comunicação e linguagem, aparição e desaparição, possibilidade e impossibilidade de alcançar o Outro em sua infinitude. Sob esse aspecto, o rosto não é visto, nem representável. "Ele é o que não se pode transformar num conteúdo, que o nosso pensamento abarcaria; é o incontível, leva-nos além" (Lévinas, 2007, p 70). O rosto do Outro é rastro, traço que revela o ente humano em um tipo de nudez, vulnerabilidade e precariedade. Tal nudez expressaria a ausência de todo "revestimento" cultural e social, uma vez que o rosto se faz visível apenas através de um processo de desfazer-se.

Dentre todas as partes do corpo, o rosto é o mais exposto, tanto ao perigo quanto à carícia; nu e transparente, o rosto é completa exterioridade, inteira relação e comunicação, sinceridade e abertura. $\mathrm{O}$ rosto fala por si e é, para o outro, única identidade re-conhecida pelo outro como realidade que se revela sem ser dominado. O rosto é mais 
que uma centelha do Infinito, é o Infinito nele mesmo (Melo, 2003, p.89).

Pode-se dizer que o rosto não é "visto", mas sim ouvido. Ao atribuir voz ao rosto, Lévinas localiza o aquém da imagem; "antes de ser imagem plástica e percepção sensível, de uma maneira mais essencial, o rosto é significação, fala; é por isso que a escuta do rosto prima sobre sua visão" (Poirié, 2007, p. 27). Esse apontamento evidencia os mecanismos de interlocução e, portanto, discursivos, que perpassam a subjetivação do que se constitui como rosto.

É importante mencionar que o rosto em Lévinas não se confunde com a face humana, muito embora uma face possa encarnar um rosto. Mas como uma imagem da face humana pode trazer à tona o rosto? Ainda que Lévinas argumente a favor de um rosto que não pode ser contido na face humana - uma vez que o rosto é a presentificação da precariedade da vida, do sofrimento que não se deixa representar - ele menciona que algumas expressões humanas podem ser significadas (substituídas por signos) a partir do rosto humano: figura que representa a dor, um clamor, uma demanda, uma finitude. Mas, ainda assim, a representação da face não dá conta de expressar o humano. O que há de irrepresentável no rosto não pode ser capturado por um dispositivo de visibilidade que tente apagar sua falha em representar a alteridade.

Assim, uma representação bem-sucedida do rosto deveria falhar em capturar o referente e evidenciar essa falha. "O humano é aquilo que limita o sucesso de qualquer prática representacional. $\mathrm{O}$ rosto não é apagado nessa falha de representação, mas é constituído exatamente nessa possibilidade" (Butler, 2011, p.27). Para Lévinas (1999), não há como uma representação imagética traduzir o "humano", pois a representação reduz os traços complexos do referente capturado, impedindo-nos de "escutar" o rosto (sofrimento vocalizado, por exemplo) através da imagem e afastando-nos da precariedade do Outro.

\section{Consideraçôes finais}

Estaria, então, a imagem destinada a rostificar os sujeitos, invisibilizando o rosto, ou seja, silenciando seu clamor e apagando 
sua unicidade em uma generalidade? Respostas a essas perguntas poderiam ser buscadas ao nos indagarmos acerca dos dispositivos que definem qual "espécie de ser humano a imagem nos mostra e a que espécie de ser humano ela é destinada, que espécie de olhar e de consideração é criada por esta operação" (Rancière, 2010, p.100). Como destaca Butler (2011), esquemas normativos e midiáticos de inteligibilidade estabelecem aquilo que será e não será humano, o que será uma vida habitável, o que será uma morte passível de ser lamentada. Esses esquemas normativos operam não apenas produzindo ideais do humano que fazem diferença entre aqueles que são mais e os que são menos humanos. Às vezes eles produzem imagens do menos que humano, à guisa do humano, a fim de mostrar como o menos humano se disfarça e nos ameaça (p.28).

A rostificação (Deleuze e Guattari, 2004) nos revela que já há violência na moldura do que é mostrado. Esta violência encaixa perfeitamente os rostos na moldura daquilo que pode ser dito e daquilo que pode ser mostrado, sem hiatos, sem faltas ou sobras. Ela é o mecanismo ou dispositivo por meio do qual certas vidas e certas mortes permanecem não representadas, ou são representadas de maneiras que efetivam sua captura (mais uma vez) pelo maquínico.

Há aqui, portanto, dois movimentos implicados: olhar para os modos de "aparência"10 performática dos sujeitos na imagem e identificar que tipo de olhar e de implicações esse "aparecer" suscita junto àqueles que observam a imagem. $\mathrm{E}$ nessas duas operações, é a "aparência”, o visível, o que está em jogo.

No movimento e gesto políticos de exposição ligados ao "aparecer", os indivíduos se transformam em sujeitos dotados de rosto, capazes de desenvolver capacidades enunciativas e demonstrativas, de reconfigurar a relação entre o visível e o dizível, entre palavras e corpos. A imagem convida à aproximação ao Outro, ao mesmo tempo em que assegura uma separação: se ela "produz uma ligação entre sujeitos separados, entre sujeitos da desligação, ela assegura a

${ }^{10}$ Enfatizamos as expressões "aparência" e "aparecer" para ressaltar uma relação de contiguidade entre uma configuração oferecida (a aparência) e a prática do visível, o modus operandi (o aparecer). 
distância que os separa, preservando-os de qualquer fusão identificadora ou massificante" (Mondzain, 2011, p.124).

Seguindo esta perspectiva, a imagem pode conferir rosto a um indivíduo, tornando-o sujeito a nossos olhos (a humanização depende da visibilidade do rosto humano), e, por isso, por permitir sua aparência, faz emergir o lugar da comunicação e da reciprocidade. Mas ela também produz uma porção de (in) comunicabilidade: um rosto que se nos apresenta via imagem pode, ao mesmo tempo, revelar um "em comum", um incomum e uma parte de outrem que não se deixa apreender, que não consegue traduzir-se em comunicação.

Lévinas (1999) menciona que há tanto representações “plásticas" do rosto que obliteram o rosto, quanto a possibilidade de o rosto operar e ser representado enquanto rosto (face humana), a partir do momento em que vocalizar ou ser entendido como resultado de uma voz que expressa um lamento, uma agonia, um sinal da precariedade da vida. O que o autor nos indica é a possibilidade de entrever o rosto através de um arranjo entre o visível e o dizível, entre o exposto e o enunciado. Nem sempre o destino da imagem é a rostificação. As fraturas e fissuras, ainda que sejam mínimas e sutis, podem ser o suficiente para o aparecer do rosto. Segundo Butler:

Não é possível, nas condições contemporâneas de representação, escutar o clamor agonizante ou ser compelido ou chamado à responsabilidade pelo rosto. Fomos deslocados do rosto, algumas vezes através da própria imagem do rosto, este que é feito para expressar o inumano, o que já está morto, aquele que não é precariedade e, portanto, não pode ser morto. (...) Seria preciso escutar o rosto à medida que ele fala em uma outra forma que a linguagem para entender a precariedade da vida que está em jogo. (...)Teríamos que interrogar a emergência e o desaparecimento do humano nos limites do que podemos saber, do que podemos ouvir, do que podemos ver, do que podemos sentir (Butler, 2011, p.32).

Além disso, os dispositivos a partir dos quais as imagens são produzidas nos revelam que, ao mesmo tempo, o rosto pode atuar como pura apresentação e relação comunicacional entre o eu e o Outro, e como instrumento maquínico de nomeação e dominação. O 
rosto pode surgir como vestígio de uma presença incapturável e como adequação consensual do eu à um projeto de subjetividade, geralmente de sujeição.

O exemplo por nós explorado revela como as imagens de crianças que se encontram na vulnerabilidade extrema e no limiar da morte são capazes de nos vincular moralmente a partir do modo como a associação entre os testemunhos dos pais, as parafernálias hospitalares e a exposição das tantas dores configuram enunciados que são endereçados a nós sem que possamos evitá-los ou prover uma resposta (seja monetária, religiosa - sob a forma de preces afetiva ou mesmo repulsiva).

O rosto surge quando somos implicados por uma demanda involuntária e não planejada que nos impõe uma autoridade moral. $\mathrm{O}$ rosto de Pedrinho e das tantas crianças que lutam pela vida nos espaços enunciativos, como do Facebook, surge quando nos endereçam seus gemidos como espécie de demandas das quais não estamos livres para recusar.

\section{Referencias}

BOLTANSKI, Luc (1999). Distant Suffering: morality, media and politics. Cambridge: Cambridge University Press.

BOLTANSKI, Luc; CHIAPELLO, Ève (2013). O novo espirito do capitalismo. São Paulo: WMF Martins Fontes.

BUTLER, Judith (2015). Relatar a si mesmo. Belo Horizonte: Autêntica. BUTLER, Judith (2014). Quadros de guerra: quando a vida é passível de luto? Rio de Janeiro: Civilização Brasileira.

BUTLER, Judith (2011). Vida precária. Contemporânea - Revista de Sociologia da UFSCar. São Carlos.

CERVELIN, Diego (2009). Sobre um rosto - um rosto, Anuário de Literatura, vol. 14, n. 1. (p.102-114).

CHOULIARAKI, Lilie (2013). The ironic spectator. Solidarity in the age of post-humanitarianism. Cambridge: Polity Press.

CHOULIARAKI, Lilie (2006). The Spectatorship of Suffering. London: Sage.

DELEUZE, G. e GUATTARI, F. (2004). Ano Zero - Rostidade. Mil Platôs Capitalismo e Esquizofrenia, vol. 3. Tradução Aurélio 
Guerra Neto, Ana Lúcia de Oliveira, Lúcia Cláudia Leão e Suely Rolnik. São Paulo: Editora 34. (p. 31-61).

FOUCAULT, Michel (1995).”O sujeito e o poder“. In: RABINOW, P.; DREYFUS, H. (eds.). M. Foucault. uma trajetória filosófica para além do estruturalismo e da hermenêutica. Rio de Janeiro: Forense Universitária.

GUIMARÃES, César; FRANÇA, Vera (2006). Experimentando as narrativas no cotidiano. In: Na Mídia na Rua: narrativas do cotidiano. Belo Horizonte: Autêntica.

JAGUARIBE, Beatriz (2006). Realismo sujo e experiência autobiográfica. In: FATORELLI, Antonio: BRUNO, Fernanda (Orgs.). Limiares da imagem. Tecnologia e estética na cultura contemporânea. Rio de Janeiro: Mauad. (p.109-137).

LAZZARATO, Maurizio (2014). Signos, máquinas, subjetividades. São Paulo: Edições Senac; n-1 edições.

LÉVINAS, Emmanuel (1999). Alterity and transcendence. New York: Columbia University Press, 1999.

LÉVINAS, Emmanuel (2007). Ética e infinito. Lisboa: Edições 70. (p.69-75).

LÉVINAS, Emmanuel (1980). Totalidade e infinito. Lisboa: Edições 70. LÉVINAS, Emmanuel (2005). Entre nós: ensaios sobre a alteridade. Petrópolis: Vozes.

LÉVINAS, Emmanuel (2011). De outro modo que ser ou para lá da essência. Trad.: José Luiz Pérez e Lavínia Leal Pereira. Lisboa: Centro de Filosofia da Universidade de Lisboa.

MONDZAIN, Marie Jose (2011). Homo spectator. Paris: Bayard. POIRIÉ, François (2007). Emmanuel Lévinas: Ensaio e Entrevistas. São Paulo: Perspectiva.

RAGO, Margareth (2013). A aventura de contar-se: feminismos, escrita de si e invenções da subjetividade. Campinas: Editora Unicamp. RANCIÈRE, Jacques (2004). Aux bords du politique. Paris: Gallimard. RANCIÈRE, Jacques (2010). O espectador emancipado. São Paulo: Martins Fontes. 



\section{Identidades urbanas nas redes: estratégias de resistência do Movimento Ocupe Estelita}

Nataly de Queiroz Lima. Universidade Federal de Pernambuco (Brasil).queiroz.nataly@gmail.com

Heitor Costa da Lima Rocha. Universidade Federal de Pernambuco (Brasil). hclrocha@gmail.com

\section{Introdução}

( paradigma da sociedade em rede está vinculado a uma série de mudanças estruturais nas relações sociopolíticas e econômicas mundiais que colocam a produção de sentidos, o que contempla as tecnologias e os conteúdos, no cerne das disputas ideológicas e de poder. No seu bojo, foram reconfigurados os processos de produção, consumo de bens e relações de trabalho, bases do capitalismo; as estruturas do Estado; a cultura e as identidades; e a participação social dos indivíduos na política.

Os novos movimentos sociais se apresentam como símbolos deste marco societário. Por isso, este artigo tem como objetivo entender como as produções simbólicas do Ocupe Estelita nas redes sociais se relacionam com questões identitárias inerentes ao contexto das cidades capitalistas. Mais especificamente, se busca absorver como a pluralidade de identidades se articula em/para espaços comunicacionais em prol de direitos sociais.

O Ocupe Estelita tem características semelhantes ao que tem sido denominado de Novos Movimentos Sociais. Estes, segundo Castells (2013), têm particularidades como: a) criam comunidades de proximidade; b) escolhem espaços carregados de valor simbólico que 
vão além do próprio ato; c) conectam ciberespaço e espaço urbano criando um novo espaço político; d) são simultaneamente globais e locais funcionando num tempo atemporal; e) têm características virais; f) "são movimentos profundamente autorreflexivos", apesar de raramente serem pragmáticos; g) possuem líderes, mas resistem à ideia de liderança tradicional, materializada no ideal de uma pessoa ser capaz de representar todo o grupo; g) procuram a mudança dos valores da sociedade, reivindicando a mudança do Estado, mas sem querer se apoderar deste utilizando as mesmas estratégias de ocupação do estado a partir do modelo vigente.

De forma geral, "o que estes movimentos sociais em rede estão propondo em sua prática é uma nova utopia no cerne da cultura da sociedade em rede: a utopia da autonomia do sujeito em relação às instituições da sociedade" (Castells, 2013, p. 170).

No conjunto, as características destes novos movimentos, além de evidenciarem um processo de busca por novas práticas democráticas, pela ressignificação dos movimentos sociais, parecem refletir um novo status para a participação social, no qual a comunicação tem papel preponderante no reordenamento das estruturas de poder, sendo o cerne de toda a ação coletiva de mobilização e de divulgação, ou seja, da sua própria existência política.

\section{O movimento ocupe estelita}

O Ocupe Estelita se constitui em um movimento não institucionalizado, cujo âmbito de ação é a cidade do Recife, capital do estado de Pernambuco. O Ocupe reúne representações de organizações da sociedade civil, de partidos políticos, de fóruns, de redes movimentalistas, mas principalmente de indivíduos sem vínculos com nenhuma organização e/ou entidade formal, que participam dos atos e mobilizações (virtuais ou presenciais) de forma autônoma. São características marcantes da sua organização a autonomia dos sujeitos, a ausência de um centro de liderança e a negação das formas tradicionais de política representativa. 


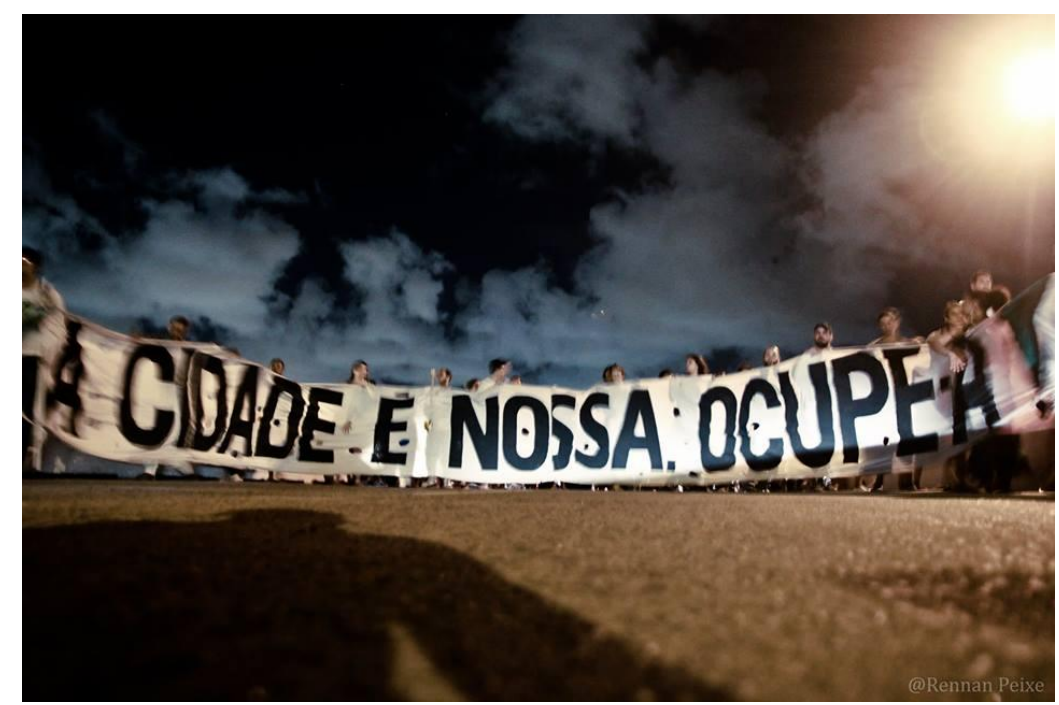

Figura 1 - Bandeira de luta do Ocupe Estelita

O movimento se mostra um catalisador de demandas sociais referentes ao direito à cidade. O Cais José Estelita é um símbolo da disputa por uma urbanidade mais humana e acessível às pessoas de diferentes classes sociais e identidades.

O coletivo se organizou, em 2012, a partir da resistência de seus militantes ao projeto Novo Recife - um empreendimento de um grupo de construtoras que pretende construir 12 torres com até 40 andares no Cais José Estelita em uma proposta que destoa do entorno histórico, com seus casarios centenários, bem como da realidade das comunidades vizinhas de baixa renda, e que, segundo alguns especialistas críticos da proposta, pode trazer impactos ambientais negativos à Bacia do Pina, um dos principais estuários da capital pernambucana. Além de significar a utilização deste espaço urbano exclusivamente para o lucro da especulação imobiliária e para ser usufruído pelas ricas oligarquias pernambucanas que poderão adquirir os dispendiosos imóveis, sem levar em conta o interesse do conjunto da população na sua utilização para o lazer coletivo e em empreendimentos com capacidade de atração turística e de geração de emprego permanentes. O Cais também é uma área estratégica para o capital imobiliário, pela sua privilegiada localização, visto que está no centro da cidade, em um dos principais trechos histórico e turístico, e próximo do bairro de Boa Viagem, um dos mais nobres do município. 
O Cais José Estelita se constitui em um conjunto de armazéns de açúcar - legado da exploração da cana-de-açúcar no Nordeste - que estavam abandonados e um pátio ferroviário, totalizando mais de 100 mil $\mathrm{m}^{2}$ de área. O terreno estava sob posse da antiga Rede Ferroviária Federal (RFFSA). A sua compra, de acordo com lideranças do Ocupe Estelita e ações movidas pelo Ministério Público Federal (MPF), está cercada de irregularidades jurídicas, como a ausência de estudos de impacto local das obras e a própria transação de venda da propriedade.

Como estratégia de articulação, de visibilidade e de advocacy, o movimento aglutinou pessoas para produzirem conteúdos para redes sociais e para realizar assessoria de imprensa. Em 2014, foi ampliado o trabalho do \#OcupeCom, grupo de comunicação do coletivo, e criada a Brigada do Audiovisual do Estelita, responsável pelas principais narrativas fílmicas do movimento (vale salientar que outros militantes também produziram vídeos sobre as ações do Ocupe e têm liberdade para postá-los das redes enquanto Ocupe). Os dois espaços contaram com profissionais de diversas áreas da comunicação (jornalistas, publicitários, cineastas, designers, etc), alguns já renomados mas que agiam, na maioria dos casos, de forma anônima por medo de represálias e/ou para garantir a segurança e continuidade das próprias estratégias de comunicação.

Parte considerável do trabalho de mediação entre o movimento e as demais pessoas, o que inclui os jornalistas de veículos de comunicação de massa, acontece por meio das redes sociais. No facebook, o grupo possui mais de sete mil curtidas; no twitter, quase cinco mil seguidores; no instagram, mais de nove mil seguidores; no youtube, mais de 260 mil visualizações.

Não se está abordando um fenômeno meramente tecnológico, mas de reconfiguração social dos usos de redes técnicas de instrumentalidade para fins de participação política que, por meio de processos de comunicação, pretendem intervir sobre a realidade.

\section{As identidades em cena}

Não há como falar de política sem incluir os sujeitos. Não há como falar de sujeitos na política ou de sujeitos políticos sem abordar as 
suas identidades. A identidade no singular não existe. As vivências individuais e socialmente partilhadas vão compondo um mosaico de fontes de significação, de filtros de mundo, que interferem na forma como as pessoas constroem a sua autoimagem e como se ligam ao mundo, relações essas iminentemente políticas.

Para os estelitantes, o Cais José Estelita não é meramente um espaço físico georreferenciado na cidade do Recife. Trata-se, na verdade, da representação do esmagamento do local e do público pelo modelo de desenvolvimento econômico marcadamente capitalista dos grandes centros urbanos, bem como, da falência do modelo de representação político partidária no âmbito do Estado. Neste sentido, não se pode deixar de registrar que este modelo de desenvolvimento econômico, de uma maneira geral, mas também especificamente de gestão autoritária e discriminatória do espaço urbano, foi acentuado depois do Golpe Militar de 1964, tendo em vista que as gestões da chamada Frente do Recife nas década de 50 e começo da década de 60 do século passado ficaram marcadas pelo seu caráter democrático e tecnicamente progressista. (Rocha \& Lima, 2014)

É no território, na cidade, onde as identidades se aglutinam em um movimento de resistência e intervenção. São as identidades, consideradas enquanto "fonte de significado e experiência de um povo" (Castells, 2013, p. 22), que parecem estar retroalimentando o movimento de participação destes ativistas.

"O Ocupe é um agregador de temáticas: LGBT, do movimento negro, do comércio do centro da cidade, do direito à moradia popular, dos movimentos culturais. E tudo isso é totalmente compreensível. Todas essas instâncias sofrem com o modelo de reprodução do capital e a cidade é o principal terreno do confronto com o capital" (L.C.P., entrevista concedida aos autores, 2014).

A identidade em questão não parece ser, apenas ou prioritariamente, a do recifense. Isto porque o espaço da cidade representa mais do que uma cultura singular, essencializada, estagnada no tempo e no espaço. A emergência de identidades de resistência, associadas a segmentos sociais considerados não hegemônicos, nas décadas de 1960 e 1970 no mundo, assim como o aprofundamento dos processos 
globalizantes e capitalistas, tornam as cidades um palco de contradições e de sujeitos plurais.

"O "local" não possui um caráter estável ou trans-histórico. Ele resiste ao fluxo homogeneizante do universalismo com temporalidades distintas e conjunturais. Não possui inscrição política fixa. (...) Seu impulso político não é determinado por um conteúdo essencial (geralmente caricaturado como "resistência da Tradição à modernidade"), mas por uma articulação com outras forças." (Hall, 2008, p.59)

As identidades se constroem subjetivamente em um complexo processo de autoreconhecimento e de interação com a cultura circundante. Não há identidade/s deslocada/s do contexto sóciohistórico onde se está inserido. Tal assertiva reconhece a influência do meio e a capacidade de resistência dos seres humanos em relação aos códigos culturais vigentes, hegemônicos e compartilhados em um determinado contexto social. A cultura enquanto produto humano e coletivo está em constante modificação. Com as identidades não é diferente.

A demarcação de uma identidade (ou de identidades) é, então, um processo político, entendido enquanto interação com a sociedade, mas também de rupturas necessárias com meio, no sentido do reconhecimento e da visibilidade de outros sujeitos e ideias que orbitam fora do núcleo hegemônico do pensamento societário. Stuart Hall (2006) destaca quão plurais as identidades se tornaram desde o sujeito iluminista, associado a uma essência inata, até a identidade do sujeito pós-moderno, não biologicamente determinado nem totalmente reflexo do meio, como o sujeito sociológico.

Nas cidades, campos geopolíticos onde se situa a cultura urbana, as identidades se afirmam e se constringem, se aquietam e se modificam. Castells (2011) destaca o papel da sociedade industrial capitalista neste processo, mas não se limita a este. Do primeiro, herdou os fluxos assimétricos e abertos, os quais possibilitam que as identidades não fiquem restritas a singularidades locais e à luta de classes. Mulheres, negros, LGBTs disputam esse espaço que, como já dissemos, não é meramente físico, é político. 
"No fundo, a luta pelo direito à cidade envolve disputas sobre diferentes modos de vida que podem ou não ser abarcados por ela. O Movimento Ocupe Estelita foi o ponto de convergência de bandeiras muito diferentes, de gays, lésbicas, transexuais, adeptos da bicicleta, do vídeo militante, da alimentação vegetariana ou vegana, de defensores dos animais e da descriminalização da maconha, dos trabalhadores do comércio informal e da moradia popular... Podemos então perguntar por que a cidade é imprescindível para cada uma dessas lutas. A resposta parece estar no direito à diversidade, frontalmente ameaçado pelo modo de vida burguês e sua fixação na dimensão privada da existência. Descobri, com o Estelita, que a luta pela cidade é a luta pelo direito de ser como se é sem ser ameaçado pela intolerância. A vivência coletiva dos espaços públicos pode ser uma forma de educação para a vida cívica e de civilização urgente das nossas elites. Ou seja, a crise urbana que vivemos ajuda a entender a crescente onda direitista e fascitóide porque, cada vez mais isolados em seus mundos particulares, os indivíduos tendem a fazer desses mundos o seu absoluto, e esquecem que os outros não precisam pedir licença para viverem de outra maneira." (ROCHA, 2015)

O Ocupe Estelita se situa no espaço da cidade, resistindo à cultura urbana capitalista, segregadora, mobilizando identidades plurais que têm como intersecção - pontos de motivação para a luta comunal os incômodos de viver o modelo de desenvolvimento econômico hegemônico, com todos os seus rebatimentos sociopolíticos e culturais.

"Venho do interior com minha família e passamos por enormes dificuldades para nos estabelecermos aqui. O maior capital que construí foi imaterial e essa foi também minha contribuição à luta. Este tipo de capital tem suas fragilidades mas também tem muita virtuosidade" (L.C.P., entrevista concedida aos autores, 2014).

Castells (2013, p. 80) destaca que, durante boa parte do século passado, os movimentos urbanos se constituíram como as principais fontes de resistência ao capitalismo e à segregação. Ao longo das décadas foram se diversificando, organizando sua 
atuação a partir do local contra as ameças advindas dos centros de poder globais, cada vez mais difíceis de serem atingidos. Os vínculos identitários, ligados a comunidades de sentido, comunidades culturais, estão no cerne da capacidade de resistir. "As culturas da urgência locais são o contraponto da intemporalidade global" (Castells, 2013, p. 84).

A solidariedade despertada pelo reconhecimento da vivência comum da exclusão e discriminação é patente nos depoimentos dos cidadãos envolvidos na luta de resistência do movimento Ocupe Estelita.

Essa causa tem a ver com algo muito maior do que só o espaço físico do Estelita, é uma luta contra essa lógica, do poder econômico oprimindo tudo, engolindo tudo, essa coisa da especulação imobiliária, as cidades sendo moldadas só em função do capital, só em função da elite. Eu fui embora do Rio por causa disso. Isso me expulsou, não permitiu que eu continuasse morando lá. Toda vez que seu contrato de aluguel vai vencer você entra em depressão, porque você acha que vai morar na rua - e todo mundo sabe como é a rua para as mulheres... eu pensei: tudo isso me incomoda tanto e eu não vou contribuir? Eu tava podendo contribuir na época, decidi acampar (J.P., entrevista concedida aos autores, 2014)

O movimento não é um mero ponto de convergência dos diferentes. O fato é que, por levantar a bandeira dos direitos urbanos, se localiza no cerne de um intenso debate sobre direitos naturais, propriedade e direitos sociais. As identidades de projeto e de resistência (Castells, 1999), em geral não hegemônicas e segregadas, têm na causa da cidade um foro privilegiado de atuação por ser uma arena de opressão mas também de possibilidade de práticas libertadoras. Parte considerável destas práticas se exercem, no ocupe, por meio das estratégias de comunicação mediadas por redes.

\section{As estratégias em rede}

Identidades plurais e processos de comunicação são a base de uma cultura democrática. No caso do Ocupe Estelita, pela amplitude identitária do movimento, as redes sociais virtuais parecem ter se adaptado à necessidade de espaço colaborativo, no qual os diferentes pudessem se encontrar em pautas comuns. O desencadear destas 
ações desemboca na construção de símbolos, sentidos e narrativas que denotam o complexo jogo de identidades sintonizadas para ampliação do exercício da cidadania e da garantia dos direitos sociais. Um procedimento eminentemente político e comunicacional, que apenas reitera a imbricação destas duas partes.

"Os agentes que dão voz a projetos de identidades que visam a transformação de códigos culturais precisam ser mobilizadores de símbolos. Devem atuar sobre a cultura da virtualidade real que delimita a comunicação na sociedade em rede, subvertendoa em função de valores alternativos e introduzindo códigos que surgem de projetos de identidade" (Castells, 2013, p. 425).

A construção e o desaguar de narrativas nas redes sociais virtuais foi o que viabilizou o projeto de visibilidade das vozes e objetivos que não conseguiam chegar aos veículos de comunicação de massa, tradicionais mediadores dos interesses públicos, devido à vinculação destes com agentes políticos e comerciais.

"As primeiras produções que fiz surgiram como uma resposta aos relatos jornalísticos. Era o espaço para a voz dos que não tinham espaço na mídia corporativista." (P.S, entrevista concedida aos autores, 2016)

"As produções audiovisuais do Ocupe contribuem para criar um campo de força discursivo. Não só elas, mas todas as ações, de comunicação ou de rua: o design, a imprensa, os atos... Isso tudo vai compondo um repertório de narrativas que passam a definir um certo ideário do movimento, muitas vezes complexos e até contraditório. A partir disso, as pessoas podem aderir, se identificar, criar empatia, se aproximar, vestir a camisa etc.” (M.P., entrevista concedida aos autores, 2016)

A produção de conteúdo do Ocupe Estelita é diversa, dialogando com setores do campo à cidade, em diversas frentes que vão desde o direito à moradia até os direitos das mulheres. No entanto, o link narrativo das produções se assenta em símbolos do Recife. As peças audiovisuais são diversas: vão do clipe musical ao documentário, do humor a entrevista com especialistas. Em geral, os estudiosos entrevistados e os artistas que gravaram vídeos têm vínculos com a 
capital pernambucana. Elementos como a Praia de Boa Viagem, ícone da elite local, também são referências identificáveis. As identidades prioritárias emergem por meio destes signos.

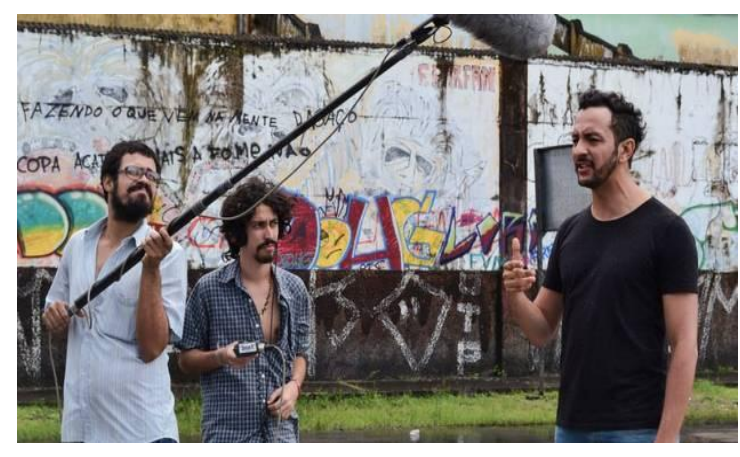

Figura 2 - Gravação do documentário Cidade Roubada, com o ator local, conhecido nacionalmente, Irandhir Santos

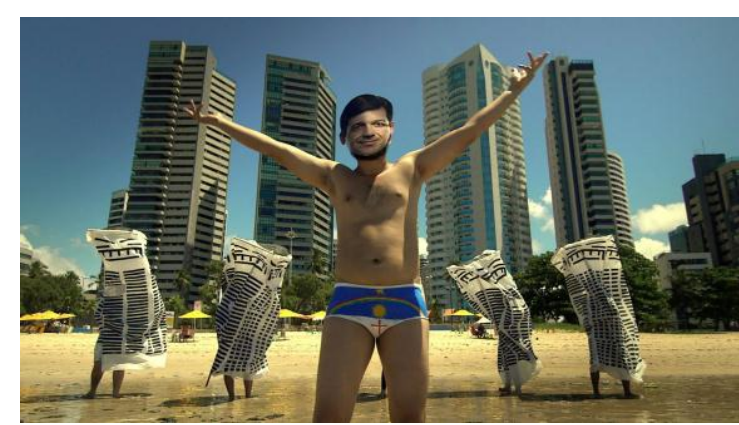

Figura 3 - Trecho do clipe musical Novo Apocalipse Recife, gravado na Praia de Boa Viagem, com seus arranha-céus. A frente, o personagem encena o prefeito da cidade do Recife, Geraldo Júlio. No seu traje de banho, a bandeira do estado de Pernambuco.

É válido salientar que o agendamento midiático nesta discussão mesmo diante de um intenso movimento de ocupação, como o que aconteceu em 2014, quando centenas de manifestantes montaram barracas no Cais e se revezaram dia a noite, para assegurar que não houvesse a derrubada dos armazéns - tem privilegiado, enquanto fontes primárias, representantes dos empresários do Novo Recife, e do poder público local, por meio da Prefeitura da Cidade do Recife.

"Neste contexto, boa parte da memória envolvendo a polêmica sobre o Novo Recife, em particular aquela que diz respeito a voz do \#OcupeEstelita, só pode ser resgatada em redes sociais, blogs, plataformas de compartilhamento de vídeos, etc. O esforço de toda a produção audiovisual do \#OcupeEstelita é justamente rachar a vocalização monocórdica da mídia hegemônica disseminando seu material na rede". (Melo, 2015, p. 04)

As escolha das redes sociais para compartilhamento das produções esteve associada ao perfil e à quantidade de público possível de atingir. 
"Usamos quatro plataformas principais: facebook, youtube, vimeo e whatsapp. Recentemente, temos usado mais o facebook mesmo porque percebemos que os filmes viralizam mais facilmente. Esse seria o principal objetivo estratégico: potencializar ao máximo o alcance das obras". (M.P, entrevista concedida aos autores, 2016)

As estratégias voltadas para as redes digitais também apontam o descrédito com os medias comercias, que, pelas vinculações com o capital político e com o capital de mercado, aparecem como incapazes (ou desinteressados) de dar espaço para outras fontes. Este fenômeno é denominado por Daniel Hallin e Paolo Mancini (2010, p. 51) como instrumentalização da mídia, ou seja, "é o controle dos media por agentes externos - partidos, político, grupos ou movimentos sociais, ou agentes econômicos que procuram influência política - que se servem deles para intervir no mundo da política”.

"Como é óbvio, na medida em que as organizações de media são instrumentalizadas desta maneira, (...) aos jornalistas faltará autonomia, os critérios políticos mais do que critérios claramente jornalísticos guiarão o exercício do jornalismo, e os media servirão interesses particulares em vez de funcionarem como um "consórcio público"11 (Hallin \& Mancini, 2010, p. $51)$.

Em geral se restringe o alcance do termo à instrumentalização política, considerando que a comercialização limita a influência da política no jornalismo. Hallin e Mancini (2010, pp. 51-52), no entanto, asseguram que acontece exatamente o contrário:

"Chama-se a atenção para o fato de os media poderem ser também "instrumentalizados" para fins comerciais: a publicidades é essencialmente isto, e as organizações de media estão muitas vezes sujeitas a formas mais latas de instrumentalização comercial, que vão desde exemplos mais notórios, como a exibição de produtos em filmes e na programação da televisão, às exigências de anunciantes, no sentido de influenciarem os conteúdos editoriais, até formas

11. Grifo nosso 
mais sutis de pressão. Como veremos, trava-se um debate considerável sobre a relação entre a comercialização dos media e a profissionalização. Alguns consideram que uma e outra estão essencialmente em harmonia, argumentando que a comercialização reduz a instrumentalização política. De uma maneira geral o nosso ponto de vista é de que a profissionalização pode ser ameaçada quer pela instrumentalização política quer pela comercialização, e na verdade em muitos casos por ambas ao mesmo tempo".

E não se pode deixar de levar em conta que os interesses comercias, em geral, estão promiscuamente imbricados com os interesses do grande capital que monopoliza a grande mídia, bem como com os dos grupos políticos que controlam o aparelho de Estado. Portanto, o grau de instrumentalização política/comercial dos media e de comprometimento do profissionalismo jornalístico depende, sobretudo, do nível de consciência/discernimento do público para rejeitar os pseudo-consensos em que interesses particulares aparecem mitificadamente como expressão do bem-comum, bem como para exigir a afirmação dos interesses verdadeiramente coletivos/públicos.

Assim, as estratégias voltadas para as redes digitais são indicadores da consolidação destas estruturas enquanto mass self communication, ou seja, instrumentos que aglutinam características de comunicação de massa (similar aos veículos massivos) e interpessoal (Castells, 2009); bem como de um processo de autonomização dos sujeitos que disputam o processo de produção de sentidos enquanto ação política de intervenção sobre o governo e as políticas públicas, como destaca um dos membros da Brigada do Ocupe Estelita. "Os vídeos servem também para incomodar. É como uma pedra no sapato dos poderes. Quando mais eficientes forem os filmes no sentido de incomodar os poderes, mais eles terão êxito" (M.P., entrevista concedida aos autores, 2016).

No movimento, os lugares de fala são plurais e, portanto, as produções simbólicas aparecem menos como a reprodução de discursos do que com um mosaico de informações de interesse comuns e de dissensos. A própria teia das redes sociais, por mais que seja possível evidenciar características de bolhas comunicacionais, possibilita o conflitos de ideias que são evidenciados, em especial no 
facebook, por ser uma plataforma com consideráveis possibilidades de interação para toda a comunidade que lá está, e não parecem ser negados pelo \#OcupeCom.

Entendendo a produção simbólica enquanto ação política, as identidades plurais situadas no espaço da cidade têm se articulado em movimentos sociais que são morfologicamente distintos dos movimentos das décadas 1980 e 1990. O exercício da horizontalidade no Ocupe Estelita se pode observar na dinâmica dos sentidos construídos coletivamente e expostos nas redes sociais virtuais de forma articulada, em termos de linguagens (escrita e audiovisual), mas também apresentam a dimensão do desafio democrático necessário de ouvir vozes plurais e muitas vezes contraditórias.

\section{Referências}

Castells, M. (2013). O poder da identidade. São Paulo: Editora Paz e Terra.

. (2009). A sociedade em rede. São Paulo: Editora Paz e Terra.

- (2013). Redes de indignação e esperança: movimentos sociais na era da internet. Rio de Janeiro: Zahar.

- (2013). O poder da comunicação. Lisboa: Fundação Calouste Gulbenkian.

- (2011). A questão urbana. São Paulo: Paz e Terra.

Hall, S. (2006). A identidade cultural na pós-modernidade. Rio de Janeiro: DP\&A.

. (2003). Da diáspora: identidades e mediações culturais. Belo

Horizonte:

Editora UFMG.

Hallin, D. C., \& Mancini, P. (2010). Sistemas de Media: Estudo Comparativo - Três Modelos de Comunicação e Política. Lisboa: Livros Horizonte. 
Melo, C. T. V. (2015). Ética, Estética e Politica no Video Vida Estelita. Rio de Janeiro: Anais XXXVIII Congresso Brasileiro de Ciências da Comunicação, 2015. Disponível em: http://portalintercom.org.br/anais/nacional2015/resumos/R1 0-1027-1.pdf, acessado em 28 de fevereiro de 2016, às $20 \mathrm{~h} 30$.

Rocha, H. C. L., \& LIMA, N. Q. (2014). Direitos em bits: estratégias de comunicação mediadas por tecnologias para a mobilização em prol de direitos humanos. In: MENDEZ, José Manuel Goméz y et all. Derechos humanos emergentes y periodismo. Universidad de Sevilla: Espanha, 2014. p. 636 - 655

Rocha, M. E. M. (2015). O Estelita é mais do que o Estelita. El País, 2015. Disponível em: http://brasil.elpais.com/brasil/2015/11/30/opinion/14488401 54 656256.html, acessado em 28 de fevereiro de 2016, às $23 \mathrm{~h} 11$. 


\title{
"Las redes son el corazón": Espacios, relaciones y conexiones en la expresión pública de los activistas en internet
}

\author{
Dorismilda Flores Márquez. Universidad De La Salle Bajío (México). \\ dfloresm@,delasalle.edu.mx / dorixfm@gmail.com
}

\section{Introducción}

$\mathrm{V}$

IVIMOS entre redes. La vida social se construye a partir de prácticas que implican ciertos tipos de relaciones entre sujetos. Las redes digitales han hecho más evidentes algunas de esas relaciones y, a la vez, han potenciado otras formas de interacción y vínculo. Esto se vuelve especialmente relevante para el activismo, la teoría clásica sobre movimientos sociales ha entendido a estos en términos de acción colectiva, de modo que el carácter relacional es central. En nuestros tiempos, la incorporación de las tecnologías digitales ha sido un elemento clave para comprender los movimientos sociales contemporáneos, la expansión considerable de sus niveles de visibilidad y de sus posibilidades de relacionarse con otros.

En este capítulo se discute el carácter relacional de la expresión pública de los activistas en internet. Los datos proceden de una investigación en la cual se abordó el vínculo entre el espacio público e internet, mediante el análisis de las prácticas de expresión pública de los activistas en internet, desde contextos locales. Se trabajó con dos grupos, para los cuales internet ha sido un elemento fundamental en 
sus trayectorias: Amigos Pro Animal -un grupo de activismo animalista- y Libros Vagabundos - un grupo de activismo cultural- .

Los hallazgos del estudio permiten afirmar que la expresión pública de los activistas en internet se configura a partir de tres elementos: las identidades activistas, la estética activista y las relaciones (FloresMárquez, 2015b). En este capítulo se presentan los principales hallazgos en el eje de las relaciones. Como se verá más adelante, éstas se desglosan en tres partes: los espacios, las redes y las conexiones.

El capítulo está organizado en cuatro partes. En primer lugar, se presenta la investigación sobre la expresión pública de los activistas en internet en el marco de un cuestionamiento más amplio sobre la relación entre el espacio público e internet. Se sintetiza el marco teórico construido a partir del diálogo interdisciplinario entre los estudios de comunicación, la sociología de los movimientos sociales y la filosofía política. Asimismo, se presenta una síntesis del enfoque metodológico etnográfico que se siguió en el estudio, algunos elementos de contexto que permiten situar los casos y los tres ejes que articulan los hallazgos de la investigación: la identidad, la estética y las relaciones.

Como se ha señalado previamente, este capítulo se concentra en el último de estos ejes, es decir, en la dimensión relacional de la expresión pública de los activistas en internet. De este modo, los apartados dos, tres y cuatro, están dedicados a discutir los espacios, las redes y las conexiones, como elementos de la dimensión relacional.

Concretamente, en el segundo apartado se abordan la red, la calle y los medios, como espacios de comunicación que se construyen a partir de las relaciones entre activistas y otros actores. Se trata de espacios sociales diferenciados, pero, a la vez, permanentemente relacionados entre sí.

En el tercer apartado, se abordan las redes de relaciones construidas por los grupos en el espacio social. Esta lógica reticular ordena las relaciones hacia el interior y hacia el exterior del grupo. Hacia el interior, las relaciones se establecen entre los integrantes del grupo. Hacia el exterior hay relaciones que se establecen con otros actores en 
la ciudad, mientras otras se establecen con otros activistas que comparten preocupaciones y proyectos alrededor del mundo.

El cuarto apartado está dedicado a explorar las conexiones que posibilitan el establecimiento de relaciones. En los casos analizados, se observa que la juventud, la tecnología, el riesgo y la globalización, operan como conexiones que dan sentido a las relaciones establecidas por los activistas.

\section{El estudio de la expresión pública de los activistas em internet}

En esta investigación se abordó el vínculo entre el espacio público e internet. Los medios de comunicación han sido considerados como elementos clave para la construcción del espacio público, pero también se han reconocido sus limitaciones, principalmente en el sentido de las desigualdades en el acceso a la expresión pública. Con la emergencia de internet, se asumió que había posibilidades de contrarrestar esas desigualdades y de aprovechar su lógica reticular para ejercer prácticas de comunicación más democráticas, horizontales y libres. Al pasar de los años, hemos visto que, incluso con la presencia de internet, las desigualdades en el acceso a la expresión pública persisten y hasta se agudizan. Sin embargo, hemos visto también una serie de apropiaciones creativas de las tecnologías digitales, que dan cuenta de los cambios.

Este vínculo entre el espacio público e internet se abordó mediante el estudio de las prácticas de expresión pública de los activistas en internet. Esta formulación incorporó tres elementos clave para ver en concreto una relación tan abstracta: las prácticas, la expresión y los activistas. Desde la perspectiva sociocultural, las prácticas, en su carácter dinámico, permiten comprender las lógicas de reproducción y transformación de la vida social. Esto implica entender al espacio público no como algo dado, sino como algo en constante construcción. Se tomaron, específicamente, las prácticas de expresión pública, es decir, aquellas prácticas comunicativas hechas para buscar la visibilidad e insertarse en la discusión de los asuntos públicos. Finalmente, se estudiaron esas prácticas de expresión pública en cierto tipo de sujetos, los activistas. La búsqueda del cambio social que hacen los activistas conlleva una búsqueda permanente por 
insertarse en las discusiones sobre lo público, a veces incluso en condiciones adversas.

La investigación partió también de dos desplazamientos clave: uno en el modo de entender el activismo y el otro en cuanto a los espacios de comunicación. Buena parte de la investigación sobre activismo y movimientos sociales se concentra en las experiencias de protesta y, sobre todo en los años recientes, en las movilizaciones globales post2010. En este trabajo se optó por desplazar la mirada hacia grupos activistas locales basados en proyectos permanentes, que buscan el cambio social mediante acciones cotidianas, orientadas a mediano y largo plazo. Asimismo, se aprecia una tendencia a estudiar el vínculo entre las movilizaciones presenciales y sus estrategias digitales, es decir, a considerar la calle y la red como espacios clave. En esta investigación se optó por abrir la mirada e incluir a los medios de comunicación junto con estos espacios, debido a que los medios de comunicación siguen siendo relevantes, sobre todo en países como los nuestros, donde el acceso a la radio y la televisión sigue siendo mayor que el acceso a internet. Se asumió así que la explicación sobre lo que ocurre en internet no se limita a internet, sino que incluye otros espacios de comunicación.

Había entonces que construir un marco teórico que permitiera comprender las prácticas de comunicación en el activismo contemporáneo. Se optó por establecer un diálogo interdisciplinario entre los estudios de comunicación desde una perspectiva sociocultural, la sociología de los movimientos sociales y la filosofía política.

Desde la perspectiva sociocultural, la comunicación se entiende como un proceso de producción de sentido, que implica la relación entre sujetos y la búsqueda de trascender el contacto para avanzar hacia la comprensión, en un contexto concreto (Fuentes Navarro y Luna Cortés, 1984; Grimson, 2014; Martín-Barbero, 2008).

La discusión sobre el espacio público se planteó a partir de los conceptos de conflicto y reconocimiento. Las sociedades democráticas contemporáneas, cada vez más diversas, pueden ser entendidas como espacios de conflicto, en tanto que en ellas se encuentran distintas visiones del mundo, que eventualmente se 
oponen y plantean desacuerdos (Benasayag y Del Rey, 2007). Lo público se entiende como la lucha por el reconocimiento de la diferencia, en contextos de desigualdad (Fraser, 2008; Honneth, 2011).

En la búsqueda de reconocimiento, los activistas ponen en juego su imaginación política y construyen redes con distintos niveles de alcance, local y global (Khasnabish, 2007; Pleyers y Glasius, 2013; Reguillo, 2013). Los movimientos sociales contemporáneos se caracterizan tanto por la defensa de causas concretas como por la conexión entre diferentes causas (Pleyers \& Glasius, 2013). En esta lógica, la tecnología no es solamente una herramienta, sino un espacio donde es posible transformar las lógicas dominantes de la comunicación, un espacio de disputa por la producción de sentido (Cardon, 2011; Escobar, 2009; Lievrouw, 2011; Milan, 2013).

Metodológicamente, la investigación tuvo un enfoque etnográfico (Guber, 2001; Hammersley \& Atkinson, 1994), orientado a recuperar la voz de los actores. Se combinaron dos tradiciones: las etnografías de internet y las etnografías de la participación. Las etnografías de/en/sobre internet (Hine, 2004, 2015) se concentran en la comprensión de las prácticas que realizan los sujetos a través y en torno a las tecnologías digitales. Las etnografías de la participación (Cefaï et al, 2012) se concentran en las prácticas políticas de los sujetos en contextos concretos.

Además, dado que en la perspectiva sociocultural se enfatiza el carácter relacional y contextual de las prácticas, se asumió que las prácticas de expresión pública en internet implican contextos concretos de producción y re vinculan tanto con la acción presencial como con los medios tradicionales de comunicación. Por esta razón, la estrategia metodológica de esta investigación incluyó tres espacios de comunicación: la red, la calle y los medios.

El trabajo de campo se realizó durante el año 2013. Se emplearon diferentes técnicas de recopilación de información: para la red, etnografía virtual en los espacios de los grupos en internet; para la calle, observación participante en las actividades presenciales de los grupos y entrevistas semi-estructuradas con activistas; para los medios, monitoreo de la cobertura mediática local. La fase de análisis 
se operó también en una lógica etnográfica, es decir, se revisaron los datos y se extrajeron de ellos las categorías, para recuperar la voz de los actores (Roulston, 2014; Thompson, 2002).

Para la selección de los casos se revisaron grupos activistas con sede en Aguascalientes y con actividad en internet. Se identificaron las causas defendidas, las formas de operación y la actividad en redes sociales virtuales. Los dos grupos abordados, Amigos Pro Animal y Libros Vagabundos, se identificaron como casos relevantes por sus perfiles, por su uso de las redes y por la notoriedad que estaban ganando en aquel momento a través de éstas.

Amigos Pro Animal es una asociación civil orientada a la protección de los animales. Se integra por alrededor de 40 activistas, cuya edad promedio era -en el momento del estudio- de 25 años. Cuenta con filiales en otras dos ciudades mexicanas. Su presencia en internet es muy amplia: sitio web, varias páginas en Facebook, Twitter, Instagram, YouTube y Google Plus.

Libros Vagabundos es un colectivo independiente que trabaja en la promoción de la lectura y las actividades culturales, como vía para el cambio social. Participan alrededor de 20 activistas en la ciudad sede, cuya edad promedio era de 19 años. El proyecto se extendió a más de 30 ciudades en seis países (México, Guatemala, Honduras, Ecuador, Perú y Colombia), mediante la réplica del modelo. Tiene presencia en internet, en Facebook, Twitter y YouTube.

Los dos grupos nacieron en Aguascalientes, México. Se trata de una ciudad caracterizada por la tensión entre la tradición y la modernidad. Social, cultural y políticamente, hay mucha resistencia al cambio. Sin embargo, económicamente, los proyectos gubernamentales de las cuatro décadas más recientes han estado orientados al fomento de la inversión extranjera, principalmente en la industria automotriz, con el fin de insertarse en las lógicas globales. En Aguascalientes, el 63.3\% de la población tiene acceso a internet, eso lo sitúa por encima de la media nacional, que es de 57.4\% (INEGI, 2015). En términos de participación, sólo el $60.6 \%$ de la población de Aguascalientes en condiciones de votar participó en las elecciones federales más recientes, frente a una media nacional de 63.2\% (Instituto Federal Electoral/El Colegio de México, 2014); asimismo, sólo el 9.0\% de los 
habitantes de Aguascalientes suele participar en organizaciones -académicas, políticas, empresariales, religiosas, sindicales, entre otras-, frente al 9.1\% que es la media nacional (Secretaría de Gobernación, 2012).

Los hallazgos permiten entender la expresión pública de los activistas en internet, como una configuración que incluye tres elementos: la identidad, la estética y las relaciones. Los activistas construyen sus identidades como un ejercicio de una ciudadanía activa, que interviene sobre los problemas para transformar su realidad social. Esto se produce en varios niveles: personal, de grupo, de causa (por ejemplo, ambientalistas, feministas) y activista en un sentido amplio. La expresión pública de estos activistas en internet se produce a partir de una estética de la imaginación, donde la crítica del mundo contemporáneo es el punto de partida para transitar hacia el mundo mejor imaginado. Finalmente, hay una serie de relaciones que se establecen entre activistas, local y globalmente y que se conforman a su vez -como se verá en los siguientes apartados- por espacios, redes y conexiones (Flores-Márquez, 2015b).

\section{La red, la calle y los medios: los espacios de la expresión pública}

La red, la calle y los medios pueden entenderse como espacios de comunicación. El espacio no es algo fijo, sino algo en permanente construcción. El espacio social se entiende como una trama de relaciones en la cual los agentes o grupos se distribuyen en función de su posición, esta última asociada a distintos tipos de capitales (Bourdieu, 1997). Son las prácticas, los movimientos y operaciones de los sujetos los que dan forma al espacio (De Certeau, 1996).

Internet, en tanto espacio, adquiere diferentes sentidos para los activistas. Se trata principalmente de un espacio de autorepresentación, de un espacio de relación y de una vía de acceso a la construcción de lo público.

Los activistas perciben a internet como un espacio libre, horizontal y democrático, en el que es posible otra comunicación. Se trata de su espacio de auto-representación, es decir, aquel donde son ellos 
mismos los que se expresan libremente, sin la presencia de intermediarios, gestores o censores.

Se trata de un espacio de relación, porque mediante internet han conocido a otros sujetos con las mismas inquietudes que ellos, en su ciudad, pero también en otras ciudades del mundo. Por ese motivo, consideran que las redes son el corazón de sus grupos.

Yo creo que Facebook e internet... para los Libros Vagabundos es

“... un brazo muy amplio con el cual podemos abarcar o llegar a mucho más y, obviamente, también una parte importante, yo diría que forma parte del corazón, porque, obviamente, mientras no conozcamos a nuestros compañeros y mientras no tengamos la capacidad de reunirnos por lo menos una vez al año para discutir hacia dónde va el proyecto a nivel internacional, pues sigue siendo Facebook nuestra forma de ponernos de acuerdo, de relacionarnos y de desarrollar nuevas ideas para nutrir el proyecto" (testimonio, activista de Libros Vagabundos, 20 de octubre de 2013).

Libros Vagabundos ha logrado extenderse como proyecto a varios países, a partir de la comunicación en internet. Amigos Pro Animal ha establecido relaciones con otros grupos en México, Estados Unidos, Canadá e Italia, también a través de internet.

Para los grupos activistas locales, el acceso a internet es su puerta de acceso a la expresión pública. Con frecuencia, los medios tradicionales dejan fuera de cobertura asuntos que para los activistas resultan fundamentales. Internet es el espacio donde estos activistas colocan asuntos en la agenda pública y luchan por el reconocimiento de sus preocupaciones de sus visiones del mundo.

Sin embargo, ganar la red no significa perder la calle (Flores-Márquez, 2015a). Para estos activistas, el espacio público urbano es muy importante. Buena parte de sus actividades cotidianas se realizan en calles y plazas públicas, así como en centros comerciales, cafés y escuelas. El espacio urbano adquiere también distintos sentidos: como espacio de encuentro, como espacio común y como espacio de transformación. 
Los activistas entienden la calle como un espacio de encuentro, es decir, como un espacio donde está la gente. Por esa razón buscan ir a encontrarla y para ello se desplazan de unos lugares hacia otros: Amigos Pro Animal lleva los animales en adopción al encuentro de posibles adoptantes en plazas públicas y centros comerciales, lo cual implica un desplazamiento de espacios más restringidos - como las tiendas de mascotas - hacia otros más libres. De igual manera, Libros Vagabundos lleva libros a la calle y las plazas públicas, de modo que hay un desplazamiento desde las librerías y bibliotecas, cuya limitante son los recursos económicos y/o el acceso, hacia espacios de libre tránsito.

En ese sentido, la calle adquiere también el sentido de espacio común, es decir, un espacio que pertenece a todos como ciudadanos y donde deberían estar presentes todos. Los activistas desarrollan actividades, como jornadas y caminatas, en el espacio público urbano. Se trata de una manera de hacer presencia, volverse visibles en la ciudad y asumir la responsabilidad de intervenir para transformarla. Los grupos abordados ocupan cotidianamente espacios de la ciudad, pero lo hacen con los permisos correspondientes por parte de las autoridades municipales. Esto responde al carácter permanente de sus acciones, a la búsqueda de establecer relaciones de colaboración más que de confrontación y, sobre todo, al contexto político-cultural local.

La calle adquiere también un sentido de espacio de transformación. En sus actividades presenciales permanentes, los activistas vuelven realidad aquello que sueñan sobre un mundo mejor. En otras palabras, identifican una problemática que, desde su percepción, no ha sido atendida adecuadamente e intervienen sobre ella. Esto implica trascender la crítica y ejercer una ciudadanía activa que asume responsabilidades en áreas descuidadas por el Estado.

Por otro lado, la red no borra los medios. En los países latinoamericanos, el acceso a internet es relativamente bajo aún, mientras que el acceso a la televisión abierta es muy alto. La principal fuente de información para grandes segmentos de la población no es internet, sino los grandes conglomerados mediáticos. Los grupos activistas buscan tener cobertura en los medios locales, porque eso les permite ser ganar visibilidad en la ciudad. Sin embargo, esta cobertura 
es baja, los grupos de la sociedad civil son tratados como actores secundarios y no gozan de una cobertura constante.

Hay relaciones permanentes entre los tres espacios. Entre la red y la calle, el vínculo se hace evidente cuando los activistas dan información sobre sí mismos, sus sueños y proyectos, e invitan a participar en sus actividades presenciales. Estas actividades suelen ser documentadas para ser difundidas posteriormente, o incluso en tiempo real. Entre la calle y los medios, el vínculo se aprecia en la búsqueda de los activistas por lograr que haya cobertura mediática de sus actividades presenciales. Entre los medios y la red, el vínculo es clave, porque mediante las redes difunden las notas en las cuales han sido cubiertos, además de que en ocasiones algunas publicaciones hechas en sus redes digitales jalan la atención mediática hacia ellas.

Los tres espacios - la red, la calle y los medios - son entendidos como espacios de relaciones. La formación de redes y la búsqueda de visibilidad son elementos clave de las relaciones, como se verá en el siguiente apartado.

\section{Redes, relaciones y visibilidad}

Las interacciones digitales dejan rastro y pueden ser visualizadas, mediante publicaciones, likes, comentarios, entre otros. Estas interacciones cotidianas sostienen y visibilizan el carácter reticular en los entornos digitales.

En un sentido amplio, se entiende por red "un conjunto de nodos interconectados" (Castells, 2001, p. 506), cuya característica es una estructura abierta. Se habla de redes sociales cuando tal interconexión se produce entre individuos, de modo que cada uno "es un 'nodo' que tiene 'enlaces' sociales (canales de comunicación y vínculos sociales) con otros individuos" (Rheingold, 2004, p. 196). Se habla de redes sociodigitales cuando esta interconexión entre sujetos, es decir, esta formación de redes sociales se produce sobre la base tecnológica de las redes digitales (Trejo Delarbre, 2015; Winocur Iparraguirre \& Sánchez Martínez, 2015).

Los activistas se integran en redes en diferentes lógicas: dentro del grupo, en la ciudad y en el mundo. 
Hacia el interior de sus grupos, los activistas forman redes en las que están en contacto permanente, mediante grupos en Whatsapp o grupos secretos en Facebook, para organizar sus actividades, intercambiar experiencias, tomar decisiones y también para socializar. El foco de estas redes está sobre la operación del propio grupo.

Hacia el exterior de sus grupos, los activistas encuentran diferentes formas de relacionarse con los otros. Establecen redes con los seguidores de sus grupos, con otros grupos activistas que operan en la misma ciudad, así como con otros actores, tales como periodistas y representantes de medios de comunicación, autoridades municipales y estatales, legisladores, asociaciones civiles, entre otros. En estas redes de relaciones, el foco de interés se sitúa en los proyectos de ciudad que se ponen en juego localmente.

También hacia el exterior, los activistas se insertan en redes que trascienden lo local y, con frecuencia, conectan las preocupaciones locales con las globales. En este sentido, los activistas se integran en redes en dos lógicas principales: forman redes de su propio grupo que se extienden hacia otras ciudades y países (por ejemplo, Libros Vagabundos Aguascalientes, Libros Vagabundos Guadalajara, Libros Vagabundos Medellín), o bien se insertan en redes de relaciones con otros grupos que trabajan por causas similares en otros lados (por ejemplo, Amigos Pro Animal, Animal Experience, Human Society International).

En el estudio se detectó que Amigos Pro Animal tiende a mantener su propia red compacta y a mantener gran cantidad de seguidores en sus redes, principalmente en Facebook. En marzo de 2013 - cuando comenzó el trabajo de campo - el grupo registraba más de 22 mil seguidores. Al cierre de este capítulo, en diciembre de 2016, el grupo contaba con casi 708 mil seguidores.

Por su parte, Libros Vagabundos tiende a mantener una red más extensa, con réplicas de su proyecto en más de 30 ciudades en seis países latinoamericanos, aunque con un menor número de seguidores. En marzo de 2013 contaban con poco más de mil seguidores en Facebook. En diciembre de 2016 habían rebasado ya los 13 mil seguidores. 
Se trata de distintas lógicas de relaciones, integración de redes, así como de visibilidad. En los dos casos abordados, el aumento en los niveles de visibilidad puede atribuirse a la articulación de coyunturas locales y de la viralidad de los contenidos. Esta construcción de redes puede explicarse por una serie de conexiones que dan sentido a las relaciones establecidas por los activistas, como se verá en el apartado siguiente.

\section{Conexiones}

Las relaciones que establecen los grupos activistas entre sí y con otros pueden ser entendidas a partir de cuatro conexiones más amplias: la juventud, la tecnología, el riesgo y la globalización.

La juventud es una conexión en dos sentidos. Los activistas son jóvenes por edad: en Amigos Pro Animal la edad promedio era de 25 años, mientras que en Libros Vagabundos era de 19 años. Sus edades están relacionadas con las preocupaciones que expresan sobre problemas sociales específicos. Los activistas son jóvenes también por trayectoria: Amigos Pro Animal se integró en 2009, mientras que Libros Vagabundos lo hizo en 2012, es decir, ninguno de los dos grupos supera los 10 años de trabajo.

La tecnología es una conexión importante en el establecimiento de relaciones de los activistas. Ésta se relaciona con la juventud, en tanto que los jóvenes activistas han crecido con internet. En este sentido, tener presencia en las redes no se asume como una estrategia de difusión, sino como algo que se ha naturalizado en su vida cotidiana: si todo el mundo está en internet, ahí es donde hay que estar. Las tecnologías digitales potencian las posibilidades de alcance y visibilidad de los grupos. No se trata, entonces, de la tecnología por sí misma, sino del modo en que ésta se ha incorporado en la vida social.

El riesgo es también una conexión. Los jóvenes activistas visualizan los riesgos de una catástrofe ecológica y humanitaria si no se interviene a tiempo. Su conformación como grupos y sus proyectos son apuestas por acciones concretas que contribuyan a enfrentar los riesgos. Muchas de estas opciones son críticas frente a los modelos dominantes de desarrollo basados en la explotación. En tales modelos, los animales y los libros -que concentran la atención de 
estos activistas-, pero también otros elementos de la vida social han sido reducidos a mercancías. La propuesta de los activistas es desmercantilizar.

Finalmente, la globalización es una conexión. Se identifica entre estas generaciones de activistas la formación de una conciencia global. Mediante las redes, los activistas comparten sus preocupaciones por las problemáticas locales y conocen otras. Entienden que se trata de preocupaciones compartidas con otros activistas de otras localidades y las identifican como problemáticas globales. Para ellos, no hay separación entre lo local y lo global. Las acciones pequeñas, realizadas cotidianamente en contextos locales, contribuyen a la transformación del mundo.

\section{Conclusiones}

El estudio de la expresión pública de los activistas en internet permite comprender las implicaciones del acceso de actores no institucionales a la expresión pública. En términos de espacios, los activistas entienden a internet como un espacio de auto-representación, relación y de intervención en los asuntos públicos. La red está profundamente relacionada con la calle y los medios. Se trata de una lucha por el reconocimiento de visiones del mundo diferentes a las dominantes.

Mediante internet, los activistas establecen relaciones, integran redes y alcanzan ciertos niveles de visibilidad, a partir de lógicas diversas. Estas redes permiten comprender la emergencia de un nuevo tipo de actor político. Sin embargo, el acceso a internet por sí mismo no explica la participación política de los jóvenes. La juventud, la tecnología, el riesgo y la globalización, operan como conexiones que permiten comprender cómo se asumen los jóvenes como activistas y cómo se integran en redes.

Para los activistas, "las redes son el corazón", ya que las redes digitales presentan posibilidades que ellos han explorado y aprovechado para relacionarse, volverse visibles, intervenir en la discusión sobre los asuntos públicos. En otras palabras, han construido redes sociales muy amplias en las redes digitales. La dimensión relacional es un elemento clave para comprender la 
expresión pública de los activistas en internet, pero a la vez lo es para comprender la comunicación en internet y, en un sentido más amplio, el modo en que nos construimos como sociedad.

\section{Referencias}

Benasayag, M. \& Del Rey, A. (2007). Éloge du conflit. París: Éditions La Découverte.

Bourdieu, P. (1997). Razones prácticas. Sobre la teoría de la acción. Barcelona: Anagrama.

Cardon, D. (2011). La démocratie internet. Promesses et limites. Paris: La Republique des Idees / Seuil.

Castells, M. (2001). La era de la información: economía, sociedad y cultura. Volumen I: La sociedad red. México: Siglo XXI Editores.

Cefaï, D., Carrel, M., Talpin, J., Eliasoph, N. \& Lichterman, P. (2012). Ethnographies de la participation. Participations, 3(4), 7-48.

De Certeau, M. (1996). La invención de lo cotidiano 1: Artes de hacer. México: UIA / ITESO.

Escobar, A. (2009). Other worlds are (already) possible: Selforganisation, complexity, and post-capitalist cultures. En J. Sen \& P. Waterman, World Social Forum. Challenging empires (págs. 393-404). Montréal: Black Rose Books.

Flores-Márquez, D. (2015a). Ganar la red no significa perder la calle:

Activismo y comunicación en la red, la calle y los medios. Media \& Jornalismo, Revista do Centro de Investigação Media e Jornalismo, número especial, pp. 167-178.

Flores-Márquez, D. (2015b). Imaginar un mundo mejor: La expresión pública de los activistas en internet (tesis doctoral). Instituto Tecnológico y de Estudios Superiores de Occidente, México.

Fraser, N. (2008). La justicia social en la era de la política de identidad: redistribución, reconocimiento y participación. Revista de Trabajo, 6, 83-99.

Fuentes Navarro, R. \& Luna Cortés, C. (1984). La comunicación como fenómeno sociocultural. En Fernández Christlieb, F. \& Yépez Hernández, M. (comp.). Comunicación y teoría social (pp. 97108). México: UNAM.

Grimson, A. (2014). Comunicación y configuraciones culturales. Versión, Estudios de Comunicación y Política, 34, 116-125. 
Guber, R. (2001). La etnografía. Método, campo y reflexividad. Bogotá: Grupo Editorial Norma.

Hammersley, M. \& Atkinson, P. (1994). Etnografía. Métodos de investigación. Madrid: Espasa.

Hine, C. (2004). Etnografia virtual. Barcelona: UOC.

Hine, C. (2015). Ethnography for the internet. Embedded, embodied and everyday. London / New York: Bloomsbury Academic.

Honneth, A. (2011). La sociedad del desprecio. Madrid: Editorial Trotta.

INEGI, Instituto Nacional de Estadística y Geografía (2014). Usuarios de las tecnologias de información por entidad federativa, 2014.

Recuperado de Módulo sobre Disponibilidad y Uso de de las Tecnologías de la Información en los Hogares:

http:/ / www3.inegi.org. $\mathrm{mx} /$ sistemas/sisept/default.aspx?t=tinf $239 \& \mathrm{~s}=\mathrm{est} \& \mathrm{c}=26487$

Instituto Federal Electoral / El Colegio de México (2014). Informe País sobre la Calidad de la Ciudadanía en México. México: Instituto Federal Electoral.

Khasnabish, A. (2007). Insurgent imaginations. Ephemera. Theory \& politics in organization, 7(4), 505-525.

Lievrouw, L.A. (2011). Alternative and activist new media. Digital media and society series. Malden: Polity.

Martín-Barbero, J. (2008). Lo público: Experiencia urbana y metáfora ciudadana. Cuadernos de Información y Comunicación, 13, 213-226.

Milan, S. (2013). Social movements and their technologies. Wiring social change. London: Palgrave Macmillan.

Pleyers, G. (2010). Alter-globalization. Becoming actors in the global age. Cambridge: Polity Press.

Pleyers, G. \& Glasius, M. (2013). La résonance des "mouvements des places": Connexiones, émotions, valeurs. Socio, 2, 59-79.

Reguillo, R. (2013). Disidencia: Frente al desorden de las cajas abiertas - México, breve y precario mapa de lo imposible. Emisférica, 10(2).

Rheingold, H. (2004). Multitudes inteligentes. La próxima revolución social. Barcelona: Gedisa.

Roulston, K. (2014). Analysing interviews. En U. Flick, The SAGE bandbook of qualitative data analysis (págs. 297-312). London: SAGE. 
Secretaría de Gobernación (2012). Encuesta Nacional sobre Cultura

Política y Prácticas Ciudadanas 2012. Recuperado de ENCUP:

http://www.encup.gob.mx/es/Encup/Bases_de_datos_2012

Thompson, J. B. (2002). Ideología y cultura moderna. Teoría crítica social en la era de la comunicación de masas. México: UAM Xochimilco.

Touraine, A. (2006). Los movimientos sociales. Revista Colombiana de Sociología, 27, 255-278.

Trejo Delarbre, R. (2015). México enredado. Auge, ligereza y

limitaciones en el uso político de las redes sociodigitales. En

Winocur Iparraguirre, R. \& Sánchez Martínez, J.A. (coord.).

Redes sociodigitales en México (pp. 17-39). México: Fondo de

Cultura Económica / CONACULTA.

Winocur Iparraguirre, R. \& Sánchez Martínez, J.A. (2015).

Introducción. En Winocur Iparraguirre, R. \& Sánchez Martínez, J.A. (coord.). Redes sociodigitales en México (pp. 9-15). México:

Fondo de Cultura Económica / CONACULTA. 


\section{La realidad sociodigitalizada. Participación ciudadana, redes sociales y medios masivos de comunicación en Córdoba, Argentina ${ }^{12}$}

Malvina Eugenia Rodríguez. Universidadad Nacional de Villa María (Argentina).malvirodriguez@gmail.com

Elizabeth Beatriz Theiler. Universidad Nacional de Villa María (Argentina). elitheiler@,hotmail.com

\section{Introducción}

L

OS DISCURSOS mediáticos, hasta el momento con reconocida se reconfiguran con los mensajes de los entornos virtuales y las realidades múltiples resultan fenómenos sociales a partir de los cuales se pueden observar las formas que adopta la recurrente disputa por la nominación del mundo social, su ordenamiento y sus posibilidades de transformación.

\footnotetext{
${ }^{12}$ Las autoras de este trabajo agradecen a la Universidad Nacional de Villa María, que subsidió la investigación base de esta ponencia: "Construcción de la realidad social desde la participación ciudadana en entornos virtuales y desde los discursos mediáticos en la provincia de Córdoba, Argentina (2013-2015)", y al personal de Insituto A.P. de Ciencias Sociales, donde se radicó el proyecto, dirigido y codirigido por las autoras. A los integrantes del equipo docente: Adrián Romero, René Rodríguez, Carla Achilli, Paula Navarro, Mariana Corradini, Rodrigo Duarte; egresados: Emanuel Barrera, Cecilia López, Carolina Fissore y Marianela Zan; estudiantes: Julieta Vázquez, Mariana Ruiz, Carina Lacey, Nuria Medrano, Rocío Álvarez, María Inés Solans y Giuliano Sangiorgio.
} 
En tal sentido, la investigación analizó la construcción de realidad social desde la participación ciudadana en nuevos entornos virtuales y su rol atribuido en los discursos mediáticos en la provincia de Córdoba, Argentina entre 2013 y 2015, tomando como casos de estudio las localidades de Córdoba Capital, San Francisco y Villa María. En el proceso de dos años de trabajo se lograron identificar, sistematizar y describir analíticamente nuevas formas de comunicación y participación ciudadana que implican la construcción de realidades socio-digitalizadas, es decir, la configuración del espacio público a partir de la publicidad que adquieren discursos privados, individuales o grupales a través de las redes sociales y de entornos de virtualidad, en tanto la cobertura mediática participa reconstruyendo dichos entornos y por ende, los canales de participación ciudadana en el espacio público.

Para ello es necesario indagar qué descripción de realidad hacen los medios masivos y cómo producen esa realidad. Siguiendo a Niklas Luhmann (2000), estas indagaciones conducen a un interrogante que, como filosofía de la sociedad de la información, se plantea: ¿Qué tipo de sociedad es ésta, que permanentemente se informa sobre sí misma? Las hipótesis de partida pueden sintetizarse de la siguiente manera:

a. La complejidad de los canales de participación ciudadana se incrementa exponencialmente con el devenir de los nuevos entornos virtuales y sus múltiples utilizaciones. Los nuevos canales configuran un mapa conflictivo de hipervinculación que acerca al ciudadano común la posibilidad de instalación de temas en la agenda pública. Los canales más significativos por su grado y velocidad en el impacto del mensaje comunicado son las redes sociales, blogs, sitios webs, entre otros, con capacidad de construir significado en diferentes grupos sociales, incorporando un sello identitario de expansión privilegiada respecto de los medios tradicionales.

b. Los medios configuran una realidad antagónica y paralela sobre la participación ciudadana en entornos virtuales, contribuyendo a la construcción de escenarios complejos donde conviven realidades múltiples. 
c. Los nuevos entornos virtuales y los medios tradicionales se retroalimentan en la construcción de agendas y discursos, configurando una realidad social múltiple y muchas veces antagónica con versiones de realidad en connivencia o competencia.

El proyecto implicó la aplicación de un diseño cuali-cuantitativo que combinó:

a) Análisis de contenido de base cuantitativa del programa "Cara y Cruz" de Radio Universidad, del programa "Radioinforme 3" de la emisora Cadena 3, ambas con sede central en la ciudad de Córdoba y del programa "Mirate Segunda Edición" del canal Mirate de Villa María.

b) Análisis de discurso del diario La Voz de San Justo, de San Francisco.

Para el análisis de contenido se trabajó con un sistema de categorías de base única para medios radiales y televisivos. Luego de revisar el corpus registrado se seleccionaron tres grandes temáticas para orientar el trabajo de campo: las elecciones 2015, la situación económica general y la violencia contra la mujer, todos de alta significación social. Si bien la investigación analiza la construcción de actualidad desde 2013 para la definición de temáticas, se trabajó sobre corpus registrados en un período menor: desde el 1 de octubre de 2014 al 15 de agosto de 2015 para el análisis de contenido; desde octubre 2014 a junio de 2015 para el análisis de discurso.

\section{Marco conceptual}

Aquello que llamamos actualidad, y que provoca entre los sujetos comentarios o fundamenta decisiones, es el producto final de la industria de la información. Mediante ese proceso industrial los MCM producen realidad social compuesta por hechos que no existen como hechos sociales antes de que los medios informativos los construyan (Verón, 1987). Paralelamente, los nuevos entornos virtuales se convierten en canales de producción y distribución de discursos tanto de políticos como de ciudadanos que cooperan, compiten o entran en colusión con los discursos de los MCM (Muraro, 1997), 
contribuyendo a una construcción compleja de realidad social digitalizada.

Partiendo de la idea de que existen varias "realidades", los MCM se ven en la necesidad de duplicarlas en función de su interés. Como sostiene Luhmann (2000) esta duplicidad se logra en la referencia a sí mismo (autorreferencia). Según este autor, este proceso se da bajo dos cogniciones: en la constitución de un sistema que se reproduce así mismo y donde el sistema observa cuándo es capaz de distinguir entre autoreferencia y heteroreferencia.

Los MCM producen y reproducen un conocimiento del mundo que termina siendo un referente para todos porque las descripciones directas que se hacen del mundo en los medios, en conjunto con las descripciones indirectas que presentan en su publicidad y su entretenimiento, comunican una realidad que sin proponérselo nos lleva a un horizonte de incertidumbre, que se alimenta de rupturas.

Asimismo, la construcción y reconstrucción de "realidad social" se dinamiza por la participación de los actores en el espacio público político (políticos, periodistas y ciudadanos) en un contexto de configuración autónoma (no necesariamente independiente pero tampoco de respuesta masiva) de los discursos, en un complejo espacio de interacción en redes que reconfiguran realidades "sociodigitalizadas".

A partir de la concepción constructivista, este proyecto se propuso analizar la participación ciudadana en nuevos entornos de virtualidad y el discurso mediático en la (re)construcción de realidad social. En este contexto, la participación ciudadana está directamente relacionada al modelo de democracia y, a la clase de vínculo que se quiere construir entre gobierno y sociedad civil. Esta concepción surge de pensar la democracia desde una perspectiva de generación de espacios de reflexión, deliberación y conocimiento que permitan el reconocimiento de limitaciones del accionar del gobierno y la intervención de la ciudadanía en los asuntos públicos (Subirats, 2001).

En términos de Cunill Grau (1999), la participación ciudadana ha sido definida como "la intervención de la sociedad civil en la esfera de lo público". Actualmente, este nuevo espacio público es tan distinto a 
las estructuras y dinámicas de los espacios públicos anteriores que existe un espacio público antes y después de las TIC. A través de ellas se modifican las reglas de la interacción social tradicional produciéndose nuevas formas de socialización y de participación virtual, tanto individual como grupal y con impacto tanto en los mismos entornos virtuales como en los espacios no virtuales.

En la era de la información (Castells, 2001) se debate la movilización de la sociedad a través del poder de las redes sociales y si se configuran como instrumentos para motivar la participación. Según Castells, las sociedades cambian a través del conflicto y se gestionan mediante la política. Así, la comunicación mediada por TIC, se está convirtiendo en un medio esencial de comunicación y organización en todos los ámbitos de la actividad. Los movimientos sociales y los agentes políticos lo utilizan transformándolo en una herramienta privilegiada para actuar, reclutar, organizar, informar, etc. En este panorama, el ciberespacio se está convirtiendo en un terreno en disputa.

Esto nos lleva a reflexionar sobre las formas de construcción de realidad que - para la opinión pública - suele presentarse como "información" por parte de los MCM. Asimismo, alienta el análisis de los contenidos que circulan en las redes sociales y que adquieren cada vez mayor importancia en la dinámica de construcción de agenda temática percibida como "realidad" por la opinión pública.

\section{Análisis y discusión}

En cuanto al reconocimiento de los canales de participación ciudadana en el proceso de construcción de la realidad en nuevos entornos virtuales, observamos en esta investigación que los medios habilitan espacios de participación fundamentalmente a través de la entrevista telefónica o grabada, en el caso de los programas radiales y televisivos, o de la particular conformación del contrato de lectura en el caso del medio gráfico. Las TIC se encuentran presentes como canal y fuente en las nuevas formas de vinculación entre medios y audiencias. Excepto en el medio de alcance nacional (Cadena3), los medios analizados se encuentran aún en una etapa incipiente de desarrollo de las nuevas tecnologías y de su inserción en los procesos de producción de noticias con participación de los públicos. 
El canal de cable Mirate - de importante audiencia en Villa María, la tercera ciudad de la provincia de Córdoba en número de habitantes y su principal informativo, no realizan un uso intensivo de las redes sociales, a pesar de disponer de las mismas y contar con importantes números de seguidores. Sin embargo, la ciudadanía se hace presente fundamentalmente a través de las consultas y entrevistas realizadas por noteros que pertenecen al equipo del programa analizado. El programa adquiere, especialmente en un año electoral, un lugar preponderante en la formación de la agenda política. El manejo de las fuentes es claramente local, aún para el abordaje de temas provinciales y nacionales. La participación de la audiencia no ofrece indicadores de debates y controversias.

En cuanto a los programas radiales se puede afirmar que poseen dos tipos de diferencias, la primera y determinante para la caracterización de su audiencia, es el posicionamiento ideológico. En el caso de Radioinforme 3 de Cadena3, podría identificarse más afín al gobierno provincial y con clara oposición al gobierno nacional kirchnerista. Por el contrario, el programa Cara y Cruz de Radio Universidad es afín al kirchnerismo y crítico del gobierno provincial.

Esto se evidencia en el tratamiento de los temas, en el tenor y nivel de controversia. No obstante, los periodistas de Radioinforme 3 intentan demostrar la aparente independencia del medio, y fundamentalmente del programa, a intereses partidarios y su apertura a la pluralidad de voces. Es decir, pervive la idea del rol neutral de los MCM como garantizador de la manifestación de todas las voces.

En el caso del medio gráfico, quedó expuesto que en correspondencia con los valores a partir de los cuales el diario analizado produce un discurso de la información podemos inferir que la prioridad y exclusividad en el ejercicio de reproducción de las voces social e institucionalmente legitimadas opera como el cierre de un circuito semántico desde el cual La Voz de San Justo propone a sus lectores un modo de conocer y comprender la realidad local/regional a partir de la cual pensar y actuar. Es decir, es el medio el que - en cierta manera - construye la visibilidad de las voces ciudadanas a partir del acuerdo tácito establecido en su contrato de lectura con la ciudadanía. 
$\mathrm{Al}$ intentar revelar el rol atribuido a la participación ciudadana en los discursos mediáticos sobre hechos de alta significación social, encontramos algunas similitudes y diferencias significativas en los distintos medios.

En el caso del canal televisivo villamariense, la centralidad de las elecciones le otorga una orientación discursiva claramente hacia el tratamiento de lo político como eje de la producción de noticias. Ahora bien, las voces ciudadanas se hacen visibles a través de las entrevistas llevadas a cabo por los noteros que, no en el estudio, pero si en la calle salen a interpelar a la población en sus ámbitos cotidianos de producción y circulación de discursos. Esto genera una importante presencia del público local al cual está dirigido el programa pero a partir de la agenda instalada por el medio.

Por otra parte, la ciudadanía se hace presente en los programas radiales a través de mensajes de texto, llamadas telefónicas, entrevistas y participación desde redes sociales, especialmente en Cadena3. Si bien prima la formación de agenda mediática como disparador para la participación, la radio permite un nivel de interacción (agradecimientos al periodista o instalación de temas coyunturales como accidentes de tránsito) que dinamiza la construcción de realidad a través de la participación ciudadana.

Ahora bien, cuando nos propusimos caracterizar los orígenes, motivaciones y destinatarios de los discursos ciudadanos en entornos virtuales sobre hechos de alta significación social, comprendimos que los medios, especialmente los radiales y televisivos, no ofrecen una cobertura continua y profunda sobre los hechos que cuentan con participación y opiniones de la ciudadanía, como para realizar inferencias del contexto que enmarca esa participación. Los medios radiales y audiovisuales poseen condicionamientos propios de sus especiales prácticas de producción periodística (inmediatez, necesidad de brevedad, espectacularización y fascinación por lo novedoso, competencia entre medios que exige la continua renovación y por ende superficialidad en el tratamiento y seguimiento de la información, entre otras) que no se han modificado desde la postulación del newsmaking, sino que por el contrario - y por la particular convivencia con otros espacios de producción habilitados por las nuevas tecnologías - se han acentuado y acelerado. 


\section{Conclusiones}

La realidad y su construcción o reconstrucción a través de los medios de comunicación y nuevos entornos virtuales, comparte como sujeto de la comunicación tanto a los medios tradicionales como a los sujetos independientes en su rol de hacedores de discursos. Ambos se constituyen en espacios capaces de producir hechos significativos desde una noticia o afirmación. Sin embargo, los MCM poseen la potestad de reconocer o no a la ciudadanía y su participación en el centro de la escena o atribuirle un espacio complementario. Los MCM (re) construyen los acontecimientos y a través de sus discursos legitiman su "ideología".

La selección de la información y su organización al interior de cada MCM implica una forma particular que tiene el medio de ver el mundo y darle un orden de prioridad; a su vez, produce una visión de mundo en sus públicos configurando así un tipo determinado de destinatario. Cada medio determina cuáles son las noticias que merecen un análisis y un lugar privilegiado dentro de su diagramación; y las jerarquizan según quiénes son los actores involucrados, las fuentes de información con las que cuentan, la gravedad del hecho, entre otras.

Con el surgimiento de las tecnologías de la información y de la comunicación (TIC), los MCM amplían los criterios de elección de tema, ya que el público tiene la posibilidad de proponer o imponer temas de agenda. El modelo comunicativo de la Era de la Información contribuye a reducir la dependencia de los canales tradicionales de comunicación.

En tal sentido, nos proyectamos proponer categorías teóricoanalíticas sobre la relación entre participación ciudadana y construcción social de la realidad en medios masivos y en nuevos entornos virtuales. Encontramos en la categoría de la "sociodigitalización" de la realidad en la actualidad, un punto de partida para comprender la compleja relación entre participación ciudadana y construcción de realidad.

Podemos afirmar, y aún reconociendo la necesidad de ampliar el trabajo de campo y el abordaje metodológico, que los medios se 
encuentran aún en posesión de la construcción de agenda, al menos de manera privilegiada. En la provincia de Córdoba, como ejemplo del interior mejor posicionado de la Argentina, el desarrollo tecnológico en y hacia los medios de comunicación masivos no ha logrado reemplazar formas anteriores de interacción ciudadana. Con lo cual, nuestra primera hipótesis no resulta completamente reconocible en los resultados de nuestro trabajo de campo.

En cuando al segundo supuesto, sí podemos observar una multiplicidad de "realidades" en las distintas configuraciones que del espacio público realizan los diferentes discursos mediáticos. El análisis de los cuatro medios ubicados en la ciudad capital y en dos de las ciudades más grandes de la provincia de Córdoba, muestran un panorama variado de selección y tratamiento de la información, independientemente de la magnitud de cada audiencia y de sus posibilidades de intervención en la producción discursiva.

En relación a la idea de retroalimentación y antagonismo entre medios tradicionales y nuevos entornos virutales de la tercera hipótesis, podemos concluir que la multiplicidad de realidades (construidas a partir de las prácticas tradicionales de los medios masivos así como las nuevas formas de sociodigitalización) se manifiestan en muchos casos antagónicas. La competencia por el decir se complejiza ante un campo que, si bien incipiente, se encamina hacia la ampliación de los canales y espacios de participación.

\section{Referencias}

Castells, M. (2001). La era de la información. Vol. II: el poder de la identidad. México: Siglo XXI.

Cunill Grau, N. (1999). "Significado de la participación ciudadana en el diseño de programas y proyectos sociales". En Alvarez Lourdes y otros (coord.) Politica social: exclusión y equidad en Venezuela durante los años noventa (pp.203-219). Caracas: nueva sociedad/cendes/ildis/fonvis.

Cheresky, I. (comp) (2006). Ciudadanía, sociedad civily participación ciudadana. Buenos Aires: Miño y Dávila.

De Moraes, D. (2010). Mutaciones de lo invisible. Comunicación y procesos culturales en la era digital. Buenos Aires: Paidós. 
Luhmann, N. (2000). La realidad de los medios de masas. Barcelona: Anthropos.

Martínez Pandiani, G. (2008). La ciberpolitica y los nuevos ciudadanos. Buenos Aires: APOC.

Menéndez, M. C. (2009). Política y medios en la era de la información. Buenos Aires: La Crujía.

Muraro, H. (2000). Políticos, periodistas y ciudadanos. De la videopolitica al periodismo de investigación. Buenos Aires: FCE.

Rodríguez, M. (2013). Partidos políticos y redes sociales en Argentina. En: Diálogo Político, 1/2103 (73-99). Montevideo: KAS. Recuperado de: http://www.kas.de/uruguay/es/publications/34656/

Subirats, J. (2001). Nuevos mecanismos de participación y democracia. En: Font, J. (coord) Ciudadanos y decisiones públicas. Barcelona: Ariel.

Theiler, E. (2012). Estado y sociedad civil. La participación ciudadana en los procesos de integración latinoamericanos. Villa María: Eduvim. Verón, E. (1987). Construir el acontecimiento. Barcelona: Gedisa. 


\section{The contribution user generated image on Facebook during the National Agrarian Strike in Colombia}

María Isabel Villa Montoya. Universidad EAFIT (Colombia). mvilla@eafit.edu.co

Javier S. Bautista. Universidad Pontificia Bolivariana (Colombia). javiersneider@gmail.com

Jhon J. Herrera. Universidad de Manizales (Colombia). jihs@umanizales.edu.co

\section{Introduction}

\& VEN though the symbiosis between the radio and social 1 networking is still at early stages, «these platforms offer an additional benefit to the traditional radio, increasing the participation venues of the listeners and potentiating a community atmosphere» (Peña and Pascual, 2013: 143, author's translation). As Facebook and the radio are both spaces of inter-relations, participation and communication, it is important to conduct case studies on the ways these two media intersect, inquiring into the possibility of altered discourses in convergent environments. It is necessary to carry out case studies in order to produce concrete evidence on the ways the specific affordances of a medium affect the other and vice versa. 
This qualitative study sets out to analyse how listeners - users of the public broadcaster of the Boyacá Governorate in Colombia, were able to contribute to the production of the radio news programme via their images on the Facebook Fan Page of the Boyacá News (Boyacá Noticias) programme.

The research uses as case study the coverage of the National Agrarian Strike in 2013, as given by the Boyacá news programme. It is possible to apply an inductive research approach to analyse this coverage, which can provide insights into the use of user generated images in social networks of the public news radio. While the case study is based on a particular situation, its methodological character can provide insights that might be useful to other similar research contexts.

This research initiative seeks to understand the ways in which the images posted by the audience contribute to the agenda setting of the medium. The research contributes to an established research area that examines the ways in which Facebook can become a tool for promoting participation and extend the range of options available for the public radio to not only provide an expanded space for the audiences to meet, but also allow the image to permeate the discourse of a sonorous medium in a digital context.

Concretely, the research seeks to answer the following questions: What are the main themes tackled by these images? What image formats are mostly used? and What do user generated images contribute to the agenda setting of the Boyacá Noticias programme of the 95.6FM Boyacá broadcaster of Tunja Boyacá Noticias?

\section{Values and functions of the informative image}

A research project inquiring into the value of image would appear problematic because the concept of value refers to a set of attributes such as scope, importance or contribution that can easily fall into the field of subjectivity. However, various theoretical approaches have been proposed since the inception of image studies, seeking to provide answers in regards to the contribution of images to society, departing from an open-ended question about their functions (Freund, 1976; Sontang, 1981). In journalism, the issue has been 
tackled in various ways. The informative image, according to Aparici et al. (2006) can appear as event or comment. As event, the value of the image lies in its ability to provide a series of objective information on the happening, whereas as comment its contribution is to provide information to complement, appreciate or interpret the facts. For Erausquin (1995: 9) it is necessary to distinguish the utility of the image from its mere presence. "Just through its mere presence on the pages of a newspaper, the photo constitutes a privileged attraction and a magnet that captures the eye" (author's translation). But, at the same time, according to the author, the image as comment is useful for providing further details around the event about the what, the who, the where, and its end results.

In the communication media, the value of the image has historically lied in its capacity to reveal not only what the information was about, but also reflect actions, gestures or interactions that may complement and not simply reiterate the news, bearing in mind that images can acquire different meanings, depending on interpretation.

From this perspective, an informed use of the possibilities for expression provided by the image, implies the ability to go beyond the illustration plane to analyse the event and put forward a specific point of view in regards to this aspect of reality. A quality that Baeza (2001) designated as fundamental to critically evaluating the value of photojournalism.

The image has become an important part of the communication media because it can bring about not only factual information, but also place the reader in the physical context that the event took place, startle, produce admiration, joy or enjoyment and practically always dye the events (Erasquin, 1995)

\section{Social networking and image}

It is useful to review the set of qualities or functions described in the previous paragraph within a digital context where the image has become a rising value. According to Rainie et al. (2012), 46\% of Internet users publish photos or videos that they themselves have created and $41 \%$ share photos or videos they have found on the Internet. 
However, while their social use increases, their documentary value, as evidence, in the communication media decreases given the increased possibilities for tweaking or photo alteration that easily accessible digital tools nowadays make possible (Mäenpää, 2014).

In the context of social networks, the informative image is repositioned in light of new possibilities defined by immediacy and ease in regards to reaching very broad and, at the same time, segmented audiences. The ability to disseminate large volumes of information through photographs or videos suggests that the image has become a powerful component of communication in social networks.

From an ideological point of view, the informative image has always been subject to the values of journalism as well as of the public, to serve freedom of expression, and called to respond to ethical criteria, marked by neutrality and objectivity (Mäenpää, 2014). Journalism as well as its entire content, digital or not, are thus called upon to act as guardians of power, maintaining the role of gatekeeper or watchdog of the ruling classes (Singer, 2010).

But, the Internet and social networks are changing the way in which the audience receives and shares information (Miller et to the., 2016), suggesting, in turn, that it is worth examining the values of public service that used to inspire photojournalism and the profession itself (Mäenpää; 2014).

This change has been the focus of recent studies on journalism in the digital era. It seems that social networks can imply a reduction in terms of production costs and therefore are often treated as low cost, second-order media the quality of which is not comparable to the quality of its competitors; in this case, communication media with established news websites that receive much more traffic (Ju et al., 2013).

However, there seems to be a consensus in that social networks can increase participation and thus facilitate alternative modes of expression for citizens, communities, or activists unable to reach society via other communication media (Lievrouw 2011; Kaigoa and 
Okura, 2016; Livingstone and Markham, 2008; Kümpel, Karnowski and Keyling, 2015).

In the political arena, this interaction requires more openness to dialogue between governments and society, and among the news producers and audiences (Chen, Sharma and Rao, 2016). Through social networks, citizens are transformed into producers of public services (Linders, 2012). Thus, social networks can come to shake the way civil society is configured within a digital space.

Different types of crises such as natural disasters or terrorist attacks have clearly showed that social networks are important means of communication and assistance (Andén-Papadopoulos and Pantti, 2013). In these cases, the images have become a source of priority information, overthrowing media that are stronger on the Internet, thanks to their capacity to broadcast information at high speed. In situations of crisis, specific affected groups create their own informative agenda and the media must rush to respond to these situations promptly to avoid losing their audiences (Kaigoa and Okura, 2016).

This danger has become an opportunity for those who take advantage of the participation interest to channel such content through their own sites such as Yahoo!'s You Witness News and CNN's I-Report (Liu et al.) 2008 in Mäenpää; 2014).

On these sites, informative image is reconfigured, adopts new functions and new problems arise from the coexistence of amateur and professional journalism. This gathering has led to a reconsideration of certain essential aspects in the analogue environment such as the value attributed to the technical quality of the image. Audiences are less and less demanding and accept blurred or pixelated images more easily for the sake of striking content that catches their attention because, as Penafield (2016: 168), notes «Now the citizen, along with technology, is the engine that drives communication" (author's translation). 


\section{The contribution of the image to agenda setting}

The agenda setting has been one of the key paradigms in communication studies for understanding how the different agendas (the media agenda, the political agenda and the public agenda) are presented in the themes covered and the importance they grant to each of them (Iyengar and Kinder, 1987; MacCombs and Shaw, 1972). As text content, images in the media contribute to shaping a subjective audience realm, who, without any access to many of the events, acquire a particular view around the facts through the images served to them by the media.

In view of the studies on the functions of Photojournalism, reviewed at the beginning of this text, the influence of the image on the agenda setting might seem indisputable. Nonetheless, research coined by the term visual agenda setting, is recent (Miller and Roberts, 2010). These researchers report the following as some of the most distinctive findings in this field: (1) the effects of image size in determining the level of importance that the audience attributes to the events, (2) the effect of negative picture content on the way a happening will be perceived or (3) increased visual memory due to the emotional engagement caused by negative picture content published by the media in situations of crisis.

In this line of work, research has focused on the effects of the media on the audiences, but studies on the effects of user generated images on communication media content are scarce. From an anthropological point of view, it seems clear that the images circulating through the social networks represent those who produce them. Thus, it seems reasonable to question the extent to which communication media echo this self-representation that is latent in the images posted on social networks. Mundane images stand out, highlighting the self-presentation through selfies that seek popularity and visibility through the construction of ideal imaginaries (Miller et al., 2016). All these characteristics are radically different from the principles guiding photojournalism when it was first creating its documentary ideology. 


\section{Methodology}

This investigation used the case study methodology, as pertinent to analysing complex situations that require precise approaches to concrete realities (Yin, 2009). The National Agrarian Strike in Colombia that took place from August 19 to September 9, 2013, was chosen as the focal object of investigation, a news event centred in the Boyacá municipality of Ventaquemada in the South American country. During those days, a series of events such as peasant protests and infiltrations of violent groups, triggering police and military action, which exceeded the limits of public force at times and led to abuse and violations of human rights (Restrepo, 2013).

The underlying causes of this protest revolved around the excessive costs of agro-industry, the treaties' effect on the farmers, the difficulties paying off credits and the unequal battle between the market and smuggling (Gutiérrez, 2013).

This crisis culminated in the establishment of an exclusive agrarian roundtable to discuss farmers' demands. The National Pact for Agro and Rural Development was discussed therein, which has been called the "process of a participatory structure propelled by the National Government and delivered by the territorial entities, the main actors of the agricultural sector and other organisations " aiming to reformulate the public policy on rural development' (Ministry of Agriculture, n.d.).

This event of social resistance is an opportunity to discuss traditionally conflicting issues in Colombia, closely related, among others, to the use and ownership of land, food production, breeding of livestock, birds and other animals, product commercialization and export which, even in 2016, continue to be controversial and a part of the negotiation process with the FARC.

The National Agrarian Strike motivates the radio broadcaster of the Boyacá Governorate to do a special coverage through its Boyacá Noticias programme. This radio space, launched on January 6, 2012, is a 3-hour news programme from 6:00 to 9:00 am that allows citizens to participate via telephone, email, Facebook and Twitter. 
Boyacá Noticias is known as the space where citizens can make complaints about and contributions to the different public and private practices that affect or benefit the society.

Interrupting the regular programme, Julio César Corredor Bernal, the leader of this special broadcast on the National Agrarian Strike on Boyaca Noticias, justifies it with the following sentence: "This is a transcending and crucial moment for life and for the development of the department..."

As case study, the National Agrarian Strike fuses together different analytical elements of a social reality marrying what is public, mobility, economy and social into a matter of public concern. This event presents a clear relationship between the different participating actors of political communication: citizens, politicians and media. Facebook messages and the coverage provided by the analogue broadcaster are therefore a pertinent case study for understanding the characteristics of audience participation in transcendental problems of political communication in a digital context.

The content analysis involved searching user posted images on the wall of the Boyacá Noticias Fan Page between August 25 and August 29, 2013. A total of 16 images were collected on August 25, 16 images on August 26, 13 images on August 27, 9 images on August 28 and 13 images on August 29, which summed up to an overall sample of 67 images.

These messages were collected through screenshots using the WebPage Full Page Screen Capture tool. With this tool, we were able to save a copy of a certain area or the entire navigation page in different formats such as .png, .jpg., bmp.

We tagged and saved the information obtained in chronological order, using a sequential name, which allowed us to organise a sample to review later on. Through the qualitative methodology, we were able to analyse the characteristics and relationships between the digital media contents.

In line with the research objectives, we isolated three variables: image value, type of message and formats used. 
To each variable, we assigned indicators, which emerged during an analytical process, previously carried out on the themes and issues discussed between the National Government, the farmers, and trade unions from the agricultural sector. This analysis was part of the coverage given by the Boyacá Noticias radio programme, noticing the same commentaries posted by the users on the broadcaster's Fan Page on Facebook.

The first variable, image value, sought to inform, convey feelings, promote, denounce and criticize. These indicators were not mutuallyexclusive and could overlap with the analysis of each image.

In the second variable, type of message we examined the content of the image. In this sense, we used as indicators the political, economic, social and cultural affairs, economic, social and cultural that the image depicted.

The indicator 'political' includes the images that refer to the messages of the Colombian Government regarding policies and regulations in the agricultural sector. The images that were categorized as economic illustrate economic issues related to the crisis, such as the costs of agro-industry or farmers' problems to pay off their debts. The category named 'social' includes the images that represent citizen's safety and public order. Finally, the category 'cultural' represents the artistic manifestations of the users, their life together as a community and specific regional particularities.

The third variable, namely 'formats used', included five possibilities: videos, caricatures, illustrated phrases, memes and photonews, which had emerged from the inductive analysis that took place during the corpus collection, aiming at categorizing the collected contents.

\section{Results}

\subsection{The documentary value}

The analysis of the images reveals that image on Facebook maintains the documentary value that has characterized the informative image since its conception and largely extends into the digital environment within the news context. The image is primarily a useful communicative means to unite or represent reality. These results 
contradict previous positions on referent displacement in digital image (Séguin, 2011). In the news field, at least, the indicial function of the image is maintained as a fundamental feature of journalistic content.

The analysis reveals that the images that stand out are not irrelevant to the news agenda, but enriching elements, generating new views on the Agrarian Strike media broadcast. In line with the image functions contemplated in this study, we found a predominance of images denouncing and criticizing the Government. The argumentative and expository functions of the image stand out to trigger collective awareness and mobilize public opinion. The user himself becomes the case study, not only as an informed and informing individual, but also as an interpreter who uses the image to portray his/her own point of view on the news event.

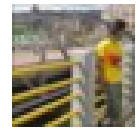

\section{Sergio Forero O > Boyacá Noticias 95.6FM}

26 de agosto de 2013 -

\section{AYER EN TUTA}

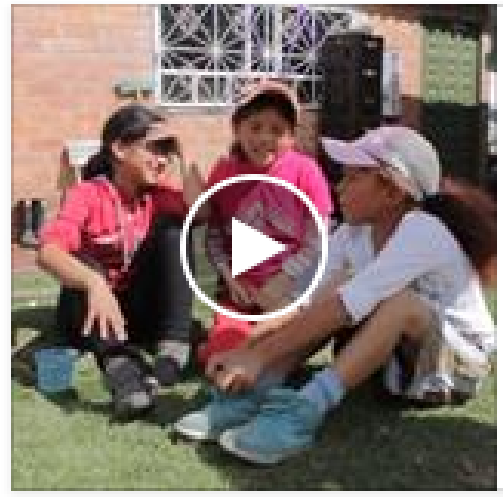

NIÑOS DE TUTA HABLAN DESPUÉS DE ABUSO POLICIAL

VIDEO DE NIÑOS EN TUTA DESPUÉS DE ENFRENTAMIENTOS EN TUTA

1 Me gusta 1 comentario

YOUTUBE.COM

\section{Me gusta}

Comentar

Compartir

Illustration 1.1 Video posted on the Boyacá Noticias Fan Page on Facebook. Facebook screenshot of Boyacá Noticias 95.6FM, August 26, 2013. 
In these images, simplicity and objectivity are put to service in order to awaken social awareness. They illustrate small events, with a limited number of actors placed in certain places that could, however, come to have a strong impact on the conflict.

\subsection{Content of genre-based images}

The analysis of the images reveals a general interest in the social aspect. While the agenda setting of the medium focuses on the political content, the user-generated images seem to be more concerned with the public order events that show the impact of the Agrarian Strike on citizens' daily life.

\section{Publicaciones de personas que visitaron la página}

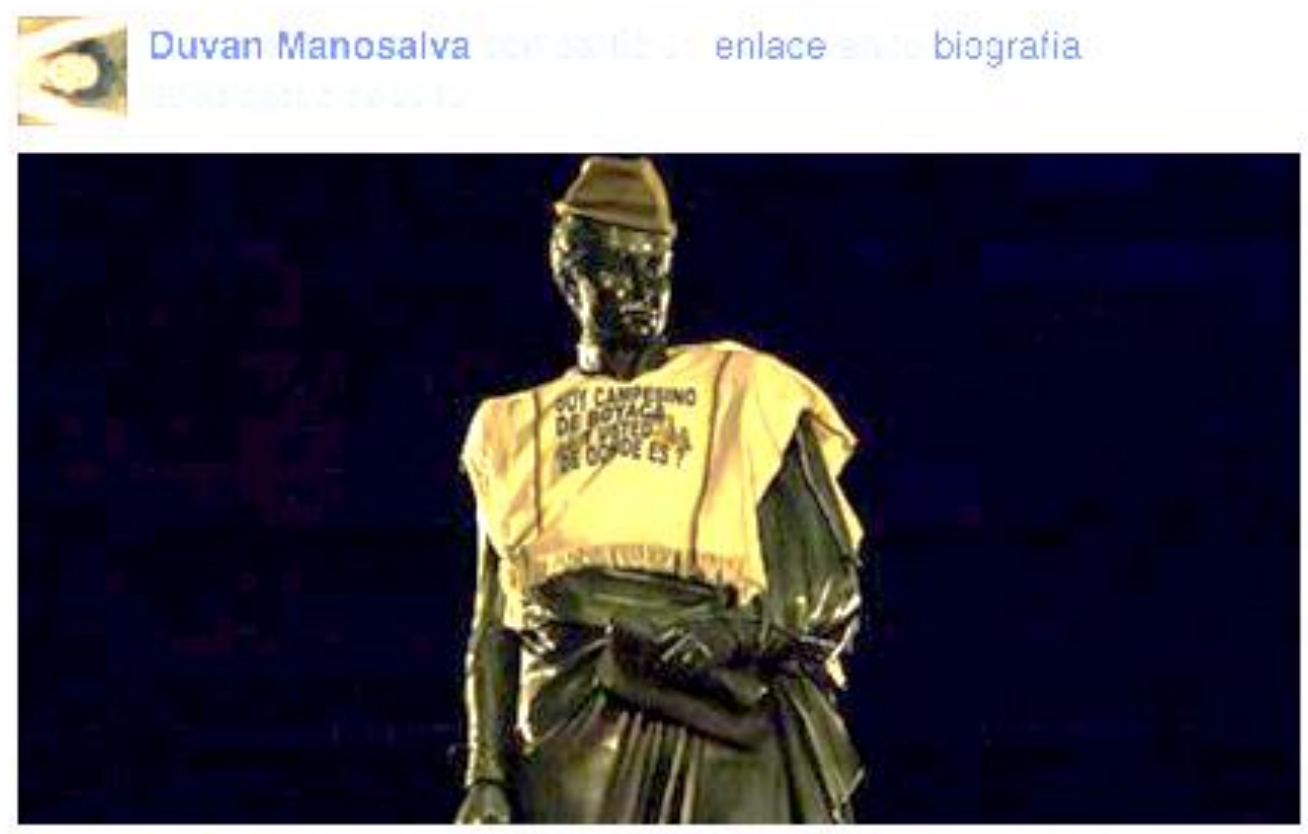

Después de años de olvido, los campesinos claman reivindicación - KienyKe

¿Porque os camocsinos ro son osclo ados? ¿For que ol gos ono sigue uganco

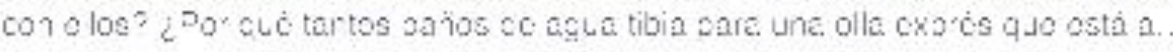

\section{Wo gusta Comentar Compartir Buffer}

Illustration 2.2 Photo posted on the Boyacá Noticias Fan Page on Facebook. Facebook screenshot of the Boyacá Noticias 95.6FM, August 28, 2013. 
Police and army actions along with the violent events that took place during the protests, were important themes represented in the images, illustrating how Facebook can channel users' concerns. These latter manifest as prevention messages alerting the community about the possible risks that may derive by the Agrarian Strike on the streets.

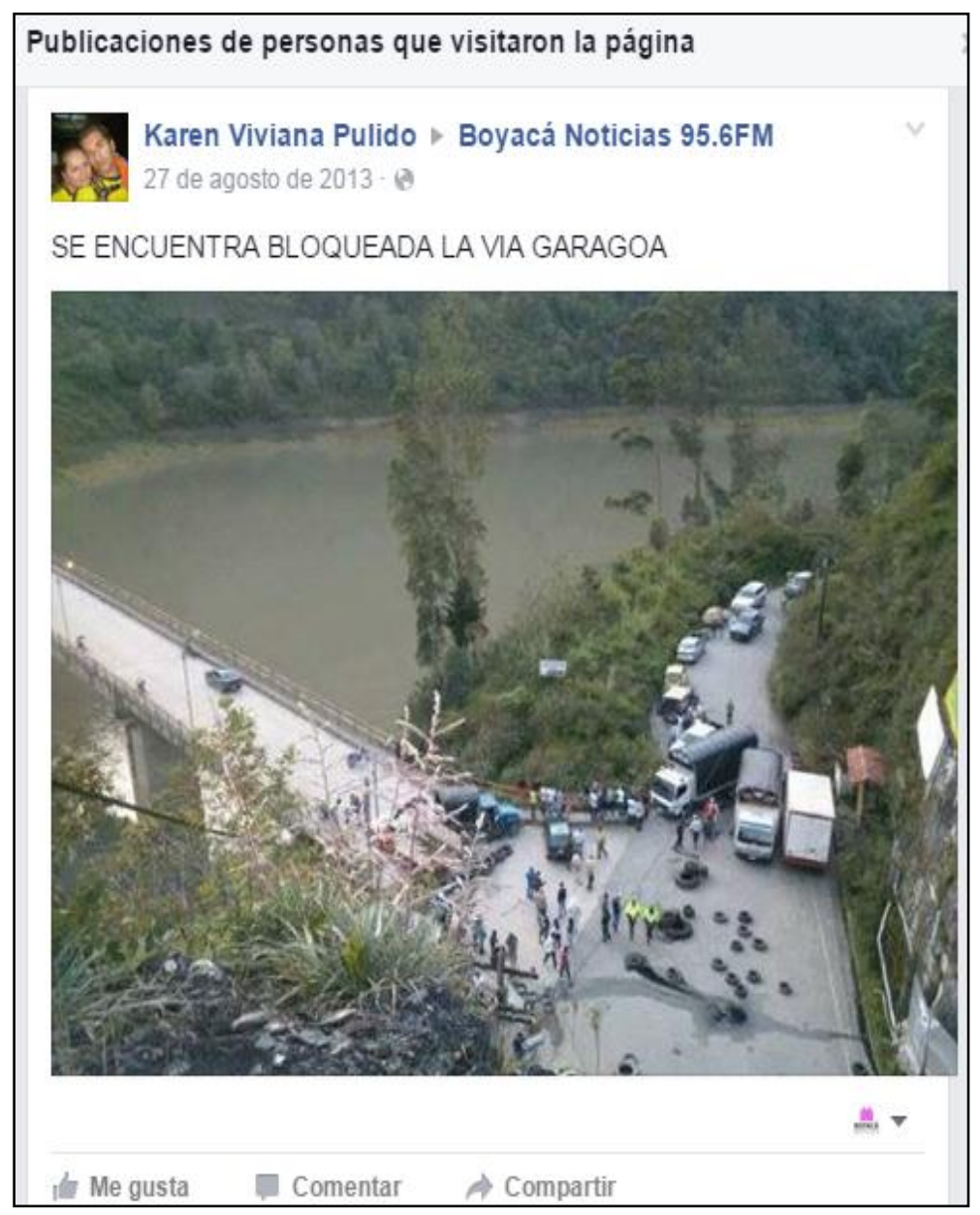

Illustration 3. Image of a roadblock. Facebook screenshot of Boyacá Noticias 95.6FM, August 27, 2013

User images are no longer tied to the news topic but move on to reflect actions, gestures and interactions that can constitute news or supplementary information in their own right, rather than simple reiterations.

There is a polysemic view underlying these images, and not an unequivocal one. All information given about the Agrarian Strike derives from the experiences of its leading actors, providing new meaning, bridging subjects' real experiences. 


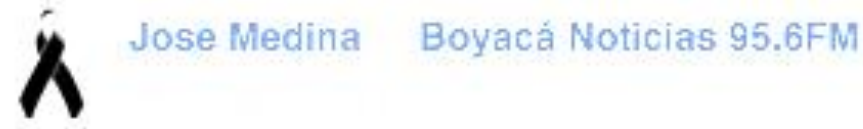

HUMILDAD

Ver traduccion

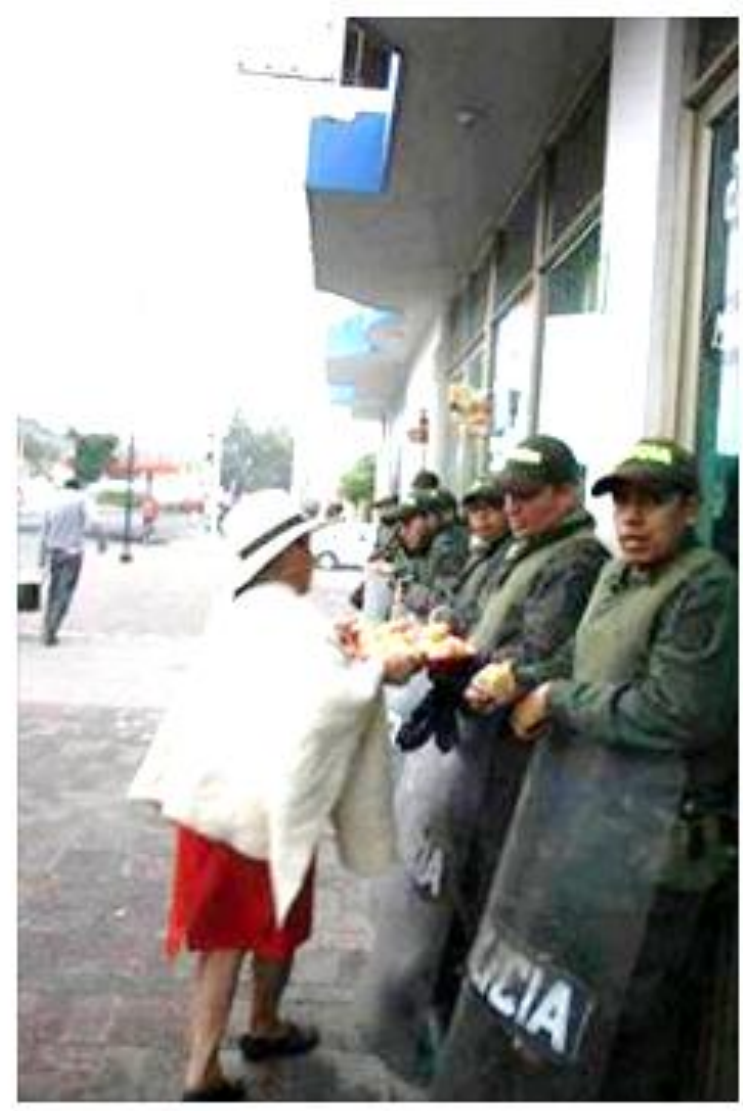

Illustration 4. Image of a farmer treating members of the National Police. Facebook screenshot of Boyacá Noticias 95.6FM, August 27, 2013

\subsection{Image formats used by users}

By format, we mean the set of technical and other characteristics of image presentation. This research found that predominant formats were photonews, followed by memes, videos, caricatures, and, lastly, 
illustrated messages. Photonews fuse together and synthesize a great sum of information. Using very brief texts, they manage to catch readers' attention and have particular effects on the reader. These effects can be much stronger and emotional than what they would have been if the content was conveyed in the form of a written text.

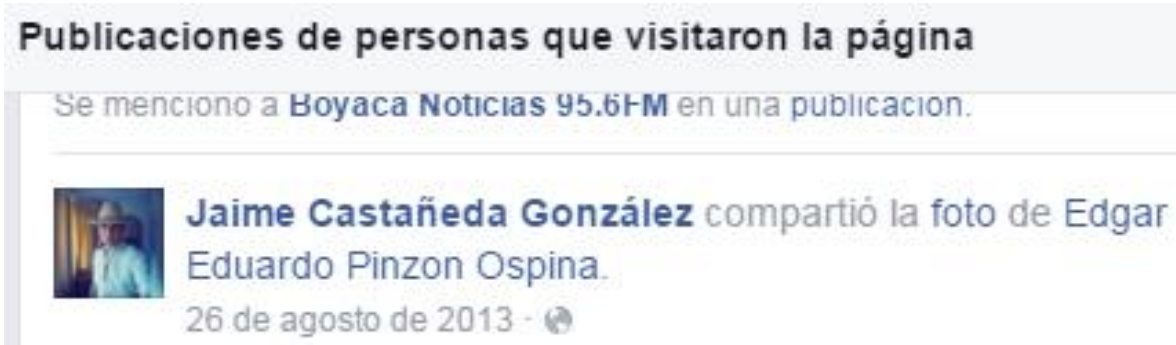

Boyacá Noticias 95.6FM este es el ruidito que le incomoda al disque presidente

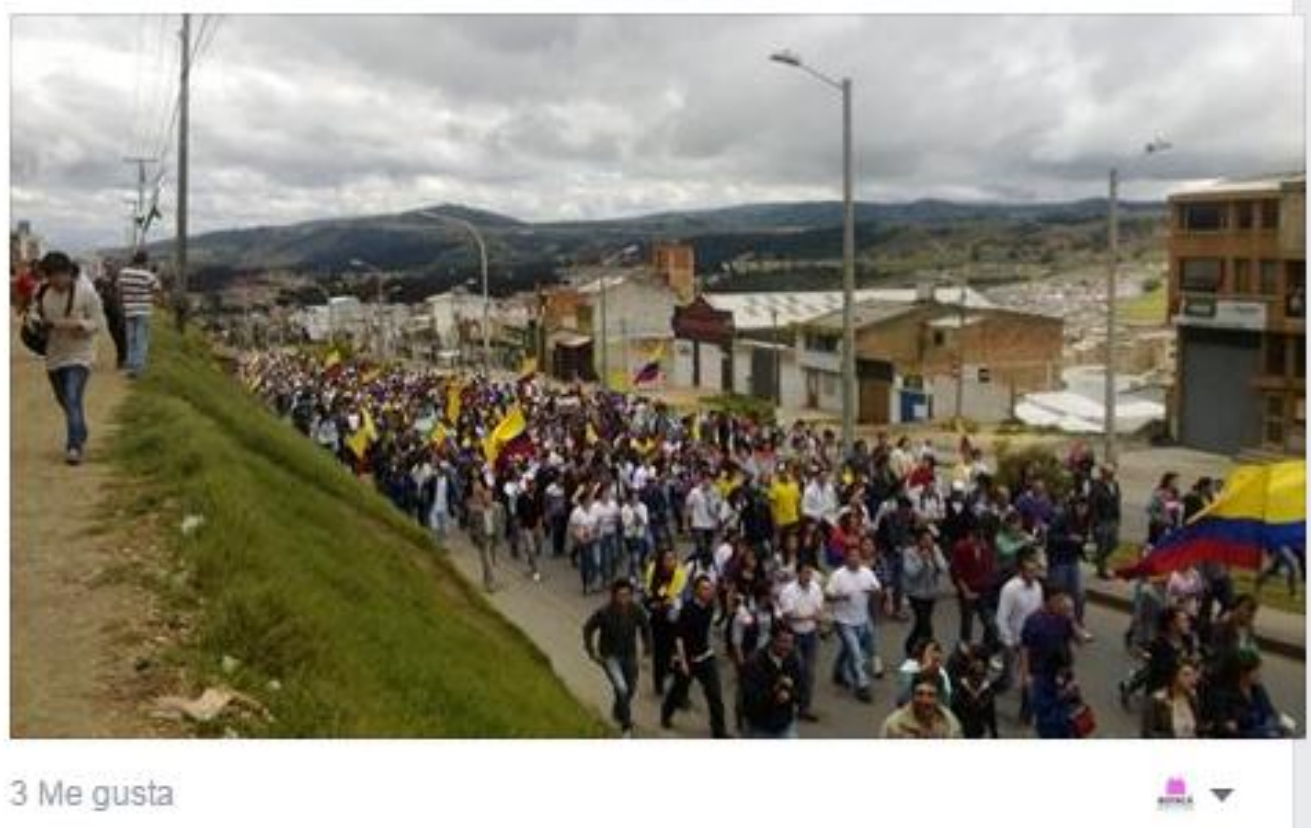

Ine gusta Comentar $\Rightarrow$ Compartir

Illustration 5. Farmer demonstration. Facebook screenshot of Boyacá Noticias 95.6FM, August 16, 2013

On the other hand, memes manage to creatively modify the sometimes centralized discourse of the media, breaking their order and rules. The images collected for this study bring out ideas that divide formal discourses, which even denied the Agrarian Strike. 


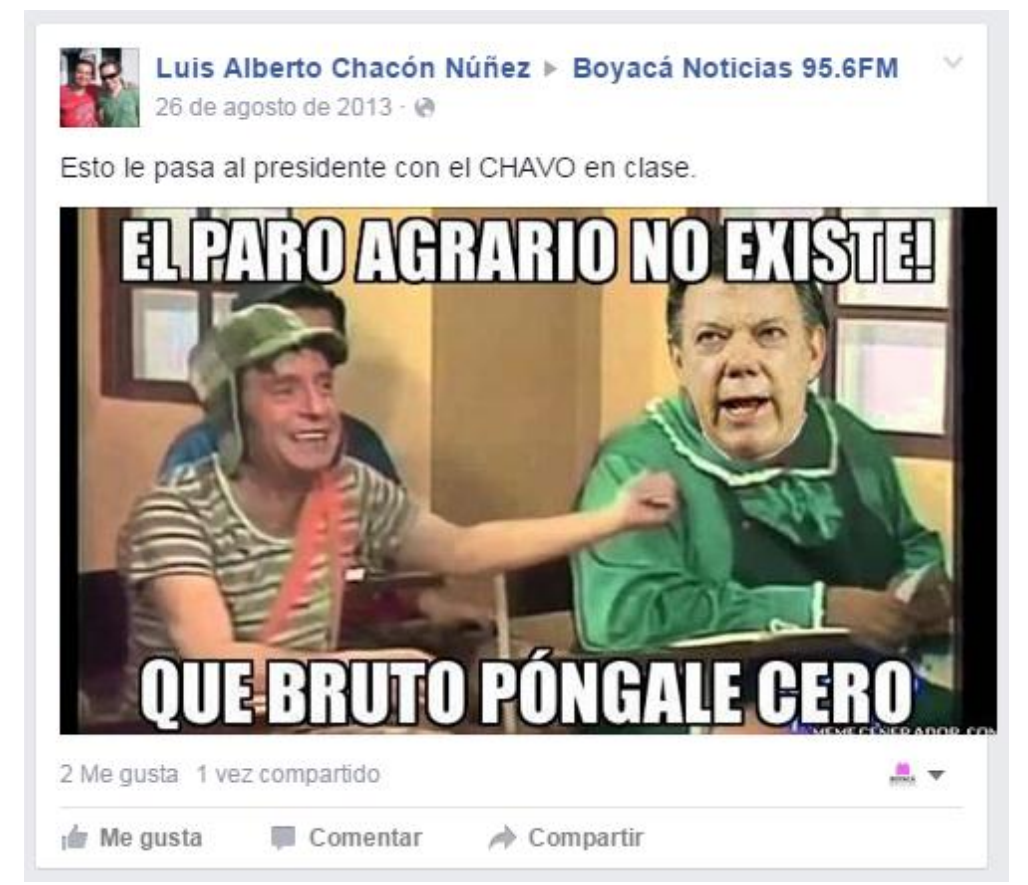

Illustration 6. Meme on account of the Colombian Government's denial of the Agrarian Strike. Facebook screenshot of the Boyacá Noticias 95.6FM, August 26, 2013.

Combining and replicating texts gives birth to a type of image transformation which is not only formal or rhetoric, but also meaningful, due to the high conceptual and ideological load it stirs.

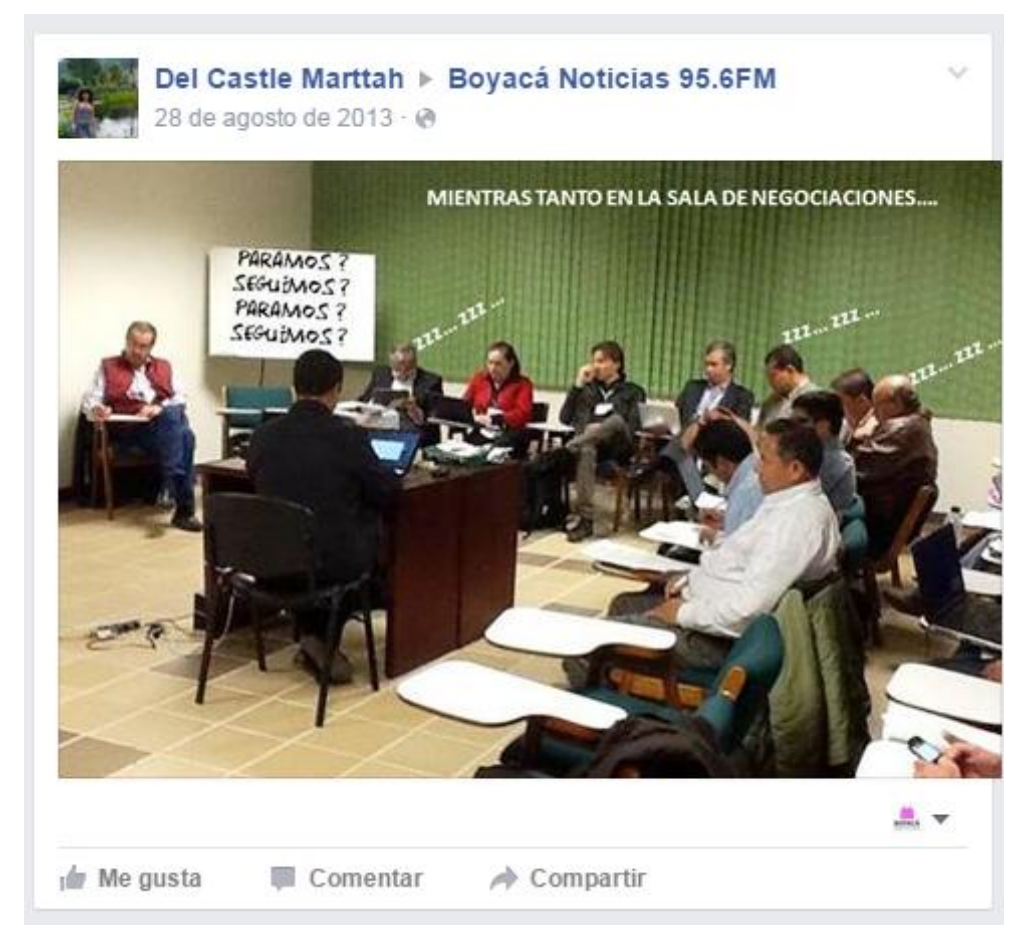

Illustration 7. Meme about the negotiations. Facebook screenshot of the Boyacá Noticias 95.6FM, August 28, 2013. 


\section{Conclusions}

Our analysis of the function of Facebook images indicates that the documentary value of the first photographs in print media is maintained on the social network. Images are tools particularly used to denounce and criticize conflicts during the National Agrarian Strike, which may be denied or suppressed by Government officials.

Images are useful for depicting roadblocks, public transport problems and demonstrations, and offering the citizens' perspective on the media coverage of the negotiations between the Government and agricultural leaders.

The content analysis of the public radio Facebook page in Colombia requires new studies that will identify the ways in which images published via social networks, and especially the memes, begin to define a new order of media agendas, irrespective of the news topic. It is necessary to extend research into the transformations of the agenda setting in the digital context. Knowing the interests of media users and the ways they interact to generate a new public agenda becomes essential. Only then will we be able to know, as Jacobson (2013) affirms, the extent to which social networks control the information agenda of the mass media and their correspondents.

\section{References}

Andén-Papadopoulos, Kari; Pantti, Mervi (2013). Re-imagining crisis reporting: Professional ideology of journalists and citizen eyewitness images. En: Journalism, Vol. 14, nº. 7, 960-977. Aparici, Roberto; García Matilla; Agustín; Fernández, Jenaro; Osuna, Sara (2006). La imagen. Análisis y representación de la Realidad. Madrid: Universidad Nacional de Educación a Distancia. Baeza, Pepe (2001). Por una función crítica de la fotografía de prensa. Barcelona: Gustavo Gili.

Campos Freire, Francisco (2008). Las redes sociales trastocan los modelos de los medios de comunicación tradicionales. En: Revista Latina de Comunicación Social, Vol 69. 287 -293. 
Chen, Rui; K. Sharm, Sushil; Rao, H. Raghav (2016). Members' site use continuance on Facebook: Examining the role of relational capital. En: Decision Support Systems, Vol. 90, 86-98

Eurasquin, Manuel Alonso (1995). Fotoperiodismo: Formas y códigos. Madrid: Síntesis.

Frend, Gisèle (1976). La fotografía como documento social. Barcelona: Gustavo Gili.

Gerhards, Jürgen; Schafer, Mike (2010). Is the internet a better public sphere? Comparing old and new media in the USA and Germany. En: New Media \& Society, Vol. 12, n¹, 144-160. Gutiérrez, María; Martí, Josep María; Ferrer, Iliana; Monclús, Belén; Ribes, Xavier (2014). Los programas radiofónicos españoles de prime time en Facebook y Twitter: Sinergias entre la radio convencional y las redes sociales. En: Revista Latina de Comunicación Social, Vol. 69, 418-434. doi: 10.4185/RLCS-20141018

Jacobson, Susan (2013). Does Audience Participation on Facebook Influence the News Agenda? A Case Study of The Rachel Maddow Show. En: Broadcast Education Association, Vol. 57, $\mathrm{n}^{\circ} 3$, 338-355. doi: 10.1080/08838151.2013.816706

Ju, Alice; Jeong, Sun Hp Chyi; Hsiang, Iris (2013). Will social media save newspapers? En: Journalism Practice, Vol. 8, 1-17. http:/ /dx.doi.org/10.1080/17512786.2013.794022.

Kaigoa, Muneo; Okura, Sae (2016). Exploring fluctuations in citizen engagement on a local government Facebook page in Japan. En: Telematics and Informatics, 33. 584-595

Kümpel, Anna Sophie; Karnowski, Veronika; Keyling, Till (2015). News sharing in social media: A review of current research on news sharing users, content, and networks. En: Social Media + Society, Vol 1, no 2, 1-14 http:/ /dx.doi.org/10.1177/2056305115610141.

Lievrouw, Leah (2011). Alternative and activist new media. Cambridge, UK;Malden, MA: Polity.

Linders, Dennis (2012). From e-government to we-government: defining a typology for citizen coproduction in the age of social media. En: Government Information Quarterly Vol. 29, n 4, 446454. http://dx.doi.org/10.1016/j.giq.2012.06.003. 
Liu, Sophia B; Palen, Leysia; Sutton, Jeannette; Hughes, Amanda L.;

Vieweg, Sarah (2008). In Search of the Bigger Picture: The

Emergent Role of On-Line Photo Sharing in Times of Disaster.

En: Proceedings of the Information Systems for Crisis

Response and Management Conference (ISCRAM) (2008).

Disponible en http://works.bepress.com/vieweg/11/

Iyengar, Shanto; Kinder, Donald (1987). News that matters: Television

and American opinion. Chicago: University of Chicago Press.

Livingstone, Sonia; Markham, Tim (2008). The contribution of media consumption to civic participation. En: The British Journal of Sociology, Vol. 59, n² 2, 351-371.

http://dx.doi.org/10.1111/j.1468-4446.2008.00197.x.

López, Fernando (2002). El Análisis de contenido como método de investigación. En: Revista de Educación, Vol. 21, n 4, 167-149.

Disponible en

rabida.uhu.es/dspace/bitstream/handle/10272/1912/b151504

34.pdf? sequence $=1$ http: $/$ / search.ebscohost.com $/$ login.aspx?dir ect $=$ true \&db $=$ ufh\&AN $=17404541$ \&lang=es\&site=ehost-live

Mäenpää, Jenni (2014). Rethinking Photojournalism: The Changing Work Practices and Professionalism of Photojournalists in the Digital Age, En: Nordicom Review, Vol. 35. n² 2, 91-104.

McCombs, Maxwell; Shaw, Donald. (1972). The agenda setting function of the mass media. En: Public Opinion Quarterly, Vol. 36, 176-187.

Miller, Andrea; Roberts, Shearon. (2010). Visual agend-setting \& proximity after Hurracane Katrina: A study of those closest to the event. En: Visual communication Quartely, Vol. 17. n 1, 31-46:

Miller, Daniel; Costa, Elisabetta; Haynes, Nell; McDonald,Tom;

Nicolescu, Razvan; Sinanan, Jolynna; Spyer, Juliano;

Venkatraman, Shriram (2016). How the World Changed. Social Media. UCL Press: University College London. Disponible en: www.ucl.ac.uk/ ucl- press

Ministerio de Agricultura (s.f.). Pacto Nacional por el Agro y el Desarrollo Rural. Disponible en:

https:/ / pactoagrario.minagricultura.gov.co/Documents/Cartill a $\% 20$ Pacto $\% 20$ Agrario.pdf

Peña, Palma; Pascual, Albert (2013). Redes sociales en la radio española. Facebook, Twitter y Community Management. En: 
ZER, Vol. 35, n 18, 123-144. Disponible en:

http://www.ehu.eus/zer/hemeroteca/pdfs/zer35-06-pena.pdf Peñafiel, Carmen (2016). Reinvención del periodismo en el ecosistema digital y narrativas transmedia. En: AdComunica. Revista de Estrategias, Tendencias e Innovación en Comunicación, Vol. 12, 163-182.

Rainie, Lee; Brenner, Joanna; Purcell, Kristen (13 sept, 2012) Photos and Videos as Social Currency Online. Online Life in Pictures. En: PewResearch Center. Disponible en: http://www.pewinternet.org/2012/09/13/photos-and-videosas-social-currency-online/

Ramos del Cano, Fátima (2014). Redes sociales y participación radiofónica: Análisis de caso de Twitter y Facebook en la Cadena SER. En: Ámbitos, Vol. 25. Disponible en: http://ambitoscomunicacion.com/2014/redes-sociales-yparticipacion-radiofonica-analisis-de-caso-de-twitter-yfacebook-en-la-cadena-ser/

Restrepo, Laura (16 sep, 2013) Especiales Pirry. La Rebelión de las Ruanas. Paro Agrario. [Archivo de Video] Disponible en: https://www.youtube.com/watch?v=4NBgdrBBEn4

Chen, Rui; K. Sharm, Sushil; Rao, H. Raghav (2016). Members' site use continuance on Facebook: Examining the role of relational capital. En: Decision Support Systems, Vol. 90, 86-98

Séguin, Jean Claude (2011). La desaparición del referente en el arte digital y sus implicaciones, 63-80. En: AdComunica. Revista de Estrategias, Tendencias e Innovación en Comunicación, Vol. 2, 63-80.

Singer, Jane B. (2010) Quality control. Perceived effects of usergenerated content on newsroom norms, values and routines.

En: Journalism Practice, Vol. 4, n 2, 127-142.

Sontang, Susan (1981). Sobre la fotografía. Traducido por Carlos Gardini. Barcelona: Edhasa.

Yin, Robert K. (2009) Case Study Research. Design and Methods. Thousand Oaks. Washington, USA: Sage Publications. 



\section{0 \\ Religião e Novas Territorialidades \\ - A Igreja na Rede}

Karina Inácio de Araujo Lambert. Universidade Federal do Espírito Santo (Brasil). karina.iaraujo@gmail.com

\section{Introdução}

A HiSTÓRIA da humanidade é marcada por processos de 1 mudanças. As condições históricas de um determinado período influem no processo de construção da identidade. Muitos autores como Featherstone (1995) consideram, que vivemos no período denominado pós-moderno, onde as mudanças nas práticas e experiências cotidianas de diferentes grupos podem estar usando "regimes de significação de diferentes maneiras desenvolvendo novos meios de orientação e estruturas de identidades" (Featherstone, 1995, p. 32). Essa condição Pós-Moderna tem como uma de suas características as tecnologias de informação. Vivemos numa época de comunicação generalizada, uma sociedade midiatizada, onde a utilização em larga escala do meios de comunicação apontam para um mudança nas formas de ser dos sujeitos pós-modernos, e consequentemente na forma como a instituições passaram a lidar com seus públicos. Vemos ascender o fenômeno da midiatização em todas as instâncias da vida em sociedade, inclusive na religião.

Assim, levando em consideração essas transformações, argumentaremos aqui a respeito de como o processo de midiatização da sociedade, principalmente com as novas tecnologias de informação, repercute sobre as formas de funcionamento do campo 
religioso. O que vemos acontecer nos nossos dias é uma espécie de corrida das instituições religiosas a fim de se manter como reguladora de sentidos, posição na qual vem perdendo terreno há algum tempo (Hervieu-Léger, 2015). De forma mais detalhada, o que acontece é que as religiões se tornaram um fenômeno cultural que perpassa todos os tempos, toda a história conduzindo comportamentos, pautando opiniões e direcionando ações, muitas vezes de sociedades inteiras. Mas a força desse fenômeno sofreu diversos abalos no decorrer dos tempos, e talvez o maior deles seja a partir do século XX. Embora as mudanças para se adaptar às circunstâncias sociais sempre aconteceram, a era da informação, como também é chamada a nossa contemporaneidade, marcada pelo fenômeno digital e por identidades muito mais fluidas e móveis, trouxe desafios que ameaçam toda a cadeia institucional religiosa.

Portanto, a pretensão deste trabalho é compreender como as instituições religiosas protestantes, por meio da interface religião/rede, buscam estabelecer novos vínculos com a sociedade a fim de manter sua legitimidade.

\section{Contextualizando religião e pós-modernidade}

"...as velhas identidades, que por tanto tempo estabilizaram o mundo social, estão em declínio, fazendo surgir novas identidades e fragmentando o indivíduo moderno, até aqui visto como um sujeito unificado" (Hall, 2014, p. 9.)

Para Hall um novo tipo de mudança estrutural está transformando as sociedades modernas no final do século XX, fragmentando as paisagens culturais que, no passado, nos tinham fornecido sólidas localizações como indivíduos sociais (Hall, 2014). As mudanças citadas por Hall datam do período da história que alguns autores denominam como Pós-modernidade, que se inicia na segunda metade do século XX (Hall, 2014), marcado por novos paradigmas que representam uma virada cultural nos hábitos e costumes. Sendo a pós-modernidade um tema bastante polêmico no meio intelectual, foge ao nosso objeto levantar discussões sobre questões relacionadas às diversas teorias relativas à passagem da modernidade para a pósmodernidade. Portanto, neste artigo adotamos a mesma posição de Fredric Jamenson (1997), o que significa afirmar que vivemos no 
período pós-moderno que é a lógica cultural da atual fase do capitalismo. Para o autor, não trata-se de uma ruptura com o período anterior, mas de uma nova etapa do desenvolvimento do capitalismo, o chamado Capitalismo Tardio.

Com as mudanças trazidas pela pós-modernidade, parecem surgir novas formas de contato com o sagrado o que pode ser explicado pelas identidades serem agora mais fluidas, fragmentadas, plurais (Hall, 2014). Hervieu-Léger vê essa nova relação entre modernidade e religião sob dois aspectos: a dispersão das crenças das condutas por um lado e a desregulação institucional por outro (Hervieu-Léger, 2015). Os indivíduos passam a experimentar novas formas de experiência religiosa, fazendo surgir novas formas do crer, diferentes daquelas transmitidas diretamente pelas instituições.

As instituições religiosas aparecem nesse cenário em uma situação de mercado com uma multiplicidade de ofertas simbólicas. Nesse momento observa-se o fortalecimento das igrejas institucionais na competição do mercado religioso.

Vemos ascender o fenômeno neopentecostal ${ }^{13}$ num momento dominado pela economia de mercado, pelo capitalismo competitivo. Regida pelas leis de mercado e pela competitividade, como afirma Berger (1985) "a religião não pode mais ser imposta mas tem que ser posta no mercado" (p. 156). Leva-se em conta os desejos do

\footnotetext{
${ }^{13}$ Segundo Ricardo Mariano, o Neopentecostalismo é uma modalidade religiosa evangélica, inspirada no modelo das "igrejas eletrônicas" norte-americanas, que surge no Brasil no final da década de 1970. Em sua diversidade de igrejas, o Neopentecostalismo guarda, por um lado, semelhanças com o pentecostalismo clássico - ênfase nos dons do Espírito Santo como explicação para curas, milagres e interpretação bíblica - e, por outro, exibe diferenças em relação a esse pentecostalismo no que tange a: liberação de hábitos da vida cotidiana, com formas de vestir, defesa da "teologia da prosperidade"; acentuada ênfase na atuação do diabo como explicação dos males, combates às religiões mediúnicas e ao catolicismo; extensa pratica de rituais de cura e exorcismos; ostensiva atuação midiática e político-partidária, estruturada, em geral, com base no modelo de gestão empresarial adotado pela Igreja Universal do Reino de Deus, Internacional da Graça de Deus, Renascer em Cristo, Mundial do Poder de Deus, Ministério Sal da Terra, e uma miríade de denominações evangélicas de origem mais recente (Mariano, 1999, p. 32-40).
} 
consumidores e o que eles esperam receber em troca ao serem participantes desta ou daquela igreja.

O contexto histórico mostra uma igreja perfeitamente compatível com o capitalismo, talvez não mais da mesma forma como Weber refletira em "A ética protestante e o espírito do capitalismo", mas como uma instituição que lança mão das estratégias de mercado para alcançar seus objetivos. Marketing, publicidade, marcas e principalmente o uso da mídia, são algumas das estratégias das instituições religiosas do século XX para alcançarem o público "consumidor". Para Mariano (1999):

Gerenciam-se igrejas com métodos modernos de administração. Criam-se empresas que orbitam em torno de atividades religiosas, como produtoras, gravadoras, agências de turismo, editoras, livrarias. Transformam-se garagens, teatros, cinemas, casas de show, fábricas e supermercados em templos (p.103).

Imersos em uma sociedade de consumo, onde tudo parece se tornar mercadoria (Featherstone, 1995), podemos assim identificar um verdadeiro mercado religioso que cada vez mais, sai da esfera onde toda forma de aproximação divina se dá no seio da instituição religiosa e da tradição, se deslocando para a mídia, que se mostra como uma nova instância organizadora das relações sociais.

Com a cultura midiática sendo parte das estratégias e táticas simbólicas das igrejas, o que se vê não é mais uma religião focada na disciplina, em pregações focadas no transcendente, mas uma religião que cede terreno para forças secularizantes adaptando suas mensagens aos anseios das massas (Mariano, 1999).

O crescimento do uso da mídia por parte das instituições religiosas protestantes as fizeram alçar voos nunca antes conquistados, aumentando seus seguidores e também desacelerando o crescimento católico que era o mais expressivo na modernidade. A população pentecostal mais que dobrou a cada década a partir de 1980, passando de 3,9 milhões em 1980 para 8,8 milhões em 1991 e 18 milhões em 2000. Já os católicos apesar de continuarem crescendo, mostram um crescimento mais lento que o médio anual, passando a partir 1991 a 2000, de um pouco mais de 3 milhões de pessoas. Apesar dessa ser a 
religião com maior número de seguidores do país, as taxas de crescimento mostram uma perda de influência da igreja católica no Brasil $^{14}$.

Mas, apesar de seu crescimento significativo e da luta constante para se manter no poder, as igrejas protestantes se deparam com o terceiro grupo que mais cresce nas estatísticas brasileiras: os sem-religião.

[...] o número de pessoas que se declaram sem religião encontra-se em constante crescimento no Brasil: 700.000 em 1970, 2 milhões em 1980, 7 milhões em 1991 e 12,5 milhões em 2000 (Tab. 1). Assim, o aumento observado entre 1991 e 2000 é excepcional, representando uma variação de 5,5 milhões de habitantes. No entanto, se fosse corrigido pela taxa de crescimento demográfico, o aumento dos "sem religião" seria da ordem de 4,4 milhões de pessoas, ou seja, menor do que o ocorrido entre 1991 e 2000,o que significa uma variação superior à taxa de crescimento demográfico do país. Em consequência, esta categoria ocupa o terceiro lugar no Brasil, em relação às declarações do Censo de 2000, situando-se após os católicos e os evangélicos pentecostais ${ }^{15}$.

O número cada vez mais expressivo dos sem-religião parece representar novas formas de se pensar o sagrado, o que faz com que as instituições religiosas, mesmo tendo avançado em números, se deparem com uma perda significativa e crescente de " sua capacidade social e cultural de impor e regular crenças e práticas" (HervieuLéger, 2015, p. 41).

[...] sem dúvida, uma fração importante das pessoas que se dizem sem religião acredita em Deus, sem participar, no entanto, das instituições religiosas e sem se sentir pertencendo a uma comunidade confessional. Nesse sentido, mais do que o crescimento do ateísmo,

${ }^{14}$ Atlas da filiação religiosa e indicadores sociais no Brasil - Cesar Romero Jacob ... [et aL]. - Rio de Janeiro: Ed. PUC-Rio ; Sao Paulo: Loyola, 2003

15 ibidem 
trata-se, ao que tudo indica, de um enfraquecimento das religiões como instituições ${ }^{16}$.

"A crença que "não desaparece, ela se desdobra e se diversifica" (Hervieu-Léger, 2014, p. 44). Essas mudanças se intensificam na segunda metade do século XX, junto com o projeto pósmoderno em que consolidam-se as tecnologias de comunicação, com a TV iniciando essa revolução informacional, e que alcança seu auge na contemporaneidade com a internet e suas evoluções que não cessam de acontecer.

A internet passa exercer um papel importante no comportamento das pessoas à medida que as instituições-casca se enfraquecem (Giddens, 2011). Na contemporaneidade podemos vislumbrar como a abundância de informação e relações sociais disponíveis nesse novo espaço, o ciberespaço, contribui para o surgimento de novas identidades, múltiplas, plurais, descentradas (Hall, 2014). "Identidades religiosas que deixam de ser reguladas, novos movimentos espirituais que proliferam, incertezas jurídicas e políticas na gestão pública das religiões" (Hervieu-Léger, 2015, p.29).

Assim, ao que parece, há uma atomização da autoridade religiosa, fazendo com que as instituições religiosas busquem novas alternativas junto aos meios de comunicação, com destaque para a internet, com o intuito de recuperar e manter sua autoridade. Com isso, mudam as formas de se lidar com o sagrado, o que culmina em grandes mudanças dentro do campo religioso para abarcar a multiplicidade de identidades que, como afirma Hall, não cessam de se fragmentar (2014) e consequentemente contribuem para a fragmentação das instituições religiosas (Hervieu-Léger, 2014).

\section{Ciberespaço e novas territorialidades religiosas}

O espaço de fluxos não é etéreo, mas ancorado nos espaços de lugar. São computadores interligados, redes de satélites, cabos de fibra ótica, servidores etc., criando uma infraestrutura concreta de constituição das redes telemáticas. Nessa fusão de espaço de lugar e espaço de

16 ibidem 
fluxo, vemos a constituição dos territórios informacionais: além do território físico, do controle simbólico, corporal, cultural, vemos surgir uma nova dimensão, um território que podemos chamar de território de controle de informação, o território digital informacional ${ }^{17}$.

Castells (1999) chama o ciberespaço de espaço de fluxos, uma nova lógica espacial que está em polaridade com os espaços de lugar, que seriam os espaços físicos de um local, o espaço urbano. Sendo o espaço, na teoria social, um local de suporte material onde se dão as práticas sociais, tendo assim uma função e um sentido social (Castells, 1972), nota-se que a sociedade em rede ao promover novas formas de práticas sociais, mediadas pelas tecnologias eletrônicas, promove $\mathrm{O}$ surgimento dessa nova forma espacial, o espaço de fluxos. "A infraestrutura tecnológica que constrói a rede define o novo espaço como as ferrovias definiam as "regiões econômicas" e os "mercados nacionais" (Castells, 1999, p.502).

A internet e sua mediação digital diminui as distâncias e as ressignificações na noção de espaço e tempo. Navegar pela internet já faz parte do cotidiano de grande parte da população brasileira ${ }^{18}$. Devido à sua penetrabilidade em quase todas as esferas da sociedade humana, a revolução da tecnologia da informação torna-se essencial para entendermos a complexidade da nova economia, sociedade e cultura em formação (Castells, 1999).

As chamadas redes sociais se popularizaram após a revolução digital, mas já existiam muito antes do mundo online. Quando falamos de redes falamos de relações, de laços. Sabe-se que os laços sociais entre os indivíduos não são exclusivos do ambiente online, o que acontece

${ }^{17}$ LEMOS, André. Cibercultura como território recombinante. Transcrição revisada da conferência ministrada no evento "Territórios Recombinantes", realizado no Instituto Goethe (ICBA), em Salvador, em agosto de 2006.

${ }^{18}$ Quando se considera todo o conjunto de pessoas com acesso ao computador com internet em casa ou no local de trabalho, o número é de 103,4 milhões. O número de pessoas que usam o smartphone para ter acesso à internet continua em crescimento no Brasil e chegou a 72,4 milhões no segundo trimestre de 2015. Pesquisa NetView - Nielsen IBOPE 2015.

$<$ http://www.nielsen.com/br/pt/press-room/2015/Brasileiros-com-internetno-smartphone-ja-sao-mais-de-70-milhoes.html> Acesso em 02/06/2016 
a partir da internet é uma verdadeira revolução não só com "novas práticas sociais, mas em alterações na própria vivência do espaço e do tempo como parâmetros da experiência social" (Castells, 1999, p. 36). Um novo paradigma surge, um paradigma tecnológico que se organiza em torno da tecnologia de informação. A rede de relações offline não deixa de existir, mas surge uma rede com muitas mais conexões, conexões essas estabelecidas e alimentadas através de ferramentas digitais

Surgem novas formas de se relacionar com a cidade, com os indivíduos, novas formas de interação social. A rede permite nos relacionarmos com diversos espaços, as fronteiras são apagadas, criam-se processos de desterritorialização, mas também de novas territorializações.

Para nossos propósitos, a característica mais importante das redes é seu efeito concomitantemente territorializador e desterritorializador, o que faz com que os fluxos que por elas circulam tenham um efeito que pode ser ora de sustentação, mais 'interno' ou construtor de territórios, ora de desestruturação, mais 'externo' ou desarticulador de territórios (Haesbaert, 2004, p. 294).

A sociedade em Rede, rompe com os limites físicos e temporais e assim permite uma sobreposição de territórios, a multiterritorialidade. Há um território virtual (Levy, 1999) que passa a ser ocupado pelos indivíduos através dos seus perfis na rede. Nas redes sociais digitais cada pessoa com acesso à internet pode criar seu perfil e a interagir com os perfis das outras pessoas. Trocam-se mensagens, áudios, vídeos, experiências, emoções, opiniões. A identidades se atualizam constantemente pelas redes sociais. A comunicação acontece sem que tenhamos que sair de casa. Ocupamos e nos movemos por diversos territórios apenas com cliques, interagimos por aplicativos de comunicação. Telas e teclados interligados em rede nos permitem, visitar, conhecer, habitar. Como Mcluhan (1964) já havia destacado, com as novas tecnologias surgem novas formas de se relacionar, de habitar. Há assim um impacto direto sobre os territórios.

Há aqui uma imbricação entre os diversos territórios que compõem essa minha experiência: o território físico (o ICBA, Salvador, Brasil...), meu território corporal e subjetivo, o território econômico, 
jurídico, cultural onde estou imerso, o meu território informacional, ao qual somente eu tenho acesso a partir de minhas senhas pessoais. Assim, o território informacional deve ser pensado nessa miríade de territórios e deve ajudar a manter a privacidade e a segurança do meu território. O reconhecimento do território informacional é comunicacional, mas também social e político. Ao aumentar a possibilidade de trocas entre consciências (blogs, fóruns, chats, redes p2p etc....), as mídias pós-massivas aumentam a probabilidade de ocorrência de processos comunicativos, ampliando as formas de recombinação. Com as tecnologias móveis e os territórios informacionais, essa potência da emissão, da conexão e da reconfiguração aumenta ainda mais as práticas de colaboração e recombinação, aliando de forma mais forte comunicação, comunidade, sociabilidade e mobilidade. (Lemos, 2006, p.45)

Inúmeros territórios são criados no espaço de fluxos, no ciberespaço, permitindo novas práticas sociais, locais de relações (Raffestin, 1993). O caráter interativo da rede tem permitido, cada vez mais, interação social, lazer, novas formas de linguagem, formação de comunidades que desenvolvem laços de sociabilidade e compartilham experiências, informações, conhecimento. Lemos traz a noção de território informacional, formado pelo espaço telemático, por senhas de acesso e lugares físicos de conexão. Esse novo território tem transformado o espaço urbano e a vivência nas grandes cidades permitindo uma constante re-territorialização.

No começo de século XXI as mídias locativas reforçam a hibridação do espaço físico com o ciberespaço, trazendo novas implicações para o espaço urbano. O fluxo comunicacional se dá por redes sem fio e dispositivos móveis, caracterizando a era da comunicação ubíqua, senciente e pervasiva (Lemos, 2006) das mídias locativas. Novas práticas sócio-comunicacionais emergem como vimos. As referências da cidade não se vinculam apenas às marcas territoriais físicas, mas a eventos informacionais dinâmicos, embarcados nos objetos $\mathrm{e}$ localidades. Essas transformações configuram a ciberurbe (Lemos, 2006, p. 11). 
Tanto as mídias locativas, quanto as mídias sociais deixam explícito que com a internet surgem novos territórios, novas ocupações. Mudase a forma de se relacionar com o espaço vivido, estabelecem-se novas relações com a cidade, com os indivíduos, com o Estado e também com a religião. Assim, o que vemos na sociedade em rede é um "processo de reterritorialização espacialmente descontínuo e extremamente complexo". (Haesbaert apud Haesbaert, 2004, p. 20). Para entender essa questão é preciso ter uma visão do território para além da dimensão material na realidade contemporânea, que, dominada pelo mundo das imagens e das representações mostra-nos um território muito mais relacional.

“[...] dentro dessas novas articulações espaciais em rede surgem territórios-rede flexíveis onde o que importa é ter acesso, ou aos meios que possibilitem a maior mobilidade física, dentro da(s) rede(s), ou aos pontos de conexão que permitam "jogar" com as múltiplas modalidades de territorialidade existentes, criando a partir daí uma nova (multi)territorialidade (Haesbaert, 2004, p.39).

A apropriação multiterritorial dos indivíduos promovem mudanças identitárias que transformam, diversificam as relações com o espaço, o território, as instituições. As identidades tornadas mais fluidas, mais diversificadas pela dinâmica em rede promovem novas territorialidades, mais descentradas, menos hierarquizadas, distantes de uma tradição unificante. As formas sociais tradicionais tem sido cada vez mais questionadas. Levy (1999) traz a noção de "desterritorialização da biblioteca" com novas formas de construção de conhecimento, assim também podemos falar de uma desterritorialização da igreja, com novas formas do crer.

É importante nos atentarmos para a importância do território físico para a instituição religiosa. A territorialidade religiosa se expressa há séculos na paisagem do santuário que representa "o marco do espaço construído e de significação simbólica da presença do sagrado” (Gil Filho, 2012, p. 101). A instituição religiosa atua com suas estruturas de gestão e ação social da religião, e se apropria tanto do lugar igreja, considerado sagrado, quanto dos seus atores sociais que são submetidos à hierarquia entre clero e leigos (Gil Filho, 2012). Ali o discurso religioso se legitima e se torna carregado de significado. 
Entretanto o que vemos na pós-modernidade é cada vez mais o templo religioso, antes local supremo da prática da fé e da autoridade eclesiástica dividindo fronteiras com o espaço virtual, e o poder, outrora concentrado nas instituições, hoje é descentrado e disseminado entre os nós das redes onde não há diferenças entre emissor e receptor e a informação circula em tempo real para todos..

No território-rede da internet, os líderes religiosos, que personificam o poder da instituição de gestão do sagrado, dividem o "púlpito virtual" com inúmeros porta-vozes que compartilham de suas crenças, muitos contra, muitos a favor da tradição cristã, mas todos com uma similaridade, abalam juntos a autoridade central das instituições que foram a única voz da religião por séculos.

As novas formas de se encarar a autoridade e a hierarquia, as novas materialidades trazidas pela web 2.0 trouxeram mudanças de identidade e consequentemente parecem mudar o discurso, os rituais e a religiosidade como tradicionalmente a conhecemos descortinando uma 'nova religião' na era digital. O crescimento protestante trazido pelas mídias de massa, como TV e rádio restringiam o discurso à instituição religiosa, sendo um canal de mão única. Com a comunicação todos-todos (Levy, 1999), característica da web, onde não há polos claramente definidos entre produtores e receptores, a instituição divide seu espaço com outros indivíduos. Agora esse espaço da experiência religiosa é um campo aberto, está em todo lugar onde o sinal de internet pode alcançar. Assim no ciberespaço há inúmeros processos de re-territorialização para prática da fé. São inúmeros sites, perfis e páginas nas redes sociais, canais de vídeos que buscam transmitir a mensagem cristã, sejam ligados a instituições religiosas ou não. A presença ou ausência na rede são fontes cruciais de dominação (Castells, 1999), portanto ao que parece, a religião tem ocupado esse território para recuperar e manter sua legitimidade.

É possível encontrar na web inúmeros exemplos de líderes religiosos que usam a rede como forma de manter sua autoridade. Por ser um território de questionamento das hierarquias em que as manifestações individuais de religiosidade ganham cada vez mais espaço, as instituições religiosas parecem ganhar mais voz ao serem encarnadas por seus líderes religiosos na web, sendo que estes, com seu carisma, alcançam muito mais seguidores nas redes sociais que as páginas de 
suas respectivas igrejas. A Igreja Universal do Reino de Deus, por exemplo, apresenta 1.871 .415 seguidores ${ }^{19}$ enquanto seu líder Edir Macedo tem 2.042.23 milhões de seguidores ${ }^{20}$.

Com a performance desses líderes a instituição se torna reconhecida por seus representantes numa busca para manter sua territorialidade na rede que vai muito além da evangelização. $\mathrm{Na}$ última onda de pesquisa americana sobre autoridade religiosa, Cheong (apud Campbel, 2012) mostra que os líderes veem a internet, não mais como uma ameaça a sua autoridade, como nas primeiras pesquisas realizadas nos anos 90, mas como um espaço de complementaridade tendo papel positivo na vida dos indivíduos. Assim eles a usam para manutenção de sua autoridade havendo uma harmonia entre as práticas online com as atividades das comunidades religiosas. Cheong também aponta para o que ela e outros pesquisadores chamam de "estratégia arbitrária" em que os líderes religiosos tem ajustado sua identidade social que passa de líderes e sábios para a de guias e mediadores de conhecimento. Por exemplo, resultados de um estudo de pastores cristãos mostrou como líderes monitoram sua comunicação on-line e justificam a validade de sua autoridade (por exemplo através da elaboração de conteúdo sobre as escrituras e sublinhando as suas próprias interpretações através de novos ministérios "on-line "e atividades de branding), a fim de reforçar a regulação normativa (Cheong et al. 2011a apud Campbel, 2012).

Vemos essas questões claramente nas páginas das redes sociais de vários líderes religiosos no Brasil com reflexões que eles fazem sobre a bíblia ou até mesmo sobre outros assuntos sejam culturais, políticos ou econômicos, em que são criados layouts a partir de estratégias de comunicação e marketing para gerar comentários e compartilhamentos sendo assim disseminados não apenas entre a comunidade cristã, pois o compartilhamento em rede alcança uma pluralidade de indivíduos. O líder posta, é ele assim o "dono" da mensagem, os sujeitos comentam, positiva ou negativamente $\mathrm{e}$ também compartilham. Essa dinâmica parece amplificar sua voz,

\footnotetext{
${ }^{19}$ https://www.facebook.com/IgrejaUniversal/?fref=ts Acesso em $03 / 06 / 2015$

${ }^{20}$ https://www.facebook.com/BispoMacedo/?fref=ts Acesso em 03/06/2015
} 
colocando os líderes religiosos em uma posição de mediadores do discurso religioso apresentado, numa posição de autoridade do discurso. Verifica-se uma ação institucional de apropriação desses espaços, em que se colocam como autoridade do discurso e portanto estabelecem uma territorialidade institucionalizada nos territórios do ciberespaço.

Portanto a territorialidade do sagrado remete a um qualitativo exercido pelos sujeitos cuja autoridade é atribuída ao transcendente, sendo essa expressão a razão de ser dos atributos absolutos transferidos ao clero especializado, ungidos pela instituição (Gil Filho, 2012, p. 97).

Assim, embora a territorialidade do sagrado na web não se limite apenas à igreja, sendo disseminada pelos nós da rede, o que vemos é uma presença cada vez mais constante dos líderes religiosos nas redes sociais, com discursos que vão muito além do religioso, numa aparente tentativa de se manter sempre presente ocupando um território cada vez maior como voz do discurso.

“Observa-se, por um lado, uma tendência à metaforização e à intelectualização das crenças tradicionais, da qual participam os teólogos das grandes igrejas a fim de restaurar a credibilidade cultural de sua mensagem em um ambiente secular (HervieuLéger, 2015, p. 47).

Os discursos desses líderes se fortalecem na esfera pública, ao se focar não apenas no sagrado, mas nas mais diversas frentes passando pela política, cultura e direitos humanos. Muitos desses líderes encontram na rede uma visibilidade que os transforma em autoridades/referências religiosas atingindo outros públicos que não só os cristão e ganhando destaque na mídia por seus discursos de rigidez moral que se tornam polêmicos por seu conservadorismo excessivo.

O pastor Silas Malafaia, líder da igreja Assembleia de Deus, é uma dessas figuras polêmicas que tem se tornado um verdadeira "celebridade" midiática. Com mais de 1 milhão de seguidores nas 
redes sociais Facebook ${ }^{21}$ e Twitter $^{22}$, esse líder se coloca como autoridade cristã, mas cada vez mais apresenta na rede um discurso muito mais voltado para o secular que para assuntos relacionados ao sagrado.

Neste ano de 2016, o pastor colocou como pauta principal de seu discurso o impeachment a que foi submetida a presidenta do Brasil, Dilma Rousseff, se mostrando um defensor ativo das políticas de direita e totalmente contrário ao governo do partido da presidenta, o $\mathrm{PT}^{23}$. No Twitter, rede social em que o líder se mostra mais ativo, com publicações diárias constantes, é possível observar que suas publicações raramente dizem respeito a crenças religiosas, sendo seu enfoque principal: críticas aos petistas, que ele costuma chamar de "esquerdopatas" e "petralhas", e a todo o governo do PT, tendo como principal alvo o ex-presidente da república, Lula, e a atual presidenta. Esse tipo de abordagem parece uma tentativa de se manter como autoridade perante toda a sociedade, estabelecendo influência política, cultural, social e não apenas religiosa em uma sociedade secularizada, em que a religião não detém mais a hegemonia de outrora como produtora de sentido.

Numa análise dos tweetts do pastor no mês de março de 2016 , verifica-se que a palavra Deus só foi citada 20 vezes, enquanto o nome Lula aparece 91 vezes no mesmo período. Nesse mês o líder religioso twittou 963 vezes, desse total apenas 27 postagens faziam menção ao sagrado e 72 a assuntos relacionados à igrejas. A maioria, 792 postagens eram referentes a assuntos políticos, a maioria criticando o governo do Partido dos Trabalhadores. O uso dessas

\footnotetext{
${ }^{21}$ Facebook é uma rede de relacionamento social com mais de 1 bilhão de usuários do mundo todo. Entre suas funcionalidades está a publicação de conteúdo pessoal em forma de vídeos, fotos e texto, o compartilhamento de links de notícias, vídeos, gifs e a criação de páginas, perfis, eventos e grupos de discussão que permite a participação ativa de seus usuários.

${ }^{22}$ Twitter é uma rede social que funciona como um microblog, que permite aos usuários enviar e receber atualizações pessoais de outros contatos (em textos de até 140 caracteres, conhecidos como "tweets").

${ }^{23}$ O PT, sigla para Partido dos trabalhadores, é uma partido de esquerda que está no poder da presidência da república ininterruptamente desde 2002.
} 
mídias por parte dos líderes religiosos é muitas vezes ligado a seu potencial evangelizador, mas o que pode-se notar é um caráter muito mais re-territorializador, com o intuito de estabelecer a autoridade eclesiástica para além dos templos. A religião e o próprio sagrado ficam em segundo plano.

A partir dos comentários percebe-se que o pastor tem muitos seguidores que o apoiam comentando positivamente a favor de suas opiniões ali colocadas, curtindo e compartilhando as postagens. Mas é possível observar muitos seguidores contrários a muitas publicações do líder na rede social. Essas pessoas além de fazerem críticas, colocam diversos questionamentos com relação ao teor das publicações do pastor. Nos comentários da publicação com mais interação ${ }^{24}$ em março de 2016, vemos muitos seguidores elogiando a postura do pastor ao falar de política, colocando-o como um "bom exemplo" para o povo brasileiro, como alguém que defende o país da corrupção. Mas, há também inúmeros seguidores que não concordam com as publicações de Malafaia questionando o porque de o pastor não falar da Bíblia, acusando-o de usar as redes sociais para fins eleitoreiros, para incitar o ódio. Ao todo foram 92 comentários nessa publicação sendo 32 de apoio ao líder religioso e 60 contrários.

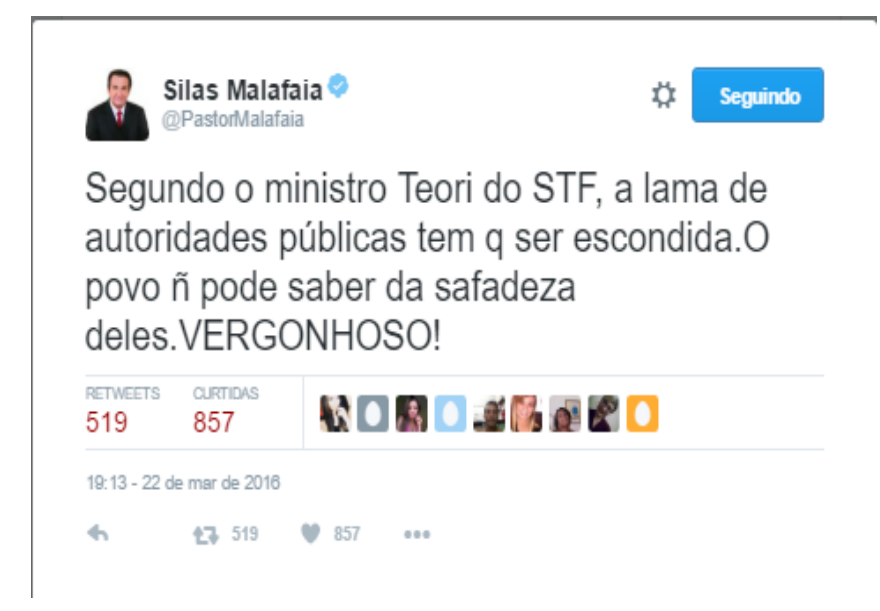

\footnotetext{
${ }^{24}$ Postagem de feita em 22 de março de 2016 às 19:13 com 857 curtidas e 483 compartilhamentos. Disponível em

$<\underline{\text { https://twitter.com/PastorMalafaia/status/712462304152047616?lang=pt }>}$ acesso em 06 de julho de 2016.
} 

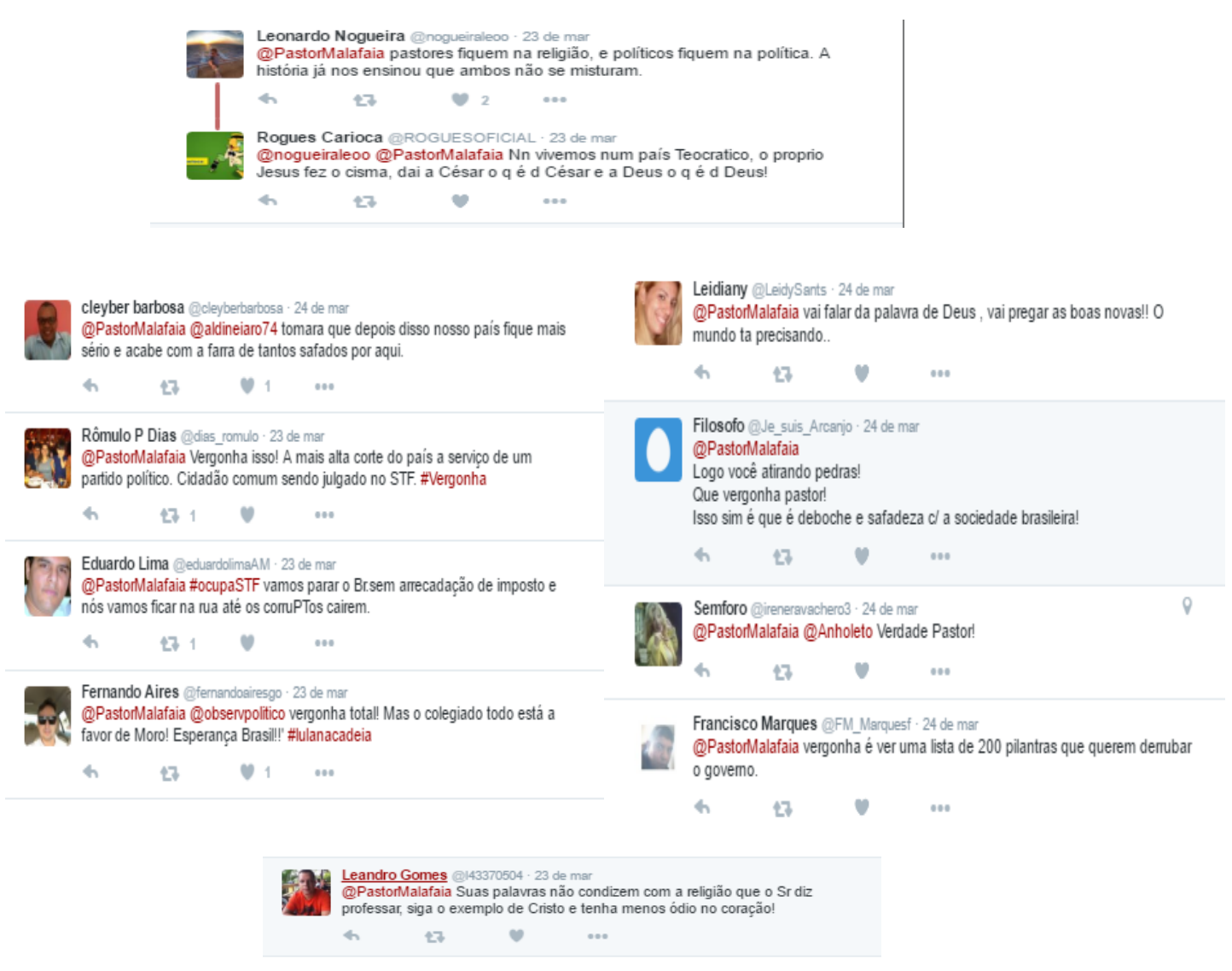

Tal situação mostra como as crenças tem se disseminado e se conformado cada vez menos com modelos estabelecidos pelas instituições, que tem sua capacidade reguladora enfraquecida (Hervieu-Léger, 2015). Vê-se uma "crise de autoridade" e consequentemente líderes que buscam legitimidade junto às mídias sociais a qualquer custo, sendo polêmicos, adentrando nos mais diversos assuntos, como forma de se manter presente e recuperar a influência que outrora a igreja já teve na sociedade.

\section{Considerações finais}

$\mathrm{Na}$ pós-modernidade e principalmente com a sociedade em rede, há um aspecto de perda da regulamentação institucional religiosa conforme descrito por Hervieu-Léger (2015), dando sinais da passagem de uma "religião instituída" para uma "religião recomposta". Assim, o que se vê são [...] "instituições que tentam renovar sua pedagogia em direção às jovens gerações cujos comportamentos e expectativas as derrotam" (Hervieu-Léger, 2015, p. 57), numa tentativa de conquistar, ou reconquistar seu espaço na cenário religioso contemporâneo em que se evidencia uma 
territorialidade institucional enfraquecida e que divide a cena com diversas outras territorialidades religiosas. Com a possibilidade de qualquer pessoas gerar conteúdo e manifestar seus pensamentos por meio de ferramentas online através de publicações em blogs e redes sociais "relativizou doutrinas e tradições teológicas e a autoridade das clássicas lideranças (pastores, bispos, presidentes de igrejas)" (Cunha, 2016, p.14).

Revela-se assim uma religião, encarnada na figura de seus líderes, que se apropria dos aparatos midiáticos, principalmente das mídias sociais digitais, para se manter na conquista, não apenas de seguidores, mas de autoridade, haja visto o interesse cada vez maior desses líderes por assuntos políticos que muitas vezes são a pauta de maior destaque em suas páginas e perfis. Assim, usa-se os meios de uma sociedade secularizada, pregando no entanto a autonomia da igreja detentora dos valores éticos e morais da fé cristã.

\section{Referências}

Campbell, Heidi. A (org.). Digital Religion: Understanding Religious Practice in New Media Worlds. New York: Routledge, 2012. Castells, Manuel. A sociedade em rede. São Paulo: Paz e Terra, 1999. Featherstone, Mike. Cultura de Consumo e Pós-Modernismo. São Paulo: Studio Nobel, 1995.

Cunha, Magali Nascimento. Elucidações contemporâneas nos estudos brasileiros em mídia e religião: a perspectiva das mediações culturais e comunicacionais. Revista FAMECOS: Porto Alegre, v. 23, n. 2, maio, junho, julho e agosto de 2016.

Giddens, Anthony. Mundo em descontrole: o que a globalização está fazendo de nós. Rio de Janeiro: Editora Record, 2011.

Gil Filho, Sylvio Fausto. Espaço de representação e territorialidade do sagrado: notas para uma teoria do fato religioso. Revista Ra'e Ga. V.3, p. 91-120, 1999.

Gil Filho, Sylvio Fausto. Espaço Sagrado: estudos em geografia da religião. Curitiba: Inter Saberes, 2012.

Haesbaert, Rogério. Território e Multiterritorialidade. Um Debate. I Seminário Nacional sobre Múltiplas

Territorialidades, Programa de Pós-Graduação em Geografia da UFRGS, Curso de Geografia da ULBRA e AGB-Porto Alegre, 23 de setembro de 2004. 
Hall, Stuart. A identidade cultural na pós-modernidade. $10^{a}$. Ed. Rio de Janeiro: Editora Lamparina, 2014.

Hervieu-Léger, Danièle. O Peregrino e o Convertido. A religião em movimento. Petrópolis - RJ: Vozes, 2015.

Jameson, Fredric. Pós-Modernismo. A Lógica Cultural do

Capitalismo Tardio. 2a ed. São Paulo: Ática, 1997.

Lévy, Pierre. Cibercultura. São Paulo: Ed. 34, 1999

Mariano, Ricardo. O futuro não será Protestante. Ciencias Sociales y Religión/Ciências Sociais e Religião, Porto Alegre, ano 1, n. 1, p. 89-114, set. 1999.

Mariano, Ricardo. Neopentecostalismo: sociologia do novo pentecostalismo no Brasil. São Paulo: Loyola, 1999. 


\section{El retroceso de una investigación: políticas públicas de inclusión digital en escuelas secundarias, en el marco de la restitución conservadora}

Leonardo González. Universidad Nacional de La Plata (Argentina). leonardo.gonzalez@presi.unlp.edu.ar

Sebastián Novomisky. Universidad Nacional de La Plata (Argentina). sebastiann@perio.unlp.edu.ar

Claudia Suárez Baldo. Universidad Nacional de La Plata (Argentina). ccsuarezbaldo@gmail.com

Julia Barba Pertine. Universidad Nacional de La Plata (Argentina). julybarba@hotmail.com

\section{Introducción}

D ENSÁBAMOS, desde el Centro de Investigación y Desarrollo en 1 Medios Industrias Culturales y Televisión (CEID - TV) presentar, este año, nuevos avances en materia de la expansión de las políticas públicas investigadas. Suponíamos que un cambio de gobierno no modificaría tan severamente la matriz política soberana desarrollada, incluso con apoyo de la oposición, durante los últimos 12 años. Pero nos equivocamos. Este nuevo, y a la vez reciclado proyecto político, en apenas tres meses, logró desarticular la matriz soberana que, con políticas de desendeudamiento se había logrado, de apoco, construir. Comenzado por el desfinanciamiento y la privatización del Satélite Argentino Arsat, el vaciamiento de la 
Televisión Pública Digital, y la entrega a Microsoft, Google y Clarín del abastecimiento de computadoras a escuelas públicas, docentes e investigadores que promovía el programa Conectar Igualdad, deslegitimando todo el desarrollo en investigaciones y tecnológicas locales que generaban, por un lado, el crecimiento tecnológico científico local, generando nuevas posibilidades de empleo, pero principalmente produciendo herramientas estratégicas para la independencia económica y política.

\section{Conectar Igualdad y el Programa Mi TV Digital a las escuelas secundarias públicas del Gran La Plata, hasta diciembre de 2014.}

Según el relevamiento realizado en esta investigación, hasta diciembre de 2014, el $91 \%$ de las escuelas consultadas recibieron las computadoras del Conectar Igualdad.

- 134 escuelas del total del registro (148) recibieron las computadoras del Conectar Igualdad.

La principal distribución de las máquinas se realizó en el año 2012, cuando se repartieron casi el 50\% de las netbooks que hoy pertenecen a lxs estudiantes y docentes de las escuelas secundarias públicas. Estas computadoras no poseen la antena de la TV Digital Abierta, que será incluida en las netbook 2013-2014.Con respecto al funcionamiento de las máquinas: Intranet (conexión intra-sistema) funciona eficientemente en un $96 \%$ de los casos consultados. En relación al mantenimiento de las computadoras la proporción es idéntica, 96\% de lxs directivxs aseguran que las máquinas son reparadas.

Sobre la capacitación a docentes para el manejo de los programas educativos de las computadoras: En 109 escuelas del total de 134, directivxs afirman que lxs docentes necesitan capacitación para el uso de las máquinas.

Del 91\% de las escuelas consultadas, las computadoras son utilizadas para "uso personal" en la institución, por fuera del contrato de enseñanza- aprendizaje del aula. Las netbook también llegan para lxs docentes y las computadoras son utilizadas para usos personales y/o capacitaciones. El espíritu de la política pública es la distribución de netbook para la inclusión digital, es decir no es solo para el aula. 
También es para las prácticas cotidianas de la vida: capacitaciones, redes sociales, escritura de trabajos y cartas, televisión, el diario, películas, radio, etc tanto de los/las docentes como de los/las alumnos/as.

En lo que respecta al uso de las netbook dentro del aula, los talleres en Escuelas Técnicas llevan la delantera. Todas las escuelas técnicas relavadas, 13 de 148, poseen Conectar Igualdad, funciona bien la Intranet e Internet, 3 de ellas Mi TV Digital y todas poseen Televisor en la escuela.

El 82\% de las escuelas consultadas poseen Internet. El 99\% de estas escuelas son clientes de Fibertel/Cablevisión, empresa del grupo Clarín. Una eficaz política de Responsabilidad Social Empresaria cubre casi la totalidad de las escuelas que poseen Internet. Cablevisión/Fibertel ofrece el servicio de Internet y cable de manera gratuita a las escuelas públicas.

Con respecto al Programa Mi TV Digital solo 14 escuelas, un $9 \%$ del total de establecimientos consultados ha solicitado el Programa.

- El mayor pedido de Mi TV Digital se produjo durante las vísperas del último mundial de Fútbol, Brasil 2014.

En 32\% de las escuelas consultadas las netbook son edición 20132014 por lo tanto, poseen la antena para recibir la señal de la TDA, pero solo un $6 \%$ de esas escuelas tiene señal de la TDA.

- Un 91\% de los establecimientos poseen televisores tradicionales. De ellas, un 80\% TV por Cable.

- En un 93\% de los casos la TV circula por las aulas, pero sin el cable. Eventualmente se transmiten videos, documentales, preseleccionados por los/las docentes.

- Según directivxs, lxs estudiantes miran TV por la netbook, por fuera de la propuesta curricular formal.

\section{Síntesis del relevamiento cuantitativo}

\subsection{Democratización de Internet}

Para la inclusión y la disminución la brecha digital es necesario democratizar Internet. Creemos que la distribución material de las 
notebooks es una política fundamental y prioritaria; sin embargo sostenemos que las escuelas necesitan Internet para potenciar la utilidad de los equipos del Conectar Igualdad. En este sentido la creación de la empresa ARSAT, con dos satélites lanzados y uno tercero en preparación, sumado a la red de fibra óptica y las antenas de TDA, nos anima a pensar la posibilidad de crear una red de conexión gratuita y soberna. Por ello celebramos la democratización de las computadoras del Conectar Igualdad, los decodificadores y antenas del Programa Mi Tv Digital, pero insistimos en la necesidad de sumar conectividad a la Web.

\subsection{Estrategia de recepción de Mi TV Digital y rechazo a la TV como herramienta formativa}

A diferencia del Conectar Igualdad, que llega a las escuelas como un derecho al acceso tecnológico/digital de estudiantes y docentes; el Programa Mi TV digital debe ser solicitado por las escuelas mediante un formulario on-line. Consideramos que esta estrategia de recepción es equivocada, pues la Escuela, históricamente, ha rechazado los contenidos de la televisión por considerarlos no formativos, mero entretenimiento o simplemente pérdida de tiempo. Es importante trabajar aquí en la transformación de los contenidos que propone la TDA, a partir de la implementación de la Ley de Servicio de Comunicación Audiovisual. La propuesta de la TDA abona más al receptor ciudadano que a las lógicas del televidente consumidor. De todas maneras el rechazo de la escuela a las pantallas nos habla más de una resistencia, de una conservación del espíritu moderno fundacional del libro, el pizarrón y el lápiz y de la relación asimétrica del conocimiento.

De manera esperar a que lxs directivxs soliciten el programa no es una buena iniciativa y consideramos que un lugar de expansión del encendido de la TDA es las escuelas. Esto debe desarrollarse de la mano de una política activa de instalación de decodificadores y antenas, junto con un trabajo de capacitación en el uso de esta nueva televisión como recurso didáctico. 


\subsection{Capacitación Docente}

La necesidad de formación es una de las constantes que surge cuando se realizan las consultas sobre el programa Conectar Igualdad. Seguramente aún no se logró un dispositivo que cumpla con muchas de las demandas existentes pero en relación a esto, el Estado Nacional ofrece cursos y paga a docentes para que asistan. El monto no es elevado pero resuelve gastos de traslado y comida. En este sentido es importante remarcar también la tarea del Programa Nacional de Formación Permanente Nuestra Escuela, desarrollado por el Instituto Nacional de Formación Docente INFOD, que capacita gratuitamente, con certificación oficial y puntaje a docentes de todo el país. Al momento, el Programa Nacional, ha capacitado a 800.000 docentes en todo el territorio Nacional.

Las políticas desarrolladas en los últimos doce años vinculadas a lo educativo y a lo comunicacional, encuentra articulaciones con un potencial inédito en el país. La posibilidad de contar, no solo con un nuevo sistema de televisión, sino que el mismo esté acompañado por una política de fomento a la producción regional y a la aparición de dos canales del Ministerio de Educación de la Nación, la llegada de más de cinco millones de netbooks entregadas en las escuelas de todo el territorio nacional y en su interior la tecnología necesaria para la recepción de la TDA, transforman hoy, un escenario de convergencia tecnológica en una realidad única.

La posibilidad de contar con recursos técnicos, contenidos educativos novedosos y una mirada, que, desde el Estado, pretende reposicionar la educación pública como un pilar de nuestra sociedad, enfrenta el desafío de profundizar lo hasta aquí realizado, reconociendo las principales limitaciones encontradas. Un sistema de soporte técnico más eficiente con conectividad en todas las escuelas a Internet, un dispositivo de capacitación docente que siga incorporando cada vez más a quienes son lxs actores fundamentales de la transformación escolar, un debate profundo sobre la necesidad de modificar con los recursos disponibles el sistema educativo nacional, la decisión de ingresar masivamente con los contenidos de la TDA a las instituciones escolares, son algunos de los desafíos pendientes para lograr cristalizar un cambio profundo en la educación argentina. 
Por ello, los resultado de ésta investigación, lejos de mostrar logros rotundos, permite reflexionar sobre el enorme potencial de lo realizado, pero la imperiosa necesidad de seguir profundizando estas líneas de trabajo.

\section{Políticas públicas de inclusión digital en escuelas, en el marco de la restitución conservadora}

Estos últimos párrafos constituyeron, durante 2014 y 2015, las conclusiones de nuestra investigación, proponiendo un rumbo en el sentido de profundizar esta investigación en coincidencia al crecimiento de los objetivos de las políticas públicas, en el marco de un proyecto político que promovía la igualdad y la justicia social como vector principal. Sin embargo, en noviembre de 2015, por legítimas elecciones, triunfó un proyecto político liberal conservador. A pesar de las promesas emitidas en campaña de continuar con lo que el gobierno de Néstor Kirchner y Cristina Fernández habían logrado en materia de ampliación de derechos, crecimiento económico local con soberanía política; la primera medida del gobierno de Mauricio Macri fue desarticular el organismo legal que regulaba la implementación de la Ley de Servicios de Comunicación Audiovisual, para permitir que las empresas de comunicaciones vuelvan a concentrarse legalmente.

Esta primera y apresurada decisión política delineó la orientación de lo que ocurriría después.Hace unas semanas, Diego Marías, jefe de Gabinete del Ministerio de Educación y Deportes de la Nación, informó a las autoridades del programa Conectar Igualdad que toda el área de asistencia e inclusión digital será desmantelada de aquí a abril próximo. El programa Conectar Igualdad es una política pública que tenía por objetivo <reducir la brecha digital y mejorar la calidad de la educación pública en la escuela secundaria para promover valores como la integración y la inclusión social $>$ (Conectar Igualdad, 2010) entregando a estudiantes de secundarios y terciarios públicos computadoras, ensambladas en Tierra del Fuego, con un sistema informático libre, denominado Huayra. Al tiempo que capacitaba a docentes para introducirlos en el mundo digital.

La decisión del gobierno no es azarosa. No se abandonan los soportes materiales, es decir la entrega de computadoras a estudiantes 
y docentes, sino que, lo que se abandona, es la producción de formatos y contenidos nacionales. Para ello fue necesario desafectar a 1100 trabajadorxs, no solo en sintonía con la matriz conservadora de achicamiento del Estado, también porque esos trabajadores sostenían el sistema soberano Huayra GNU Linux. Esta decisión coincide con el encuentro que, Mauricio Macri, tuvo con el CEO de Windows, Sayta Nadella, en el mes de enero en Davos. Allí, el referente de la compañía trasnacional, le prometió al gobierno argentino, la entrega gratuita del sistema operativo Windows y sus servicios de almacenamiento virtual para estudiantes, docentes e investigadores.

En buena medida, lo que ocurre si se desarticula el área de desarrollo es dejar de reinventar la rueda. Microsoft ofreció todo un paquete y de forma gratuita, ¿Para qué entonces complicarse con más desarrollo? Por supuesto, después está la cuestión ideológica, pero ese es otro tema.Diego Marías.

El gigante estadounidense también le ofreció a Macri la posibilidad de brindar asesoramiento a unos 100 investigadores locales para que profundicen sus conocimientos de esta plataforma. Microsoft, Google y la pata local, Clarín son las encargadas de convertir la soberanía política, económica y cultural en un formidable negocio. Algo similar sucede con el Satélite Argentino Arsat, empresa del Estado nacional creada para brindar servicios de telecomunicaciones, también responsable del desarrollo de satélites y la infraestructura terrestre para el sistema de televisión digital en Argentina. Arsat, financiada enteramente por el Estado nacional, creó las condiciones para la soberanía satelital/ informática. Luego de que el flamante ministro de Comunicaciones Oscar Aguad y el diplomático francés Jean-Michel Casa, mantuvieron un encuentro en el que analizaron la firma de un acuerdo marco de cooperación en el ámbito de las comunicaciones satelitales y de las aplicaciones espaciales, anticipándose a la visita del presidente de Francia, Francois Hollande, en febrero último. Rumores afirman que ARSAT 1 y ARSAT 2 pasan a control de la empresa Francesa "TALENT". La empresa francesa tiene contratos con Clarín para la distribución de la señal de internet local. Entonces, es probable que todxs lxs argentinxs le paguemos a Clarín y a la empresa francesa para que nos venda 
internet de nuestro propio satélite. El grupo de multimedios acordó con Macri ser el único proveedor de internet en establecimientos del Estado. De esta manera le cedimos la soberanía informática al monopolio Clarín. Para levar adelante esta empresa, se despidieron 22 empleados. "Son cargos jerárquicos, no se tocó a ningún científico", admitieron desde el organismo, reconociendo el cambio de rumbo ideológico que inaugura este encuentro y dejando a "lxs científicxs" también a las orden de Clarín.

Despidos de trabajadores del Estado, la suspensión de programas públicos, la enajenación de la capacidad de decidir, continua, día a día, sumando capítulos.El gobierno de Mauricio Macri decidió retirar al estado argentino de la cadena Telesur, la señal internacional impulsada en el año 2005 por el fallecido presidente Hugo Chávez como una forma de hacer frente a las cadenas norteamericanas como la CNN que bajo el lema "Nuestro norte es el sur". La decisión de abandonar la empresa La Nueva Televisión del Sur C.A. -integrada por los gobiernos de Venezuela, Cuba, Bolivia, Nicaragua, Uruguay y Argentina- fue tomada por el ministro de Medios y Contenidos Públicos, Hernán Lombardi, y el secretario de Comunicación Pública, Jorge Grecco. Argentina tenía hasta entonces el 16\% de las acciones. La emisión -advirtieron- dejará de ser de inclusión obligatoria en las grillas de todos los cableoperadores del país, algo que había sido dictado el 9 de septiembre de 2010 por la hoy disuelta Autoridad Federal de Servicios de Comunicación Audiovisual (Afsca). También, dejará de emitirse en la Televisión Digital Abierta, que dicho sea de paso el macrismo paralizó la inversión sobre este sistema de televisión cuando estaba a punto de ampliarse su alcance."Nuestro país no tenía ninguna injerencia en los contenidos de la señal ni en su gerenciamiento. Esta determinación va en línea con lo que nos hemos propuesto para los medios públicos en términos de pluralismo y austeridad", dijo el ministro Lombardi. Telesur es una de las pocas voces críticas que podía verse en la TDA. Esto constituye, al contrario de las declaraciones de Lombardi, un atropello a la calidad de la TDA, una fenomenal censura a la diversidad de opiniones y la consolidación de un discurso único como nunca antes visto en la televisión argentina en democracia. Otro ejemplo del vaciamiento de la TDA, es la enajenación del Fútbol para Todos. Actualmente el único contenido que produce la TDA es Fútbol para Todos, el resto 
de su programación, en los canales públicos (PakaPaka-EncuentroTV Publica) es repetida, es decir producida años anteriores.Fútbol Para Todos es su única producción y fue entregada, en sus porciones más jugosas, los partidos más importantes a Telefe, Canal 13 (Clarín) y América TV, por solo el $10 \%$ de sus potenciales ganancias en ventas de publicidad. Produce el Estado Nacional y las ganancias son para los Multimedios, a cambio, claro, de complicidad, complacencia, amistad, silencio.

\section{Consideraciones finales}

El "espíritu" En una conferencia dictada en la Facultad de Periodismo y Comunicación Social de la Universidad Nacional de La Plata, denominadaSituación actual de la educación argentina, contexto y perspectivas, Adriana Puiggros, afirmó que la autonomía de las universidades estaba en crisis por la extraordinaria toma de deuda externa que estaría planificando el gobierno Mauricio Macri, y cómo, producto de esta lógica de desarrollo, la creciente "mercantilización de lo público". De modo que, si volvemos a la lógica del endeudamiento, volvemos a los condicionamientos políticos y económicos, volvemos a los orientaciones internacionales para la investigación.

El desarrollo de este proyecto de investigación, que realizamos desde el Centro de Investigación y Desarrollo en Medios Industrias Culturales y Televisión (CEID - TV) se vio terriblemente modificado por el rotundo cambio en las condiciones macro económicas, sociales, educativas, culturales, que insistimos, en tres meses, el gobierno de Mauricio Macri decretó. Imaginábamos, para este año, presentar nuevos avances en materia del alcance concreto de las políticas públicas y nos encontramos con un escenario completamente adverso. Un Estado en franco retroceso, despidiendo trabajadores, desfinanciando y desarticulando políticas públicas, enajenando sus empresas y su soberanía. El modelo de desarrollo de este gobierno es el endeudamiento externo, ésta es la política fundamental. Un Estado reducido, administrativo, funcional al capital, que busca inversores externos para el desarrollo privado local. 100 días bastaron para desmoronar la matriz soberana construida por 12 años de kirchnerismo. 
En este camino, la inclusión digital en particular, pero fundamentalmente la inclusión social en general, corre serios riesgos. El abandono del desarrollo e investigación en tecnologías propias, a partir la generosa oferta de las multinacionales, es, de nuevo, aceptar los condicionamientos de la dependencia. Ésta es la cuestión ideológica que no le interesa $\mathrm{Al}$ funcionario Marías, como tampoco le debe interesar la concentración y extranjerización de la economía, los millones de puestos de trabajo perdidos, la desinversión y la fuga de científicos la precarización laboral, el ajuste social que estas políticas traen, inevitablemente aparejadas.

\section{Referencias}

Crettaz, José. (2016, 27 de marzo) El Estado Argentino se va de la cadena Telesur. En La Nación digital. Recuperado de http://www.lanacion.com.ar/1883455-el-estado-argentino-seva-de-la-cadena-telesur

Gonzalez, Leonardo. (2014-2015) Proyecto de Investigación Políticas públicas de Inclusión tecnológico/Digital. Procesos formativos en escuelas públicas de la provincia de Buenos Aires: Tv digital y Conectar Igualdad, en el Centro de Investigación y Desarrollo en Medios Industrias Culturales y Televisión (CEID - TV) Facultad de Periodismo y Comunicación Social de la Universidad Nacional de La Plata, Argentina.

Novomisky, Sebastián; GERMANIER, Fernanda García (2013) Televisión y Nuevas Tecnologías en América Latina. Centro de Investigación y Desarrollo em Comunicación, Industrias Culturales y Televisión (CeID-TV).

Palladino, Alejandro. (2016, 5 de marzo) Despidos en Conectar Igualdad. En Diario digital Contexto. Recuperado de http://www.diariocontexto.com.ar/2016/03/05/despidos-enconectar-igualdad-una-medida-que-deja-destruido-al-programa Consulta

Pauloni, Silvina; CODONI, María Florencia (2013) Conceptos y Contextos sobre la TV. Centro de Investigación y Desarrollo en Comunicación, Industrias Culturales y Televisión (CeID-TV). 2013. 
Programa Conectar Igualdad. Disponible en

http://www.conectarigualdad.gob.ar/seccion/sobre-programa$\underline{6}$

Programa Nacional de Formación Permanente Nuestra Escuela.

Disponible en http://nuestraescuela.educacion.gov.ar/el-portaleduc-ar-en-nuestra-escuela/

Puiggros, Adriana. Conferencia Situación actual de la educación argentina, contexto y perspectivas.Facultad de Periodismo y Comunicación Social. Febrero 2016

Struminger, Brenda. (2016, 13 de enero) Arsat admite que despidió a 22 empleados: "Son cargos jerárquicos, no se tocó a ningún científico" En La Nación digital. Recuperado de http://www.lanacion.com.ar/1861764-arsat-admite-quedespidio-a-22-empleados-son-cargos-jerarquicos-no-se-toco-aningun-cientifico

Television digital abierta. Disponible em http://www.tda.gob.ar/contenidos/tv digital.html 



\title{
Cyberbullying: Retos para una ciudadanía inclusiva, tolerante y respetuosa de las diferencias en el ciberespacio
}

\author{
Patricia Henríquez Coronel ${ }^{25}$. \\ Universidad Laica Eloy Alfaro de Manabí (Ecuador) y Universidad de \\ Los Andes (Venezuela). henriquezpatri@gmail.com
}

\section{Introducción}

T A PREMISA de partida para este artículo es que el discurso $\checkmark$ acerca de las apremiantes necesidades de adquisición de habilidades y competencias cognitivas y técnicas para hacer frente a los retos de la Sociedad de la Información y el Conocimiento seguramente ha opacado otro reto de tanta valía como ese. No es otro que la adquisición de competencias del "saber convivir" que promuevan una ciudadanía responsable, respetuosa y tolerante ante la diversidad, en los distintos contextos virtuales que los jóvenes habitan.

Se nos antoja tan importante lo cognitivo como lo socio afectivo en la formación de la persona para esta sociedad tecnocultural (Rueda, 2004); por eso queremos poner en relieve la necesidad de realizar intervenciones e investigaciones en programas que promuevan una

\footnotetext{
${ }^{25}$ La autora agradece al Consejo de Desarrollo Científico, Humanístico y Tecnológico CDCHT de la ULA por el financiamiento de esta investigación bajo el código NUTA-H-373-14-04-F
} 
ciudadanía digital responsable desde las familias ${ }^{26}$ y las escuelas, lo que ciertamente coadyuvara a la prevención y tratamiento adecuado del cyberbullying y otras amenazas propias de entornos virtuales como el ciberespacio.

Basta analizar la ligereza con que se profieren insultos junto a la rapidez y masividad con que despiadadamente se "lincha digitalmente" a una persona en las redes sociales para entender lo lejos que se ha llegado en esa ausencia de ciudadanía digital en el ciberespacio. Una muestra reciente de tal afirmación es el caso de la académica de la Universidad de Cambridge Mary Beard ${ }^{27}$ y el aluvión de hirientes críticas que, sobre su aspecto personal, circularon en redes sociales desde su aparición en el programa divulgativo "Meet the Romans" de BBC TWO. De modo que conviene recordar con Lindo (2015) "cómo nuestra naturaleza no es menos agresiva que la de aquellos viejos imperios que hoy tenemos por más crueles."

Al hilo de estas ideas, este artículo presenta los resultados parciales de una investigación titulada "Nuevas prácticas comunicativas: Cyberbullying en estudiantes de bachillerato en edades comprendidas entre 12 y 17 años en San Cristóbal" financiada ${ }^{28}$ por el Consejo de Investigación CDCHT de la Universidad de Los Andes que persigue como objetivo final la promoción de buenas prácticas en el uso de las herramientas TIC, cónsonas con el reconocimiento de la alteridad y el respeto por la diversidad, que eviten situaciones de acoso juvenil tan frecuentes en las ciberculturas juveniles (Henríquez, 2012). Por eso aunque esta investigación incluye un área descriptiva exhaustiva

${ }^{26}$ Recientemente la Fundación Telefónica lanzo su programa Familia Digital como "el Centro de Recursos para Padres de Movistar cuyo objetivo es impulsar la educación digital y contribuir a crear un Internet mejor para los niños y adolescentes". La importancia de este recurso es que no sólo se dirige a las familias, cuya función en la educación de ciudadanos es central, sino a educadores y todas aquellas personas involucradas en la educación de los niños". Este espacio puede ser consultado desde http://familiadigital.net/

${ }^{27}$ Los interesados pueden seguir la historia en detalle en el articulo "Las palabras hieren" firmado por Elvira Lindo y publicado por el diario El País de España el 9 de octubre en la siguiente URL http://elpais.com/elpais/2015/10/09/estilo/1444394159_483109.html ${ }^{28}$ Este proyecto recibió financiamiento del CDCHT ULA bajo el código NUTA-H-373-14-04-F. 
acerca del cyberbullying, causas, tipología, patrones temporales, herramientas usadas, perfil de los agresores, grado en que las victimas comunican el problema, quisimos para este trabajo centrarnos en los aspectos relacionados con los efectos emocionales del cyberbullying y las actuaciones de los adultos frente a casos de cyberbullying en el contexto estudiado. Ambas cuestiones serían las bases para el diseño de propuestas relacionadas con programas preventivos.

\section{Marco teórico}

Internet representa para los jóvenes un mundo tan real como el mundo físico en el que habitan. Dentro de Internet cobran vida verdaderas ciberculturas juveniles (Urresti, 2008) como ámbitos de encuentro virtual entre jóvenes al margen de distancia para intercambiar datos, relacionarse para configurar la imagen de sí mismo y tomar conciencia de la generación a la que pertenecen. Los jóvenes cuyos cuerpos habitan la ciudad tienen en Internet otro self deslocalizado y destemporalizado.

Por eso en el mundo virtual de Internet, podemos encontrar por un lado un potencial enorme de servicios, herramientas, información y espacios de socialización útiles para los jóvenes y por otro una serie de riesgos y amenazas tal como sucede en el mundo real. Una de estas amenazas de Internet es el cyberbulling.

Cyberbulling $^{29}$ es el uso de los servicios y recursos de Internet, videojuegos online o telefonía móvil para ejercer el acoso psicológico entre iguales. Aftab (2006) especifica que el ciberbullying se produce "cuando un niño, pre-adolescente o adolescente es atormentado, amenazado, acosado, humillado, avergonzado o se convierte en blanco de otro niño, pre-adolescente o adolescente usando Internet, tecnologías interactivas y digitales o teléfonos celulares.

Para Kowalski, Limber y Agatston (2010) el problema del acoso escolar no es nuevo lo que es diferente es el instrumento o herramienta por el que se materializa la agresión. Belsey(2006) afirma que bullying y cyberbullying difieren en intensidad y en frecuencia,

\footnotetext{
${ }^{29}$ A lo largo de este trabajo usaremos el término cyberbullying, en inglés, por ser la voz más frecuente en la literatura especializada del tema. Sin embargo en ocasiones usaremos el sinónimo ciberacoso.
} 
siendo mayor la de cyberbullying porque ocurre en una generación que siempre está conectada. Las tecnologías móviles han hecho las comunicaciones mas ubicuas por tanto se puede agredir desde cualquier lugar y en cualquier momento.

Con relación a los tipos de ciberacoso, la literatura suele presentar indistintamente las herramientas TIC usadas para ejecutar el cyberbullying (Smith, Peter, Jess Mahdavi, Manuel Carvalho y Neil Tippett, 2006; Hernández y Solano, 2007; Aviles, 2009) como la propia conducta agresora. Algunos como Willard(2006) o Kowalski, Limber y Agatson(2010) indican que dada la versatilidad de las TIC, la cual implica distintos usos para una sola herramienta, resulta más adecuado distinguir las conductas de agresión y no las herramientas usadas. Las conductas de agresión mas frecuentes se refieren a insultos electrónicos, hostigamiento, denigración, suplantación de identidad, desvelamiento y sonsacamiento de información que la víctima no quería publicar, exclusión y ostracismo.

Centrándonos en el aspecto que será eje de este artículo, los efectos del cyberbullying, estos son variados y pueden ir desde los casos extremos de suicidio de la víctima o de asesinato del agresor, hasta los casos que tienen otro tipo de consecuencias que no desencadenan acciones físicas contundentes. Estas consecuencias, sin embargo, dejan huella en la emocionalidad de quien lo sufre y se evidenciada en depresión, baja autoestima, ansiedad social, problemas de concentración entre otros. En un estudio de Kowalski y Witte (2006) las victimas dijeron sentirse tristes, deprimidos, rabiosos, estresados y confundidos. Mientras los agresores dijeron sentirse: agresivos, vengativos, felices y satisfechos.

Algunos autores se inclinan a sugerir que los efectos del cyberbullying son a largo plazo incluso peores que los del acoso escolar tradicional (bullying) por su ubicuidad, característica que dificulta a la victima escapar de la situación. Solo desconectando de las comunicaciones electrónicas podría librarse y esto tiene un alto costo en la socialización de los jóvenes que ocurre de forma habitual en este entorno. Además el mayor alcance del ciberacoso hace que los espectadores de la agresión sean exponencialmente mayores que los del acoso tradicional; hay por tanto mayor exposición pública de la víctima y pueden aumentar los sentimientos de vergüenza. 
En cuanto a la prevención de episodios de acoso, sin duda la clave la tiene una educación, que como decíamos antes propenda a formar competencias del "saber convivir" también en el ciberespacio. Bill Belsey, maestro canadiense, creador de www.cyberbullying.ca y quizás una de las personas más reputadas en la prevención de las conductas de cyberbullying señala que la única clave del asunto es la educación y la sensibilización porque una vez que la conducta agresora ha ocurrido es difícil y costoso en tiempo lograr resarcir a la víctima.

Padres, maestros y demás adultos alrededor de los jóvenes tienen un gran compromiso en la prevención del ciberacoso. No se trata simplemente de decir a los hijos que tienen que tratar a los demás con respeto. Después de años de investigación se ha comprobado que los adultos no pueden transmitir un mensaje solo una vez y esperar que los menores lo hayan recibido y que lo incorporen a la práctica. Por otra parte y por cuanto los padres rara vez están presentes en el mundo online de los niños y los adolescentes, es de fundamental importancia que en la familia existan pautas específicas sobre la conducta en el ciberespacio y crear un entorno doméstico que favorezca la supervisión.

Los maestros y los consejos escolares deben fijar normas claras sobre el uso de las TIC entre los escolares, que fomenten el trato digno, respetuoso y tolerante hacia las diferencias, en síntesis el "saber convivir". Normas que deben hacer explícita la prohibición del cyberbullying y considerar las sanciones en caso de que ocurra. Padres y maestros deben concertar acuerdos acerca del compromiso que tienen en la formación de ciudadanía digital en los jóvenes y su implicación directa en programas de educación para el "saber convivir".

\section{Marco metodológico}

Se trata de una investigación descriptiva, que persigue proveer un registro amplio de los casos de cyberbullying entre escolares de una ciudad particular ${ }^{30}$, que hasta ahora no han sido investigados. El

\footnotetext{
${ }^{30}$ La investigación ha sido realizada en la ciudad de San Cristóbal en Venezuela. Esta localidad ha sido conmovida en los últimos años por noticias aparecidas en los medios de comunicación acerca de suicidios e incluso agresiones con final de deceso en jóvenes escolares.
} 
estudio busca por tanto describir situaciones o acontecimientos; no está interesada en comprobar explicaciones ni en probar determinadas hipótesis.

En este caso, ciertamente el problema del cyberbullying es poco conocido y menos estudiado en el contexto geográfico y temporal en que se plantea esta investigación de allí la relevancia y necesidad de abordar su estudio.

La primera fase en este estudio permitió determinar las características que se iban a describir tales como la frecuencia de cyberbullying como interrogante principal y las preguntas siguientes acerca de sus características, tipos, perfil de los agresores, grado en que las victimas comunican el problema, actuación de los amigos, padres o adultos que intervienen, los sentimientos de los agredidos.

La población objeto de la investigación han sido los escolares de la ciudad que potencialmente pudieran ser agredidos o agresores en episodios de cyberbullying. En este caso particular se trataría de estudiantes cuyas edades oscilan entre los 7 y los 17 años, sin embargo estudios anteriores (Fight Crime Preteen, 2006 en Kowalski, Limber y Agatston, 2010, p. 124) han confirmado que las tasas más altas de cyberbullying se encuentran entre los 12 y los 17 años, por eso se ha decidido tomar la población a estudiar dentro de ese rango etario.

El muestreo empleado fue el de conveniencia que sugiere la posibilidad de que el investigador determine los elementos que deben componer la muestra atendiendo a características de especial interés para el estudio. Se han seleccionado tres instituciones educativas de la ciudad que representan los dos criterios de escogencia fijados: a) Origen socioeconómico. Los escolares de estos centros pertenecen a los distintos estratos socioeconómicos del país, que de acuerdo a los datos del BCV son el A, B, C, D y E, siendo el de mayores ingresos el estrato A. Se ha seleccionado un centro escolar privado (IEA) cuyos alumnos provienen principalmente de estratos A y B, un centro escolar concertado $^{31}$ (IEB) cuyos alumnos provienen de estratos B, C

${ }^{31}$ Se trata de un centro que recibe financiamiento parcial del Estado, por tanto los padres pagan sólo una pequeña matricula mensual por la educación de sus hijos 
y D y, finalmente, un centro público cuyos alumnos son de estratos D y E (IEC). b) Tipología de centro educativo. Se han escogido centros de todas las tipologías existentes en el país: público, privado y concertado.

En cada centro escolar se espero la participación voluntaria ${ }^{32}$ de los estudiantes comprendidos en el rango etario previamente fijado. Se conto con un total de 193 alumnos distribuidos así

\begin{tabular}{|l|l|l|}
\hline IEA & IEB & IEC \\
\hline 74 alumnos & 74 alumnos & 45 alumnos \\
\hline
\end{tabular}

Dicen Kowalski, Limber y Agatston (2010) que la mayoría de las investigaciones existentes sobre acoso se basa en las encuestas y explican que una de las razones para confiar en ellas es que son fáciles de administrar y pueden ser contestadas por un gran número de personas. Además los cuestionarios aplicados para el estudio del cyberbullying suelen ser derivaciones de o adaptaciones de cuestionarios previos usados en casos de bullying que cuentan con gran fiabilidad y valor predictivo.

En esta investigación se ha usado un cuestionario construido por los autores partiendo de sendos cuestionarios: a) el cuestionario empleado por Smith, P. Mahdavi, J., Carvalho, M. y N. Tippetten (2006) en un amplio estudio en 14 escuelas de Londres cuyo objeto fue comprender de forma general el acoso o intimidación cibernética y su prevalencia en niños de entre 11-16 años y b). El cuestionario de Crochane(2008) para explorar cyberbullying entre estudiantes de escuelas rurales y urbanas en Saskatchewan al oeste de Canadá.

Ambos cuestionarios fueron traducidos del inglés al español por una experta cuya lengua nativa es el inglés. Posteriormente fueron adaptados a los modismos de la zona, se suprimieron algunos ítems y se añadieron otros que valoraban la emocionalidad envuelta en el ciberacoso.

La versión final del cuestionario construido tiene 47 preguntas, 43 de respuesta múltiple y 4 de respuesta abierta. Toma entre 20 y 25

\footnotetext{
${ }^{32}$ La participación voluntaria del encuestado pareció el método más honesto y responsable por lo delicado del tema.
} 
minutos para ser contestado. El cuestionario es anónimo y se garantiza a los participantes absoluta confidencialidad de los datos suministrados.

El instrumento fue validado por tres expertos: dos del área de evaluación y estadística y un experto en idiomas. Los criterios para la validación de cada ítem fueron la pertinencia, relevancia y claridad del ítem, valorado en escala del 1 al 5.

El cuestionario fue aplicado en el lapso de dos meses por la investigadora y dos auxiliares de investigación. Los datos fueron cargados a un programa de procesamiento estadístico y para su procesamiento se calcularon medidas de estadística descriptiva tales como frecuencias, medias y desviaciones estándar.

\section{Resultados del estudio}

Atendiendo a la especificidad y características de cada centro escolar los resultados se presentan de forma separada para las variables más generales (edad, género, acceso a TIC) y englobados en las variables en las que nos interesa profundizar el análisis tales como efectos del cyberbullying y acciones de los adultos responsables en los casos reportados de acoso.

\section{a. Datos demográficos}

Aquí consideramos las variables edad, género y acceso a las computadoras y a Internet desde casa y desde los centros escolares.

\section{Centro Escolar A (IEA)}

\section{La tabla No 1 resume los resultados obtenidos en el Centro Escolar A}

\begin{tabular}{|l|l|}
\hline No total de encuestados & 74 \\
\hline No de mujeres & 49 \\
\hline No de hombres & 23 \\
\hline Promedio de edad & 14 años \\
\hline
\end{tabular}

Tabla 1. Datos demográficos del IEA 
Con relación al acceso a las TIC se tiene que un $91,9 \%$ posee computador e Internet en casa y 94,6\% tiene acceso a Internet desde sus teléfonos móviles. Estos resultados confirman la condición socioeconómica de los alumnos que les garantiza una amplia disponibilidad a las TIC desde sus hogares.

Con relación al acceso desde el centro escolar, se obtuvo que $81 \%$ de los encuestados tiene acceso a computador en el colegio y $20 \%$ tiene acceso a Internet. En general se trata de un grupo de alumnos con amplias posibilidades de conectividad, especialmente porque se conectan a través del dispositivo móvil en un 70\% lo que les garantiza la ubicuidad en el acceso.

\section{Centro Escolar B (IEB)}

La tabla 2 resume las variables demográficas

\begin{tabular}{|l|l|}
\hline No total de encuestados & 74 \\
\hline No de mujeres & 38 \\
\hline No de hombres & 36 \\
\hline Promedio de edad & 13 años \\
\hline
\end{tabular}

Tabla 2. Datos demográficos del IEB

Respecto al acceso TIC se encontró que $76 \%$ posee computador en casa y 69\% tiene acceso a Internet desde ese computador. Adicionalmente un $51 \%$ de los encuestados en este centro escolar tiene acceso a Internet desde sus teléfonos móviles.

\section{Centro Escolar C (IEC)}

La tabla 3 resume las variables demográficas

\begin{tabular}{|l|l|}
\hline No total de encuestados & 45 \\
\hline No de mujeres & 23 \\
\hline No de hombres & 22 \\
\hline Promedio de edad & 15 años \\
\hline
\end{tabular}

Tabla 3. Datos demográficos del IEC 
Respecto al acceso TIC se encontró que $80 \%$ posee computador en casa y $73 \%$ tiene acceso a Internet desde ese computador. El acceso a Internet desde los teléfonos móviles de los encuestados es de un $56 \%$. Destaca que solo el 4\% dice tener acceso a computador en el centro escolar, lo que podría ser explicable por cuanto no todos los centros públicos del país poseen laboratorios de computadores. Igualmente reportan no tener acceso a Internet desde el colegio ${ }^{33}$.

\section{b. Frecuencia de cyberbulyying en los centros estudiados}

El segundo bloque de preguntas se refería a si el alumno ha sido víctima de cyberbullying y con qué frecuencia ha ocurrido el acoso. El gráfico No 1 resume los resultados obtenidos para los tres centros escolares.

Los resultados parecen indicar que en general, en las tres instituciones escolares, el acoso pudo haber sido episódico, mas no un problema reiterado en el tiempo. De hecho la frecuencia disminuye en la medida en que la periodicidad es mayor.

A continuación se preguntaba al encuestado que había sido acosado, cuáles eran las herramientas que usaron para acosarle. El grafico No 2 muestra que en los tres centros escolares, difiere las herramientas mas frecuentes para el acoso. Así, en el IEA el cyberbullying ocurre más frecuentemente por chat seguido de redes sociales y finalmente SMS. En el IEB, aparecen con resultados casi idénticos en primer y segundo lugar el chat y los SMS mientras baja a tercer lugar el acoso por redes sociales. Finalmente en el IEC en primer lugar se acosa por redes sociales, luego por SMS y en tercer lugar por email, no apareciendo el chat entre las opciones escogidas.

En cualquier caso, merece la pena acotar que la alta presencia de las redes sociales como herramienta de acoso, es un dato seguramente

\footnotetext{
${ }^{33}$ Esto podría entenderse como una consecuencia del nivel socioeconómico de los alumnos del centro pero también podría deberse al cumplimiento de la circular 001 promulgada el 16 de mayo de 2011 por el Ministerio del Poder Popular para la Educación de Venezuela a través de la zona educativa, la cual establece restricciones para el uso del celular dentro de las instituciones educativas, no sólo para evitar captar fotografías y videos que puedan subir a internet, sino porque les dificulta mantenerse atentos durante las clases.
} 
consistente con lo indicado en el informe CEPAL ${ }^{34}$ de que somos los latinoamericanos los mayores usuarios de redes sociales en todo el mundo.

Gráfico No 1 Frecuencia de episodios de cyberbullying

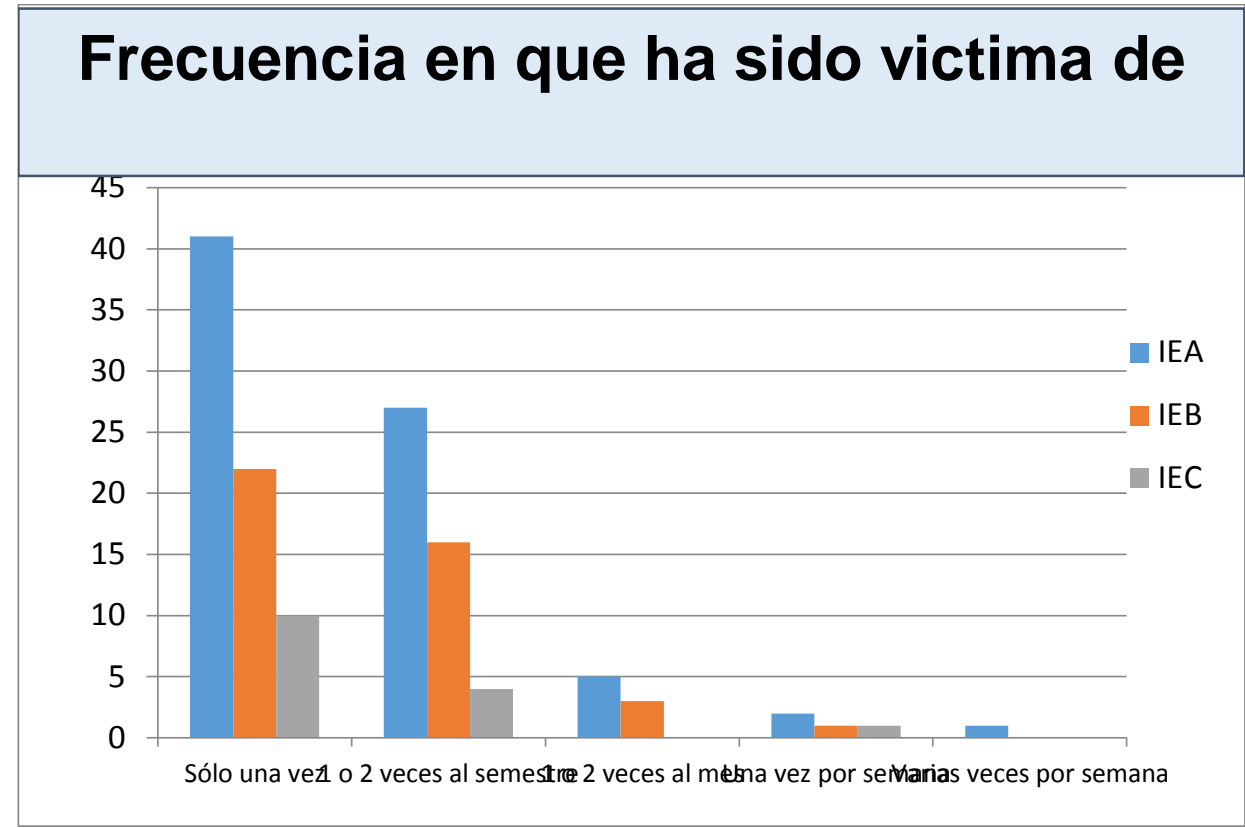

Gráfico No 2 Herramientas usadas para el cyberbullying

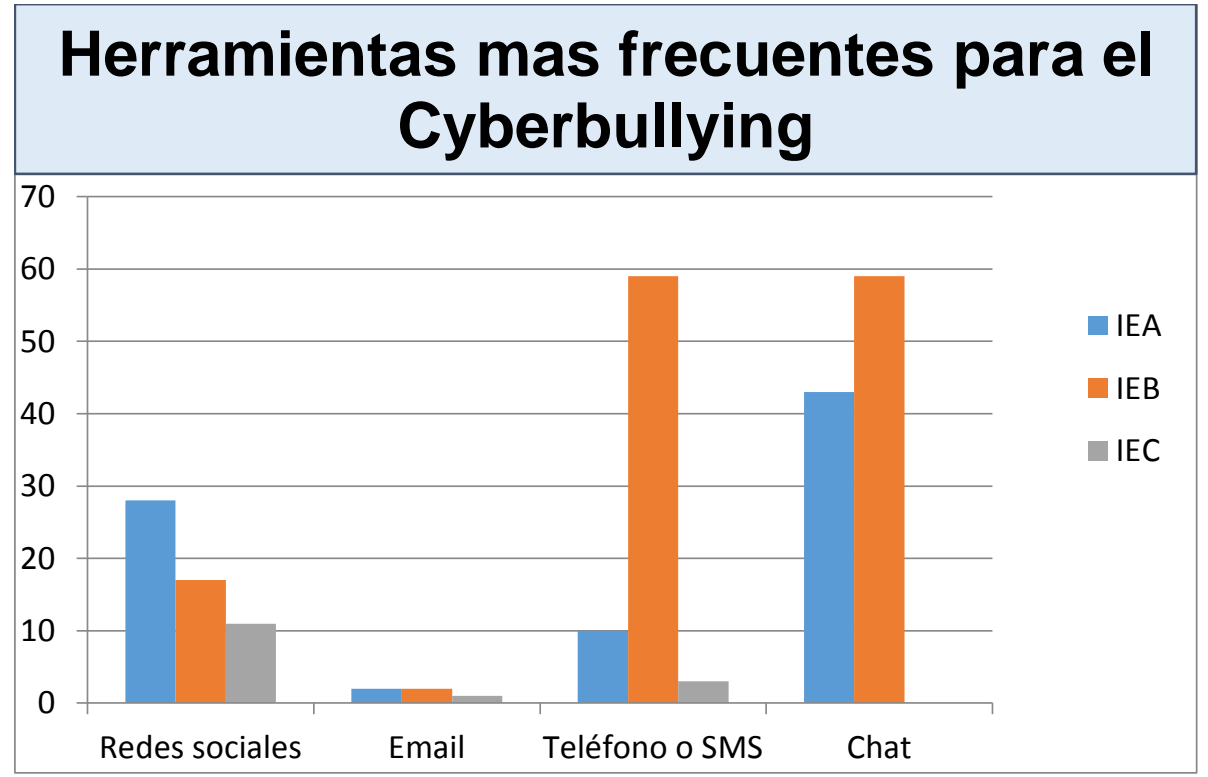

${ }^{34} \mathrm{El}$ informe CEPAL titulado "La nueva Revolución digital. De la Internet del consumo a la Internet de la producción" indica que hay más usuarios de redes en América Latina que en cualquier otro lugar del mundo 
Quisimos indagar sobre la percepción de los encuestados acerca de las causas por las que creen ser víctimas del acoso. Abordamos este asunto mediante un ítem abierto porque creemos que este es uno de los aspectos más importantes de cara a los programas de prevención. La opinión que más se repite es que son víctimas de acoso por "ser diferentes", en su forma de actuar, en sus gustos e incluso en los comentarios que publican en sus perfiles de redes sociales. A continuación comentan que son víctimas de acoso por "envidia" de los demás hacia ellos y finalmente por "ganas de fastidiar".

\section{c. Efectos de cyberbulyying en los centros estudiados}

Entrando ya en la consideración de los efectos emocionales en la víctima durante el acoso, se aprecia en el grafico No 3 que los sentimientos que predominan en los alumnos durante el acoso son de tristeza, ira y miedo, lo cual coincide con la mayoría de resultados de otras investigaciones.

Gráfico No 3 Efectos del cyberbullying durante el ataque

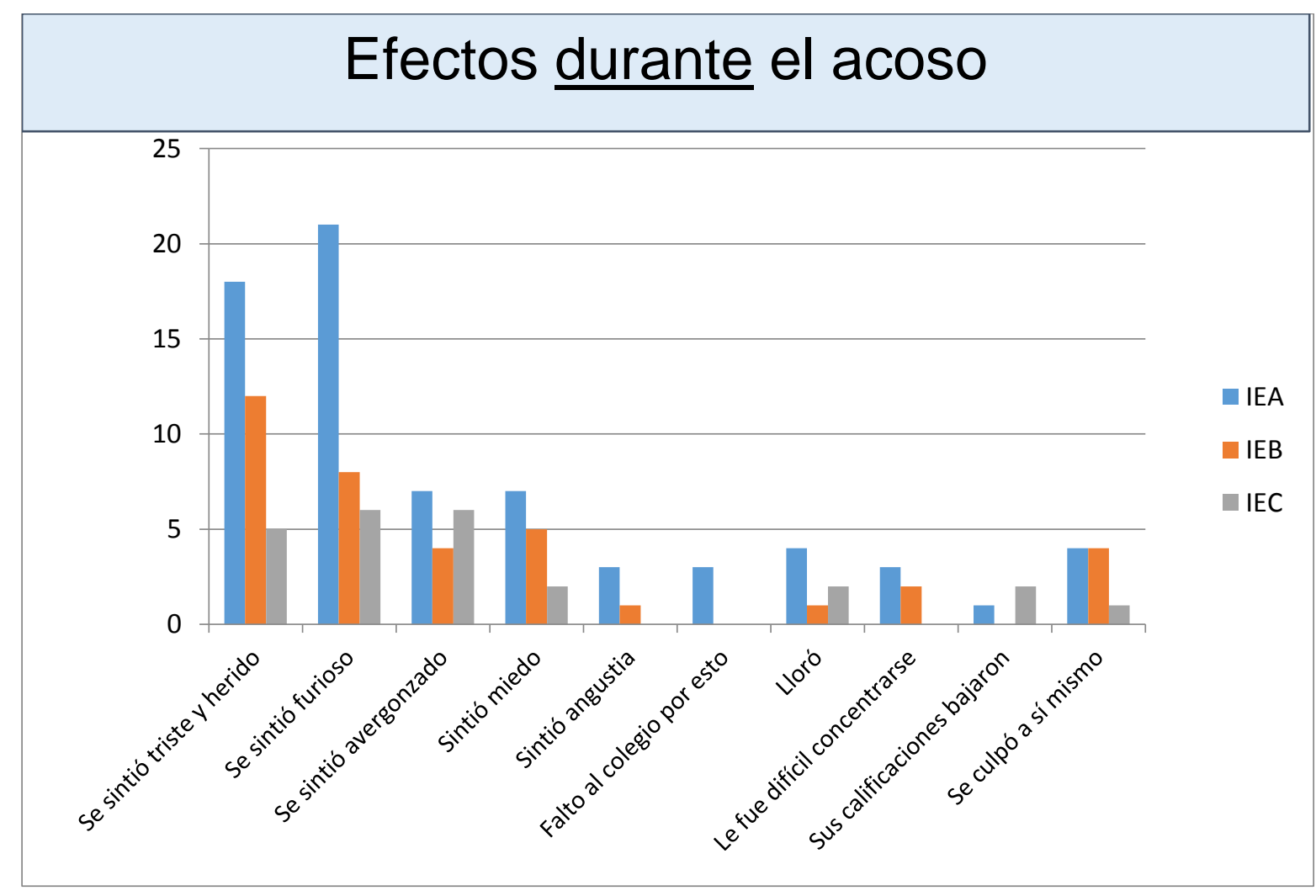

Esta pregunta se acompaña de otra abierta donde se pedía que expresaran otros sentimientos, distintos a las opciones del ítem anterior. Dos alumnos dijeron que la situación les provoco risa; otro 
señalo "no les paro" lo cual parece referirse a un sentimiento de indiferencia y finalmente hay quien dice sentirse "desconcertado".

También nos interesaron los efectos posteriores al acoso y se encontró lo siguiente:

Gráfico No 4 Efectos del cyberbullying posteriores el ataque

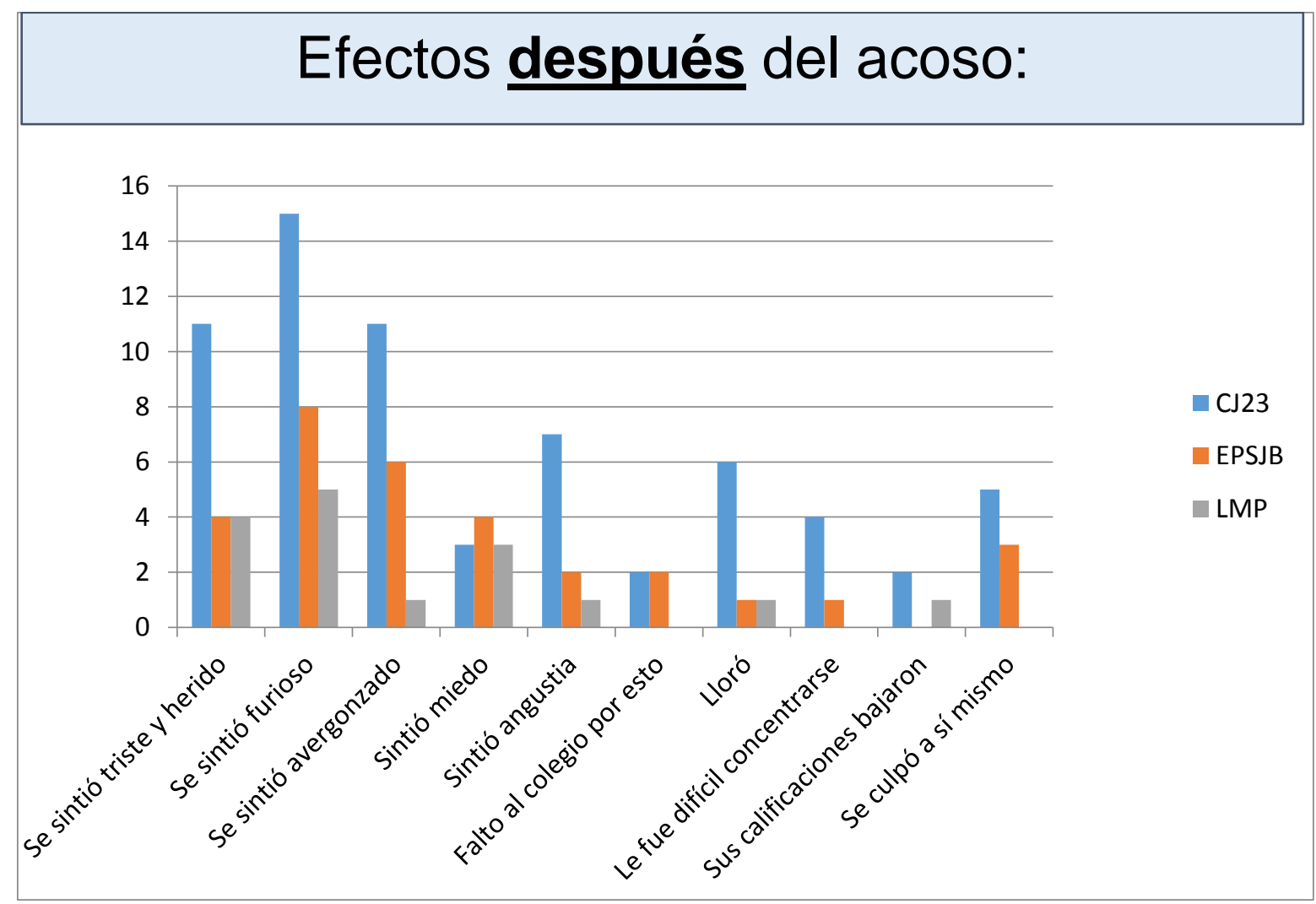

En general puede observarse en todas las instituciones que los efectos disminuyen una vez que ha cesado el acoso. Las emociones que mas persisten son la ira, la tristeza y el miedo mientras la vergüenza aumenta después de la agresión.

\section{d.Mediación adulta}

Finalmente sobre la mediación de los adultos cuando ocurrieron los episodios de cyberbullying formulamos tres cuestiones: a) si el encuestado solicitó ayuda entonces, cómo fue la respuesta obtenida, b) si es que obtuvo ayuda en que consistió la misma y, finalmente, c) si valora la ayuda obtenida como efectiva para superar el acoso. Los resultados indican lo siguiente: 
Gráfico No 5. Solicitud de ayuda

\section{Si acudiste a alguien para pedir ayuda ¿Cómo fue la respuesta de esa persona?}

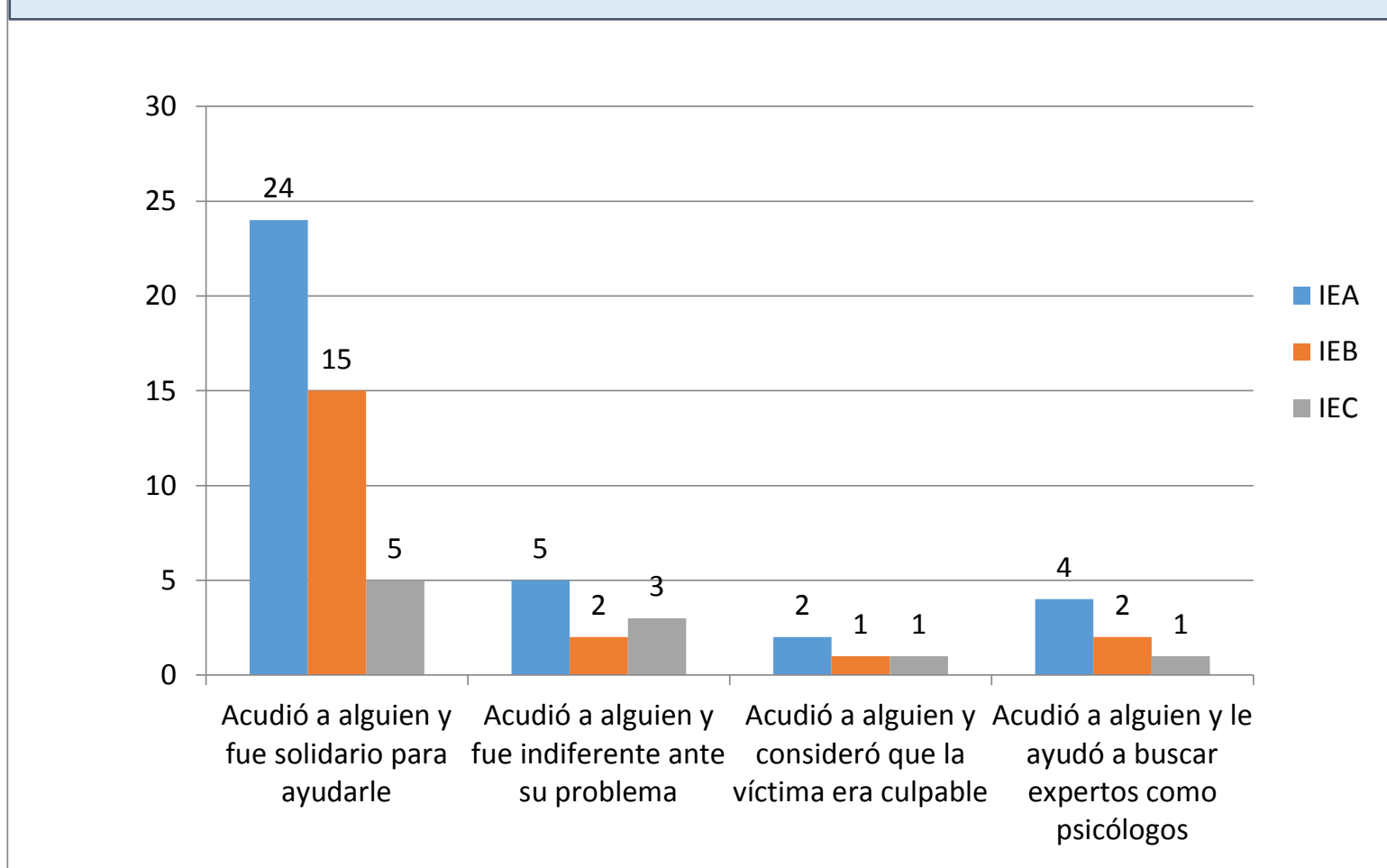

Llama la atención que el IEA tiene el mayor porcentaje de encuestados que buscaron ayuda (32\%) frente al IEB (20\%) y el IEC $(9 \%)$. Sin embargo en los tres casos predomina la actuación positiva y solidaria de quien le ha ayudado al agredido frente a unos mínimos casos en los que la solicitud de ayuda no fue respondida. A continuación interesaba saber cómo se hizo efectiva la ayuda al agredido y preguntamos entonces por las acciones básicas recomendadas en la literatura: asistencia psicológica, legal e incluso tecnológica para detener el acoso. Los resultados fueron los siguientes:

Destaca claramente que la ayuda suele hacerse efectiva casi siempre bajo la forma de "consejo" y en pocos casos mediante la búsqueda de ayuda experta a través de profesionales de la psicología, el derecho o la tecnología. 
Gráfico No 6. Tipo de ayuda prestada

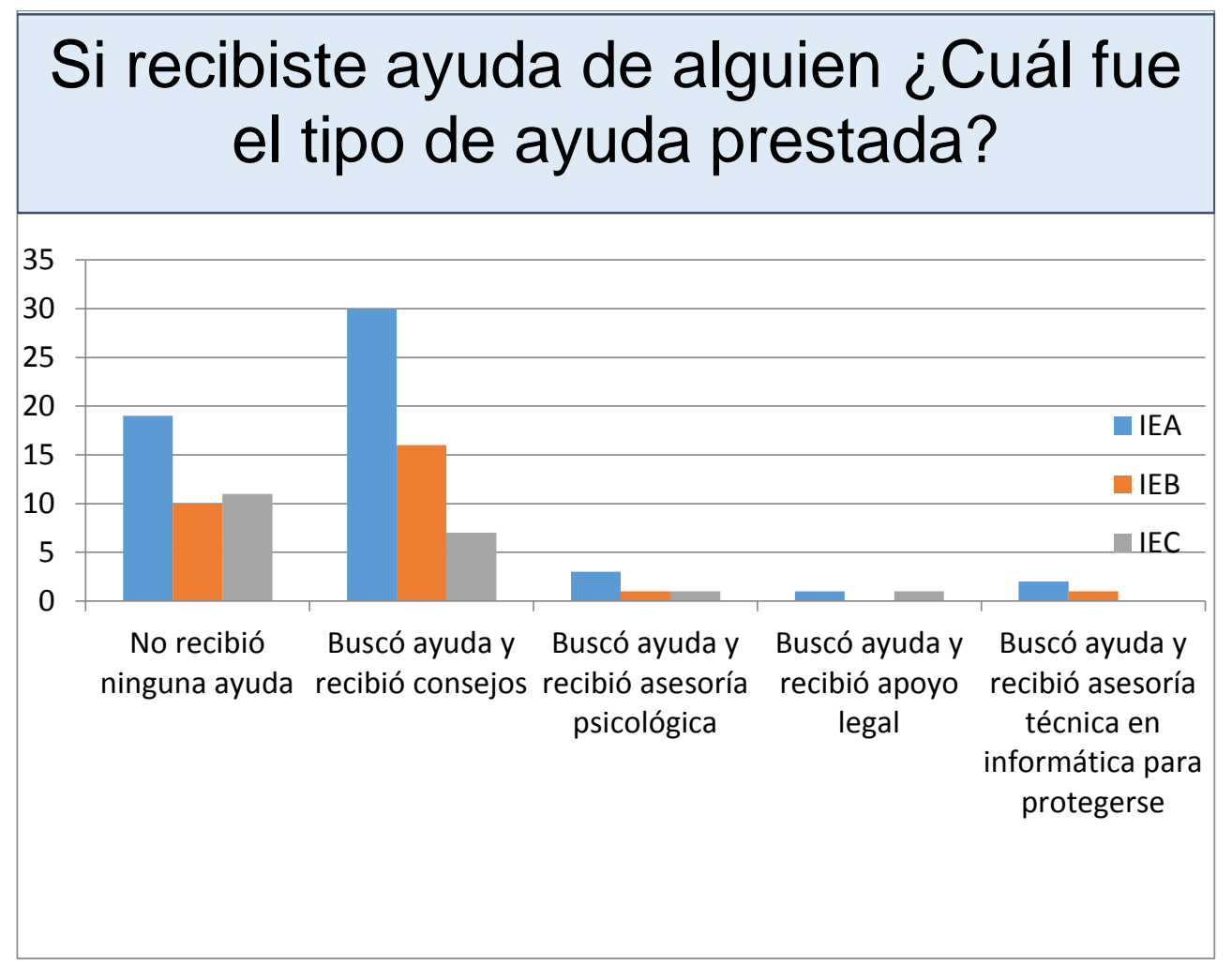

Finalmente llama la atención que los agredidos en el caso de IEA y IEB han considerado - en su mayoría- que la ayuda recibida no fue efectiva para superar la agresión. Sólo los encuestados del IEC han valorado como efectiva la ayuda recibida.

\section{Conclusiones}

El estudio del cyberbullying realizado revela una incidencia del fenómeno de cyberbullying entre los jóvenes de la ciudad, aunque no en su versión clásica de fenómeno reiterado y persistente en el tiempo sino más bien a modo de episodios eventuales. Esta condición matizaría de algún modo los efectos y consecuencias del acoso.

Los escolares de todos los centros estudiados, disponen de una alta conectividad en sus hogares y en muchos casos este acceso se extiende a cualquier lugar, ya que lo hacen a través de sus dispositivos móviles. Las herramientas de uso más habitual entre jóvenes como las redes sociales y los chat (especialmente vía (OWhatapps) son aquellas con más incidencia de casos de acoso evidentemente debido a la explotación frecuente de ellas. 
Distintas investigaciones como las de CTendencias digitales y más recientemente la CEPAL revelan que América Latina es una de las zonas del mundo con mayor penetración en uso de redes sociales (Argentina a la cabeza de CFacebook por ejemplo). Además esos mismos estudios revelan que el uso de las redes sociales en la región es en esencia lúdico. Los programas de prevención y de ciudadanía digital deberían incidir fuertemente en el uso responsable de las redes sociales.

La percepción de muchos de las personas encuestadas respecto a las causas del cyberbullying se relaciona con la intolerancia ante las diferencias, por eso son acosados quienes son distintos en su forma de hablar, de vestir, de socializar. Esto es un claro indicio de la importancia del fomento de una ciudadanía digital tolerante y respetuosa de la alteridad como forma de prevenir el cyberbullying.

La emocionalidad de quienes son agredidos se ve afectada de distintas maneras pero predominan las emociones negativas del tipo ira, miedo y tristeza. Mientras las conductas evasivas como las faltas a la escuela o el descenso en el rendimiento escolar se recuperan con facilidad una vez ha cesado el acoso, las emociones negativas persisten en el tiempo. Los programas de prevención deben estimular la educación emocional que permita a los jóvenes reconocer las emociones que experimentan y lidiar con ellas

La solicitud de ayuda no puede considerarse la conducta predominante en los casos estudiados. Si bien un alto porcentaje de los encuestados lo hizo en IEA y IEB, no ha ocurrido así en IEC. Cualquier programa de educación en ciudadanía digital y prevención de cyberbullying debe incidir en el reconocimiento del cyberbullying como un problema que afecta al joven y que no debe enfrentar en solitario sino con la ayuda de quienes le rodean y de personal experto. Los chicos, especialmente los más jóvenes, pueden creer que "controlan" la situación por sí mismos, logrando a veces agudizar el problema.

Los adultos que han sido informados por el agredido de la situación de acoso tienden a centrar las acciones de ayuda en el "consejo", pero seguramente esta ayuda será más efectiva si además del soporte emocional y la solidaridad demostrada al agredido, se canaliza 
mediante la ayuda de expertos del ámbito psicológico, legal y tecnológico.

Los entornos virtuales como las redes sociales, e-mail, chat, mensajería móvil... se han convertido en una parte esencial del día a día de los jóvenes y buena parte de su socialización ocurre en ellos, por tanto la educación para "saber convivir" en estos entornos será central en la prevención del cyberbullying.

\section{Referencias}

Aftab, Parry (7 / 9 / 2006). El ciberacoso es el riesgo más frecuente para los niños. Entrevista digital publicada por el Diario El Pais. Disponible en:

http:/ / elpais.com/diario/2006/09/07/ciberpais/1157593222_ 850215.html

Aviles, J. M. (2009). Ciberbullying. Diferencias entre el alumnado de secundaria. Boletin de Psicologia No 96, 79-96.

Belsey, B (2006). Cyberbullying: an emerging threat to the "allwayson" generation. Retrieved July 4, 2006, from www.cyberbullying.ca

CEPAL (2015). Informe "La nueva Revolución digital. De la Internet del consumo a la Internet de la producción". Disponible desde http:/ / www.cepal.org/es/publicaciones/38604-la-nuevarevolucion-digital-la-internet-consumo-la-internet-la-produccion

Cochrane, K.(2008). Exploring Cyberbullying In Saskatchewan. Tesis de grado para optar al títulode Magister en Educación de la University of Saskatchewan

Henríquez y otros(2012). Nativos digitales: aproximación a los patrones de consumo y hábitos de uso de internet, videojuegos y celulares. Caso: Colegio Juan XXIII de San Cristóbal. Revista Educación y Pedagogía. Universidad de Manizales.

Hernández; M. y I. Solano. (2007). Ciberbullying, un problema de acoso escolar. RIED, 17-36.

Lindo, E.(10/9/2015). “Las palabras hieren” Diario El País de España. Disponible desde: http://elpais.com/elpais/2015/10/09/estilo/1444394159_483 109.html 
Kowalski, Limber y Agatson. (2010). Cyber Bullying. El acoso escolar en la er@digit@1. Henao: Desclee de Brouwer, s.a.

Kowalski,R.M. y Witte, J.(2006). Youth Internet survey. Disponible en http:/ /www.camss.clemson.edu

Rueda, R.(2004). Tecnoculturas y sujeto cyborg: esbozos de una tecnopolítica educativa. En Nómadas. Medios de Comunicación: Tecnologías, política y educación. IESCO. 21,70-81.

Smith, P. , Mahdavi, J., Carvalho,M. y N.Tippett. (2006). An investigation into cyberbullying, it forms, awareness and impact and the relationship between age and gender in cyberbullying . Londres: Universidad de Londres.

Urresti, M.(2008)(Ed.).Ciberculturas juveniles. Buenos Aires: La crujía.

Ybarra, M y K.Mitchell(2004). Online aggressors and targets. A comparison of associated youth characteristics. Journal of child psychology, 45, 1308-1316.

Willard, N. (2006). Cyber bullying and cyber threats: responding to the challenge of online social cruelty, threats and distress.Eugene, OR: Center for safe and Responsible Internet USE. 


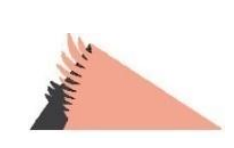

\section{Biografía de los editores}

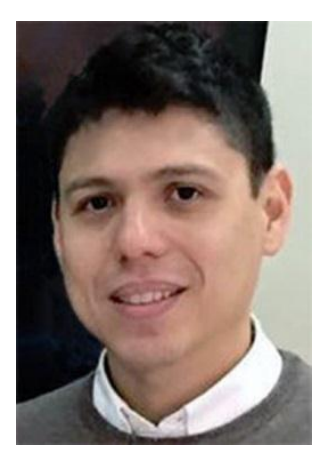

\section{Carlos Arcila Calderón (Universidad de}

Salamanca, España). Profesor del Departamento de

Sociología y Comunicación de la Universidad de

Salamanca (España). Miembro del Observatorio de

Contenidos Audiovisuales (OCA). Editor del Anuario

Electrónico de Estudios en Comunicación Social

"Disertaciones". Doctor Europeo en "Comunicación, Cambio Social y Desarrollo" por la Universidad Complutense de Madrid. Máster en Data Science y Máster en Periodismo, ambos por la Universidad Rey Juan Carlos (URJC). Ha sido profesor de la Universidad del Rosario (Colombia), la Universidad del Norte (Colombia), la Universidad de Los Andes (ULA) (Venezuela); investigador post-doctoral de la URJC; e investigador asociado de la Universidad Católica Andrés Bello (UCAB) (Venezuela). Además, ha sido profesor invitado de la Universidad Nacional de Educación a Distancia (UNED) (España), la Universidad de la Sabana (Colombia), la Universidad de Santiago de Compostela (España), la Universidad Mayor (Chile) y la Universidade Estadual Paulista (Brasil).

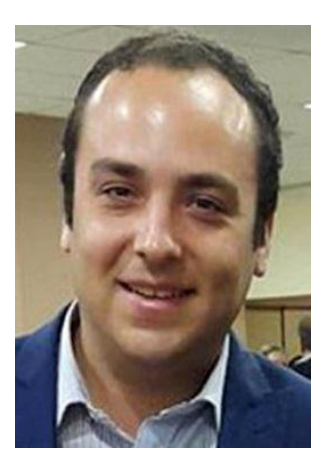

Daniel Barredo Ibáñez (Universidad del Rosario, Colombia). Profesor de carrera principal en el programa de Periodismo y Opinión Pública de la Universidad del Rosario (Colombia), actualmente lidera el proyecto de I+D "Esfera pública y participación ciudadana: Un abordaje de la construcción de la interacción en los principales cibermedios colombianos", financiado por el fondo de proyectos de 
Gran Cuantía de la Universidad del Rosario, además de participar como investigador adjunto en el proyecto de $\mathrm{I}+\mathrm{D}$ "La influencia de la audiencia en la innovación periodística y gestión de la participación: riesgos y oportunidades", financiado por el Ministerio de Economía de España. Es autor de diez libros académicos, cinco libros literarios y más de setenta artículos de investigación o capítulos de libro sobre temas vinculados a los medios sociales, el discurso organizacional o la comunicación de España, Colombia, México o Ecuador. Es doctor en Periodismo por la Universidad de Málaga, máster y experto en Comunicación y licenciado en Filología Hispánica y en Comunicación Audiovisual por la Universidad de Granada.

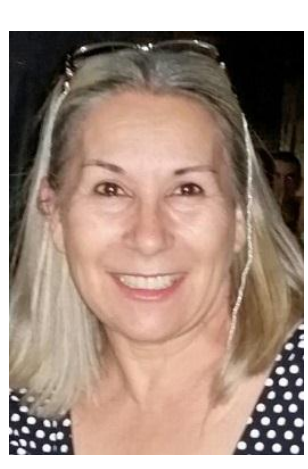

Cosette Castro (Universidad Católica de Brasília, Brasil). Postdoctora por la Cátedra de la Unesco en Comunicación para el Desarrollo Regional UNESCO/UMESP, Brasil; Doctora en Comunicación y Periodismo por la Universidad Autónoma de Barcelona -UAB- España. Tiene una Maestría en Comunicación y Cultura por la PUC/RS, Brasil y una Especialización en Educación Popular por Unisinos/RS, Brasil. Actualmente es profesora de la PósGraduación en Comunicación de la Universidad Católica de Brasília UCB/Brasil. Es Coordinadora del GT de Contenidos Digitales del Plan eLAC2018 para Sociedad de la Información en América Latina y Caribe y Vicecoordinadora del GT de Comunicación Digital, Redes y Procesos de ALAIC. Tiene más de 100 artículos publicados en libros y periódicos y 8 libros publicados sobre temas de Comunicación, TIC, Televisión, Convergencia de Medios e Inclusión Social en Brasil y América Latina disponibles en portugués, español e inglés. 